\title{
Electron-Reservoir Effect on a Perylene Diimide Tethered Rhenium Bipyridine Complex for $\mathrm{CO}_{2}$ Reduction
}

\author{
Josh D. B. Koenig ${ }^{\mathrm{a}}$, Zachary Dubrawski ${ }^{\mathrm{a}}$, Keerthan R. Rao ${ }^{\mathrm{b}}$, Janina Willkomm ${ }^{\mathrm{a}}$, Benjamin S. \\ Gelfand $^{\mathrm{a}}$, Chad Risko ${ }^{\mathrm{b}}$, Warren E. Piers ${ }^{\mathrm{a}}$, and Gregory C. Welch ${ }^{\mathrm{a} *}$ \\ ${ }^{a}$ Department of Chemistry, University of Calgary, 2500 University Drive N.W., Calgary, \\ Alberta, T2N 1N4, Canada. \\ ${ }^{\mathrm{b}}$ Department of Chemistry \& Center for Applied Energy Research, University of Kentucky, \\ Lexington, Kentucky 40506, United States \\ * Corresponding Author \\ Email: gregory.welch@ucalgary.ca \\ Phone Number: 1-403-210-7603
}

\section{- Abstract}

Here we report on a molecular catalyst with a built-in electron-reservoir for enhanced $\mathrm{CO}_{2}$ conversion. The synthesis and characterization of this $\mathrm{N}$-annulated perylene diimide (PDI) photosensitized $\operatorname{Re}($ bpy) supramolecular dyad [Re(bpy-TAz-PDI)], as well as successful electroand photocatalytic $\mathrm{CO}_{2}$-to- $\mathrm{CO}$ conversion, are detailed herein. Upon electrochemical reduction in the presence of $\mathrm{CO}_{2}$ and a proton source, $\operatorname{Re}(\mathbf{b p y}-\mathbf{T A z}-\mathbf{P D I})$ exhibited significant current enhancement, where the onset of electrocatalytic $\mathrm{CO}_{2}$ reduction for $\operatorname{Re}(\mathbf{b p y}-\mathbf{T A z}-\mathbf{P D I})$ occurred at a much less negative potential than standard Re(bpy) complexes. At an applied potential of $-1.8 \mathrm{~V}$ vs. $\mathrm{Fc}^{+/ 0}, 400 \mathrm{mV}$ lower than the benchmark $\operatorname{Re}(\mathrm{dmbpy})$ catalyst, $\operatorname{Re}(\mathbf{b p y}-\mathbf{T A z}$-PDI) was able to achieve the same catalytic activity $\left(\mathrm{TON}_{\mathrm{co}}=24\right)$ and Faradaic efficiency $(\mathrm{FE}=92 \%)$ during controlled potential electrolysis (CPE) experiments. Through a combination of UV-visible-nearIR spectroelectrochemistry (SEC), FTIR SEC, and chemical reduction experiments, it was shown that the PDI-moiety served as an electron-reservoir for Re(bpy), thereby allowing catalytic activity at lower overpotentials. Density functional theory (DFT) studies probing the optimized geometries, frontier molecular orbitals, and spin-densities of various catalytic intermediates revealed that the geometric configuration of PDI, relative to the $\operatorname{Re}(b p y)$-moiety, plays a critical role in accessing electrons from the electron-reservoir. The near identical performance of $\operatorname{Re}(\mathbf{b p y}-\mathbf{T A z}-\mathbf{P D I})$ at lower overpotentials relative to the benchmark $\operatorname{Re}(\mathrm{dmbpy})$ catalyst highlights the utility of organic chromophore electron-reservoirs as a method for lowering the required overpotential for $\mathrm{CO}_{2}$ conversion. 


\section{- Introduction}

The conversion of combustion products (i.e. $\mathrm{CO}_{2}, \mathrm{H}_{2} \mathrm{O}$ ) back to chemical precursors and fuels using electrons derived from renewable resources is one viable path towards lowering carbonemissions and closing the carbon-loop. ${ }^{1,2}$ In theory, solar radiation provides enough energy to perform these thermodynamically and kinetically uphill chemical reactions; but in practice, catalysts are required to enable efficient product delivery. ${ }^{3,4}$ While heterogeneous electrocatalysts are favored for their scalability and facile device integration, these materials often suffer from a lack of product selectivity. ${ }^{5-7}$ The use of single-atom heterogeneous electrocatalysts can help enhance product selectivity. ${ }^{8-10}$ However, the rational design of molecular catalysts affords a more systematic method to tune and improve catalyst activity and product selectivity. ${ }^{11,12}$ Though most molecular catalysts require a high overpotential to drive electrocatalytic $\mathrm{CO}_{2}$ reduction, issues concerning the durability of these systems can often be resolved by immobilizing these molecular catalysts. ${ }^{13-19}$ For these catalysts to be employed in long-lasting and industrially-relevant devices, catalyst design should emphasize the importance of accomplishing these chemical processes efficiently at the lowest overpotential possible..$^{2,20-23}$

One of the most well-explored $\mathrm{CO}_{2}$ reduction catalyst motifs, first introduced by Lehn and coworkers ${ }^{24}$ is based upon $\operatorname{Re}(2,2$ '-bipyridine $)(\mathrm{CO})_{3} \mathrm{Cl}[\operatorname{Re}(b p y)]$. The synthetic versatility of the bpy ligand means catalyst properties can be tailored to lower overpotentials for $\mathrm{CO}_{2}$ electrocatalysis through use of either electronically varied substituents ${ }^{25-28}$ or second-sphere $\mathrm{H}$ bonding groups (see Supporting Information, SI, Table S1) ${ }^{29-31}$ Moreover, these catalysts can be tethered to photosensitizers, such as the ruthenium(II) diimine complexes investigated by Ishitani and co-workers, to generate supramolecular dyads that are capable of $\mathrm{CO}_{2}$ photocatalysis. ${ }^{32-34}$ Despite the many design principles established for these $\mathrm{Ru}^{\mathrm{II}}-\mathrm{Re}^{\mathrm{I}}$ supramolecular dyads, the extension of these principles towards other organic chromophore photosensitizers is less common. Beyond porphyrins, ${ }^{35-37}$ rylene (di)imides such as naphthalimide, ${ }^{38}$ naphthalene diimide, ${ }^{39-41}$ and perylene diimide (PDI) ${ }^{42,43}$ have also been used to photosensitize $\operatorname{Re}(\mathrm{bpy})$. While the photophysical properties of these rylene (di)imide functionalized $\operatorname{Re}(\mathrm{bpy})$ supramolecular dyads have been thoroughly investigated, surprisingly only the naphthalimidefunctionalized rhenium diimine complexes reported by Gobetto and co-workers ${ }^{38}$ were examined as $\mathrm{CO}_{2}$ electro- and photocatalysts.

Recognizing the structural diversity and catalytic potential of these hybrid supramolecular dyad systems, we targeted a versatile $\mathrm{N}$-annulated PDI photosensitized $\mathrm{Re}$ (bpy) complex. PDIs are ideally suited for photosensitization because they possess high molar absorptivity and redox stability. $^{44,45}$ Relative to other PDI materials, N-annulation provides a pair of nonbonding electrons that can donate into the $\pi$-system of the PDI chromophore. ${ }^{46,47}$ This electron donation slightly destabilizes the frontier molecular energy levels, which improves the energetic match between Re(bpy) and the PDI chromophore. ${ }^{47}$ Moreover, the pyrrolic nitrogen on $\mathrm{N}$-annulated PDI provides a synthetically versatile handle through which the dyads' physical and optoelectronic properties may be further tuned. ${ }^{47-50}$ And unlike previously reported rylene diimide systems, ${ }^{39-43}$ imide functionalization of the perylene precursor may be done symmetrically, making this $\mathrm{N}$-annulated PDI system synthetically more accessible and scalable. Herein we report the synthesis, characterization, and catalytic properties of an $\mathrm{N}$-annulated PDI tethered $\mathrm{Re}$ (bpy) supramolecular dyad [Re(bpy-TAz-PDI)] capable of $\mathrm{CO}_{2}$-to-CO electro- and photocatalysis. We show through a series of controlled potential electrolysis (CPE) and 
spectroelectrochemistry (SEC) experiments, as well as density functional theory (DFT) calculations that $\mathrm{N}$-annulated PDI acts as an electron-reservoir for $\operatorname{Re}(b p y)$, enabling efficient $\mathrm{CO}_{2}$ reduction at an overpotential $400 \mathrm{mV}$ lower than conventional $\mathrm{Re}$ (bpy) catalysts.

\section{- Synthesis and Characterization}

The synthesis of $\mathbf{R e}(\mathbf{b p y}-\mathbf{T A z}-\mathbf{P D I})$ (Scheme 1), starting from $\mathrm{N}$-annulated PDI, ${ }^{47}$ exploited an alkylation of the pyrrolic nitrogen with 1,2-dibromoethane followed by an azide-substitution, according to an established literature procedure. ${ }^{48}$ The $\mathrm{C} 2$ tether length was selected to mimic the design principles outlined for the $\mathrm{Ru}{ }^{\mathrm{II}}-\mathrm{Re}^{\mathrm{I}}$ supramolecular dyads, where short tether-lengths have proven critical for efficient electron-transfer. ${ }^{32-34}$ Next, $\mathrm{N}_{3}$-PDI was attached to alkynefunctionalized bipyridine via copper catalyzed alkyne-azide cycloaddition, ${ }^{48}$ generating the ligand (bpy-TAz-PDI). Lastly, bpy-TAz-PDI was metallated with $\operatorname{Re}(\mathrm{CO})_{5} \mathrm{Cl}$ to afford $\operatorname{Re}(\mathbf{b p y}-$ TAz-PDI) in an overall yield of $38 \%$, over 4 synthetic steps (see SI for more details).

\section{Scheme 1. Synthesis of bpy-TAz-PDI Ligand and Re(bpy-TAz-PDI) Supramolecular Dyad}

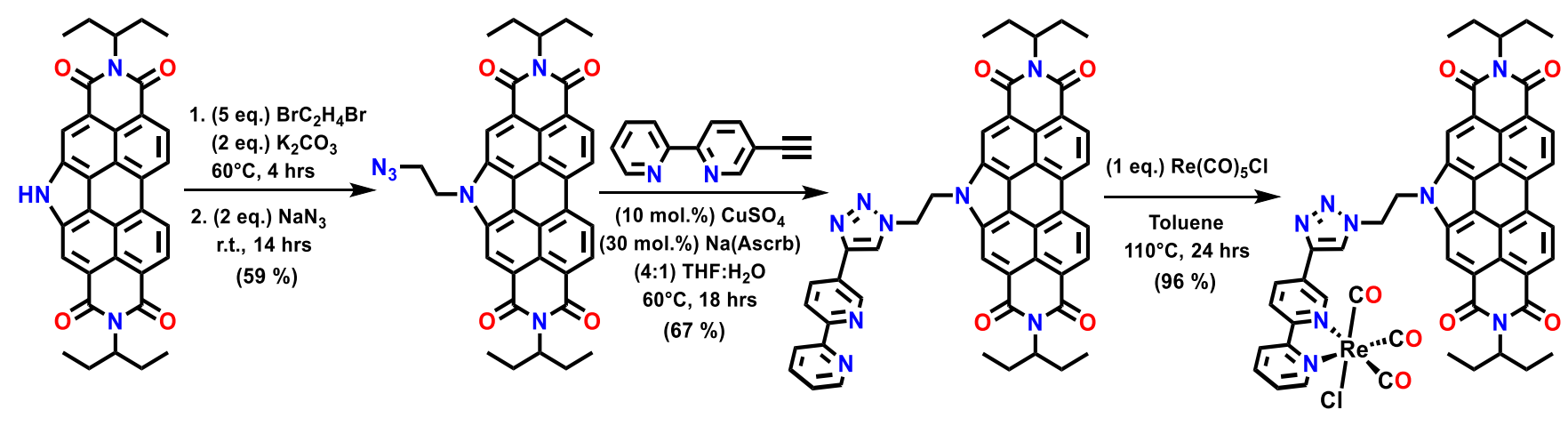

PDI

$\mathrm{N}_{3}$-PDI

bpy-TAz-PDI

$\operatorname{Re}($ bpy-TAz-PDI)

The identity of $\mathbf{R e}(\mathbf{b p y}-\mathbf{T A z}-\mathrm{PDI})$ was confirmed by MALDI-TOF MS and elemental analysis (Figure S20-S21). Evidence supporting Re metallation was provided by NMR, UV-visiblenearIR (UV-vis-nIR), and FTIR spectroscopies. In the ${ }^{1} \mathrm{H}$ NMR spectrum, the aromatic peaks in $\operatorname{Re}(\mathbf{b p y}-\mathbf{T A z}-\mathbf{P D I})$ attributed to the bipyridine-moiety were deshielded relative to bpy-TAz-PDI, indicating incorporation of the electron-withdrawing Re metal center (Figures S5 - S6). The optical properties of the ligand and $\operatorname{Re}(\mathbf{b p y}-\mathbf{T A z}-\mathbf{P D I})$ were nearly identical, differing only in an additional MLCT band $(\lambda=343 \mathrm{~nm})$ (Figures S22 - S23). By FTIR, three $v_{\text {co }}$ stretches (1901, 1920, and $2024 \mathrm{~cm}^{-1}$ ) emerged for $\operatorname{Re}(\mathbf{b p y}$-TAz-PDI) at similar frequencies to other reported Re(bpy) complexes (Figures S24-S25). ${ }^{51}$

Single crystals suitable for connectivity mapping by X-ray diffraction crystallography were obtained by layering ethyl acetate on top of a $\mathrm{CH}_{2} \mathrm{Cl}_{2}$ solution of $\operatorname{Re}(\mathbf{b p y}-\mathbf{T A z}-\mathbf{P D I})$. Weak diffraction and unresolvable twinning prevented the unambiguous confirmation of the single crystal structure. However, the connectivity map provided sufficient evidence that the Re metal center was chelated by the bpy-moiety of the bpy-TAz-PDI ligand (Figure S64). Moreover, bpy 
and PDI can be oriented within reasonable $\pi-\pi$ stacking distances, which would facilitate electron transfer (vide infra). The bulky PDI-moiety also occupied a space that was opposite of the axial chloride, suggesting that there are possible conformations in which PDI would not sterically hinder interactions between $\mathrm{Re}$ and $\mathrm{CO}_{2}$ during electrocatalysis. ${ }^{52,53}$

\section{- Electrochemistry}

Cyclic voltammetry (CV) experiments performed on $\operatorname{Re}($ bpy-TAz-PDI) displayed two oxidation and four reduction events (Figure 1; all reported redox processes were referenced relative to $\left.\mathrm{Fc}^{+/ 0}\right)$. The first irreversible oxidation $\left(\mathrm{E}_{\mathrm{p}}=+1.01 \mathrm{~V}\right)$ was attributed to the $\mathrm{Re}^{\mathrm{I} / \mathrm{I}}$ redox process. ${ }^{54}$ The second quasi-reversible oxidation $\left(\mathrm{E}_{1 / 2}=+1.15 \mathrm{~V}\right)$, as well as the first and second reversible reduction events $\left(\mathrm{E}_{1 / 2}=-1.19 \mathrm{~V}\right.$ and $\left.-1.48 \mathrm{~V}\right)$ can be assigned as PDI-centered redox events via direct comparison to the ligand (Figure S29). This type of electrochemical behavior is characteristic of $\mathrm{N}$-annulated PDI materials. ${ }^{47,48,55}$ The third and fourth reductions $\left(\mathrm{E}_{1 / 2}=-1.79 \mathrm{~V}\right.$ and $\mathrm{E}_{\mathrm{p}}=-2.20 \mathrm{~V}$, respectively) were analogous to other $\operatorname{Re}(\mathrm{bpy})$ complexes, such as $\operatorname{Re}\left(4,4^{\prime}-\right.$ dimethyl-2,2'-bipyridine $)(\mathrm{CO})_{3} \mathrm{Cl}[\operatorname{Re}(\mathrm{dmbpy})]$ (Figure S31), ${ }^{25}$ suggesting that these events correspond to the quasi-reversible $\mathrm{bpy}^{0 / \bullet-}$ and irreversible $\mathrm{Re}^{\mathrm{I} / 0}$ redox couples, respectively. ${ }^{24-38}$ Variable scan rate analysis of $\operatorname{Re}(\mathbf{b p y}-\mathbf{T A z}-\mathbf{P D I})$ under argon was in accordance with the Randles-Sevcik equation, indicating the dyad exhibits a diffusion-limited current response (Figure S32). It should be noted that the calculated diffusion coefficient for $\operatorname{Re}(\mathbf{b p y}-\mathbf{T A z}-\mathbf{P D I})$ $\left(\mathrm{D}=4 \times 10^{-6} \mathrm{~cm}^{2} \mathrm{~s}^{-1}\right)$ was approximately half that of $\operatorname{Re}(\mathrm{dmbpy})\left(\mathrm{D}=1 \times 10^{-5} \mathrm{~cm}^{2} \mathrm{~s}^{-1}\right)$. These data, when combined with the absence of low-energy shoulders in the UV-vis-nIR spectrum of $\operatorname{Re}\left(\right.$ bpy-TAz-PDI), indicate there is minimal PDI-related aggregation in solution. ${ }^{56}$

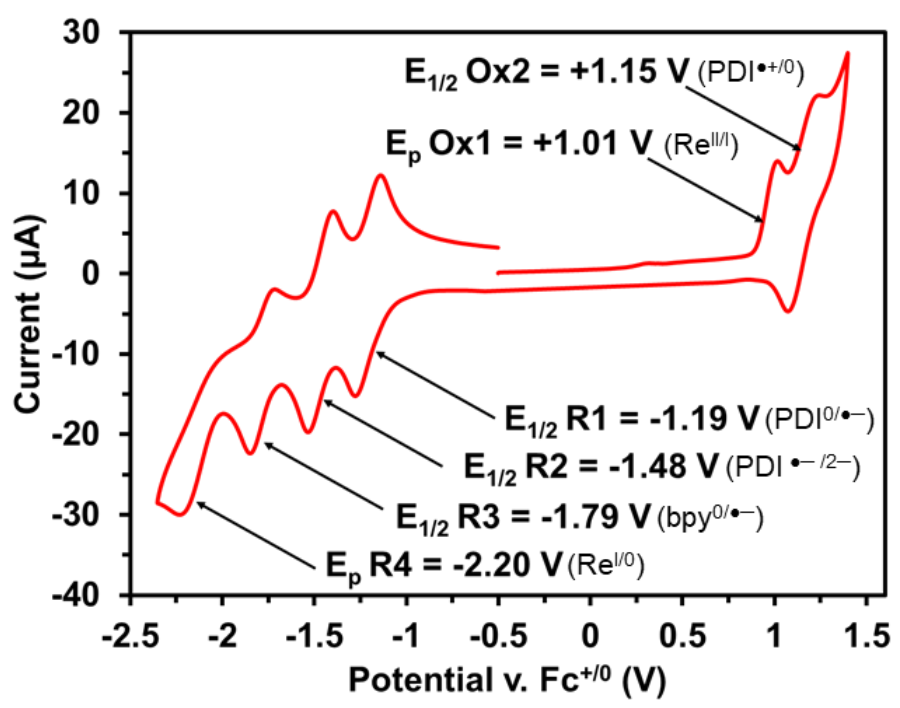

Figure 1. Assigned CV of $\mathrm{Re}\left(\right.$ bpy-TAz-PDI) recorded at $100 \mathrm{mV} / \mathrm{s}$, under argon in $\mathrm{CH}_{2} \mathrm{Cl}_{2}$ with $0.1 \mathrm{M}$ TBAPF 6 supporting electrolyte $(\mathrm{WE}=$ glassy carbon, $\mathrm{CE}=\mathrm{Pt}-$ wire, $\mathrm{RE}=\mathrm{Ag} / \mathrm{AgCl}$, and $\mathrm{Fc}^{+/ 0}$ as internal reference standard) 
Under an atmosphere of $\mathrm{CO}_{2}$, the $\mathrm{CV}$ of $\mathbf{R e}(\mathbf{b p y}$-TAz-PDI) did not show significant current enhancement in either DMF or MeCN (Figure 2). Upon addition of either phenol (PhOH) or 2,2,2-trifluoroethanol (TFE), however, a large current enhancement plateau was observed at the fourth reduction event in both solvents. This type of current enhancement can often be indicative of electrocatalytic $\mathrm{CO}_{2}$ reduction capabilities for $\mathrm{Re}(\mathrm{bpy})$-derived complexes (Figure S34). ${ }^{24-38}$ Closer inspection of these CVs revealed minor changes to the PDI-based reduction events. Incrementally increasing the amount of TFE further caused the first reduction to change from fully reversible to quasi-reversible (Figures S30 and S34). At the same time, the second reduction event shifted to a less negative potential. These observations may be attributed to stabilization of the PDI imide oxygen atoms via either protonation of the $\mathrm{PDI}^{2-}$ imides and/or the proton-source stabilizing $\mathrm{PDI}^{2-}$ through hydrogen-bonding interactions. ${ }^{57,58}$ Perhaps the more significant change in these $\mathrm{CVs}$ was that the onset of $\mathrm{CO}_{2}$ reduction current enhancement for $\operatorname{Re}($ bpy-TAz-PDI) now occurred at the third reduction event (Figure 2B, inset). This shift in current enhancement suggests that PDI functionalization results in a lowering of the electrocatalytic $\mathrm{CO}_{2}$ reduction overpotential, despite a lack of direct $\pi$-conjugation to $\operatorname{Re}(b p y)$. Notably, the onset of $\mathrm{CO}_{2}$ current enhancement for $\operatorname{Re}(\mathbf{b p y}-\mathbf{T A z}-\mathbf{P D I})$ is $160 \mathrm{mV}$ lower than the less conjugated naphthalimide-functionalized rhenium diimine complexes previously reported by Gobetto and co-workers. ${ }^{38}$ These results clearly indicate that selection of chromophore (or conjugated unit) is critical to these hybrid systems, which opens a new and relevant approach for structurally engineering $\mathrm{CO}_{2}$ conversion catalysts.
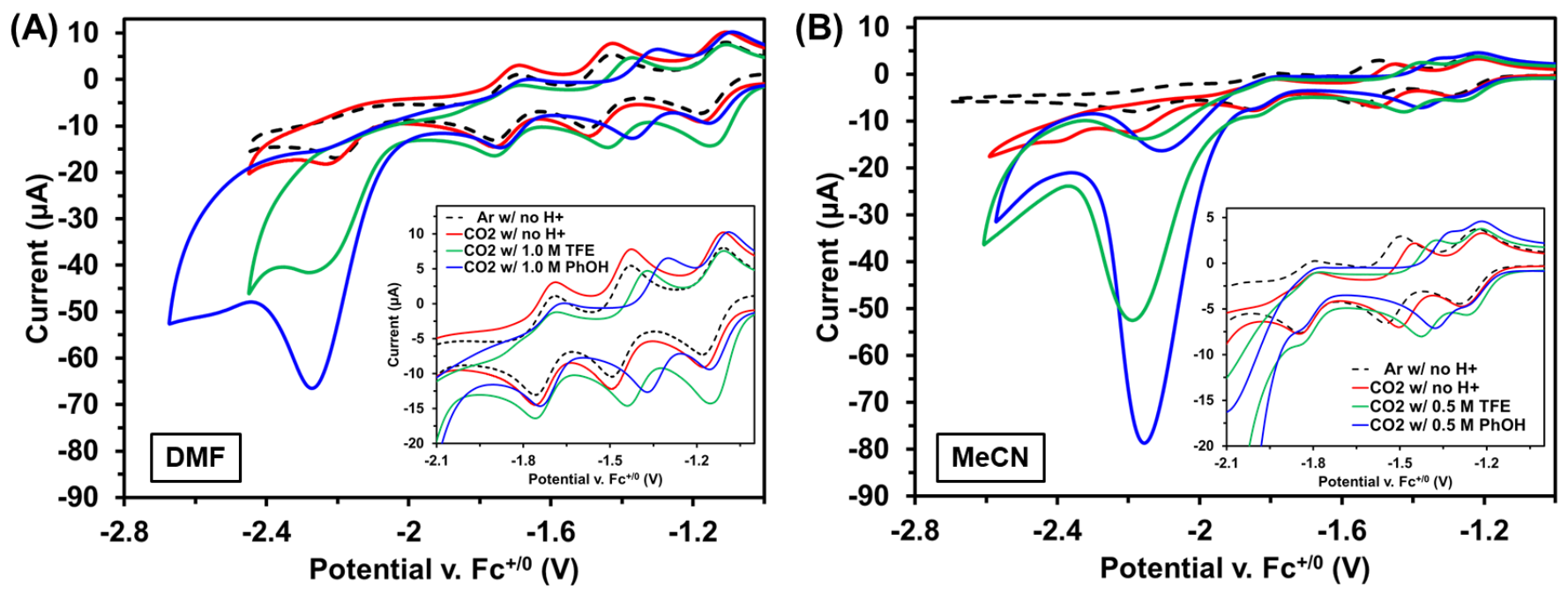

Figure 2. CVs of Re(bpy-TAz-PDI) (black) in DMF (A) and $\mathrm{MeCN}$ (B) comparing the effects of adding no proton source (red), TFE (green) and $\mathrm{PhOH}$ (blue) on catalytic current enhancement under atmospheric $\mathrm{CO}_{2}$

By comparing the peak currents under $\mathrm{CO}_{2}$ with 2.0 M TFE (icat; Figure S33) relative to those measured under inert conditions ( $\mathrm{i}_{\mathrm{p}}$; Figures S31-S32), it is possible to estimate the observed non-electrochemical rate constant during $\mathrm{CO}_{2}$ conversion (see SI for more details). ${ }^{28}$ Using this $\mathrm{i}_{\text {cat }} / \mathrm{i}_{\mathrm{p}}$ method (scan rate, $v=25 \mathrm{~V} / \mathrm{s}$ ), the observed catalytic rate constants $\left(\mathrm{k}_{\mathrm{obs}}\right)$ for $\mathbf{R e}(\mathbf{b p y}-\mathbf{T A z}$ PDI) were calculated to be 330 and $320 \mathrm{~s}^{-1}$, for $\mathrm{i}_{\text {cat }}$ values measured in DMF at the third $\left(\mathrm{E}_{1 / 2}=\right.$ 
$-1.79 \mathrm{~V})$ and fourth $\left(\mathrm{E}_{\mathrm{p}}=-2.25 \mathrm{~V}\right)$ reduction events, respectively. Under identical testing conditions, the kobs for $\operatorname{Re}(\mathrm{dmbpy})$ was determined to be $1100 \mathrm{~s}^{-1}$ at the $\mathrm{Re}^{\mathrm{I} / 0}$ reduction event $\left(\mathrm{E}_{\mathrm{p}}\right.$ $=-2.35 \mathrm{~V})$. The smaller $\mathrm{k}_{\text {obs }}$ for $\operatorname{Re}(\mathbf{b p y}-\mathbf{T A z}-\mathbf{P D I})$ may be attributed to either a lower nucleophilicity for $\mathrm{CO}_{2}$ (given the dramatically lower overpotential) ${ }^{59}$ or perhaps a difference in the electrocatalytic $\mathrm{CO}_{2}$ reduction mechanism, relative to $\operatorname{Re}(\mathrm{dmbpy}){ }^{60}$ Regardless, these calculated $\mathrm{k}_{\text {obs }}$ can be used to generate a catalytic Tafel plot (Figure 3), which clearly emphasizes $\operatorname{Re}($ bpy-TAz-PDI)'s ability to attain substantially higher catalytic activity than comparable nonPDI substituted Re(bpy) catalysts, at much lower overpotentials. ${ }^{28-30,61,62}$

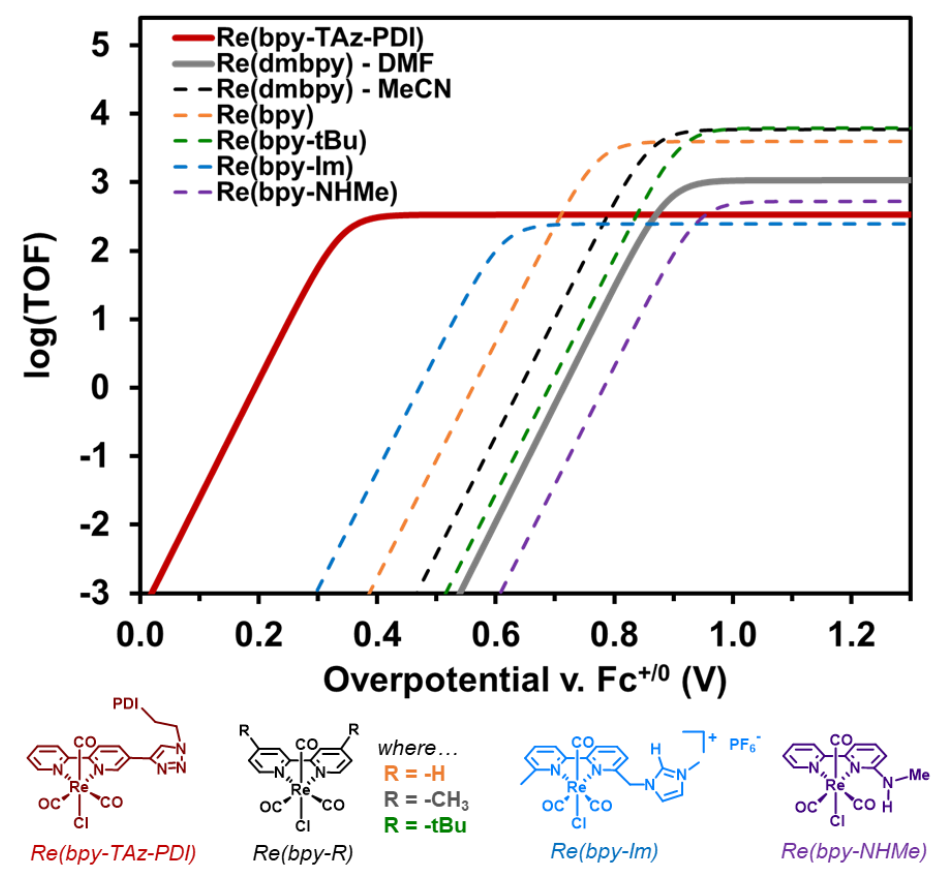

Figure 3. Catalytic Tafel plot comparing Re(bpy-TAz-PDI) (red) and Re(dmbpy) (gray) to other $\operatorname{Re}($ bpy) derivatives. Solid lines indicate measurements were performed in DMF with 2 M TFE at $v=25 \mathrm{~V} / \mathrm{s}$. Dashed lines indicate $\mathrm{E}_{\mathrm{cat} / 2}$ values were obtained from literature, where: all Re(bpy$\mathrm{R})$ experiments were performed in $\mathrm{MeCN}$ with $1 \mathrm{M} \mathrm{PhOH}$ at $v=25 \mathrm{~V} / \mathrm{s},{ }^{28} \mathrm{Re}(\mathrm{bpy}-\mathrm{Im})$ was evaluated in MeCN with $2.8 \mathrm{M}$ water at $v=3 \mathrm{~V} / \mathrm{s}^{29}$ and $\mathrm{Re}(\mathrm{bpy}-\mathrm{NHMe}$ ) was measured in MeCN with $2 \mathrm{M}$ TFE at $v=0.1 \mathrm{~V} / \mathrm{s}^{30}$

\section{- Electro- and Photocatalytic $\mathrm{CO}_{2}$ Reduction}

To assess the $\mathrm{CO}_{2}$ conversion activity of $\operatorname{Re}(\mathbf{b p y}-\mathrm{TAz}-\mathbf{P D I})$, a series of controlled potential electrolysis (CPE) experiments were performed in a two-compartment cell, separated by fine glass frit (Figure S37) ${ }^{62}$ While the shift in onset potential and overall current enhancement for $\operatorname{Re}($ bpy-TAz-PDI) redox events were more pronounced in $\mathrm{MeCN}$, the complex's gradual precipitation from $\mathrm{MeCN}$ necessitated all CPE experiments to be performed in DMF. To benchmark the CPE setup, experiments were performed using Re(dmbpy) and TFE as a proton source. $\operatorname{Re}(\mathrm{dmbpy})$ was chosen as the benchmark catalyst because the installation of electrondonating groups on the bipyridine-moiety has been shown to significantly increase catalyst 
activity, making this catalyst among the top-performing $\operatorname{Re}(\mathrm{bpy})$ derivatives when a protonsource, like TFE, is present. ${ }^{25,28}$

At an applied potential where half of the maximum current enhancement was observed $\left(\mathrm{E}_{\text {cat } / 2} \approx\right.$ $-2.20 \mathrm{~V}), \operatorname{Re}(\mathrm{dmbpy})$ reached a $\mathrm{TON}_{\mathrm{co}}$ of $24 \pm 1$, with a maximum Faradaic efficiency (FE) of $94 \pm 2 \%$, over the 6-hour experiments (Figure 4). At the same applied potentials, Re(bpy-TAzPDI) achieved a modest $\mathrm{TON}_{\mathrm{co}}$ of $13 \pm 1$, with an $\mathrm{FE}$ of $87 \pm 10 \%$. Prolonging the CPE experiments to 24 hours increased the $\mathrm{TON}_{\mathrm{co}}$ and decreased the $\mathrm{FE}_{\mathrm{co}}$ for both catalysts; $\operatorname{Re}(d m b p y)$ achieved a $\mathrm{TON}_{\text {co }}$ of 49 and a FE of $61 \%$, while $\operatorname{Re}(\mathbf{b p y}-\mathbf{T A z}-\mathrm{PDI})$ reached a $\mathrm{TON}_{\mathrm{co}}$ of 34 and a FE of $79 \%$ (Table S2). Other than $\mathrm{H}_{2}$, no other gaseous or liquid products were detected during CPE experiments.

Lowering the applied potential of these CPE experiments by $400 \mathrm{mV}(\mathrm{E}=-1.80 \mathrm{~V})$, in order to better match the onset of $\mathrm{CO}_{2}$ current enhancement for $\operatorname{Re}(\mathbf{b p y}-\mathbf{T A z}-\mathbf{P D I})$, provided significantly different reactivity for the two complexes. The catalytic activity in $\operatorname{Re}($ dmbpy) was effectively shut down at this applied potential, achieving a $\mathrm{TON}_{\mathrm{co}}<2$ and an FE $<40 \%$ after 6 hours of CPE. At the same applied potential, the $\mathrm{TON}_{\mathrm{co}}$ and $\mathrm{FE}$ of $\operatorname{Re}(\mathbf{b p y}-\mathbf{T A z}-\mathbf{P D I})$ were both improved to $24 \pm 4$ and $92 \pm 7 \%$, respectively. Evidently, lowering the applied potential was beneficial to the catalytic activity of $\operatorname{Re}(\mathbf{b p y}-\mathbf{T A z}-\mathbf{P D I})$. Prolonged CPE experiments of 24 and 48 hours resulted in $\mathrm{TON}_{\mathrm{co}}$ of 54 and 84, while FE dropped to values between $42-47 \%$ (Figure S40). As no significant amounts of $\mathrm{H}_{2}$ (or liquid products) were detected during these prolonged CPE experiments, the apparent drop in FE can be partially attributed to a minor PDI-related degradation process (Figure S41). ${ }^{63-65}$
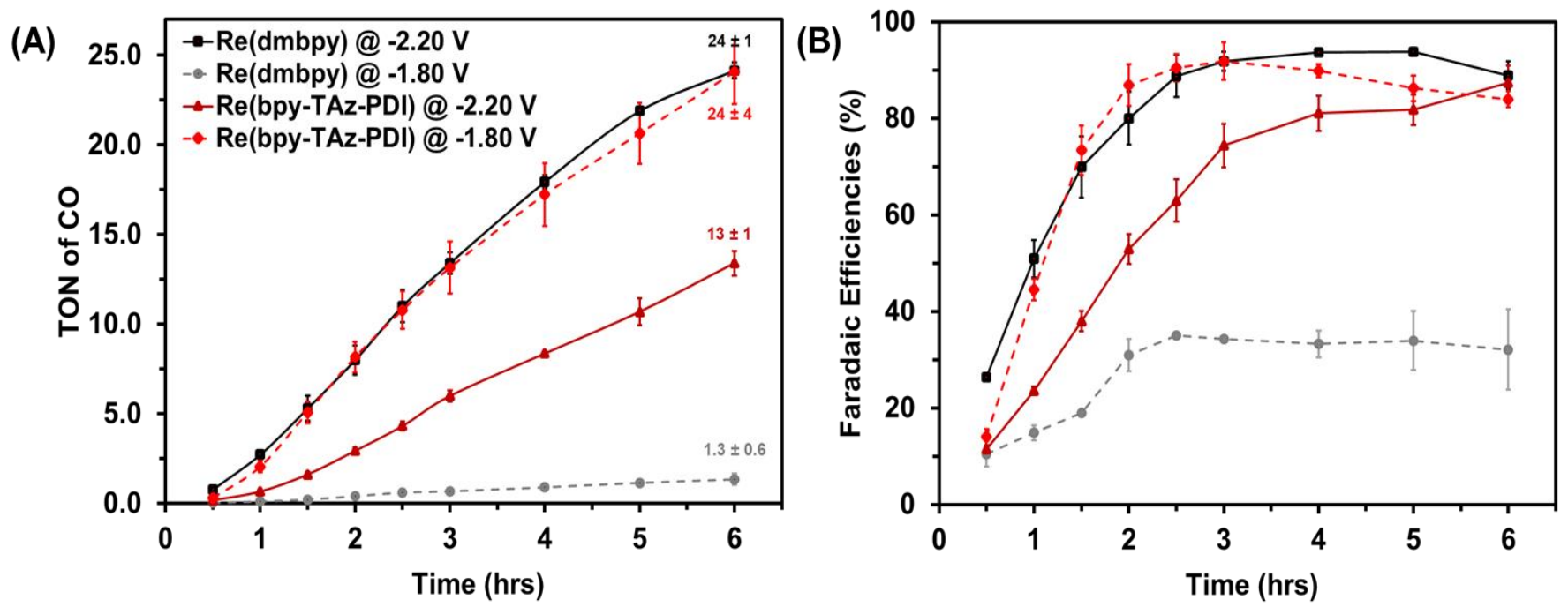

Figure 4. Comparing average $\mathrm{TON}_{\mathrm{co}}(\mathrm{A})$ and faradaic efficiencies of $\mathrm{CO}$ formation (B) achieved by $\operatorname{Re}($ dmbpy) (grey) and $\operatorname{Re}($ bpy-TAz-PDI) (red) during CPE experiments at different applied potentials $(\mathrm{E}=-1.80 \mathrm{~V}$ depicted with dashed lines and $\mathrm{E}=-2.20 \mathrm{~V}$ depicted with solid lines)

Additional CPE experiments were carried out to investigate key operating parameters of $\mathrm{CO}_{2}$ conversion. Under dark conditions, $\operatorname{Re}(\mathbf{b p y}-\mathbf{T A z}-\mathbf{P D I})$ exhibited no difference in electrocatalytic 
$\mathrm{CO}_{2}$ reduction activity (Table $\mathrm{S} 2$, entry 14). Control experiments omitting $\mathrm{CO}_{2}$, TFE, and/or $\operatorname{Re}(\mathbf{b p y}-\mathbf{T A z}-\mathbf{P D I})$ all produced $\mathrm{H}_{2}$ as the only gaseous product (Table $\mathrm{S} 2$, entries 16-18). Also, pairing the benchmark catalyst $\operatorname{Re}(\mathrm{dmbpy})$ and the ligand bpy-TAz-PDI together did not lead to increased $\mathrm{CO}_{2}$ reduction activity when CPE was performed at $-1.80 \mathrm{~V}$ (Table S2, entry 19). Together, these experiments strongly suggest that the tether connecting PDI and the Re(bpy)moiety is essential to the electron transfer process. Moreover, the electron-transfer occurring between the PDI and the Re(bpy)-moiety is not light-mediated but is likely proton-coupled. However, it should be noted that at an applied potential of $-1.80 \mathrm{~V}$, the irradiation of $\operatorname{Re}(\mathbf{b p y}-$ TAz-PDI) with blue light $(\lambda=470 \pm 30 \mathrm{~nm})$ was found to enhance the rate CO production (Entry 15; $\mathrm{TON}_{\mathrm{co}}=35$, after 6 hours). Further investigation is required to understand the influence of blue light on $\mathrm{CO}_{2}$ conversion, as the catalytic enhancement may be attributed to photo-assisted $\mathrm{CO}$ cleavage ${ }^{66,67}$ and/or photoelectrochemical $\mathrm{CO}_{2}$ reduction (Figure S42). ${ }^{68,69}$

Expanding upon these observations, the photocatalytic $\mathrm{CO}_{2}$ reduction capabilities of $\mathbf{R e}(\mathbf{b p y}$ TAz-PDI) were assessed by employing the same blue light source, as the use of UV light is known to cause deactivation and/or degradation of Re(bpy) catalysts. ${ }^{70,71}$ While the emission spectrum of the blue light does not perfectly match the $\lambda_{\max }$ of $\operatorname{Re}(\mathbf{b p y}-\mathbf{T A z}-\mathbf{P D I})$ (Figure S28), the light source is sufficiently energetic to photoexcite the PDI chromophore. The catalyst (65 $\mu \mathrm{M})$ was dissolved in a $(5: 1)$ mixture of DMF : triethanolamine (TEOA), where TEOA simultaneously functioned as the proton source and the sacrificial electron donor. ${ }^{72}$ Using these conditions, $\operatorname{Re}(\mathbf{b p y}-\mathbf{T A z}-\mathbf{P D I})$ produced $\mathrm{CO}\left(\mathrm{TON}_{\mathrm{co}}=8.4 \pm 0.9\right)$ after 18 hours of irradiation, with a high selectivity of $\sim 17: 1 \mathrm{CO}: \mathrm{H}_{2}$ (Table S3). Under the same conditions, Re(dmbpy) achieved a $\mathrm{TON}_{\mathrm{co}}$ of $1.9 \pm 0.2$ after 18 hours, where $\mathrm{CO}$ was the only observable gaseous product. Adding TFE to the reaction mixture caused suppressed formation of both $\mathrm{CO}$ and $\mathrm{H}_{2}$ for $\operatorname{Re}\left(\right.$ bpy-TAz-PDI), whilst $\operatorname{Re}\left(\right.$ dmbpy) experienced complete deactivation in photocatalytic $\mathrm{CO}_{2}$ reduction. The addition of TFE may be hindering the reaction dynamics between TEOA and the catalyst. $^{72,73}$ In the absence of light, $\mathrm{CO}_{2}$, or TEOA, neither catalyst produced any $\mathrm{CO}$ or $\mathrm{H}_{2}$. We may therefore attribute the over 4-fold enhanced photocatalytic activity for $\operatorname{Re}(\mathbf{b p y}-\mathbf{T A z}-\mathbf{P D I})$ to the better overlap between the absorbance profile of the catalyst and the emission spectrum of the irradiation source. This result again emphasizes the promise of the hybrid supramolecular dyad design approach.

\section{- Mechanistic Investigation}

During the first 30 minutes of all CPE experiments with $\mathbf{R e}(\mathbf{b p y}-\mathbf{T A z}$-PDI), it was observed that the color of the bulk solution progressed from orange to dark blue. Inspecting the current vs. time plot (Figure S38A), current passed over this induction period rapidly decayed and minimal CO was produced. However, after this catalyst equilibration period, there was a sudden and sustained increase in passed current (Figure S38B), accompanied by a steady production of CO. Thus, to better probe the electrocatalytic $\mathrm{CO}_{2}$ reduction mechanism of $\operatorname{Re}(\mathbf{b p y}-\mathbf{T A z}-\mathbf{P D I})$, a series of UV-vis-nIR SEC, FTIR SEC, and chemical reduction experiments were performed.

By UV-vis-nIR SEC, applying a potential of $-1.2 \mathrm{~V}$ (R1) caused a color transition from orange to green, which was accompanied by a bathochromic shift in the wavelength of maximum absorption $\left(\lambda_{\max }\right)$ from $521 \mathrm{~nm}$ to $690 \mathrm{~nm}$ (Figure 5A). The characteristic PDI vibronic finestructure simultaneously decreased and new absorption bands in the near-IR region emerged at 
780, 840, and $925 \mathrm{~nm}$. This same color change was observed with bpy-TAz-PDI (Figure S35), confirming the assignment of a $\mathrm{PDI}^{0 / \bullet-}$ reduction. ${ }^{74}$ Decreasing the potential to $-1.5 \mathrm{~V}$ (R2) caused the solution to progress from green to blue. During this color change, the $\lambda_{\max }$ at $690 \mathrm{~nm}$ partially decreased while the absorption fine-structure in the near-IR essentially disappeared. At the same time, two strong absorption bands appeared at 617 and $652 \mathrm{~nm}$. Once again, the same transition was observed with the ligand, confirming the color change was due to PDI ${ }^{\bullet-12-}$ reduction. ${ }^{58}$ Further decreasing the applied potential to $-1.8 \mathrm{~V}$ (R3) did not result in any significant changes to the SEC spectra of $\mathbf{R e}(\mathbf{b p y}-\mathbf{T A z}-\mathbf{P D I})$ as the optical contribution from bpy $^{0 / \bullet-}$ reduction would be minor. ${ }^{70,71}$ All electrochemically generated species were also detected when UV-vis-nIR SEC experiments were performed with TFE (Figure S36B).
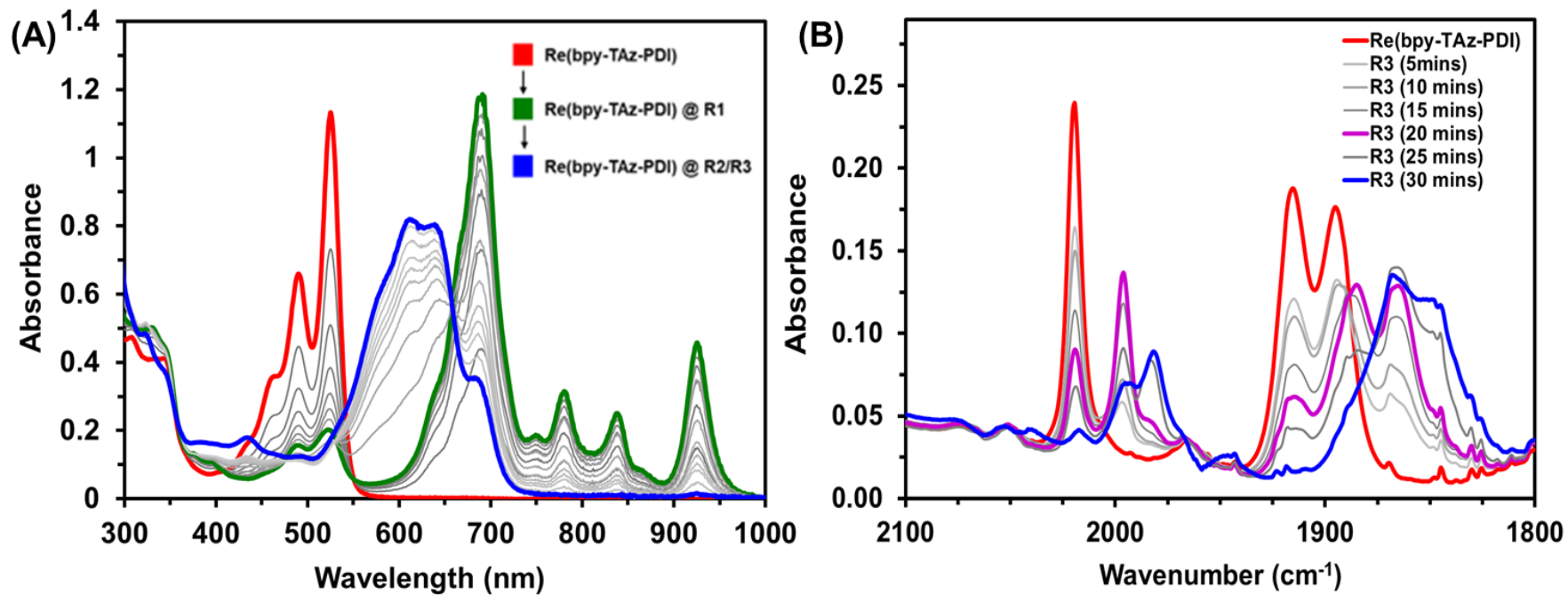

Figure 5. UV-vis-nIR SEC (A) and FTIR SEC (B) absorbance spectra of Re(bpy-TAz-PDI). Spectra were obtained by holding constant applied potentials, where R1, R2, and R3 = -1.2, -1.5 , and $-1.8 \mathrm{~V}$ vs. $\mathrm{Fc}^{+/ 0}$, respectively. All experiments were performed under argon in DMF with 0.1 $\mathrm{M}$ TBAPF 6 supporting electrolyte $(\mathrm{WE}=\mathrm{Pt}$-mesh, $\mathrm{CE}=\mathrm{Pt}$-wire, pseudo-RE $=$ Ag-wire $)$

By FTIR SEC, applied potentials of R1 and R2 did not alter the $v_{\text {co }}$ of $\operatorname{Re}(\mathbf{b p y}-\mathbf{T A z}-\mathbf{P D I})$. These data suggest that excess charge was therefore located mostly on the PDI-moiety, with minimal delocalization onto the Re(bpy)-moiety. Increasing the applied potential to R3, however, caused noticeable transitions in the $v_{\text {co }}$ (Figure 5B). Similar to the systems reported by Kubiak and coworkers, ${ }^{51,52}$ the bpy ${ }^{0 / \bullet-}$ reduction can be characterized by a shift to lower wavenumbers for $v_{\text {co }}$ to $1861,1884,1995 \mathrm{~cm}^{-1}$. Over time, these $v_{\text {co }}$ further shifted to 1845,1866 , and $1980 \mathrm{~cm}^{-1}$, indicating that the electron has delocalized between bpy and Re, eventually shifting electrondensity towards the metal center. ${ }^{54}$ During this equilibration process, it is proposed that a formal $\mathrm{Re}^{\mathrm{I} / 0}$ reduction occurs, leading to the displacement of the axial chloride ligand from Re.

To confirm the assignments made by UV-vis-nIR SEC and FTIR SEC, the reduced $\operatorname{Re}(\mathbf{b p y}-$ TAz-PDI) species were independently synthesized (see SI for full experimental details). Each chemically reduced product was characterized by ${ }^{1} \mathrm{H}$ NMR (Figures S10-S13), as well as UVvis-nIR and FTIR absorption spectroscopies (Figure S26 and S27). The optical and magnetic 
properties of all three anionic $\operatorname{Re}(\mathbf{b p y}-\mathbf{T A z}-\mathbf{P D I})$ complexes correlated well with the corresponding electrochemical processes determined by SEC. As expected, the singly and triply reduced complexes exhibited paramagnetic ${ }^{1} \mathrm{H}$ NMR spectra, while the doubly reduced complex possessed a diamagnetic ${ }^{1} \mathrm{H}$ NMR spectrum. ${ }^{57}$ The aromatic resonances of this chemically reduced product were shifted slightly upfield relative to the $\mathbf{R e}(\mathbf{b p y}-\mathbf{T A z}-\mathbf{P D I})$, suggesting more electron-donating in character of the PDI-moiety.

The chemically reduced $\operatorname{Re}(\mathbf{b p y}-\mathbf{T A z}-\mathbf{P D I})$ species were also investigated using electron paramagnetic resonance (EPR) spectroscopy. As expected for a PDI-based organic radical, the singly reduced species exhibited an axial resonance with $\mathrm{g}_{\mathrm{per}}=2.0009, \mathrm{~g}_{\mathrm{par}}=2.0037$, and no observable hyperfine splitting (Figure S14). ${ }^{75,76}$ The EPR spectrum of the triply reduced species displayed a small hyperfine coupling between the bpy-based radical and the rhenium metal center $\left[\mathrm{a}\left({ }^{183,185} \mathrm{Re}\right)=1.65 \mathrm{mT}\right]$ (Figure S15), which would only be observed if line-broadening contributions from ${ }^{35,37} \mathrm{Cl}$ were removed. Previous interpretations of related paramagnetic $\operatorname{Re}($ bpy) complexes have ascribed this type of coupling pattern to an equilibrium process between the chloro-associated (6-coordinate) and chloro-dissociated (5-coordinate) species. ${ }^{77,78}$

To further probe the $\mathrm{CO}_{2}$ reduction mechanism, a DFT-based investigation was undertaken. All calculations were performed using the M06 functional, ${ }^{79}$ the 6-31G(d,p) Pople basis set for all non-metal elements, ${ }^{80-82}$ and the LANL2DZ basis set for rhenium ${ }^{83-85}$ (see SI Section VIII for more details). All optimized geometries described herein were determined to be minima on the potential energy surface through normal mode analyses. The DFT-optimized structure of groundstate $\operatorname{Re}(\mathbf{b p y}$-TAz-PDI) showed excellent correlation with the single-crystal X-ray diffraction connectivity map (Figure S64). We note that in the optimized ground-state geometry of the complex that the PDI and Re(bpy-TAz) are near each other, with the alkyl arm folded to bring the moieties in proximity. Attempts to optimize the geometry of $\operatorname{Re}(\mathbf{b p y}-\mathbf{T A z}-\mathbf{P D I})$ starting from an extended conformation were unable to deliver an optimized structure, confirming intramolecular folding is important to this system. Optimized geometries were also determined for each constituent component of $\operatorname{Re}(\mathbf{b p y}-\mathbf{T A z}-\mathbf{P D I})$, namely $\operatorname{Re}(\mathrm{bpy}-\mathrm{TAz})$ and $\mathrm{N}$-annulated PDI, to facilitate the construction of a molecular orbital (MO) diagram (Figure S43), which corresponded well to the assigned redox processes derived from the electrochemical measurements (Figure 1). The localized natures of the frontier MOs reveal that the two fragments are nearly electronically isolated, which is reasonable considering the system is not through conjugated.

We next turned our attention to the natures of the electronic states in the proposed reaction cycle (Figure 6). Emphasis was placed on the optimized geometries, frontier MOs, and spin-density maps to demonstrate the distributions of the electron spin in these states. From the ground-state $\mathbf{R e}^{\mathbf{I}}$ (bpy-TAz-PDI) ${ }^{\mathbf{0}}$ (Figure 6A), one electron can be added to the system without significantly affecting the molecular geometry of the complex (Figure S44). The electron spin-density for the doublet state of $\mathbf{R e}^{\mathbf{I}}(\mathbf{b p y}-\mathbf{T A z}-\mathbf{P D I})^{-}$is localized on PDI, as one may expect, correlating well with the calculated highest occupied $\alpha$-spin orbital (HO $\alpha \mathrm{O}$; Figure S45).

Adding a second electron to the system to generate $\mathbf{R e}^{\mathbf{I}}(\mathbf{b p y}-\mathbf{T A z}-\mathbf{P D I})^{\mathbf{2}}$ also did not greatly change the molecular geometry (Figure S46). Both the singlet and triplet states of $\mathbf{R e}^{\mathrm{I}}(\mathbf{b p y}-\mathbf{T A z}-$ PDI ${ }^{2-}$ were considered based on the lowest unoccupied $\alpha$-spin orbital (LU $\left.\alpha \mathrm{O}\right)$ and the lowest unoccupied $\beta$-spin orbital (LUßO) of $\mathbf{R e}^{\mathbf{I}}(\mathbf{b p y}-\mathbf{T A z}-\mathbf{P D I})^{-}$. It should be noted that an 
unrestricted open-shell calculation for $\mathbf{R e}^{\mathbf{I}}(\mathbf{b p y}-\mathbf{T A z}-\mathbf{P D I})^{\mathbf{2 -}}$ converged with all electrons paired on PDI, and the energy difference between the singlet and triplet states is small $(\sim 0.2 \mathrm{eV})$. The spin-density of the triplet state of $\mathbf{R e}^{\mathbf{I}}(\mathbf{b p y}-\mathbf{T A z}-\mathbf{P D I})^{\mathbf{2}}$ is clearly delocalized across the entire complex, where Re-CO anti-bonding interactions are observed (Figure S47). The HOMO of the singlet state, however, showed no Re-CO anti-bonding character (Figure S48). Given that the isolated doubly reduced product was diamagnetic and no $\Delta v_{\text {co }}$ was observed in our FTIR SEC experiments at applied potentials of R2, it is highly likely that $\mathbf{R e}^{\mathrm{I}}(\mathbf{b p y}-\mathbf{T A z}-\mathbf{P D I})^{{ }^{2}-}$ favors the singlet state.

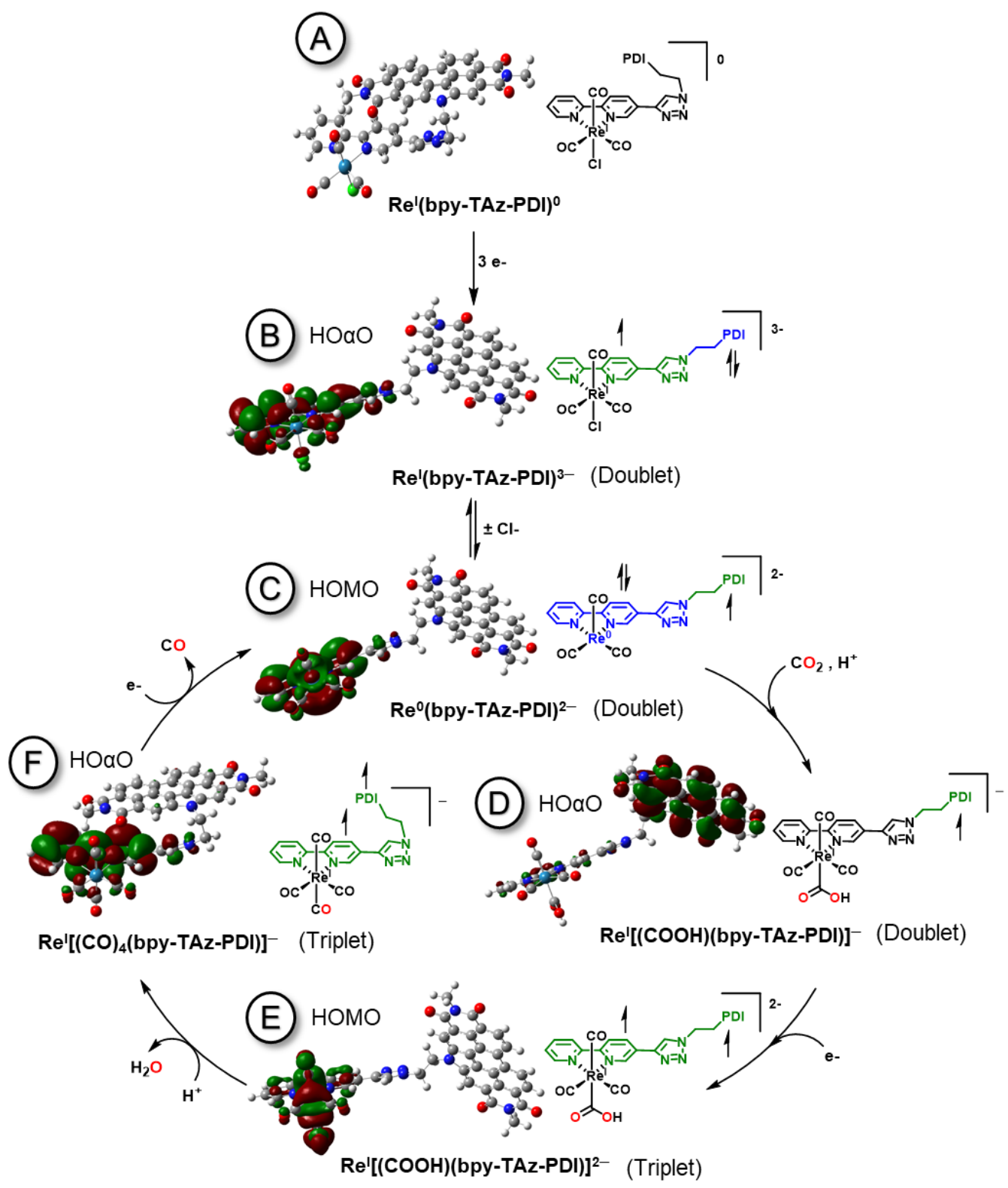

Figure 6. Optimized geometries and relevant $\mathrm{HOMO}$ or $\mathrm{HO} \alpha \mathrm{O}$ for the tentative proposed electrocatalytic $\mathrm{CO}_{2}$ cycle of Re(bpy-TAz-PDI), determined at the M06/6-31G(d,p)/LANL2DZ level of theory. Black, green, or blue coloration of the Re(bpy-TAz) and PDI structural moieties indicate the presence of zero, one, or two additional electrons, respectively. 
A further one-electron reduction of the complex to $\mathbf{R e}^{\mathbf{I}}(\mathbf{b p y}-\mathbf{T A z}-\mathbf{P D I})^{\mathbf{3}-}$ results in a substantial geometric rearrangement (Figures 6B and S49). Instead of PDI being folded over the Re(bpyTAz)-moiety, the alkyl arm extends to separate the PDI and Re(bpy-TAz) moieties. Looking at the MOs of the doublet state of $\operatorname{Re}^{\mathbf{I}}(\mathbf{b p y}-\mathbf{T A z}-\mathbf{P D I})^{\mathbf{3}-}$, the HOMO is PDI-localized, while the $\mathrm{HO} \alpha \mathrm{O}$ is exclusively $\mathrm{Re}(\mathrm{bpy}-\mathrm{TAz}$ ) in character (Figure S50). The extended geometry of the $\mathbf{R e}^{\mathrm{I}}(\mathbf{b p y}-\mathbf{T A z}-\mathbf{P D I})^{\mathbf{3}^{-}}$likely results from electrostatic repulsion between the negatively charged $\mathrm{PDI}^{2-}$ and $\operatorname{Re}(\mathrm{bpy}-\mathrm{TAz})^{\bullet-}$ moieties.

From the FTIR SEC data, $\operatorname{Re}^{\mathbf{I}}(\mathbf{b p y}-\mathbf{T A z}-\mathbf{P D I})^{\mathbf{3}^{3-}}$ was observed to undergo dissociation of the axial chloride-ligand to generate the five-coordinate $\mathbf{R e}^{\mathbf{0}}(\mathbf{b p y}-\mathbf{T A z}-\mathbf{P D I})^{\mathbf{2}}{ }^{-}$(Figure $\left.6 \mathrm{C}\right)$. Geometry optimization calculations performed on the five-coordinate $\operatorname{Re}^{\mathbf{0}}(\mathbf{b p y}-\mathbf{T A z}-\mathbf{P D I})^{\mathbf{2}}$ species showed that PDI was still in an extended state relative to the $\operatorname{Re}($ bpy-TAz)-moiety (Figure S51). Examining the MOs of this doublet state of $\mathbf{R e}^{\mathbf{0}}(\mathbf{b p y}-\mathbf{T A z}-\mathbf{P D I})^{\mathbf{2}-}$, the $\mathrm{HO \alpha O}$ is PDI-centered, while the HOMO is distributed over the Re(bpy-TAz)-moiety (Figure S52) in a similar way to the system reported by Kubiak and co-workers. ${ }^{86}$ These MOs imply that an electron was transferred from the $\mathrm{PDI}^{2-}$ electron-reservoir to the 5-coordinate $\operatorname{Re}(\mathrm{bpy}-\mathrm{TAz})$. Such an electron transfer process may have occurred either by a through-bond mechanism similar to $\mathrm{Ru}^{\mathrm{II}}-\mathrm{Re}^{\mathrm{I}}$ systems ${ }^{32-34}$ or by a through-space mechanism that was facilitated by the orientation of the chromophore. ${ }^{36}$

Experimentally there was no direct evidence of the catalyst adopting either a $\operatorname{Re}^{0}\left(\mathrm{bpy}-\mathrm{TAz}{ }^{\bullet-}\right)$ or a $\operatorname{Re}^{-\mathrm{I}}$ conformation. ${ }^{51,52,87,88}$ We note that attempts to reconcile experimental and theoretical data on $\mathbf{R e}^{\mathbf{0}}(\mathbf{b p y}-\mathbf{T A z}-\mathbf{P D I})^{\mathbf{2}-}$ via calculations with the SMD implicit solvation model, ${ }^{89}$ explicit inclusion of DMF in the coordination sphere of $\operatorname{Re}(b p y-T A z)$ (Figure S53), or explicit protonation of the $\mathrm{PDI}^{2-}$ imide oxygens (Figure S54) each resulted in the same MO and spindensity descriptions. While the electronic configuration for the calculated $\mathbf{R e}^{\mathbf{0}}(\mathbf{b p y}-\mathbf{T A z}-\mathbf{P D I})^{\mathbf{2}-}$ species was not detected experimentally, the possibility of an electron-transfer that results in a $\operatorname{Re}^{0}\left(\right.$ bpy-TAz $\left.{ }^{\bullet-}\right)$ conformation cannot be precluded either. And based on the symmetry of the HOMO being appropriate for a proton-mediated, two-electron nucleophilic attack on $\mathrm{CO}_{2}$, this species is likely a key intermediate in the catalytic cycle. ${ }^{86}$

Since $\mathrm{CO}$ was the major product of $\mathrm{CPE}$ experiments, the intermediate formed following $\mathrm{CO}_{2}$ activation would most likely be $\mathbf{R e}^{\mathrm{I}}[(\mathbf{C O O H})(\mathbf{b p y}-\mathbf{T A z}-\mathbf{P D I})]^{-}$(Figure 6D). The optimized geometry of this intermediate still demonstrated an extended bpy-TAz-PDI ligand and the spindensity for the doublet state was largely located on PDI (Figure S55). Subsequent reduction of this intermediate to form $\mathbf{R e}^{\mathrm{I}}[(\mathbf{C O O H})(\mathbf{b p y}-\mathbf{T A z}-\mathbf{P D I})]^{2-}$ slightly altered the molecular geometry (Figures 6E and S57A). While both the singlet and triplet states of $\mathbf{R e}^{\mathrm{I}}[(\mathbf{C O O H})(\mathbf{b p y}-$ TAz-PDI)] ${ }^{2-}$ were considered, the triplet state is $\sim 0.4 \mathrm{eV}$ more stable. The spin-density for the triplet state of $\operatorname{Re}^{\mathrm{I}}[(\mathbf{C O O H})(\mathbf{b p y}-\mathbf{T A z}-\mathbf{P D I})]^{2-}$ shows significant electron-delocalization across the entire bpy-TAz-PDI ligand, consistent with MO contributions of $\alpha$-spin electrons from both the $\mathrm{HO} \alpha \mathrm{O}-1$ and the $\mathrm{HO} \alpha \mathrm{O}$ (Figure S58). Moreover, appreciable back-bonding interactions were observed between $\mathrm{Re}$ and $\mathrm{COOH}$, which could facilitate the proton-assisted displacement of $\mathrm{H}_{2} \mathrm{O}$, en route to forming $\mathbf{R e}^{\mathrm{I}}\left[(\mathbf{C O})_{4}(\mathbf{b p y}-\mathbf{T A z}-\mathbf{P D I})\right]^{-.87}$

The optimized geometry of $\operatorname{Re}^{\mathrm{I}}\left[(\mathbf{C O})_{4}(\mathbf{b p y}-\mathbf{T A z}-\mathbf{P D I})\right]^{-}$shows that PDI re-folds over the $\operatorname{Re}($ bpy-TAz)-moiety (Figure S60). Here, the triplet state is more energetically favorable (by $\sim 0.5$ 
$\mathrm{eV}$ ) than the corresponding spin-paired singlet state. The spin-density map of the triplet state, containing both $\mathrm{HO} \alpha \mathrm{O}-1$ and $\mathrm{HO} \alpha \mathrm{O}$ (Figure S61), is suggestive of extensive electrondelocalization. Moreover, there were still back-bonding interactions between $\mathrm{Re}$ and $\mathrm{CO}$ in the $\mathrm{HO} \alpha \mathrm{O}$, which could assist with the displacement of $\mathrm{CO}$. Adding another electron to the system, generating $\operatorname{Re}^{\mathrm{I}}\left[(\mathbf{C O})_{4}(\text { bpy-TAz-PDI) }]^{2-}\right.$, dramatically impacts the molecular geometry (Figure S62). Not only was twisting observed in the bpy-TAz ligand, there is also a distinct lengthening in one of the axial Re-CO bonds (Figure S62C). The spin-density of this pseudo 5-coordinate species is entirely on PDI, suggesting the electron was added to the LU $\beta O$ of the preceding species. Furthermore, the spin-density of $\operatorname{Re}^{\mathrm{I}}\left[(\mathbf{C O})_{4}(\mathbf{b p y}-\mathbf{T A z}-\mathbf{P D I})\right]^{2-}$ was similar to that of 5coordinate $\mathbf{R e}^{\mathbf{0}}(\mathbf{b p y}-\mathbf{T A z}-\mathbf{P D I})^{2-}$, indicating the regeneration of this active species.

Combining these computational studies, along with the CPE, SEC and chemical reduction experiments, a tentative mechanism can be proposed (outlined in Figure 6). Following the formal three-electron reduction of $\operatorname{Re}(\mathbf{b p y}-\mathbf{T A z}-\mathbf{P D I})$, the third electron equilibrates between bpy ${ }^{0 / \bullet-}$ and $\mathrm{Re}^{\mathrm{I} / 0}$ to liberate the axial chloro-ligand and open a site for $\mathrm{CO}_{2}$ activation and reduction. In a similar manner to the system reported by Li et. al. ${ }^{20}$ losing the chloro-ligand triggers a shift in the electron-density from the strongly electron-donating $\mathrm{PDI}^{2-}$ electron-reservoir towards the $\operatorname{Re}\left(\right.$ bpy)-moiety. This shift of electron-density allows $\operatorname{Re}(\mathbf{b p y}-\mathbf{T A z}-\mathbf{P D I})$ to reduce $\mathrm{CO}_{2}$, in a proton-coupled electron transfer process, emphasizing the cooperativity between the catalyst and the electron-reservoir. By analogy to other $\operatorname{Re}\left(\right.$ bpy)-based systems, ${ }^{51,52,87,88} \operatorname{Re}(\mathbf{b p y}$-TAz-PDI) must undergo a successive reduction and proton-assisted displacement of $\mathrm{H}_{2} \mathrm{O}$ to generate a tetracarbonyl species. This tetracarbonyl species would undergo a subsequent reduction to liberate $\mathrm{CO}$ and thus regenerate the electrocatalytically active 5-coordinate species.

\section{- Conclusion}

In conclusion, we have reported the synthesis and characterization of a PDI photosensitized $\operatorname{Re}\left(\right.$ bpy) supramolecular dyad. In the presence of $\mathrm{CO}_{2}$ and a proton source, $\operatorname{Re}(\mathbf{b p y}-\mathbf{T A z}$-PDI) electrocatalytically reduced $\mathrm{CO}_{2}$ at an applied potential $400 \mathrm{mV}$ lower than the benchmark catalyst, $\operatorname{Re}\left(\mathrm{dmb}\right.$ y). Moreover, $\operatorname{Re}(\mathbf{b p y}-\mathbf{T A z}-\mathbf{P D I})$ was found to reduce $\mathrm{CO}_{2}$ photocatalytically with 4-fold higher activity, relative to Re(dmbpy). Through a combination of CPE, UV-vis-nIR SEC, FTIR SEC, and chemical reduction experiments, it was elucidated that the PDI-moiety acted as an electron-reservoir. This electron-reservoir effect allowed for enhanced catalytic $\mathrm{CO}_{2}$ reduction activity at significantly lower overpotentials. DFT studies on relevant catalytic intermediates revealed that: (1) the PDI works cooperatively with the $\operatorname{Re}(b p y)$-moiety to manage electrons, and (2) the geometric orientation between PDI and the Re(bpy)-moiety is important to the electron-transfer dynamics for $\mathbf{R e}(\mathbf{b p y}-\mathbf{T A z}-\mathbf{P D I})$ during $\mathrm{CO}_{2}$ reduction, where an extended conformation was favorable. These results could help guide future molecular design by thoughtfully tailoring both the chromophore (electron reservoir) and metal-ligand complex. Research is currently ongoing to understand the impact of tether-length, as well as light irradiation on electro- and photocatalytic activity in these $\operatorname{Re}(\mathbf{b p y}-\mathbf{T A z}-\mathbf{P D I})$ systems.

This work clearly demonstrates the utility of organic chromophore electron reservoirs to effectively lower the overpotential required for $\mathrm{CO}_{2}$ reduction for $\mathrm{Re}(\mathrm{bpy})$ complexes. Operating these molecular electrocatalysts at lower overpotentials not only decreases the required energetic input, but it may also improve system longevity. ${ }^{38,90}$ Moreover, these chromophores may serve as 
useful electrode anchoring units (i.e. through $\pi$-stacking), a strategy that is well-known to simultaneously increase catalyst activity and longevity. ${ }^{13-19}$ Combining these concepts of diminished overpotential and improved catalyst stability together may afford the prospect of developing industrially feasible devices. ${ }^{2,20-23}$ Given the abundance of photoactive $\pi$-conjugated chromophores, an opportunity exists to systematically synthesize a variety of supramolecular dyad $\mathrm{CO}_{2}$ reduction catalysts that have tailored properties to maximize performance.

\section{- Supporting Information}

Experimental details; MALDI-TOF MS; elemental analysis; NMR, UV-vis-nIR, FTIR, and SEC spectra; cyclic voltammograms; CPE data; computational methods/data; crystallographic methods/data (PDF)

\section{- Acknowledgements}

GCW acknowledges the Canada Research Chairs Program, CFI JELF (34102), NSERC DG (2019-04392), and the University of Calgary. WEP acknowledges the Canada Research Chairs Program. JK acknowledges Alberta Graduate Excellence Scholarship (AGES) and NSERC CGSD scholarship programs. This research was undertaken thanks in part to funding from the Canada First Research Excellence Fund (CFREF). CR and KR acknowledge funding by the Research Corporation for Science Advancement (RCSA) Cottrell Scholars program (Award No. 24432); computing resources on the Lipscomb High Performance Computing Cluster were provided by the University of Kentucky Information Technology Department and the Center for Computational Sciences (CCS).

\section{- References}

(1) Keith, D. W.; Holmes, G.; Angelo, D. S.; Heidel, K. A Process for Capturing CO2 from the Atmosphere. Joule 2018, 2 (8), 1573-1594. https://doi.org/10.1016/j.joule.2018.05.006.

(2) Luna, P. D.; Hahn, C.; Higgins, D.; Jaffer, S. A.; Jaramillo, T. F.; Sargent, E. H. What Would It Take for Renewably Powered Electrosynthesis to Displace Petrochemical Processes? Science 2019, 364 (6438). https://doi.org/10.1126/science.aav3506.

(3) Windle, C. D.; Perutz, R. N. Advances in Molecular Photocatalytic and Electrocatalytic CO2 Reduction. Coord. Chem. Rev. 2012, 256 (21), 2562-2570. https://doi.org/10.1016/j.ccr.2012.03.010.

(4) Costentin, C.; Robert, M.; Savéant, J.-M. Catalysis of the Electrochemical Reduction of Carbon Dioxide. Chem. Soc. Rev. 2013, 42, 2423-2436. https://doi.org/10.1039/C2CS35360A.

(5) Zhou, Y.; Che, F.; Liu, M.; Zou, C.; Liang, Z.; Luna, P. D.; Yuan, H.; Li, J.; Wang, Z.; Xie, H.; Li, H.; Chen, P.; Bladt, E.; Quintero-Bermudez, R.; Sham, T.-K.; Bals, S.; Hofkens, J.; Sinton, D.; Chen, G.; Sargent, E. H. Dopant-Induced Electron Localization Drives CO 2 Reduction to C 2 Hydrocarbons. Nat. Chem. 2018, 1. https://doi.org/10.1038/s41557-018-0092-x.

(6) Kibria, M. G.; Edwards, J. P.; Gabardo, C. M.; Dinh, C.-T.; Seifitokaldani, A.; Sinton, D.; Sargent, E. H. Electrochemical CO2 Reduction into Chemical Feedstocks: From Mechanistic Electrocatalysis Models to System Design. Adv. Mater. 2019, 31 (31), 1807166. https://doi.org/10.1002/adma.201807166. 
(7) Nam, D.-H.; De Luna, P.; Rosas-Hernández, A.; Thevenon, A.; Li, F.; Agapie, T.; Peters, J. C.; Shekhah, O.; Eddaoudi, M.; Sargent, E. H. Molecular Enhancement of Heterogeneous CO 2 Reduction. Nat. Mater. 2020, 19 (3), 266-276. https://doi.org/10.1038/s41563-020-0610-2.

(8) Zheng, T.; Jiang, K.; Wang, H. Recent Advances in Electrochemical CO2-to-CO Conversion on Heterogeneous Catalysts. Adv. Mater. 2018, 30 (48), 1802066. https://doi.org/10.1002/adma.201802066.

(9) Zheng, T.; Jiang, K.; Ta, N.; Hu, Y.; Zeng, J.; Liu, J.; Wang, H. Large-Scale and Highly Selective CO2 Electrocatalytic Reduction on Nickel Single-Atom Catalyst. Joule 2019, 3 (1), 265-278. https://doi.org/10.1016/j.joule.2018.10.015.

(10) Xia, C.; Zhu, P.; Jiang, Q.; Pan, Y.; Liang, W.; Stavitski, E.; Alshareef, H. N.; Wang, H. Continuous Production of Pure Liquid Fuel Solutions via Electrocatalytic CO 2 Reduction Using SolidElectrolyte Devices. Nat. Energy 2019, 4 (9), 776-785. https://doi.org/10.1038/s41560-019-0451-x.

(11) Takeda, H.; Cometto, C.; Ishitani, O.; Robert, M. Electrons, Photons, Protons and Earth-Abundant Metal Complexes for Molecular Catalysis of CO2 Reduction. ACS Catal. 2017, 7, 70-88. https://doi.org/10.1021/acscatal.6b02181.

(12) Francke, R.; Schille, B.; Roemelt, M. Homogeneously Catalyzed Electroreduction of Carbon Dioxide-Methods, Mechanisms, and Catalysts. Chem. Rev. 2018, 118 (9), 4631-4701. https://doi.org/10.1021/acs.chemrev.7b00459.

(13) Oh, S.; Gallagher, J. R.; Miller, J. T.; Surendranath, Y. Graphite-Conjugated Rhenium Catalysts for Carbon Dioxide Reduction. J. Am. Chem. Soc. 2016, 138 (6), 1820-1823. https://doi.org/10.1021/jacs.5b13080.

(14) Hu, X.-M.; Rønne, M. H.; Pedersen, S. U.; Skrydstrup, T.; Daasbjerg, K. Enhanced Catalytic Activity of Cobalt Porphyrin in CO2 Electroreduction upon Immobilization on Carbon Materials. Angew. Chem. 2017, 129 (23), 6568-6572. https://doi.org/10.1002/ange.201701104.

(15) Reuillard, B.; Ly, K. H.; Rosser, T. E.; Kuehnel, M. F.; Zebger, I.; Reisner, E. Tuning Product Selectivity for Aqueous CO2 Reduction with a Mn(Bipyridine)-Pyrene Catalyst Immobilized on a Carbon Nanotube Electrode. J. Am. Chem. Soc. 2017, 139 (41), 14425-14435. https://doi.org/10.1021/jacs.7b06269.

(16) Orchanian, N. M.; Hong, L. E.; Marinescu, S. C. Immobilized Molecular Wires on Carbon-Cloth Electrodes Facilitate CO2 Electrolysis. ACS Catal. 2019, 9 (10), 9393-9397. https://doi.org/10.1021/acscatal.9b03134.

(17) Orchanian, N. M.; Hong, L. E.; Skrainka, J. A.; Esterhuizen, J. A.; Popov, D. A.; Marinescu, S. C. Surface-Immobilized Conjugated Polymers Incorporating Rhenium Bipyridine Motifs for Electrocatalytic and Photocatalytic CO2 Reduction. ACS Appl. Energy Mater. 2019, 2 (1), 110-123. https://doi.org/10.1021/acsaem.8b01745.

(18) Willkomm, J.; Bertin, E.; Atwa, M.; Lin, J.-B.; Birss, V.; Piers, W. E. Grafting of a Molecular Rhenium CO2 Reduction Catalyst onto Colloid-Imprinted Carbon. ACS Appl. Energy Mater. 2019, 2 (4), 2414-2418. https://doi.org/10.1021/acsaem.9b00216.

(19) Sinha, S.; Sonea, A.; Shen, W.; Hanson, S. S.; Warren, J. J. Heterogeneous Aqueous CO2 Reduction Using a Pyrene-Modified Rhenium(I) Diimine Complex. Inorg. Chem. 2019, 58 (16), 10454-10461. https://doi.org/10.1021/acs.inorgchem.9b01060.

(20) Qiao, X.; Li, Q.; Schaugaard, R. N.; Noffke, B. W.; Liu, Y.; Li, D.; Liu, L.; Raghavachari, K.; Li, L. Well-Defined Nanographene-Rhenium Complex as an Efficient Electrocatalyst and Photocatalyst for Selective CO2 Reduction. J. Am. Chem. Soc. 2017, 139 (11), 3934-3937. https://doi.org/10.1021/jacs.6b12530.

(21) Wang, M.; Torbensen, K.; Salvatore, D.; Ren, S.; Joulié, D.; Dumoulin, F.; Mendoza, D.; LassalleKaiser, B.; Işci, U.; Berlinguette, C. P.; Robert, M. CO 2 Electrochemical Catalytic Reduction with a Highly Active Cobalt Phthalocyanine. Nat. Commun. 2019, 10 (1), 1-8. https://doi.org/10.1038/s41467-019-11542-w. 
(22) Ren, S.; Joulié, D.; Salvatore, D.; Torbensen, K.; Wang, M.; Robert, M.; Berlinguette, C. P. Molecular Electrocatalysts Can Mediate Fast, Selective CO2 Reduction in a Flow Cell. Science 2019, 365 (6451), 367-369. https://doi.org/10.1126/science.aax4608.

(23) Salvatore, D.; Berlinguette, C. P. Voltage Matters When Reducing CO2 in an Electrochemical Flow Cell. ACS Energy Lett. 2020, 5 (1), 215-220. https://doi.org/10.1021/acsenergylett.9b02356.

(24) Hawecker, J.; Lehn, J.-M.; Ziessel, R. Electrocatalytic Reduction of Carbon Dioxide Mediated by $\mathrm{Re}(\mathrm{Bipy})(\mathrm{CO}) 3 \mathrm{Cl}$ (Bipy = 2,2'-Bipyridine). J. Chem. Soc. Chem. Commun. 1984, O (6), 328-330. https://doi.org/10.1039/C39840000328.

(25) Smieja, J. M.; Kubiak, C. P. Re(Bipy-TBu)(CO)3Cl-improved Catalytic Activity for Reduction of Carbon Dioxide: IR-Spectroelectrochemical and Mechanistic Studies. Inorg. Chem. 2010, 49 (20), 9283-9289. https://doi.org/10.1021/ic1008363.

(26) Sampson, M. D.; Nguyen, A. D.; Grice, K. A.; Moore, C. E.; Rheingold, A. L.; Kubiak, C. P. Manganese Catalysts with Bulky Bipyridine Ligands for the Electrocatalytic Reduction of Carbon Dioxide: Eliminating Dimerization and Altering Catalysis. J. Am. Chem. Soc. 2014, 136, 54605471. https://doi.org/10.1021/ja501252f.

(27) Machan, C. W.; Yin, J.; Chabolla, S. A.; Gilson, M. K.; Kubiak, C. P. Improving the Efficiency and Activity of Electrocatalysts for the Reduction of CO2 through Supramolecular Assembly with Amino Acid-Modified Ligands. J. Am. Chem. Soc. 2016, 138 (26), 8184-8193. https://doi.org/10.1021/jacs.6b03774.

(28) Clark, M. L.; Cheung, P. L.; Lessio, M.; Carter, E. A.; Kubiak, C. P. Kinetic and Mechanistic Effects of Bipyridine (Bpy) Substituent, Labile Ligand, and Brønsted Acid on Electrocatalytic CO2 Reduction by $\operatorname{Re}(B p y)$ Complexes. ACS Catal. 2018, 8 (3), 2021-2029. https://doi.org/10.1021/acscatal.7b03971.

(29) Sung, S.; Kumar, D.; Gil-Sepulcre, M.; Nippe, M. Electrocatalytic CO2 Reduction by ImidazoliumFunctionalized Molecular Catalysts. J. Am. Chem. Soc. 2017, 139 (40), 13993-13996. https://doi.org/10.1021/jacs.7b07709.

(30) Hellman, A. N.; Haiges, R.; Marinescu, S. C. Rhenium Bipyridine Catalysts with Hydrogen Bonding Pendant Amines for CO2 Reduction. Dalton Trans. 2019, 48 (38), 14251-14255. https://doi.org/10.1039/C9DT02689D.

(31) Haviv, E.; Azaiza-Dabbah, D.; Carmieli, R.; Avram, L.; Martin, J. M. L.; Neumann, R. A Thiourea Tether in the Second Coordination Sphere as a Binding Site for CO2 and a Proton Donor Promotes the Electrochemical Reduction of $\mathrm{CO} 2$ to $\mathrm{CO}$ Catalyzed by a Rhenium Bipyridine-Type Complex. J. Am. Chem. Soc. 2018, 140 (39), 12451-12456. https://doi.org/10.1021/jacs.8b05658.

(32) Sahara, G.; Ishitani, O. Efficient Photocatalysts for CO2 Reduction. Inorg. Chem. 2015, 54, 50965104. https://doi.org/10.1021/ic502675a.

(33) Koike, K.; C. Grills, D.; Tamaki, Y.; Fujita, E.; Okubo, K.; Yamazaki, Y.; Saigo, M.; Mukuta, T.; Onda, K.; Ishitani, O. Investigation of Excited State, Reductive Quenching, and Intramolecular Electron Transfer of Ru( Ii )-Re( i ) Supramolecular Photocatalysts for CO 2 Reduction Using Time-Resolved IR Measurements. Chem. Sci. 2018, 9 (11), 2961-2974. https://doi.org/10.1039/C7SC05338J.

(34) Yamazaki, Y.; Ohkubo, K.; Saito, D.; Yatsu, T.; Tamaki, Y.; Tanaka, S.; Koike, K.; Onda, K.; Ishitani, O. Kinetics and Mechanism of Intramolecular Electron Transfer in $\mathrm{Ru}(\mathrm{II})-\operatorname{Re}(\mathrm{I})$ Supramolecular CO2-Reduction Photocatalysts: Effects of Bridging Ligands. Inorg. Chem. 2019, 58 (17), 11480-11492. https://doi.org/10.1021/acs.inorgchem.9b01256.

(35) Windle, C. D.; George, M. W.; Perutz, R. N.; Summers, P. A.; Sun, X. Z.; Whitwood, A. C. Comparison of Rhenium-Porphyrin Dyads for CO2 Photoreduction: Photocatalytic Studies and Charge Separation Dynamics Studied by Time-Resolved IR Spectroscopy. Chem. Sci. 2015, 6 (12), 6847-6864. https://doi.org/10.1039/C5SC02099A.

(36) Lang, P.; Pfrunder, M.; Quach, G.; Braun-Cula, B.; Moore, E. G.; Schwalbe, M. Sensitized Photochemical CO2 Reduction by Hetero-Pacman Compounds Linking a ReI Tricarbonyl with a 
Porphyrin Unit. Chem. - Eur. J. 2019, 25 (17), 4509-4519.

https://doi.org/10.1002/chem.201806347.

(37) Kuramochi, Y.; Fujisawa, Y.; Satake, A. Photocatalytic CO2 Reduction Mediated by Electron Transfer via the Excited Triplet State of Zn(II) Porphyrin. J. Am. Chem. Soc. 2020, 142 (2), 705709. https://doi.org/10.1021/jacs.9b12712.

(38) Franco, F.; Cometto, C.; Garino, C.; Minero, C.; Sordello, F.; Nervi, C.; Gobetto, R. Photo- and Electrocatalytic Reduction of $\mathrm{CO} 2$ by $\left[\mathrm{Re}(\mathrm{CO}) 3 \alpha, \mathrm{A}^{\prime}\right.$-Diimine-(4-Piperidinyl-1,8-Naphthalimide)Cl] Complexes. Eur. J. Inorg. Chem. 2015, 2015 (2), 296-304. https://doi.org/10.1002/ejic.201402912.

(39) Martinez, J. F.; La Porte, N. T.; Wasielewski, M. R. Electron Transfer from Photoexcited Naphthalene Diimide Radical Anion to Electrocatalytically Active $\operatorname{Re}(\mathrm{Bpy})(\mathrm{CO}) 3 \mathrm{Cl}$ in a Molecular Triad. J. Phys. Chem. C 2018, 122 (5), 2608-2617. https://doi.org/10.1021/acs.jpcc.7b11999.

(40) Martinez, J. F.; La Porte, N. T.; Chaudhuri, S.; Sinopoli, A.; Bae, Y. J.; Sohail, M.; Batista, V. S.; Wasielewski, M. R. Effect of Electronic Coupling on Electron Transfer Rates from Photoexcited Naphthalenediimide Radical Anion to $\operatorname{Re}(\mathrm{Bpy})(\mathrm{CO}) 3 X$. J. Phys. Chem. C 2019, 123 (16), 1017810190. https://doi.org/10.1021/acs.jpcc.8b12264.

(41) Martinez, J. F.; La Porte, N. T.; Wasielewski, M. R. Electron Transfer from Photoexcited Naphthalene-1,4:5,8-Bis(Dicarboximide) Radical Anion to $\mathrm{Mn}(\mathrm{Bpy})(\mathrm{CO}) 3 \mathrm{X}$ and $\operatorname{Re}(\mathrm{Bpy})(\mathrm{CO}) 3 \mathrm{X}$ CO2 Reduction Catalysts Linked via a Saturated Methylene Bridge. J. Photochem. Photobiol. Chem. 2019, 372, 21-28. https://doi.org/10.1016/j.jphotochem.2018.11.047.

(42) Hedström, S.; Chaudhuri, S.; La Porte, N. T.; Rudshteyn, B.; Martinez, J. F.; Wasielewski, M. R.; Batista, V. S. Thousandfold Enhancement of Photoreduction Lifetime in Re(Bpy)(CO)3 via SpinDependent Electron Transfer from a Perylenediimide Radical Anion Donor. J. Am. Chem. Soc. 2017, 139 (46), 16466-16469. https://doi.org/10.1021/jacs.7b09438.

(43) Porte, N. T. L.; Martinez, J. F.; Hedström, S.; Rudshteyn, B.; Phelan, B. T.; Mauck, C. M.; Young, R. M.; Batista, V. S.; Wasielewski, M. R. Photoinduced Electron Transfer from Rylenediimide Radical Anions and Dianions to $\operatorname{Re}(\mathrm{Bpy})(\mathrm{CO}) 3$ Using Red and near-Infrared Light. Chem. Sci. 2017, 8 (5), 3821-3831. https://doi.org/10.1039/C6SC05103K.

(44) Liu, Z.; Wu, Y.; Zhang, Q.; Gao, X. Non-Fullerene Small Molecule Acceptors Based on Perylene Diimides. J. Mater. Chem. A 2016, 4 (45), 17604-17622. https://doi.org/10.1039/C6TA06978A.

(45) Chen, W.; Zhang, Q. Recent Progress in Non-Fullerene Small Molecule Acceptors in Organic Solar Cells (OSCs). J. Mater. Chem. C 2017, 5 (6), 1275-1302. https://doi.org/10.1039/C6TC05066B.

(46) Nowak-Król, A.; Shoyama, K.; Stolte, M.; Würthner, F. Naphthalene and Perylene Diimides Better Alternatives to Fullerenes for Organic Electronics? Chem. Commun. 2018, 54 (98), 1376313772. https://doi.org/10.1039/C8CC07640E.

(47) Hendsbee, A. D.; Sun, J.-P.; Law, W. K.; Yan, H.; Hill, I. G.; Spasyuk, D. M.; Welch, G. C. Synthesis, Self-Assembly, and Solar Cell Performance of N-Annulated Perylene Diimide NonFullerene Acceptors. Chem. Mater. 2016, 28 (19), 7098-7109. https://doi.org/10.1021/acs.chemmater.6b03292.

(48) Cann, J. R.; Cabanetos, C.; Welch, G. C. Synthesis of Molecular Dyads and Triads Based Upon NAnnulated Perylene Diimide Monomers and Dimers. Eur. J. Org. Chem. 2018, 2018 (48), 69336943. https://doi.org/10.1002/ejoc.201801383.

(49) Vespa, M.; Cann, J. R.; Dayneko, S. V.; Melville, O. A.; Hendsbee, A. D.; Zou, Y.; Lessard, B. H.; Welch, G. C. Synthesis of a Perylene Diimide Dimer with Pyrrolic N-H Bonds and NFunctionalized Derivatives for Organic Field-Effect Transistors and Organic Solar Cells. Eur. J. Org. Chem. 2018, 2018 (33), 4592-4599. https://doi.org/10.1002/ejoc.201801055.

(50) Guo, Y.; Ma, Z.; Niu, X.; Zhang, W.; Tao, M.; Guo, Q.; Wang, Z.; Xia, A. Bridge-Mediated Charge Separation in Isomeric N-Annulated Perylene Diimide Dimers. J. Am. Chem. Soc. 2019, 141 (32), 12789-12796. https://doi.org/10.1021/jacs.9b05723.

(51) Benson Eric E.; Sampson Matthew D.; Grice Kyle A.; Smieja Jonathan M.; Froehlich Jesse D.; Friebel Daniel; Keith John A.; Carter Emily A.; Nilsson Anders; Kubiak Clifford P. The Electronic States of Rhenium Bipyridyl Electrocatalysts for CO2 Reduction as Revealed by X-ray Absorption 
Spectroscopy and Computational Quantum Chemistry. Angew. Chem. Int. Ed. 2013, 52 (18), 48414844. https://doi.org/10.1002/anie.201209911.

(52) Machan, C. W.; Sampson, M. D.; Chabolla, S. A.; Dang, T.; Kubiak, C. P. Developing a Mechanistic Understanding of Molecular Electrocatalysts for CO2 Reduction Using Infrared Spectroelectrochemistry. Organometallics 2014, 33 (18), 4550-4559. https://doi.org/10.1021/om500044a.

(53) Machan, C. W.; Chabolla, S. A.; Yin, J.; Gilson, M. K.; Tezcan, F. A.; Kubiak, C. P. Supramolecular Assembly Promotes the Electrocatalytic Reduction of Carbon Dioxide by $\operatorname{Re}(\mathrm{I})$ Bipyridine Catalysts at a Lower Overpotential. J. Am. Chem. Soc. 2014, 136 (41), 14598-14607. https://doi.org/10.1021/ja5085282.

(54) Christensen, P.; Hamnett, A.; Muir, A. V. G.; Timney, J. A. An in Situ Infrared Study of CO2 Reduction Catalysed by Rhenium Tricarbonyl Bipyridyl Derivatives. J. Chem. Soc. Dalton Trans. 1992, No. 9, 1455-1463. https://doi.org/10.1039/DT9920001455.

(55) Koenig, J. D. B.; Laventure, A.; Welch, G. C. Harnessing Direct (Hetero)Arylation in Pursuit of a Saddle-Shaped Perylene Diimide Tetramer. ACS Appl. Energy Mater. 2019, 2 (12), 8939-8945. https://doi.org/10.1021/acsaem.9b01978.

(56) McAfee, S. M.; Dayneko, S. V.; Josse, P.; Blanchard, P.; Cabanetos, C.; Welch, G. C. Simply Complex: The Efficient Synthesis of an Intricate Molecular Acceptor for High-Performance AirProcessed and Air-Tested Fullerene-Free Organic Solar Cells. Chem. Mater. 2017, 29 (3), 13091314. https://doi.org/10.1021/acs.chemmater.6b04862.

(57) Shirman, E.; Ustinov, A.; Ben-Shitrit, N.; Weissman, H.; Iron, M. A.; Cohen, R.; Rybtchinski, B. Stable Aromatic Dianion in Water. J. Phys. Chem. B 2008, 112 (30), 8855-8858. https://doi.org/10.1021/jp8029743.

(58) Seifert, S.; Schmidt, D.; Würthner, F. An Ambient Stable Core-Substituted Perylene Bisimide Dianion: Isolation and Single Crystal Structure Analysis. Chem. Sci. 2015, 6 (3), 1663-1667. https://doi.org/10.1039/C4SC03671A.

(59) Costentin, C.; Savéant, J.-M. Towards an Intelligent Design of Molecular Electrocatalysts. Nat. Rev. Chem. 2017, 1 (11), 0087. https://doi.org/10.1038/s41570-017-0087.

(60) Rountree, E. S.; McCarthy, B. D.; Eisenhart, T. T.; Dempsey, J. L. Evaluation of Homogeneous Electrocatalysts by Cyclic Voltammetry. Inorg. Chem. 2014, 53 (19), 9983-10002. https://doi.org/10.1021/ic500658x.

(61) Azcarate, I.; Costentin, C.; Robert, M.; Savéant, J.-M. Through-Space Charge Interaction Substituent Effects in Molecular Catalysis Leading to the Design of the Most Efficient Catalyst of CO2-to-CO Electrochemical Conversion. J. Am. Chem. Soc. 2016, 138 (51), 16639-16644. https://doi.org/10.1021/jacs.6b07014.

(62) Koenig, J. D. B.; Willkomm, J.; Roesler, R.; Piers, W. E.; Welch, G. C. Electrocatalytic CO2 Reduction at Lower Overpotentials Using Iron(III) Tetra(Meso-Thienyl)Porphyrins. ACS Appl. Energy Mater. 2019, 2 (6), 4022-4026. https://doi.org/10.1021/acsaem.9b00761.

(63) Hao, L.; Jiang, W.; Wang, Z. Integration of Nitrogen into Coronene Bisimides. Tetrahedron 2012, 68 (45), 9234-9239. https://doi.org/10.1016/j.tet.2012.08.084.

(64) Schulze, M.; Steffen, A.; Würthner, F. Near-IR Phosphorescent Ruthenium(II) and Iridium(III) Perylene Bisimide Metal Complexes. Angew. Chem. Int. Ed. 2015, 54 (5), 1570-1573. https://doi.org/10.1002/anie.201410437.

(65) Li, G.; Zhao, Y.; Li, J.; Cao, J.; Zhu, J.; Sun, X. W.; Zhang, Q. Synthesis, Characterization, Physical Properties, and OLED Application of Single BN-Fused Perylene Diimide. J. Org. Chem. 2015, 80 (1), 196-203. https://doi.org/10.1021/jo502296z.

(66) Cometto, C.; Chen, L.; Lo, P.-K.; Guo, Z.; Lau, K.-C.; Anxolabéhère-Mallart, E.; Fave, C.; Lau, T.C.; Robert, M. Highly Selective Molecular Catalysts for the CO2-to-CO Electrochemical Conversion at Very Low Overpotential. Contrasting Fe vs Co Quaterpyridine Complexes upon Mechanistic Studies. ACS Catal. 2018, 3411-3417. https://doi.org/10.1021/acscatal.7b04412. 
(67) Fernández, S.; Franco, F.; Casadevall, C.; Martin-Diaconescu, V.; Luis, J. M.; Lloret-Fillol, J. A Unified Electro- and Photocatalytic CO2 to CO Reduction Mechanism with Aminopyridine Cobalt Complexes. J. Am. Chem. Soc. 2020, 142 (1), 120-133. https://doi.org/10.1021/jacs.9b06633.

(68) Sahara, G.; Kumagai, H.; Maeda, K.; Kaeffer, N.; Artero, V.; Higashi, M.; Abe, R.; Ishitani, O. Photoelectrochemical Reduction of $\mathrm{CO} 2$ Coupled to Water Oxidation Using a Photocathode with a $\mathrm{Ru}(\mathrm{II})-\mathrm{Re}(\mathrm{I})$ Complex Photocatalyst and a CoOx/TaON Photoanode. J. Am. Chem. Soc. 2016, 138 (42), 14152-14158. https://doi.org/10.1021/jacs.6b09212.

(69) Kamata, R.; Kumagai, H.; Yamazaki, Y.; Sahara, G.; Ishitani, O. Photoelectrochemical CO2 Reduction Using a $\mathrm{Ru}(\mathrm{II})-\mathrm{Re}(\mathrm{I})$ Supramolecular Photocatalyst Connected to a Vinyl Polymer on a $\mathrm{NiO}$ Electrode. ACS Appl. Mater. Interfaces 2019, 11 (6), 5632-5641. https://doi.org/10.1021/acsami.8b05495.

(70) Sato, S.; Matubara, Y.; Koike, K.; Falkenström, M.; Katayama, T.; Ishibashi, Y.; Miyasaka, H.; Taniguchi, S.; Chosrowjan, H.; Mataga, N.; Fukazawa, N.; Koshihara, S.; Onda, K.; Ishitani, O. Photochemistry of Fac-[Re(Bpy)(CO)3Cl]. Chem. Weinh. Bergstr. Ger. 2012, 18 (49), 1572215734. https://doi.org/10.1002/chem.201202734.

(71) Lang, P.; Giereth, R.; Tschierlei, S.; Schwalbe, M. Unexpected Wavelength Dependency of the Photocatalytic CO2 Reduction Performance of the Well-Known (Bpy)Re(CO)3Cl Complex. Chem. Commun. 2019, 55 (5), 600-603. https://doi.org/10.1039/C8CC08742C.

(72) Morimoto, T.; Nakajima, T.; Sawa, S.; Nakanishi, R.; Imori, D.; Ishitani, O. CO2 Capture by a Rhenium(I) Complex with the Aid of Triethanolamine. J. Am. Chem. Soc. 2013, 135 (45), 1682516828. https://doi.org/10.1021/ja409271s.

(73) Kou, Y.; Nabetani, Y.; Masui, D.; Shimada, T.; Takagi, S.; Tachibana, H.; Inoue, H. Direct Detection of Key Reaction Intermediates in Photochemical CO2 Reduction Sensitized by a Rhenium Bipyridine Complex. J. Am. Chem. Soc. 2014, 136 (16), 6021-6030. https://doi.org/10.1021/ja500403e.

(74) Pekdemir, F.; Orman, E. B.; Selçuki, N. A.; Özkaya, A. R.; Salih, B.; Şengül, A. Spectroscopic, Electrochemical and Electrocolorimetric Properties of Novel 2-(2'-Pyridyl)-1H-Benzimidazole Appended Bay-Substituted Perylene Diimide Triads. J. Photochem. Photobiol. Chem. 2019, 379, 54-62. https://doi.org/10.1016/j.jphotochem.2019.04.039.

(75) Kumar, Y.; Kumar, S.; Bansal, D.; Mukhopadhyay, P. Synthesis and Isolation of a Stable Perylenediimide Radical Anion and Its Exceptionally Electron-Deficient Precursor. Org. Lett. 2019, 21 (7), 2185-2188. https://doi.org/10.1021/acs.orglett.9b00490.

(76) Zhang, A.; Jiang, W.; Wang, Z. Fulvalene-Embedded Perylene Diimide and Its Stable Radical Anion. Angew. Chem. Int. Ed. 2020, 59 (2), 752-757. https://doi.org/10.1002/anie.201912536.

(77) Scheiring, T.; Klein, A.; Kaim, W. EPR Study of Paramagnetic Rhenium(I) Complexes $($ Bpy $>>>>->>) \operatorname{Re}(\mathrm{CO}) 3 \mathrm{X}$ Relevant to the Mechanism of Electrocatalytic CO2 Reduction $\uparrow . J$. Chem. Soc. Perkin Trans. 2 1997, No. 12, 2569-2572. https://doi.org/10.1039/A702467C.

(78) Wang, M.; Weyhermüller, T.; Bill, E.; Ye, S.; Wieghardt, K. Structural and Spectroscopic Characterization of Rhenium Complexes Containing Neutral, Monoanionic, and Dianionic Ligands of 2,2'-Bipyridines and 2,2':6,2'-Terpyridines: An Experimental and Density Functional Theory (DFT)-Computational Study. Inorg. Chem. 2016, 55 (10), 5019-5036. https://doi.org/10.1021/acs.inorgchem.6b00609.

(79) Zhao, Y.; Truhlar, D. G. The M06 Suite of Density Functionals for Main Group Thermochemistry, Thermochemical Kinetics, Noncovalent Interactions, Excited States, and Transition Elements: Two New Functionals and Systematic Testing of Four M06-Class Functionals and 12 Other Functionals. Theor. Chem. Acc. 2008, 120 (1), 215-241. https://doi.org/10.1007/s00214-007-0310-x.

(80) Hariharan, P. C.; Pople, J. A. The Influence of Polarization Functions on Molecular Orbital Hydrogenation Energies. Theor. Chim. Acta 1973, 28 (3), 213-222.

https://doi.org/10.1007/BF00533485. 
(81) Petersson, G. A.; Bennett, A.; Tensfeldt, T. G.; Al-Laham, M. A.; Shirley, W. A.; Mantzaris, J. A Complete Basis Set Model Chemistry. I. The Total Energies of Closed-shell Atoms and Hydrides of the First-row Elements. J. Chem. Phys. 1988, 89 (4), 2193-2218. https://doi.org/10.1063/1.455064.

(82) Petersson, G. A.; Al-Laham, M. A. A Complete Basis Set Model Chemistry. II. Open-shell Systems and the Total Energies of the First-row Atoms. J. Chem. Phys. 1991, 94 (9), 6081-6090. https://doi.org/10.1063/1.460447.

(83) Hehre, W. J.; Ditchfield, R.; Pople, J. A. Self-Consistent Molecular Orbital Methods. XII. Further Extensions of Gaussian-Type Basis Sets for Use in Molecular Orbital Studies of Organic Molecules. J. Chem. Phys. 1972, 56 (5), 2257-2261. https://doi.org/10.1063/1.1677527.

(84) Hay, P. J.; Wadt, W. R. Ab Initio Effective Core Potentials for Molecular Calculations. Potentials for the Transition Metal Atoms Sc to Hg. J. Chem. Phys. 1985, 82 (1), 270-283. https://doi.org/10.1063/1.448799.

(85) Wadt, W. R.; Hay, P. J. Ab Initio Effective Core Potentials for Molecular Calculations. Potentials for Main Group Elements Na to Bi. J. Chem. Phys. 1985, 82 (1), 284-298. https://doi.org/10.1063/1.448800.

(86) Smieja, J. M.; Benson, E. E.; Kumar, B.; Grice, K. A.; Seu, C. S.; Miller, A. J. M.; Mayer, J. M.; Kubiak, C. P. Kinetic and Structural Studies, Origins of Selectivity, and Interfacial Charge Transfer in the Artificial Photosynthesis of CO. Proc. Natl. Acad. Sci. 2012, 109 (39), 15646-15650. https://doi.org/10.1073/pnas.1119863109.

(87) Riplinger, C.; Sampson, M. D.; Ritzmann, A. M.; Kubiak, C. P.; Carter, E. A. Mechanistic Contrasts between Manganese and Rhenium Bipyridine Electrocatalysts for the Reduction of Carbon Dioxide. J. Am. Chem. Soc. 2014, 136 (46), 16285-16298. https://doi.org/10.1021/ja508192y.

(88) A. Grice, K.; X. Gu, N.; D. Sampson, M.; P. Kubiak, C. Carbon Monoxide Release Catalysed by Electron Transfer : Electrochemical and Spectroscopic Investigations of [Re(Bpy-R)(CO) 4 ](OTf) Complexes Relevant to CO 2 Reduction. Dalton Trans. 2013, 42 (23), 8498-8503. https://doi.org/10.1039/C3DT50612F.

(89) Marenich, A. V.; Cramer, C. J.; Truhlar, D. G. Universal Solvation Model Based on Solute Electron Density and on a Continuum Model of the Solvent Defined by the Bulk Dielectric Constant and Atomic Surface Tensions. J. Phys. Chem. B 2009, 113 (18), 6378-6396. https://doi.org/10.1021/jp810292n.

(90) Costentin, C.; Drouet, S.; Robert, M.; Savéant, J.-M. A Local Proton Source Enhances CO2 Electroreduction to CO by a Molecular Fe Catalyst. Science 2012, 338 (6103), 90-94. https://doi.org/10.1126/science.1224581. 
*** Table of Contents (TOC) Graphic ***

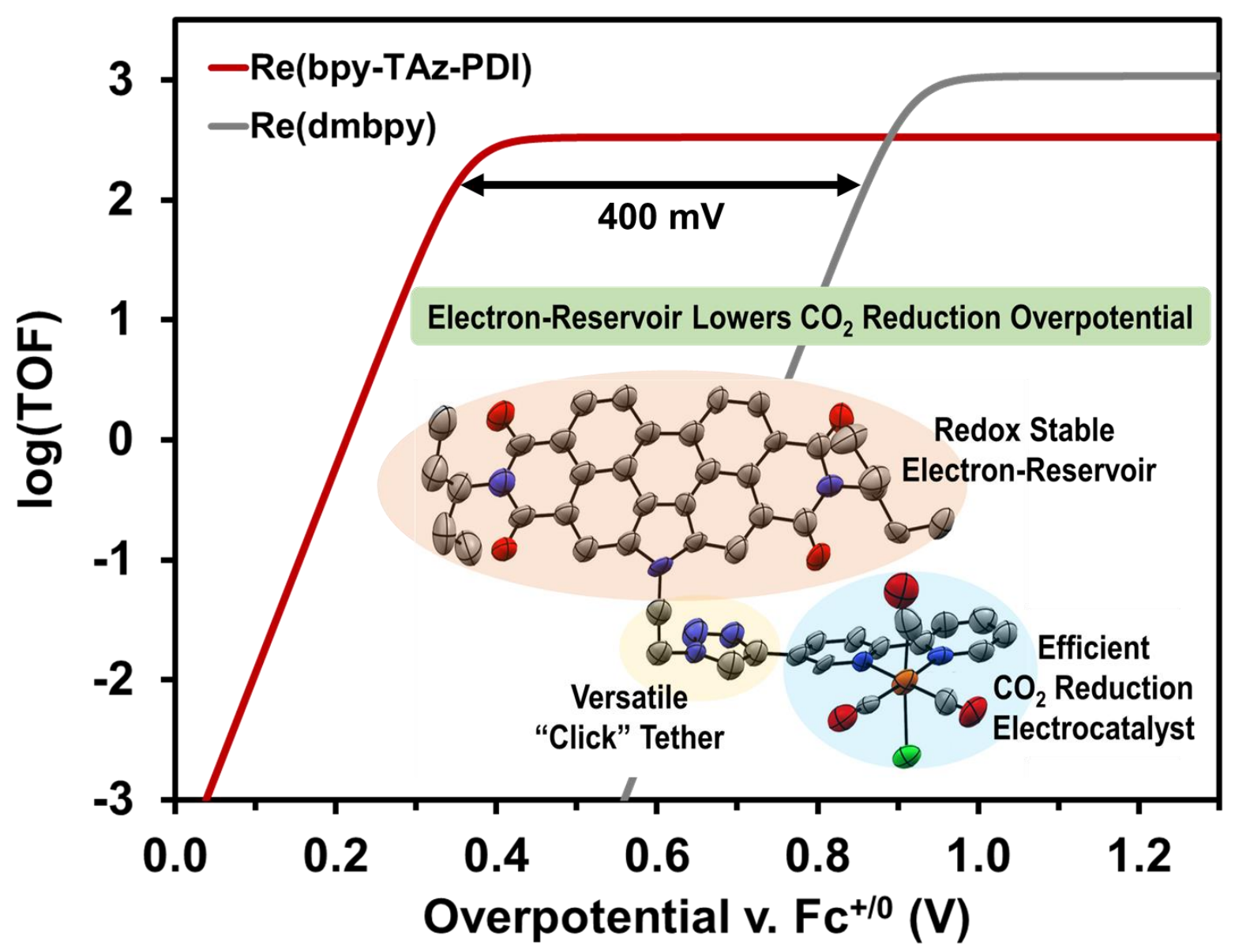

*** Table of Contents (TOC) Graphic *** 



\section{Electron-Reservoir Effect on a Perylene Diimide Tethered Rhenium Bipyridine Complex for $\mathrm{CO}_{2}$ Reduction}

\section{(Supporting Information)}

Josh D. B. Koenig ${ }^{\mathrm{a}}$, Zachary Dubrawski ${ }^{\mathrm{a}}$, Keerthan R. Rao ${ }^{\mathrm{b}}$, Janina Willkomm $^{\mathrm{a}}$, Benjamin S. Gelfand $^{\mathrm{a}}$, Chad Risko ${ }^{\mathrm{b}}$, Warren E. Piers ${ }^{\mathrm{a}}$, and Gregory C. Welch ${ }^{\mathrm{a} *}$

a Department of Chemistry, University of Calgary, 2500 University Drive N.W., Calgary, Alberta, T2N 1N4, Canada.

${ }^{\mathrm{b}}$ Department of Chemistry \& Center for Applied Energy Research, University of Kentucky, Lexington, Kentucky 40506, United States

* Corresponding Author

Email: gregory.welch@ucalgary.ca

Phone Number: 1-403-210-7603

Keywords: $\mathrm{CO}_{2}$ reduction; electrochemical catalysis; molecular catalysis; rhenium; bipyridine; $\operatorname{Re}($ bpy); perylene diimide; PDI

\section{TABLE OF CONTENTS}

1. Materials and Methods

$\mathrm{S} 2-\mathrm{S} 4$

2. Synthetic/Experimental Procedures $\quad$ S5 - S9

3. ${ }^{1} \mathrm{H} \&{ }^{13} \mathrm{C}$ NMR and EPR Spectroscopies $\quad$ S10 - S17

4. MALDI-TOF MS \& CHN Elemental Analysis $\quad$ S18 - S20

5. UV-Vis \& FTIR Spectroscopy $\quad$ S21 - S24

6. Cyclic Voltammetry \& Spectroelectrochemistry S25 - S28

7. Electro- and Photocatalytic $\mathrm{CO}_{2}$ Reduction $\quad$ S29-S34

8. Density Functional Theory Calculations $\quad$ S35 $-\mathbf{S 4 5}$

9. X-ray Diffraction Crystallography S46 - S51

10. References $\quad$ S52 - S54 


\section{Methods and Materials}

Materials: All air-free reactions were carried out under an atmosphere of argon using standard glove box or high vacuum line (Schlenk) techniques unless otherwise stated. For inert atmosphere manipulations, reagents and solvents were stored in argon-filled glove boxes prior to use. THF was dried and degassed over activated alumina using a solvent purification system, dried further with $\mathrm{Na}$ /benzophenone and vacuum distilled prior to use. $\mathrm{MeCN}-\mathrm{d}_{3}(99.8 \% \mathrm{D}$, Sigma-Aldrich) was transferred into a Schlenk flask and dried over $20 \% \mathrm{w} / \mathrm{v}$ activated $3 \AA$ molecular sieves for at least $24 \mathrm{~h}$ then vacuum distilled prior to use. ${ }^{1} \mathrm{KC}_{8}$ was synthesized according to literature procedure. ${ }^{2}$ All other reactants, reagents, and catalysts were purchased from Millipore-Sigma or Fisher Scientific and used without further purification.

Nuclear Magnetic Resonance (NMR): ${ }^{1} \mathrm{H}$ and ${ }^{13} \mathrm{C}$ NMR spectroscopy experiments were recorded using a Bruker Avance III $500 \mathrm{MHz}$ spectrometer. All experiments were performed in either chloroform-d $\left(\mathrm{CDCl}_{3}\right)$ or acetonitrile- $\mathrm{d}_{3}\left(\mathrm{MeCN}-\mathrm{d}_{3}\right)$. Chemical shifts (referenced to residual solvent) were reported in parts per million (ppm). Multiplicities were reported as follows: singlet (s), doublets (d), triplets (t), quartet (q), pentet (p), doublet of doublets (dd), doublet of triplets $(\mathrm{dt})$, doublet of quartets $(\mathrm{dq})$, triplet of doublets (td), triplet of triplets (tt), doublet of doublet of doublets (ddd), and multiplets (m).

High-resolution MALDI-TOF (HR MALDI-TOF): High-resolution MALDI-TOF mass spectrometry measurements were performed courtesy of Johnson $\mathrm{Li}$ in the Chemical Instrumentation Facility at the University of Calgary (UofC). Sample solution $(\sim 1 \mu \mathrm{g} / \mathrm{mL}$ in $\mathrm{CH}_{2} \mathrm{Cl}_{2}$ ) was mixed with matrix trans-2-[3-(4-tert-Butylphenyl)-2-methyl-2propenylidene]malononitrile (DCTB) solution $(\sim 5 \mathrm{mg} / \mathrm{ml}$ in methanol). All spectra were acquired using a Bruker Autoflex III Smartbeam MALDI-TOF, set to the positive reflective mode (Na:YAG $355 \mathrm{~nm}$ laser settings: laser offset $=62-69$; laser frequency $=200 \mathrm{~Hz}$; and number of shots $=300$ ). The target used was Bruker MTP 384 ground steel plate target.

CHN Elemental Analysis: Elemental analyses were performed by Johnson Li in the Chemical Instrumentation Facility at the UofC. A Perkin Elmer 2400 Series II CHN Elemental Analyzer was used to obtain $\mathrm{CHN}$ data, using $\sim 1.5 \mathrm{mg}$ of sample (with particle sizes ranging between 0.2 and $0.5 \mathrm{~mm}$ in diameter).

UV-Visible Spectroscopy (UV-Vis): Optical absorption measurements were performed using Agilent Technologies Cary $60 \mathrm{UV}-\mathrm{V}$ is spectrometer at ambient conditions. All solution UV-Vis spectra were measured with 2 or $10 \mathrm{~mm}$ quartz cuvettes, using $\mathrm{CH}_{2} \mathrm{Cl}_{2}, \mathrm{~N}, \mathrm{~N}$-dimethylformamide (DMF), or tetrahydrofuran (THF) as solvent. Stock solutions $(\sim 1 \mathrm{mg} / \mathrm{mL})$ of each compound were prepared, serially diluted to concentrations between $10^{-5}-10^{-6} \mathrm{M}$, and then used to construct calibration curves for determining molar absorptivity.

Fourier Transform Infrared Spectroscopy (FTIR): All IR absorption measurements were performed using an Agilent Technologies Cary 630 FTIR spectrometer at room temperature. FTIR spectra were measured from $\mathrm{CH}_{2} \mathrm{Cl}_{2}$ or DMF solutions of the analyte, using either the dialpath module (pathlength $=30$ microns) or the transmission module. Solid samples were made from anhydrous potassium bromide $(\mathrm{KBr})$, prepared in an argon filled glovebox, and analyzed with air-free techniques. 
Electron Paramagnetic Resonance (EPR): X-band EPR spectra $(9.34 \mathrm{GHz})$ were recorded on a Bruker EMX 10/12 spectrometer equipped with VT capabilities with a 10-inch magnet and a $12 \mathrm{kV}$ power supply. Dry and degassed toluene or THF was used as the solvent. Spectra were simulated with EasySpin ${ }^{3}$ using the Simultispin GUI package. ${ }^{4}$

Spectroelectrochemistry (SEC): All UV-vis SEC and FTIR SEC experiments were conducted using a LabOmak IR-SEC cell fitted with $\mathrm{CaF}_{2}$ windows (pathlength $=0.2 \mathrm{~mm}$ ), a Pt-mesh working electrode (WE), a Pt-wire counter electrode (CE), an Ag-wire pseudo-reference electrode $(\mathrm{RE})$, and $\mathrm{Fc}^{+/ 0}$ as an internal reference standard. The cell was filled with DMF solutions $(\sim 0.1 \mathrm{~mL})$ containing $0.5 \mathrm{mM}$ analyte and $0.1 \mathrm{M} \mathrm{TBAPF}$. Solutions were sparged with argon in a scintillation vial for 15 minutes prior to use. Blank DMF solutions containing $0.1 \mathrm{M}$ $\mathrm{TBAPF}_{6}$ were used to baseline correct spectra at each voltage step.

Cyclic Voltammetry (CV): All electrochemical measurements were performed using a $\mathrm{CH}$ Instruments Inc. Model 1200B Series Handheld Potentiostat. A standard 3-electrode setup was utilized, consisting of a freshly polished glassy carbon disk WE, Pt-wire $\mathrm{CE}, \mathrm{Ag} / \mathrm{AgCl}$ pseudo$\mathrm{RE}$, and ferrocene $\left(\mathrm{Fc}^{+/ 0}\right)$ as an internal standard. All cyclic voltammetry experiments were performed at a scan rate of $100 \mathrm{mV} / \mathrm{s}$ (unless otherwise specified). Sample solutions, with 0.5 $\mathrm{mM}$ compound and $0.1 \mathrm{M}$ tetrabutylammonium hexafluorophosphate (TBAPF6) supporting electrolyte, were prepared in anhydrous $\mathrm{CH}_{2} \mathrm{Cl}_{2}, \mathrm{MeCN}$, or DMF. All electrochemical solutions were sparged with dry gas (either argon or $\mathrm{CO}_{2}$ ) for 15 minutes prior to measurements.

The impact of proton source concentration on catalytic current enhancement was tested using two weak acids, phenol (PhOH: $\mathrm{pKa}=18.8)$ or 2,2,2-trifluoroethanol $(\mathrm{TFE} ; \mathrm{pKa}=24.0) .{ }^{5}$ Two initial measurements were run, the first under argon and the second after the solution was sparged with $\mathrm{CO}_{2}$. To the $\mathrm{CO}_{2}$-saturated sample (0.23 $\mathrm{M}$ in DMF and $0.25 \mathrm{M}$ in $\left.\mathrm{MeCN}\right)$, the specified proton-source was added incrementally until a maximal current enhancement was achieved.

Controlled Potential Electrolysis (CPE): CPE experiments were performed with a customized two-compartment H-shaped cell, using a Princeton Applied Research VersaSTAT 3 potentiostat. A glassy carbon plate $(20 \mathrm{~mm} \times 8 \mathrm{~mm} \times 2 \mathrm{~mm})$ was used as the WE, along with a Pt-mesh CE, and a non-aqueous $\mathrm{Ag} / \mathrm{AgCl}$ pseudo-RE. For all experiments using the two-compartment $\mathrm{H}-$ shaped cell $(44.1 \mathrm{~mL})$, two solutions were prepared: an active solution $(0.5 \mathrm{mM}$ catalyst $+0.1 \mathrm{M}$ $\left.\mathrm{TBAPF}_{6}+\mathrm{TFE}\right)$, and a blank solution $(0.1 \mathrm{M} \mathrm{TBAPF} 6+\mathrm{TFE})$. The glassy carbon plate WE and $\mathrm{Ag} / \mathrm{AgCl}$ pseudo-RE were immersed into the active solution in the cathodic compartment, while the Pt-mesh CE was immersed into the blank solution in the anodic compartment. The potentiostat, using the chronoamperometry setting, applied a constant voltage for the duration of testing. Small headspace aliquots $(50 \mu \mathrm{L})$ were periodically removed from the flask/cell to analyze gaseous product distribution.

Gas chromatography (GC): GC headspace analysis (50 $\mu \mathrm{L}$ aliquots) was performed using an Agilent Technologies 7890B GC, equipped with a PoraPlot Q and PLOT molecular sieve (5 A) column (oven temperature $60-120{ }^{\circ} \mathrm{C}$ ) in series and a VICI pulsed discharge Helium ionization detector. The flow rate of the carrier gas (helium) was approximately $5 \mathrm{~mL} \mathrm{~min}^{-1}$. The system was calibrated using a customized gas mixture, containing known concentrations of: $\mathrm{H}_{2}, \mathrm{CO}$, $\mathrm{CH}_{4}$, ethylene, and ethane. 
Photochemistry: $\mathrm{CO}_{2}$ photocatalysis experiments were performed using a $10 \mathrm{~mL} \mu$ wave vial that was sealed with a rubber septum. The catalyst $(65 \mu \mathrm{M})$ was dissolved in either a $(5: 1: 0)$ or a (4:1:1) mixture of DMF : triethanolamine : TFE. Samples were sparged with $\mathrm{CO}_{2}$ for 20 minutes prior to be irradiated with a Thor Labs Blue LED $\left(\lambda=470 \pm 30 \mathrm{~nm} ; 4.0 \mathrm{~mW} \mathrm{~cm}{ }^{-2}\right)$. Headspace aliquots $(50 \mu \mathrm{L})$ were removed periodically from the vials to analyze gaseous products.

\section{Data Handling/Calculations:}

i) Randles Sevcik Equation (ip scan rate dependency for diffusion-controlled processes) ${ }^{6}$

$$
i_{p}=0.4463 n F A c_{c a t} \sqrt{\frac{n F v D}{R T}}
$$

Where: $i_{p}=$ peak current of redox wave, $\mathrm{n}=\#$ of electrons transferred, $\mathrm{F}=$ Faradaic constant, $\mathrm{A}=$ geometric area of the working electrode, $\mathrm{c}_{\mathrm{cat}}=$ catalyst concentration, $v=$ scan rate, $\mathrm{D}=$ diffusion coefficient, $\mathrm{R}=$ universal gas constant, and $\mathrm{T}=$ temperature.

ii) Determination of $k_{\text {obs }}$ using the $i_{\text {cat }} / i_{p}$ analysis ${ }^{7}$

$$
\frac{i_{c a t}}{i_{p}}=2.2406 \sqrt{\frac{R T}{n F v} n^{\prime} k_{o b s}}
$$

Where: $\mathrm{i}_{\text {cat }}=$ peak current of redox wave under catalytic conditions, $\mathrm{i}_{\mathrm{p}}=$ peak current of redox wave, $\mathrm{R}=$ universal gas constant, $\mathrm{T}=$ temperature, $\mathrm{n}=\#$ of electrons transferred, $\mathrm{F}=$ Faradaic constant, $v=$ scan rate, $\mathrm{n}^{\prime}=$ \# of catalyst molecules required per turnover $\left(\mathrm{n}^{\prime}=1\right)$, and $\mathrm{k}_{\mathrm{obs}}=$ observed catalytic rate constant.

iii) Tafel Plot ${ }^{8}$

$$
T O F=\frac{T O F_{\max }}{\left(1+\exp \left[\left(\frac{F}{R T}\right)\left(E_{t r}^{0}-E_{c a t}^{0}\right)\right]\right) \times \exp \left[-\left(\frac{F}{R T}\right) \eta\right]}
$$

Where: $\mathrm{TOF}=$ turnover frequency, $\mathrm{TOF}_{\max }=\mathrm{k}_{\mathrm{obs}}, \mathrm{F}=$ Faradaic constant, $\mathrm{R}=$ gas constant, $\mathrm{T}=$ temperature, $\mathrm{E}_{\mathrm{tr}}^{0}=$ thermodynamic redox potential of $\mathrm{CO}_{2} / \mathrm{CO}$ in $\mathrm{DMF}\left(-1.46 \mathrm{~V} \mathrm{vs} . \mathrm{Fc}^{+/ 0}\right)$ or in $\mathrm{MeCN}\left(-1.12 \mathrm{~V}\right.$ vs. $\left.\mathrm{Fc}^{+/ 0}\right),{ }^{7-9} \mathrm{E}_{\text {cat }}^{0}=$ catalyst standard potential of $\mathrm{E}_{1 / 2}$, and $\eta$ : overpotential $\left(\mathrm{E}_{\mathrm{tr}}^{0}-\right.$ Eelectrode). 


\section{Synthetic/Experimental Procedures}

\section{5-[2-((Trimethylsilyl)-1-ethynyl]-2,2'-bipyridine}

Starting material, 5-bromo-2,2'-bipyridine, was synthesized using modified literature procedure. ${ }^{10}$

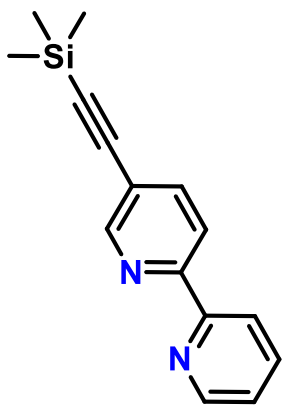

A $20 \mathrm{~mL}$ glass pressure vial was charged with 5-bromo-2,2'-bipyridine (1.05 g, $4.5 \mathrm{mmol}$, 1eq.) and copper iodide ( $86 \mathrm{mg}, 0.45 \mathrm{mmol}, 0.1$ eq.). The vial was brought into the glovebox, where $\mathrm{Pd}\left(\mathrm{PPh}_{3}\right)_{4}(258 \mathrm{mg}, 0.22 \mathrm{mmol}, 0.05$ eq.) was added prior to sealing the vial. After removing the $\mu$ wave vial from the glovebox, a thoroughly degassed mixture of (1:1) diisopropylamine : toluene $(16 \mathrm{~mL})$ was transferred into the vial using a Cannula line. Next, trimethylsilylacetylene (1.9 mL, $13.4 \mathrm{mmol}, 3$ eq.) was injected into the reaction mixture and then the vial was placed in a $60{ }^{\circ} \mathrm{C}$ bead bath for 14 hours, monitoring progress by thin layer chromatography (TLC). Upon reaction completion, the mixture was passed through a Celite plug (eluting with $\mathrm{CH}_{2} \mathrm{Cl}_{2}$ ) and solvent was removed by rotary evaporation. The dark brown crude mixture was re-dissolved in minimal $\mathrm{CH}_{2} \mathrm{Cl}_{2}$, adhered to silica, and then purified using a short silica plug. The plug was first washed with hexanes, followed by a $(5: 1)$ hexanes : ethyl acetate mixture. The latter solvent mixture was removed by rotary evaporation to afford a pale-yellow solid that matched known literature data $(0.92 \mathrm{~g}, 3.6 \mathrm{mmol}, 81 \%$ yield $) .{ }^{11}$ No additional purification was required.

${ }^{1} \mathrm{H} \mathrm{NMR}\left(500 \mathrm{MHz}, \mathrm{CDCl}_{3}\right) \delta 8.74(\mathrm{dd}, J=2.1,0.9 \mathrm{~Hz}, 1 \mathrm{H}), 8.69(\mathrm{ddd}, J=4.8,1.8,0.9 \mathrm{~Hz}$, $1 \mathrm{H}), 8.40(\mathrm{dt}, J=8.0,1.1 \mathrm{~Hz}, 1 \mathrm{H}), 8.37(\mathrm{dd}, J=8.2,0.9 \mathrm{~Hz}, 1 \mathrm{H}), 7.88(\mathrm{dd}, J=8.2,2.1 \mathrm{~Hz}, 1 \mathrm{H})$, $7.83(\mathrm{td}, J=7.7,1.8 \mathrm{~Hz}, 1 \mathrm{H}), 7.32(\mathrm{ddd}, J=7.5,4.8,1.2 \mathrm{~Hz}, 1 \mathrm{H}), 0.29$ (s, 9H).

\section{5-ethynyl-2,2'-bipyridine}

A $100 \mathrm{~mL}$ rbf was charged with 5-[2-((Trimethylsilyl)-1-ethynyl]-2,2'bipyridine (0.92 g, 3.6 mmol, 1 eq.) and $\mathrm{K}_{2} \mathrm{CO}_{3}$ (1.99 g, 14.4 mmol, 4 eq.). The mixture was dissolved in methanol $(25 \mathrm{~mL})$ and stirred vigorously at room temperature. Reaction progress was monitored by TLC until all starting material was consumed. Upon reaction completion, the mixture was filtered through a Celite plug (eluting with $\mathrm{CH}_{2} \mathrm{Cl}_{2}$ ) and then solvent was removed by rotary evaporation. The resulting crude solid was re-dissolved in $\mathrm{CH}_{2} \mathrm{Cl}_{2}$, adhered to silica, and then purified using a short silica plug. The plug was washed with hexanes, then a $(5: 1)$ hexanes : ethyl acetate mixture. This solvent

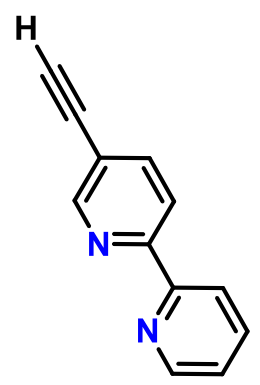
mixture was removed by rotary evaporation to afford a fluffy white solid that also matched known literature data $(0.64 \mathrm{~g}, 3.6 \mathrm{mmol}, 98 \%$ yield $) .{ }^{11}$ No further purification was required.

${ }^{1} \mathrm{H} \mathrm{NMR}\left(500 \mathrm{MHz}, \mathrm{CDCl}_{3}\right) \delta 8.76(\mathrm{dd}, J=2.1,0.9 \mathrm{~Hz}, 1 \mathrm{H}), 8.67(\mathrm{ddd}, J=4.8,1.8,0.9 \mathrm{~Hz}$, $1 \mathrm{H}), 8.43-8.34(\mathrm{~m}, 2 \mathrm{H}), 7.88(\mathrm{dd}, J=8.2,2.1 \mathrm{~Hz}, 1 \mathrm{H}), 7.80(\mathrm{td}, J=7.8,1.8 \mathrm{~Hz}, 1 \mathrm{H}), 7.30$ (ddd, $J=7.5,4.8,1.2 \mathrm{~Hz}, 1 \mathrm{H}), 3.29(\mathrm{~s}, 1 \mathrm{H})$. 


\section{Bromo-ethyl-N-annulated Perylene Diimide (BrEt-PDI)}

Starting material, $\mathrm{N}$-annulated PDI, was synthesized using literature procedure. ${ }^{12}$

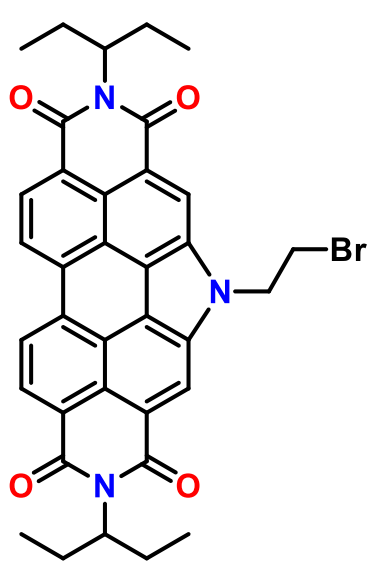

$\mathrm{N}$-annulated PDI (600 mg, $1.1 \mathrm{mmol}, 1$ eq.) and $\mathrm{K}_{2} \mathrm{CO}_{3}(310 \mathrm{mg}, 2.2$ $\mathrm{mmol}, 2$ eq.) were added to a $20 \mathrm{~mL}$ glass pressure vial and dissolved in DMF $(10 \mathrm{~mL})$. The vial was sealed, sparged with $\mathrm{N}_{2}$ for 15 minutes, and then 1,2-dibromoethane $(0.48 \mathrm{~mL}, 5.5 \mathrm{mmol}, 5$ eq.) was added to the solution. The mixture was placed into a $60{ }^{\circ} \mathrm{C}$ bead bath and left to stir for 4 hours, monitoring reaction progress by TLC. When reaction progress was completed, the mixture was diluted with $\mathrm{CH}_{2} \mathrm{Cl}_{2}(50 \mathrm{~mL})$, poured through a short Celite plug, and then solvent was removed using rotary evaporation. Next, the crude solid was subsequently re-dissolved in $\mathrm{CH}_{2} \mathrm{Cl}_{2}$ and purified using a silica plug (eluted with $\mathrm{CH}_{2} \mathrm{Cl}_{2}$ ). After solvent was removed by rotary evaporation, the isolated burgundy product was precipitated from a $(19: 1) \mathrm{MeOH}: \mathrm{H}_{2} \mathrm{O}$ mixture and collected by vacuum filtration $(440 \mathrm{mg}, 0.68 \mathrm{mmol}, 61 \%$ yield).

${ }^{1} \mathrm{H} \mathrm{NMR}\left(500 \mathrm{MHz}, \mathrm{CDCl}_{3}\right) \delta 9.03(\mathrm{~s}, 2 \mathrm{H}), 8.99(\mathrm{~d}, J=8.0 \mathrm{~Hz}, 2 \mathrm{H}), 8.87(\mathrm{~d}, J=8.0 \mathrm{~Hz}, 2 \mathrm{H})$, $5.31(\mathrm{t}, J=6.2 \mathrm{~Hz}, 2 \mathrm{H}), 5.23(\mathrm{dddd}, J=15.4,9.5,7.6 \mathrm{~Hz}, 2 \mathrm{H}), 4.05(\mathrm{t}, J=6.2 \mathrm{~Hz}, 2 \mathrm{H}), 2.36$ (ddq, $J=14.8,9.6,7.5 \mathrm{~Hz}, 4 \mathrm{H}), 2.08-1.95(\mathrm{~m}, 4 \mathrm{H}), 0.99(\mathrm{t}, J=7.5 \mathrm{~Hz}, 12 \mathrm{H})$.

${ }^{13} \mathrm{C} \mathrm{NMR}\left(126 \mathrm{MHz}, \mathrm{CDCl}_{3}\right) \delta 165.93,164.71,134.36,132.44,128.03,127.37,124.37,123.63$, $121.46,119.47,118.28,117.74,57.25,47.55,29.97,24.65,10.89$.

$\underline{\text { HRMS }}\left([\mathrm{M}-\mathrm{H}]^{+}\right)$calculated for $\mathrm{M}=\mathrm{C}_{36} \mathrm{H}_{32} \mathrm{~N}_{3} \mathrm{O}_{4} \mathrm{Br}: 648.1492$; detected $[\mathrm{M}-\mathrm{H}]^{+}: 648.1511$

\section{Azide-ethyl-N-annulated Perylene Diimide (N-PDI)}

$\mathrm{N}_{3}$-PDI was synthesized using a slightly modified literature procedure. ${ }^{13}$

BrEt-PDI (440 mg, $0.68 \mathrm{mmol}, 1$ eq.) and $\mathrm{NaN}_{3}(83.2 \mathrm{mg}, 1.3 \mathrm{mmol}, 2$ eq.) were added to a $100 \mathrm{~mL}$ rbf and dissolved in DMF $(25 \mathrm{~mL})$. The solution was sealed and left to stir overnight at room temperature. Upon reaction completion (as indicated by TLC), the mixture was poured into $\mathrm{MeOH}(125 \mathrm{~mL})$ and $\mathrm{H}_{2} \mathrm{O}(\sim 10 \mathrm{~mL})$ was added to induce precipitation. The resulting brick red precipitate was collected by vacuum filtration (415 mg, $0.67 \mathrm{mmol}, 98 \%$ yield).

${ }^{1} \mathrm{H} \mathrm{NMR}\left(500 \mathrm{MHz}, \mathrm{CDCl}_{3}\right) \delta 8.96(\mathrm{~s}, 2 \mathrm{H}), 8.86(\mathrm{~d}, J=7.9 \mathrm{~Hz}, 2 \mathrm{H})$, $8.80(\mathrm{~d}, J=8.3 \mathrm{~Hz}, 2 \mathrm{H}), 5.22(\mathrm{tt}, J=9.5,5.8 \mathrm{~Hz}, 2 \mathrm{H}), 4.97(\mathrm{t}, J=5.5$ $\mathrm{Hz}, 2 \mathrm{H}), 4.07$ (t, $J=5.5 \mathrm{~Hz}, 2 \mathrm{H}$ ), 2.37 (ddq, $J=14.8,9.4,7.5 \mathrm{~Hz}, 4 \mathrm{H}$ ), $2.03(\mathrm{tt}, J=13.5,7.4 \mathrm{~Hz}, 4 \mathrm{H}), 1.00(\mathrm{t}, J=7.5 \mathrm{~Hz}, 12 \mathrm{H})$.

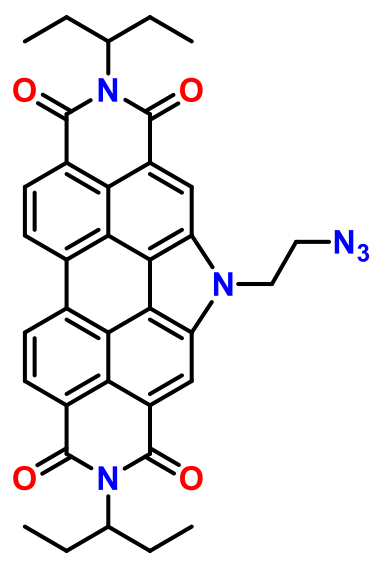

${ }^{13} \mathrm{C} \mathrm{NMR}\left(126 \mathrm{MHz}, \mathrm{CDCl}_{3}\right) \delta 165.87,164.51,134.22,132.16,127.73,127.37,124.19,123.40$, $121.81,119.22,117.98,117.65,57.27,51.27,45.37,24.64,10.94$.

$\underline{\text { HRMS }}\left([\mathrm{M}-\mathrm{H}]^{+}\right)$calculated for $\mathrm{M}=\mathrm{C}_{36} \mathrm{H}_{32} \mathrm{~N}_{6} \mathrm{O}_{4}: 611.2401$; detected $[\mathrm{M}+\mathrm{H}]^{+}: 611.2377$ 


\section{Bipyridine-Triazole-N-annulated Perylene Diimide (bpy-TAz-PDI)}

This compound was synthesized using a slightly modified literature procedure. ${ }^{13}$

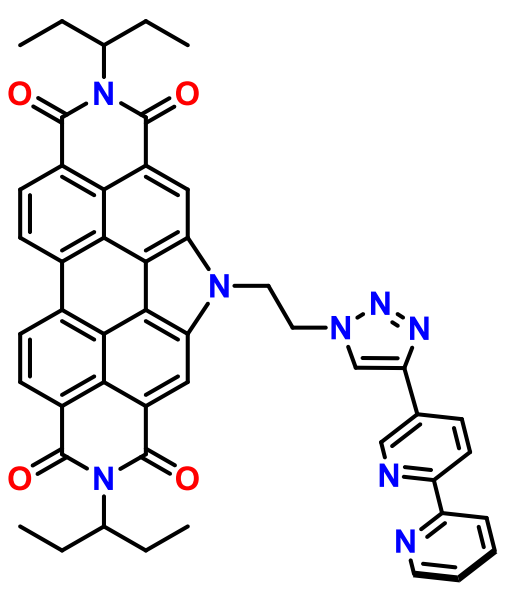

$\mathrm{N}_{3}$-PDI (310 mg, $0.52 \mathrm{mmol}, 1$ eq.) and 5-ethynyl-2,2'-bipyridine (100 mg, $0.56 \mathrm{mmol}, 1.1$ eq.) were combined in a $20 \mathrm{~mL}$ glass pressure vial with $\mathrm{CuSO}_{4}(20 \mathrm{mg}, 0.05 \mathrm{mmol}, 0.1$ eq.) and sodium ascorbate (60 mg, $0.18 \mathrm{mmol}, 0.3 \mathrm{eq}$.$) . The vial was sealed and$ then $\mathrm{N}_{2}$-sparged for 30 minutes. A degassed mixture of (4:1) THF $: \mathrm{H}_{2} \mathrm{O}(20 \mathrm{~mL})$ was transferred into the vial using a Cannula line. The mixture was purged an additional 5 minutes, then placed into a $60{ }^{\circ} \mathrm{C}$ bead bath for 18 hours. After TLC showed consumption of all starting material, the brick red mixture was poured into $\mathrm{MeOH}$ (with a small amount of $\mathrm{H}_{2} \mathrm{O}$ ) and collected by vacuum filtration. The crude solid was re-dissolved in $\mathrm{CH}_{2} \mathrm{Cl}_{2}$, adhered to silica, and then purified using a short silica plug. The plug was eluted first using hexanes : acetone gradient $(4: 1 \rightarrow 1: 1)$, followed by flashing the plug with $\mathrm{CH}_{2} \mathrm{Cl}_{2}+10 \% \mathrm{MeOH}$ to afford the desired compound. Solvent was removed by rotary evaporation and the resulting bright orange solid was precipitated into $\mathrm{MeOH}$ and collected by vacuum filtration $(261 \mathrm{mg}, 0.33 \mathrm{mmol}, 67 \%)$.

${ }^{1} \mathrm{H}$ NMR $\left(500 \mathrm{MHz}, \mathrm{CDCl}_{3}\right) \delta 9.00(\mathrm{~d}, J=7.8 \mathrm{~Hz}, 2 \mathrm{H}), 8.86(\mathrm{~d}, J=6.0 \mathrm{~Hz}, 2 \mathrm{H}), 8.81-8.70(\mathrm{~m}$, $3 \mathrm{H}), 8.66(\mathrm{~s}, 1 \mathrm{H}), 8.33(\mathrm{~d}, J=4.8 \mathrm{~Hz}, 2 \mathrm{H}), 8.03(\mathrm{~d}, J=8.0 \mathrm{~Hz}, 1 \mathrm{H}), 7.81(\mathrm{dd}, J=12.0,8.0 \mathrm{~Hz}, 1 \mathrm{H})$, $7.55(\mathrm{~s}, 1 \mathrm{H}), 7.34-7.28(\mathrm{~m}, 1 \mathrm{H}), 5.50(\mathrm{t}, J=5.7 \mathrm{~Hz}, 2 \mathrm{H}), 5.19(\mathrm{t}, J=5.7 \mathrm{~Hz}, 2 \mathrm{H}), 5.18-5.11(\mathrm{~m}$, $2 \mathrm{H}), 2.29(\mathrm{dq}, J=7.9 \mathrm{~Hz}, 4 \mathrm{H}), 1.95(\mathrm{dq}, J=14.0,7.0 \mathrm{~Hz}, 4 \mathrm{H}), 0.91(\mathrm{t}, J=7.4 \mathrm{~Hz}, 12 \mathrm{H})$.

${ }^{13} \mathrm{C} \mathrm{NMR}{ }^{* * *}$ not obtained due to very poor solubility of bpy-TAz-PDI $(<0.5 \mathrm{mg} / \mathrm{mL}) * * * *$

$\underline{\text { HRMS }}\left([\mathrm{M}+\mathrm{H}]^{+}\right)$calculated for $\mathrm{M}=\mathrm{C}_{48} \mathrm{H}_{40} \mathrm{~N}_{8} \mathrm{O}_{4}:$ : 793.3245; detected $[\mathrm{M}+\mathrm{H}]^{+}: 793.3241$

CHN theoretical (\%) C: 72.71, H: 5.09, N: 14.13; found (\%) C: 72.49, H: 4.99, N: 13.68;

UV-vis $\lambda\left(x 10^{4} \mathrm{M}^{-1} \mathrm{~cm}^{-1}\right): 306 \mathrm{~nm}(2.5) ; 458 \mathrm{~nm}$ (1.6); $488 \mathrm{~nm}$ (3.1); $521 \mathrm{~nm}$ (5.9)

\section{$\operatorname{Re}($ bpy-TAz-PDI $)(\mathrm{CO})_{3} \mathrm{Cl}$}

Bpy-TAz-PDI (200 mg, $0.25 \mathrm{mmol}, 1$ eq.) and $\operatorname{Re}(\mathrm{CO})_{5} \mathrm{Cl}$ (91.2 $\mathrm{mg}, 0.25 \mathrm{mmol}, 1$ eq.) were combined in a $20 \mathrm{~mL}$ glass pressure vial. The vial was sealed and then $\mathrm{N}_{2}$-sparged for 15 minutes. Degassed toluene $(16 \mathrm{~mL})$ was transferred into the vial using a Cannula line. The mixture was purged an additional 15 minutes, then placed into a $110{ }^{\circ} \mathrm{C}$ bead bath for 14 hours. After TLC showed consumption of all starting material, solvent was removed from the red mixture by rotary evaporation. The crude solid was dissolved in $\mathrm{CH}_{2} \mathrm{Cl}_{2}$, adhered to silica, and then purified by silica-plug. The plug used a gradient $(1: 1 \rightarrow 0: 1)$ hexanes : THF mixture to remove the impurities and then elute the product. Solvent was removed by

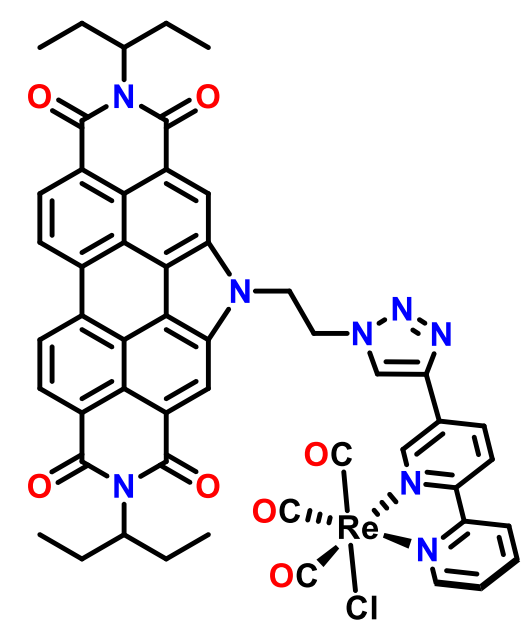


rotary evaporation and the resulting red solid was precipitated into $\mathrm{MeOH}$ and collected by vacuum filtration (266 mg, $0.24 \mathrm{mmol}, 96 \%$ yield).

${ }^{1} \mathrm{H}$ NMR $\left(500 \mathrm{MHz}, \mathrm{CDCl}_{3}\right) \delta 9.01(\mathrm{~d}, J=5.4 \mathrm{~Hz}, 1 \mathrm{H}), 8.98(\mathrm{~d}, J=2.0 \mathrm{~Hz}, 1 \mathrm{H}), 8.93(\mathrm{~d}, J=8.0$ $\mathrm{Hz}, 2 \mathrm{H}), 8.82(\mathrm{~s}, 2 \mathrm{H}), 8.74(\mathrm{~s}, 2 \mathrm{H}), 8.49(\mathrm{~d}, J=8.5 \mathrm{~Hz}, 1 \mathrm{H}), 8.13(\mathrm{dd}, J=15.9,8.4 \mathrm{~Hz}, 2 \mathrm{H}), 8.04$ $(\mathrm{dd}, J=8.6,7.0 \mathrm{~Hz}, 1 \mathrm{H}), 7.89(\mathrm{~s}, 1 \mathrm{H}), 7.52(\mathrm{dt}, J=8.0,2.0 \mathrm{~Hz}, 1 \mathrm{H}), 5.52(\mathrm{~d}, J=6.3 \mathrm{~Hz}, 2 \mathrm{H})$, $5.28(\mathrm{~d}, J=6.1 \mathrm{~Hz}, 2 \mathrm{H}), 5.16(\mathrm{~s}, 2 \mathrm{H}), 2.29(\mathrm{q}, J=7.5 \mathrm{~Hz}, 4 \mathrm{H}), 1.96(\mathrm{dp}, J=14.1,7.3 \mathrm{~Hz}, 4 \mathrm{H})$, $0.92(\mathrm{td}, J=7.4,3.9 \mathrm{~Hz}, 12 \mathrm{H})$.

${ }^{1} \mathrm{H}$ NMR $\left(500 \mathrm{MHz}, \mathrm{CD}_{3} \mathrm{CN}\right) \delta 8.98(\mathrm{~d}, J=4.2 \mathrm{~Hz}, 1 \mathrm{H}), 8.90(\mathrm{~s}, 1 \mathrm{H}), 8.35-8.20(\mathrm{~m}, 8 \mathrm{H}), 8.14$ $(\mathrm{td}, J=7.8,1.4 \mathrm{~Hz}, 1 \mathrm{H}), 8.07$ (br s, $1 \mathrm{H}), 7.87$ (br s, 1H), 7.61 (t, $J=6.8 \mathrm{~Hz}, 1 \mathrm{H}), 5.09-4.95$ (m, $4 \mathrm{H}), 4.93-4.81(\mathrm{~m}, 2 \mathrm{H}) 1.33-1.21(\mathrm{~m}, 8 \mathrm{H}), 0.93-0.79(\mathrm{~m}, 12 \mathrm{H})$

${ }^{13} \mathrm{C} \mathrm{NMR}\left(126 \mathrm{MHz}, \mathrm{CDCl}_{3}\right) \delta 154.63,153.90,152.61,149.03,141.79,138.42,135.18,134.15$, $132.58,126.49,124.43,123.91,122.56,122.48,121.84,121.53,119.68,57.17,50.66,45.95$, $24.56,10.86$. *some quaternary centers were not visible*

$\underline{\text { HRMS }}\left([\mathrm{M}-\mathrm{Cl}]^{+}\right)$calculated for $\mathrm{M}=\mathrm{C}_{51} \mathrm{H}_{40} \mathrm{~N}_{8} \mathrm{O}_{7} \mathrm{ReCl}: 1063.2572$; detected $[\mathrm{M}-\mathrm{Cl}]^{+}: 1063.2572$

$\underline{\mathrm{CHN}}$ theoretical (\%) C: 55.76, H: 3.67, N: 10.20; found (\%) C: $55.30 \mathrm{H}: 3.75, \mathrm{~N}: 9.98$;

$\underline{\mathrm{UV} \text {-vis }} \lambda\left(\mathrm{x} 10^{4} \mathrm{M}^{-1} \mathrm{~cm}^{-1}\right): 307 \mathrm{~nm}(2.1) ; 343 \mathrm{~nm}$ (1.6); $456 \mathrm{~nm}(1.7) ; 487 \mathrm{~nm}$ (3.2); $521 \mathrm{~nm}(6.0)$

FTIR $v_{c o}\left(\mathrm{~cm}^{-1}\right): 1901,1920$, and 2024 in $\mathrm{CH}_{2} \mathrm{Cl}_{2} ; 1895,1915$, and 2019 in DMF.

\section{Chemical Reduction of $\operatorname{Re}(b p y-T A z-P D I)$}

General chemical reduction procedure was modified from an existing literature procedure. ${ }^{14}$

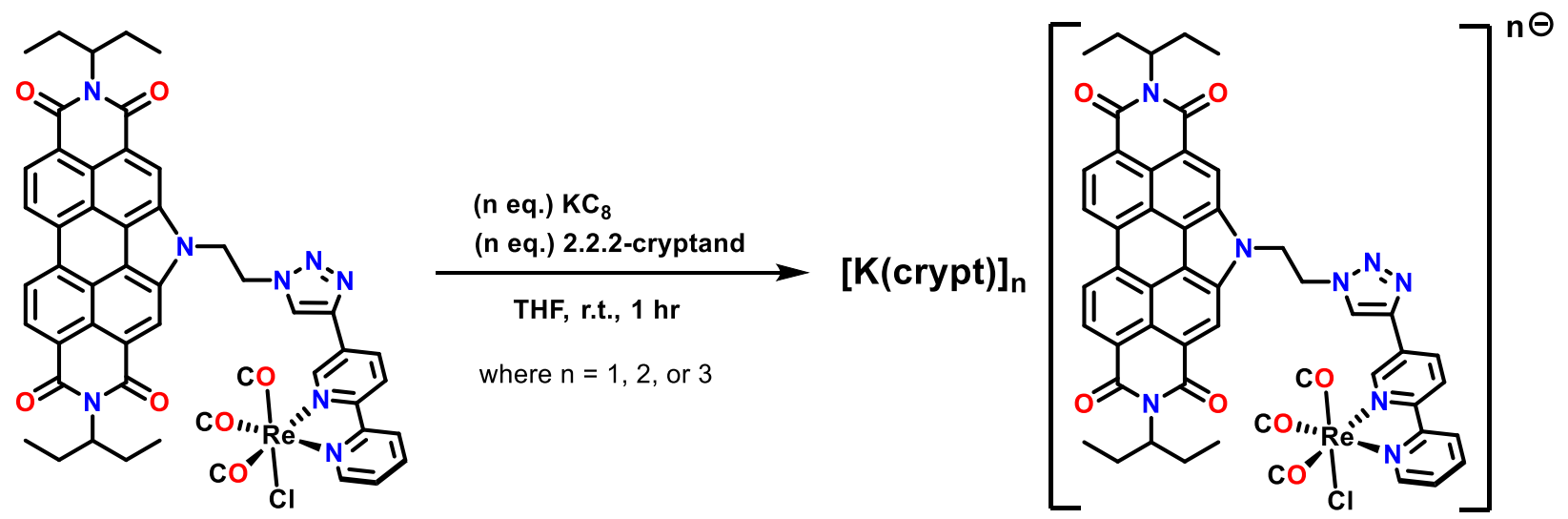

In an argon-filled glovebox, Re(bpy-TAz-PDI) (15 mg, $0.014 \mathrm{mmol}, 1$ eq.) was added to a 20 $\mathrm{mL}$ scintillation vial and dissolved in anhydrous THF $(5 \mathrm{~mL})$. To the stirring solution, $\mathrm{KC}_{8}(2.0$ $\mathrm{mg}, 0.015 \mathrm{mmol}, 1.1$ eq.) was added in a single portion. Reaction progress was monitored by taking one drop aliquots for UV-vis and FTIR spectroscopic analyses. Upon reaction completion, 2.2.2-cryptand ( $5.7 \mathrm{mg}, 0.015 \mathrm{mmol}, 1.1 \mathrm{eq}$.) was added to the solution, which was left to stir at room temperature for 1 hour. The solution was subsequently passed through a $0.2 \mu \mathrm{m} \mathrm{PTFE}$ syringe filter (with small additional THF washing) and then taken out of the glovebox. Solvent 
was removed in vacuo on a Schlenk line to yield the highly air-sensitive one-electron reduced product, [K(crypt)][Re(bpy-TAz-PDI)], in quantitative yield. Appropriately scaling the total equivalents of $\mathrm{KC}_{8}$ and 2.2.2-cryptand to 2.1 eq. or 3.1 eq., the same procedure was applied to acquire the two- or three- electron reduced products, $[\mathrm{K}(\mathrm{crypt})]_{2}[\operatorname{Re}(\mathrm{bpy}-\mathrm{TAz}-\mathrm{PDI})]$ and $[\mathrm{K}(\mathrm{crypt})]_{3}[\operatorname{Re}(\mathrm{bpy}-\mathrm{TAz}-\mathrm{PDI})]$, respectively.

\section{$[\mathrm{K}($ crypt $)][\operatorname{Re}($ bpy-TAz-PDI $)]$}

${ }^{1} \mathrm{H}$ NMR (500 MHz, CD ${ }_{3} \mathrm{CN}$ ) $\delta 9.07$ (br s), 8.97 (br s), 8.19 (br s), 8.00 (br s), 7.54 (br s), 3.49

(br s, K[crypt]), 3.44 (br s, K[crypt]), 2.44 (br s, K[crypt]), 0.62 (br s), -0.40 (br s).

$\underline{\mu_{\text {eff }}}\left(\mathrm{THF}\right.$, Evans, $\left.25^{\circ} \mathrm{C}\right)=2.04 \mu \mathrm{B}(\mathrm{S}=1 / 2)$.

$\underline{\text { UV-vis }} \lambda(*=$ major): $322 \mathrm{~nm} ; 487 \mathrm{~nm} ; 509 \mathrm{~nm} ; 690 \mathrm{~nm} * ; 780 \mathrm{~nm}$

FTIR $v_{c o}(\mathrm{KBr}): 1888 \mathrm{~cm}^{-1}, 1913 \mathrm{~cm}^{-1}$, and $2017 \mathrm{~cm}^{-1}$

\section{$[\mathrm{K}(\mathrm{crypt})]_{2}[\operatorname{Re}(\mathrm{bpy}-\mathrm{TAz}-\mathrm{PDI})]$}

${ }^{1} \mathrm{H}$ NMR $\left(500 \mathrm{MHz}, \mathrm{CD}_{3} \mathrm{CN}\right) \delta 8.84(\mathrm{~m}, 2 \mathrm{H}), 8.62(\mathrm{~d}, \mathrm{~J}=4.6 \mathrm{~Hz}, 2 \mathrm{H}), 8.36(\mathrm{~d}, \mathrm{~J}=8.2 \mathrm{~Hz}, 2 \mathrm{H})$, $8.32(\mathrm{~d}, \mathrm{~J}=8.2,2 \mathrm{H}), 8.13(\mathrm{~s}, 2 \mathrm{H}), 8.07-8.00(\mathrm{~m}, 2 \mathrm{H}), 7.84(\mathrm{td}, \mathrm{J}=7.6 \mathrm{~Hz}, 1.43 \mathrm{~Hz}, 2 \mathrm{H}), 7.24-$ $7.17(\mathrm{~m}), 7.00-6.86(\mathrm{~m}, 1 \mathrm{H}) 6.77-6.62(\mathrm{~m}, 2 \mathrm{H}), 5.34(\mathrm{t}, 4.68 \mathrm{~Hz}, 1 \mathrm{H}), 3.58(\mathrm{~s}$, crypt), $3.52(\mathrm{t}, \mathrm{J}=$ $5.7 \mathrm{~Hz}$, crypt), 3.39 (s, K[crypt]), 3.34 (t, J = 4.7 Hz, K[crypt]), 2.56 (t, J = 5.7 Hz, crypt), 2.34 (t, J = 4.7 Hz, K[crypt]), $0.70(\mathrm{~m})$.

$\underline{\mathrm{UV} \text {-vis }} \lambda(*=$ major $): 321 \mathrm{~nm} ; 585 \mathrm{~nm} ; 621 \mathrm{~nm} * ; 653 \mathrm{~nm} * ; 693 \mathrm{~nm}$

$\underline{\text { FTIR }} v_{c o}(\mathrm{KBr}): 1888 \mathrm{~cm}^{-1}, 1913 \mathrm{~cm}^{-1}$, and $2017 \mathrm{~cm}^{-1}$

\section{$[K(\text { crypt })]_{3}[\operatorname{Re}($ bpy-TAz-PDI $)]$}

$\underline{{ }^{1} \mathrm{H} \text { NMR }}\left(500 \mathrm{MHz}, \mathrm{CD}_{3} \mathrm{CN}\right) \delta 3.48(\mathrm{~s}, 12 \mathrm{H}, \mathrm{K}[\mathrm{crypt}]), 3.44(\mathrm{t}, 12 \mathrm{H}, \mathrm{J}=4.7 \mathrm{~Hz}, \mathrm{~K}[\mathrm{crypt}]), 2.44$ $(\mathrm{t}, 12 \mathrm{H}, \mathrm{J}=4.7 \mathrm{~Hz})$.

بeff_(THF, Evans, $\left.25^{\circ} \mathrm{C}\right)=1.94 \mu \mathrm{B}(\mathrm{S}=1 / 2)$.

$\underline{\mathrm{UV} \text {-vis }} \lambda\left({ }^{*}=\right.$ major $): 321 \mathrm{~nm} ; 585 \mathrm{~nm} ; 621 \mathrm{~nm} * ; 653 \mathrm{~nm} * ; 693 \mathrm{~nm}$

$\underline{\text { FTIR }} v_{c o}(\mathrm{KBr}): 1852 \mathrm{~cm}^{-1}, 1877 \mathrm{~cm}^{-1}$, and $1980-1992 \mathrm{~cm}^{-1}$ 


\section{3. ${ }^{1} \mathrm{H} \&{ }^{13} \mathrm{C}$ NMR and EPR Spectroscopies}

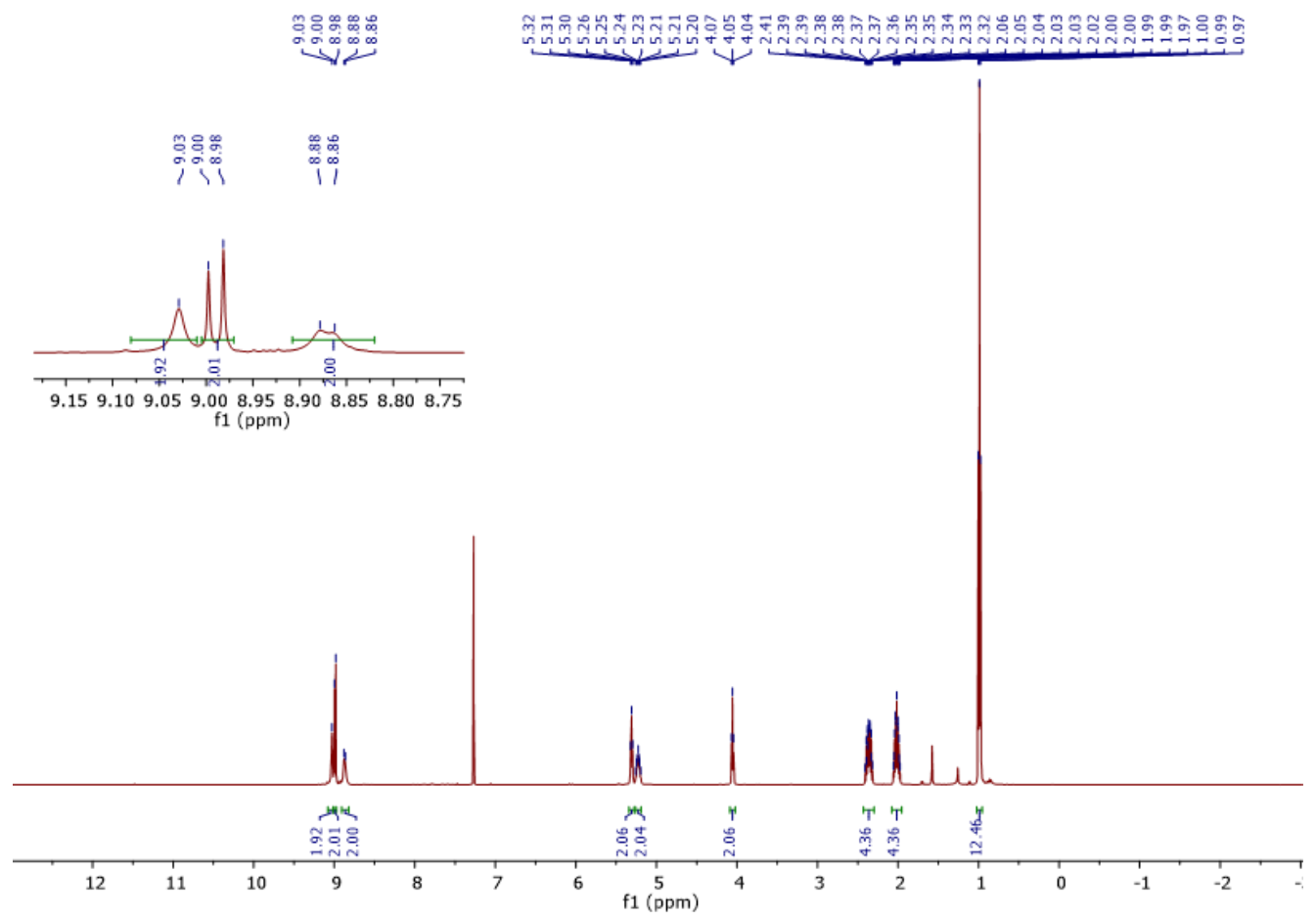

Figure S1. ${ }^{1} \mathrm{H}$ NMR spectrum of BrEt-PDI (500 MHz, $\left.\mathrm{CDCl}_{3}\right)$

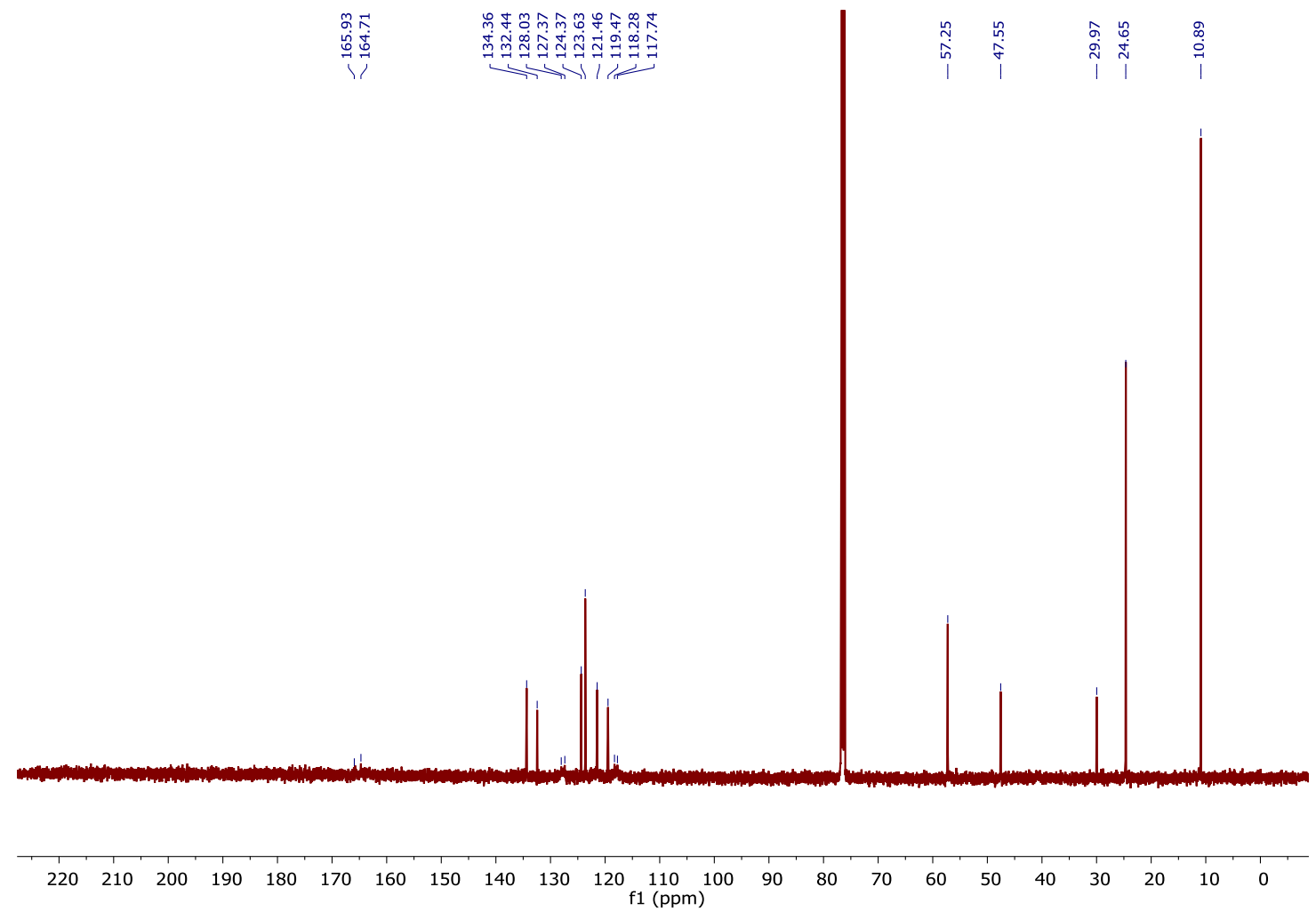

Figure S2. ${ }^{13} \mathrm{C}\left\{{ }^{1} \mathrm{H}\right\}$ NMR spectrum of BrEt-PDI (126 MHz, $\left.\mathrm{CDCl}_{3}\right)$ 


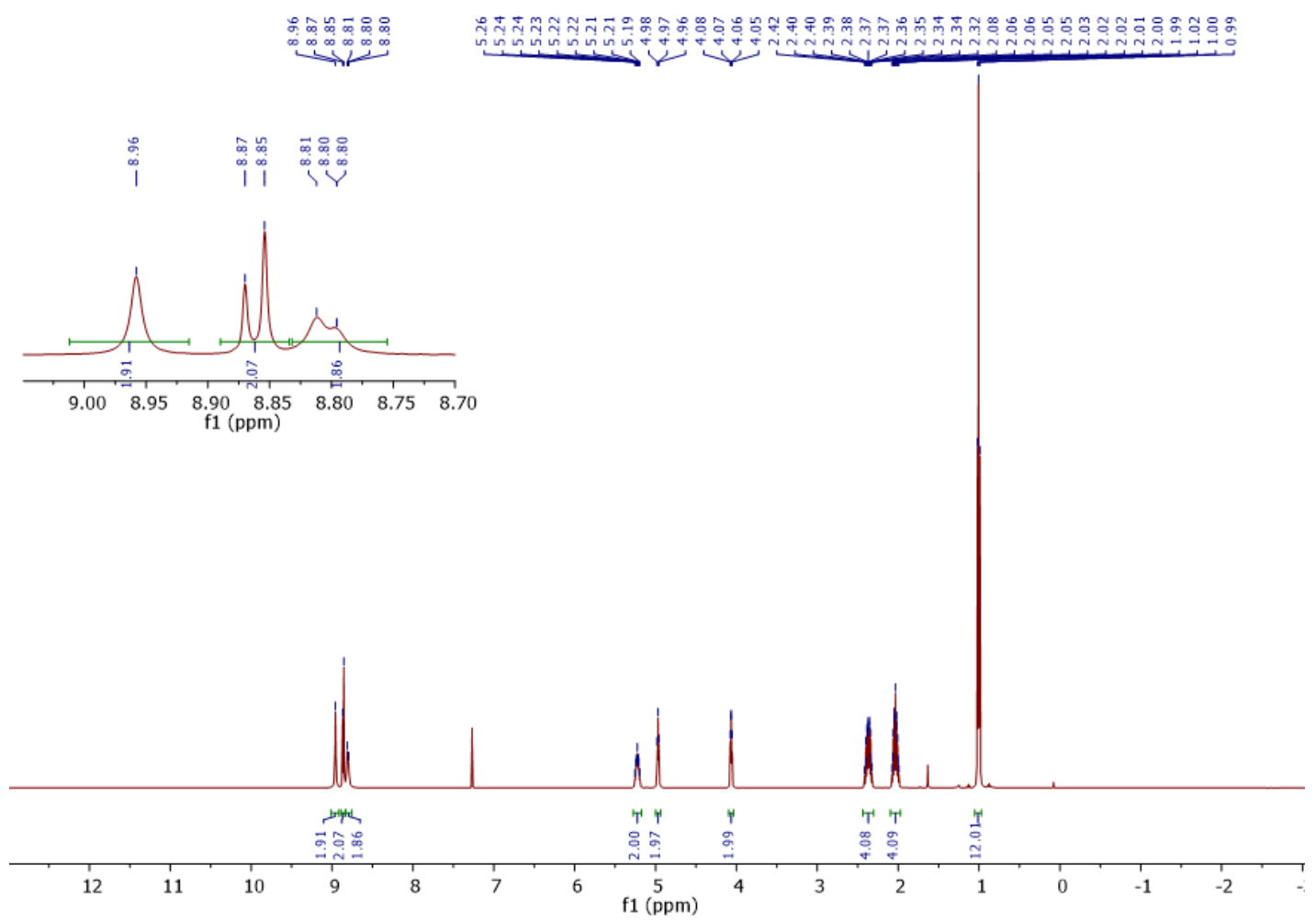

Figure S3. ${ }^{1} \mathrm{H}$ NMR spectrum of $\mathrm{N}_{3}$-PDI $\left(500 \mathrm{MHz}, \mathrm{CDCl}_{3}\right)$

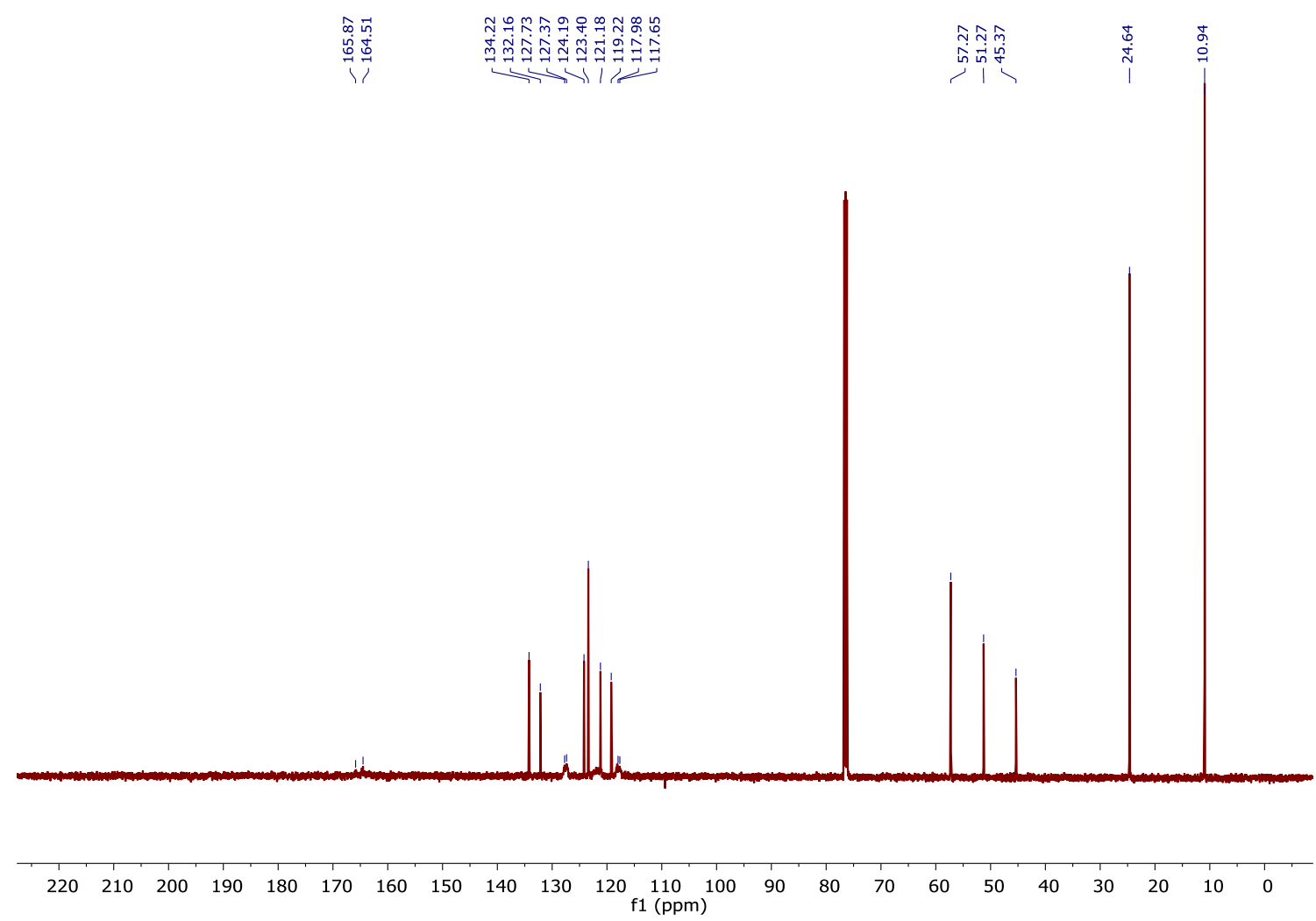

Figure S4. ${ }^{13} \mathrm{C}\left\{{ }^{1} \mathrm{H}\right\}$ NMR spectrum of $\mathrm{N}_{3}$-PDI $\left(126 \mathrm{MHz}, \mathrm{CDCl}_{3}\right)$ 


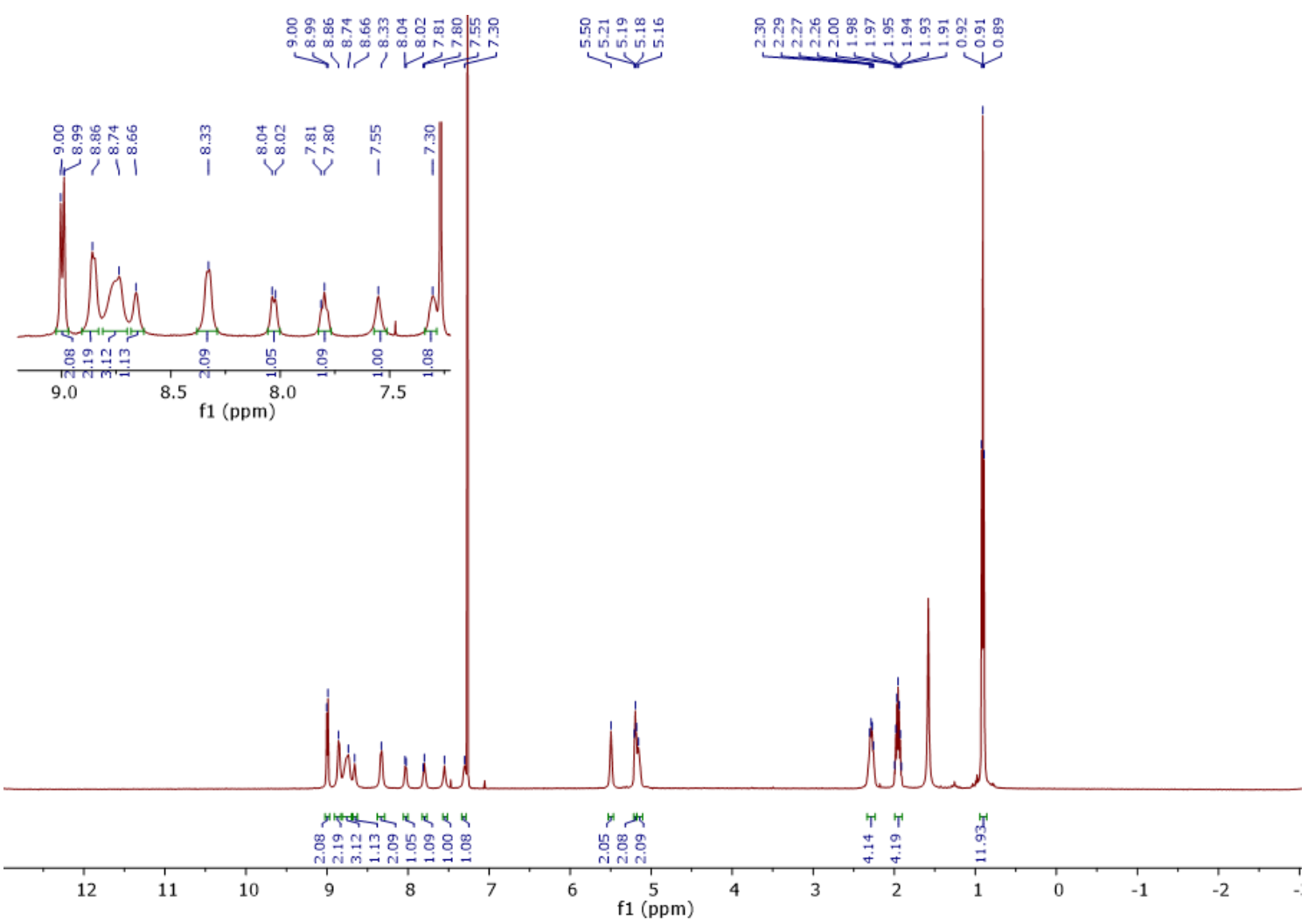

Figure S5. ${ }^{1} \mathrm{H}$ NMR spectrum of bpy-TAz-PDI $\left(500 \mathrm{MHz}, \mathrm{CDCl}_{3}\right)$

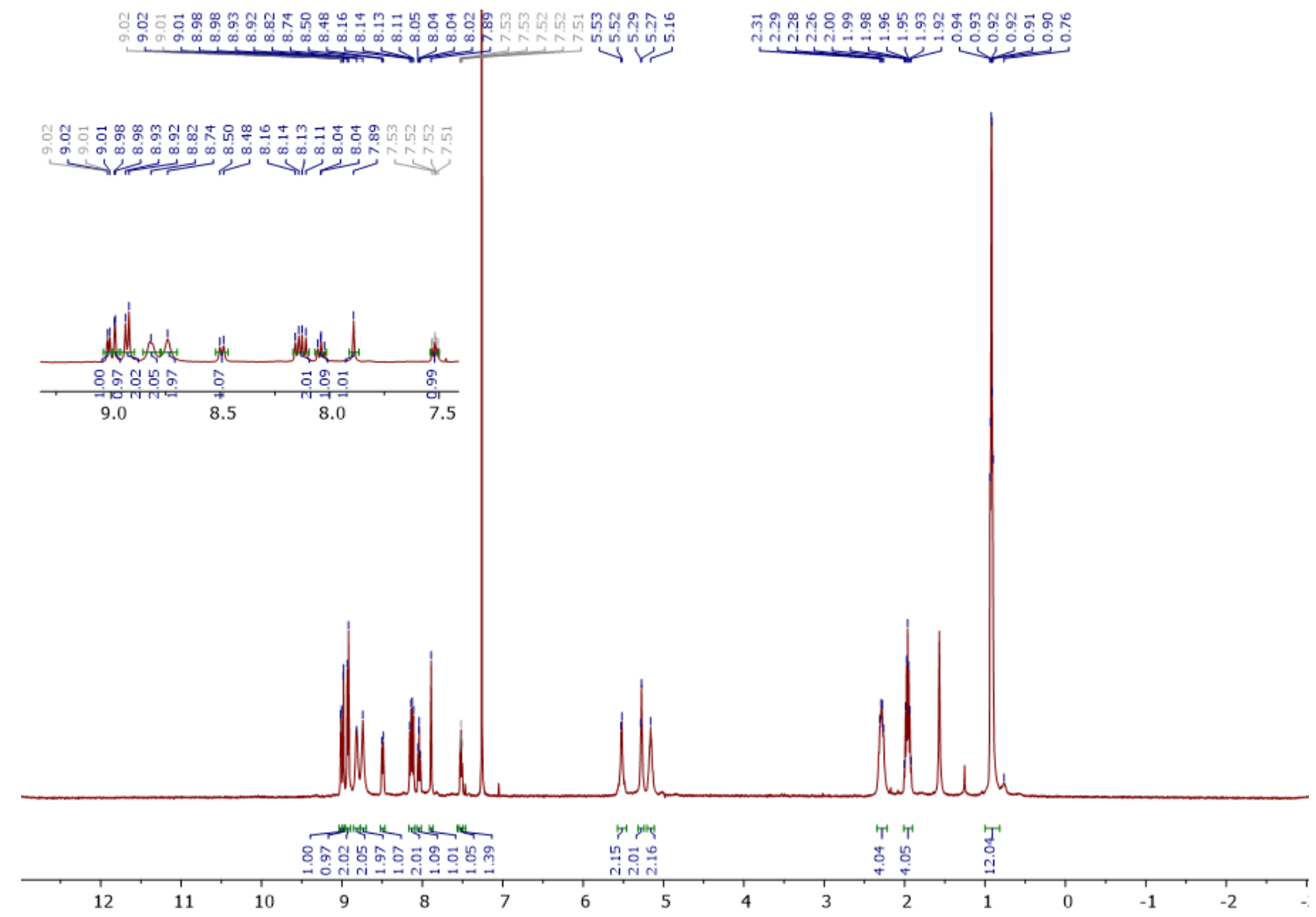

Figure S6. ${ }^{1} \mathrm{H}$ NMR spectrum of $\mathrm{Re}(\mathrm{bpy}-\mathrm{TAz}-\mathrm{PDI})\left(500 \mathrm{MHz}, \mathrm{CDCl}_{3}\right)$ 


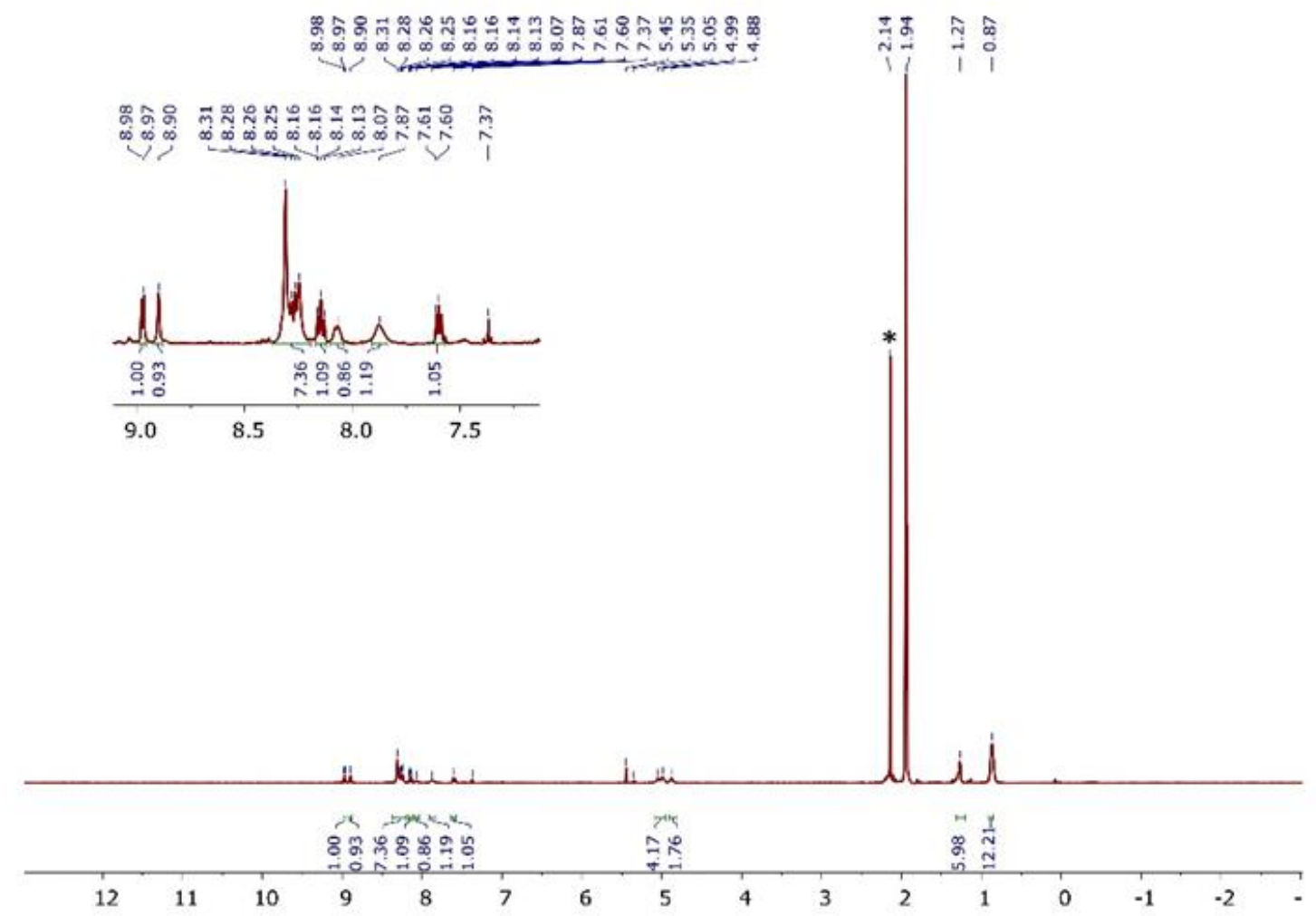

Figure S7. ${ }^{1} \mathrm{H}$ NMR spectrum of $\mathrm{Re}(\mathrm{bpy}-\mathrm{TAz}-\mathrm{PDI})\left(500 \mathrm{MHz}, \mathrm{CD}_{3} \mathrm{CN}\right) ; *$ = solvent impurity
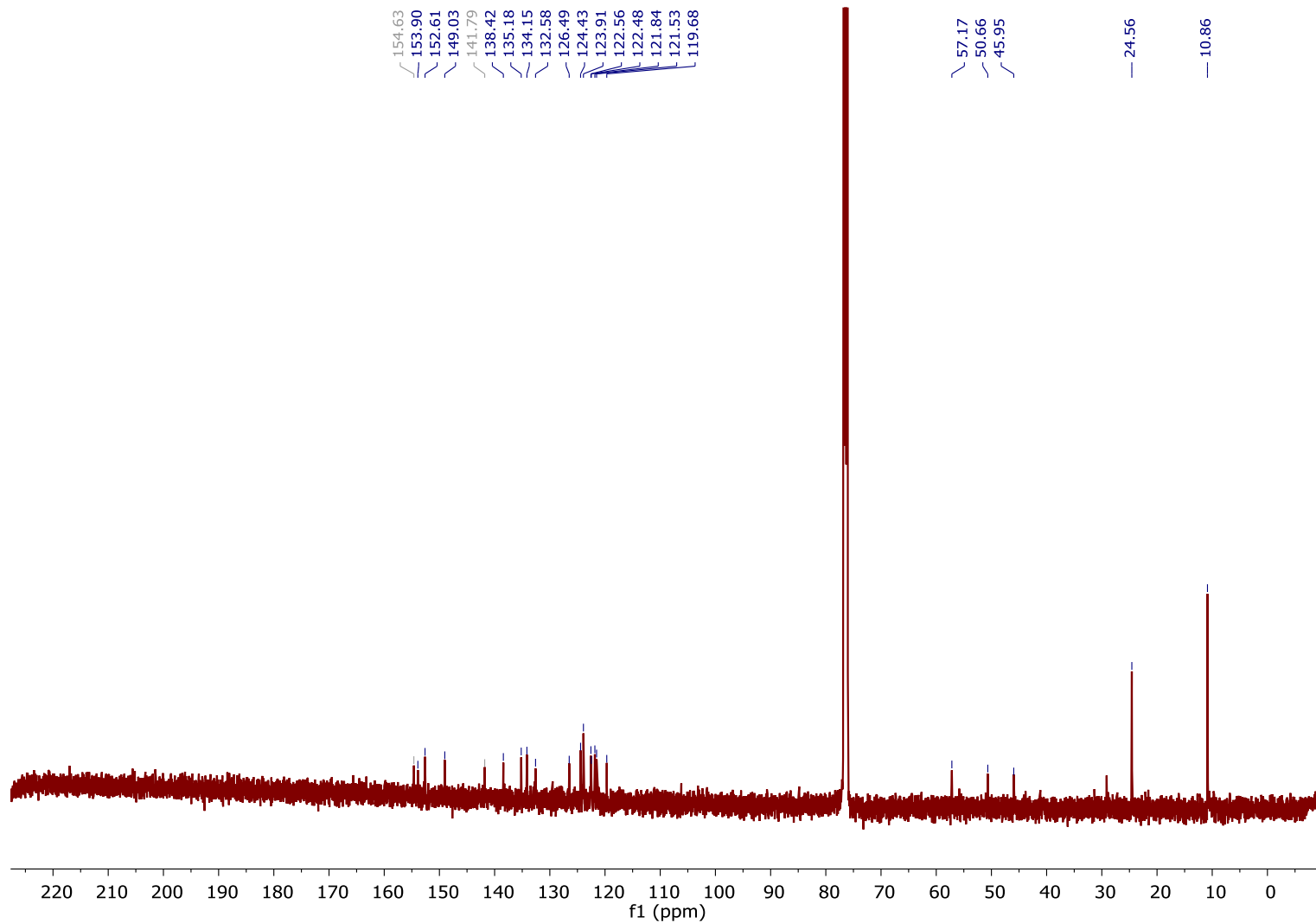

Figure S8. ${ }^{13} \mathrm{C}\left\{{ }^{1} \mathrm{H}\right\}$ NMR spectrum of $\mathrm{Re}(\mathrm{bpy}-\mathrm{TAz}-\mathrm{PDI})\left(126 \mathrm{MHz}, \mathrm{CDCl}_{3}\right)$ 

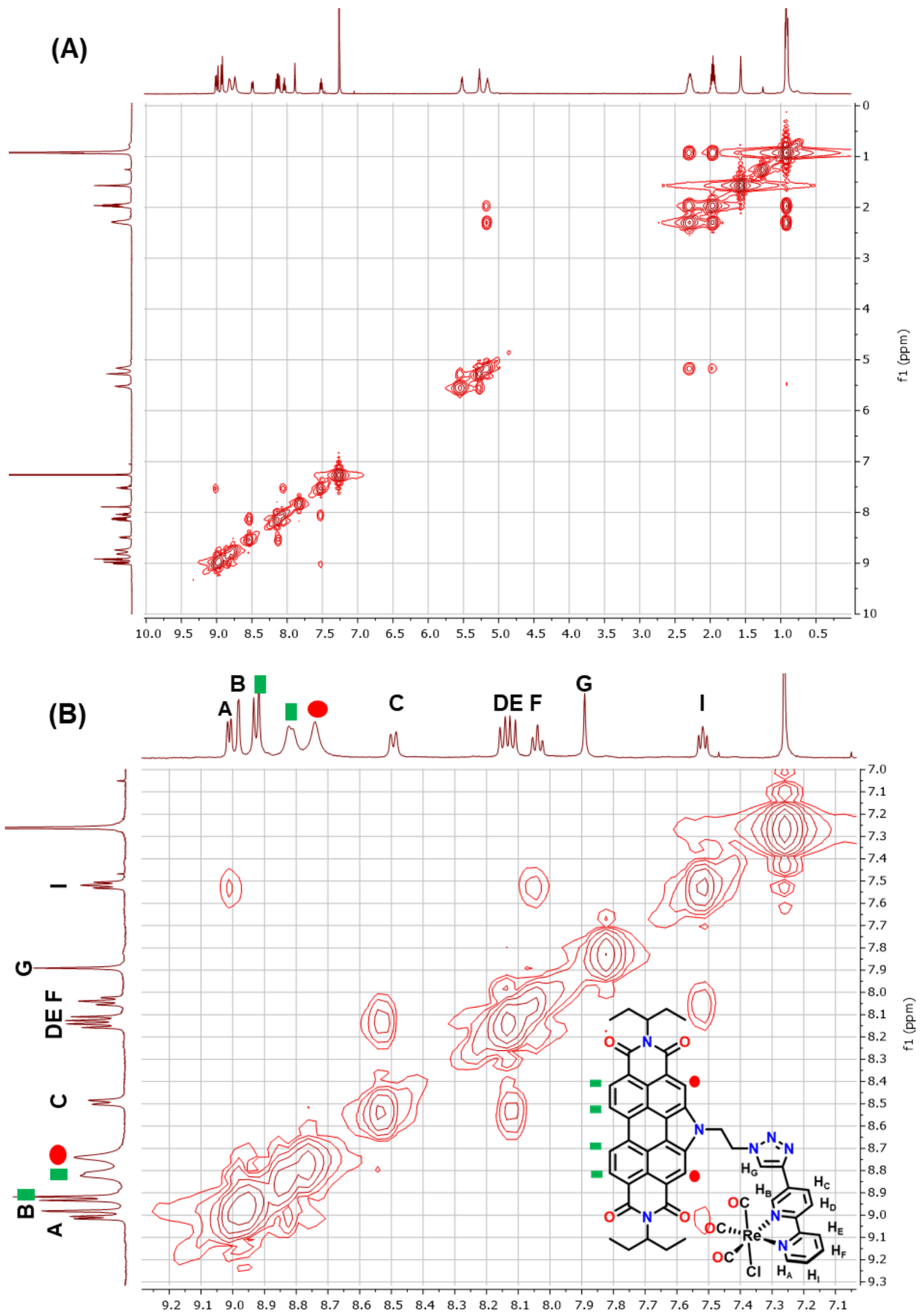

Figure S9. ${ }^{1} \mathrm{H}-{ }^{1} \mathrm{H}$ COSY spectrum (A) and assignment of aromatic peaks (B) of Re(bpy-TAzPDI) $\left(500 \mathrm{MHz}, \mathrm{CDCl}_{3}\right)$ 


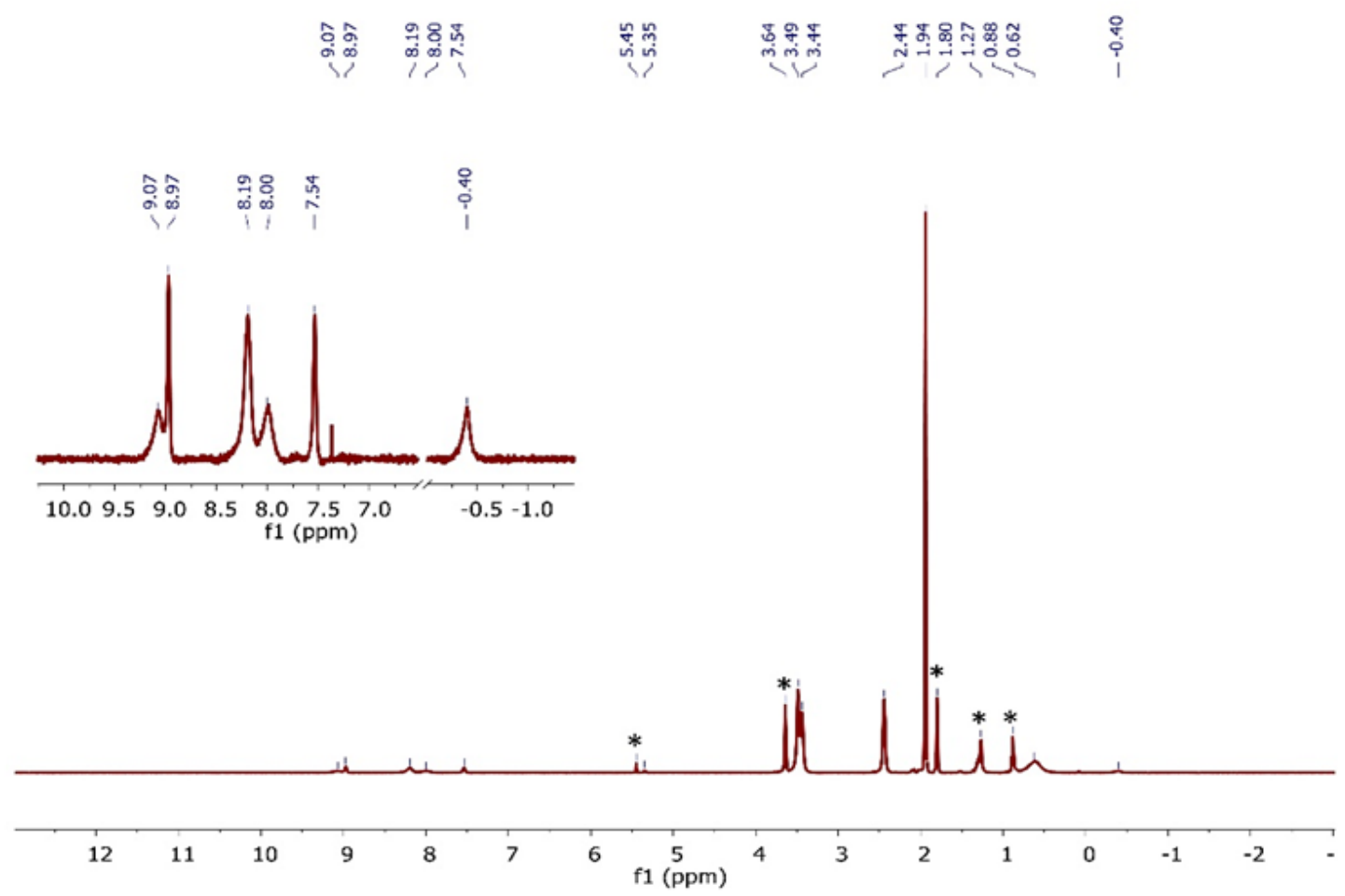

Figure S10. ${ }^{1} \mathrm{H}$ NMR spectrum of $[\mathrm{K}(\mathrm{crypt})][\mathrm{Re}(\mathrm{bpy}-\mathrm{TAz}-\mathrm{PDI})]\left(500 \mathrm{MHz}, \mathrm{CD}_{3} \mathrm{CN}\right)$; * = solvent impurities 15

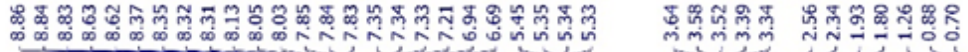

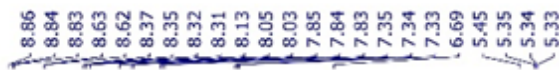
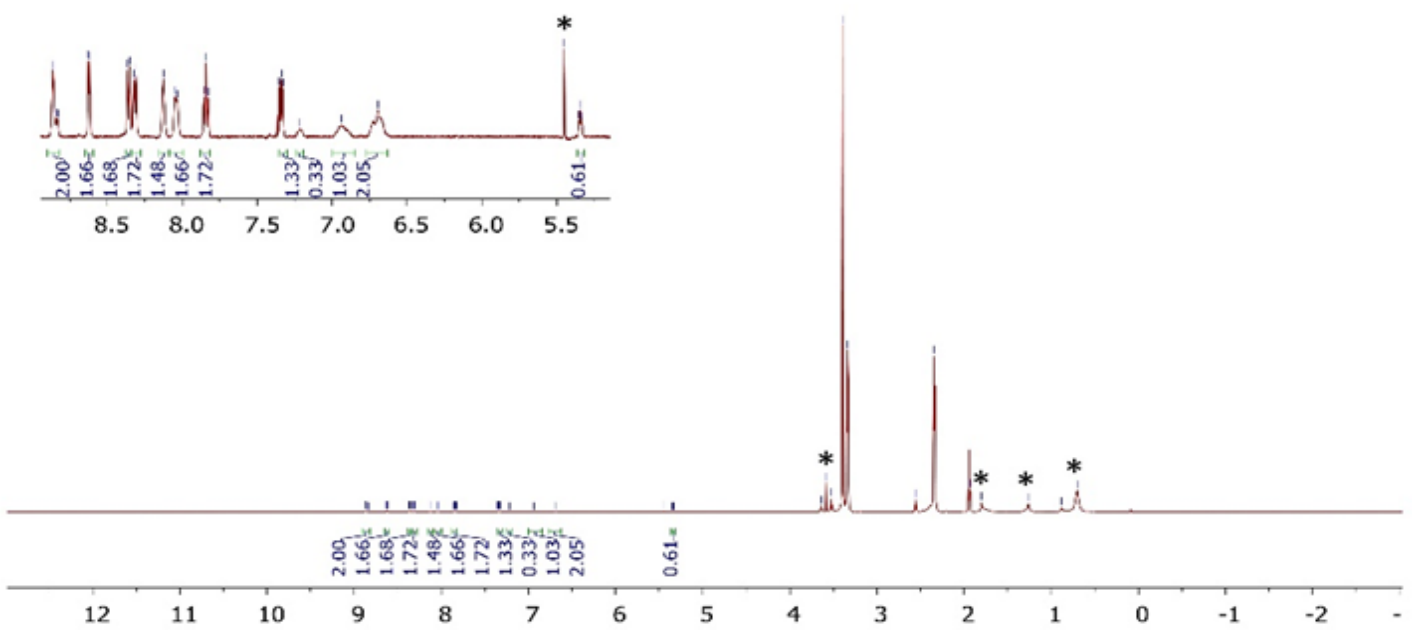

Figure S11. ${ }^{1} \mathrm{H}$ NMR spectrum of $[\mathrm{K}(\mathrm{crypt})]_{2}[\mathrm{Re}(\mathrm{bpy}-\mathrm{TAz}-\mathrm{PDI})]\left(500 \mathrm{MHz}, \mathrm{CD}_{3} \mathrm{CN}\right) ; *$ solvent impurities ${ }^{15}$ 


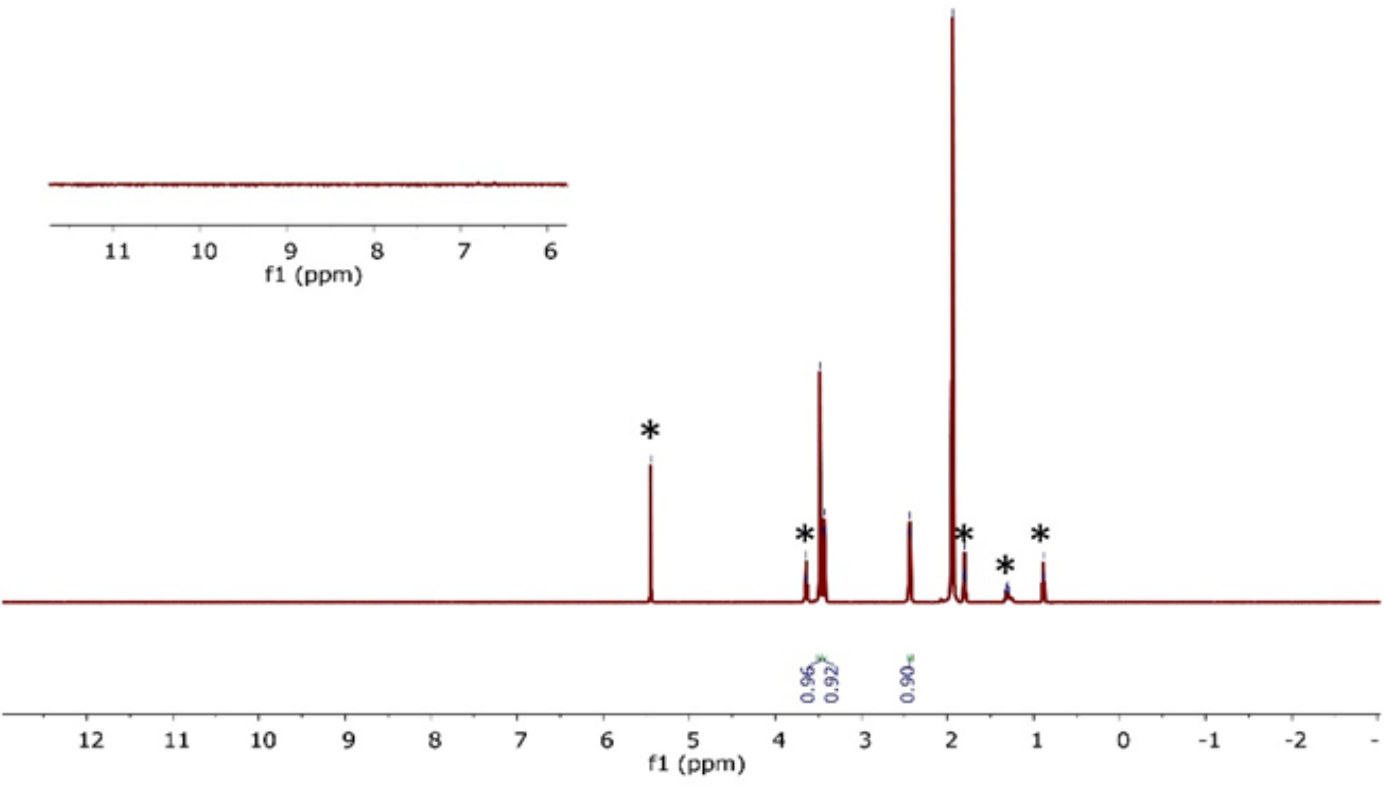

Figure S12. ${ }^{1} \mathrm{H}$ NMR spectrum of $[\mathrm{K}(\mathrm{crypt})]_{3}[\mathrm{Re}(\mathrm{bpy}-\mathrm{TAz}-\mathrm{PDI})]\left(500 \mathrm{MHz}, \mathrm{CD}_{3} \mathrm{CN}\right) ; *$ solvent impurities ${ }^{15}$
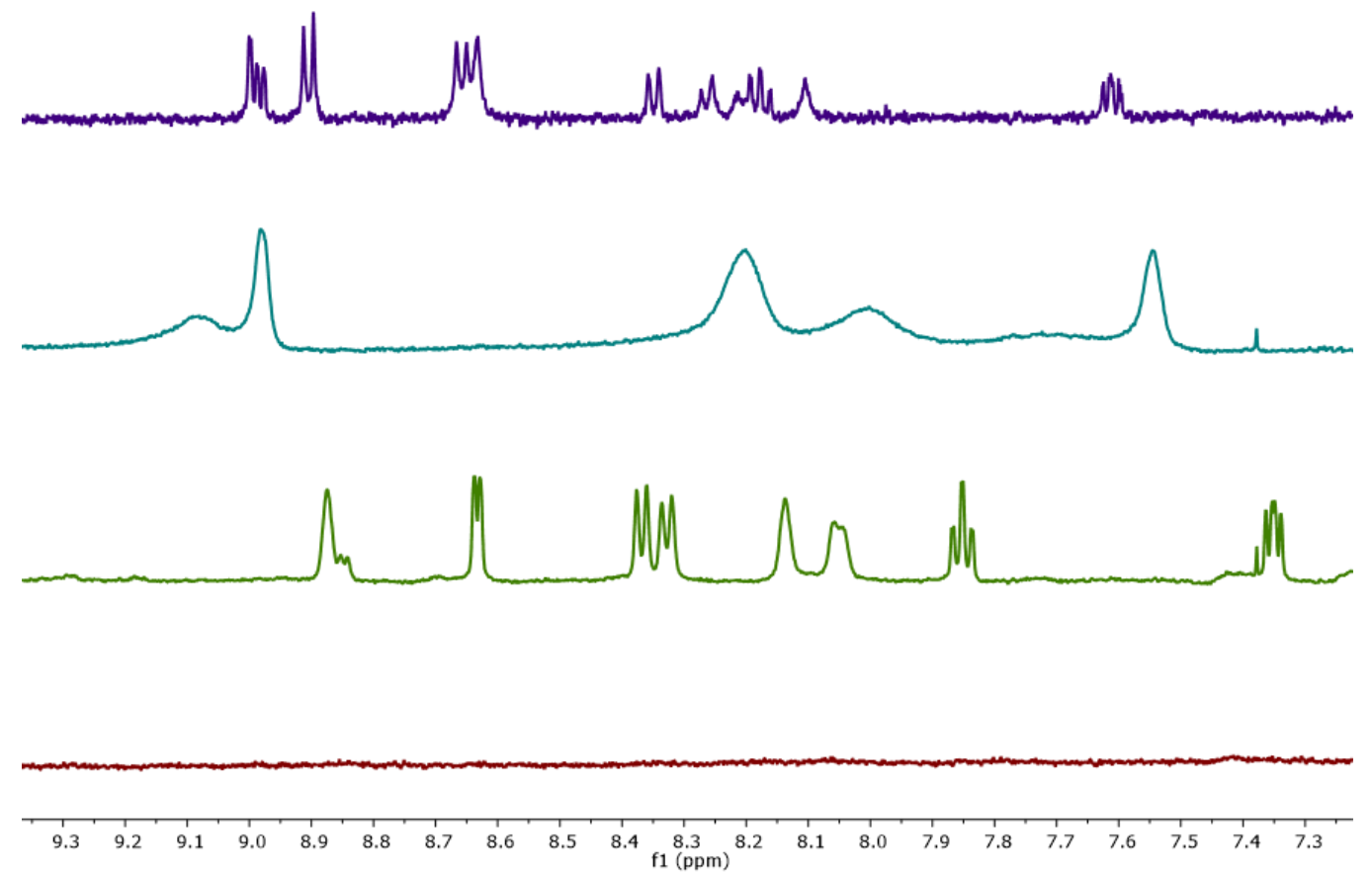

Figure S13. Enhanced view of aromatic ${ }^{1} \mathrm{H}$ NMR resonances $\left(500 \mathrm{MHz}, \mathrm{CD}_{3} \mathrm{CN}\right)$ for $\mathrm{Re}(\mathrm{bpy}-$ TAz-PDI) (purple), [K(crypt)][Re(bpy-TAz-PDI)] (teal), [K(crypt) $]_{2}[\operatorname{Re}($ bpy-TAz-PDI)] (green), and $[\mathrm{K}(\mathrm{crypt})]_{3}[\operatorname{Re}(\mathrm{bpy}-\mathrm{TAz}-\mathrm{PDI})]$ (red) 


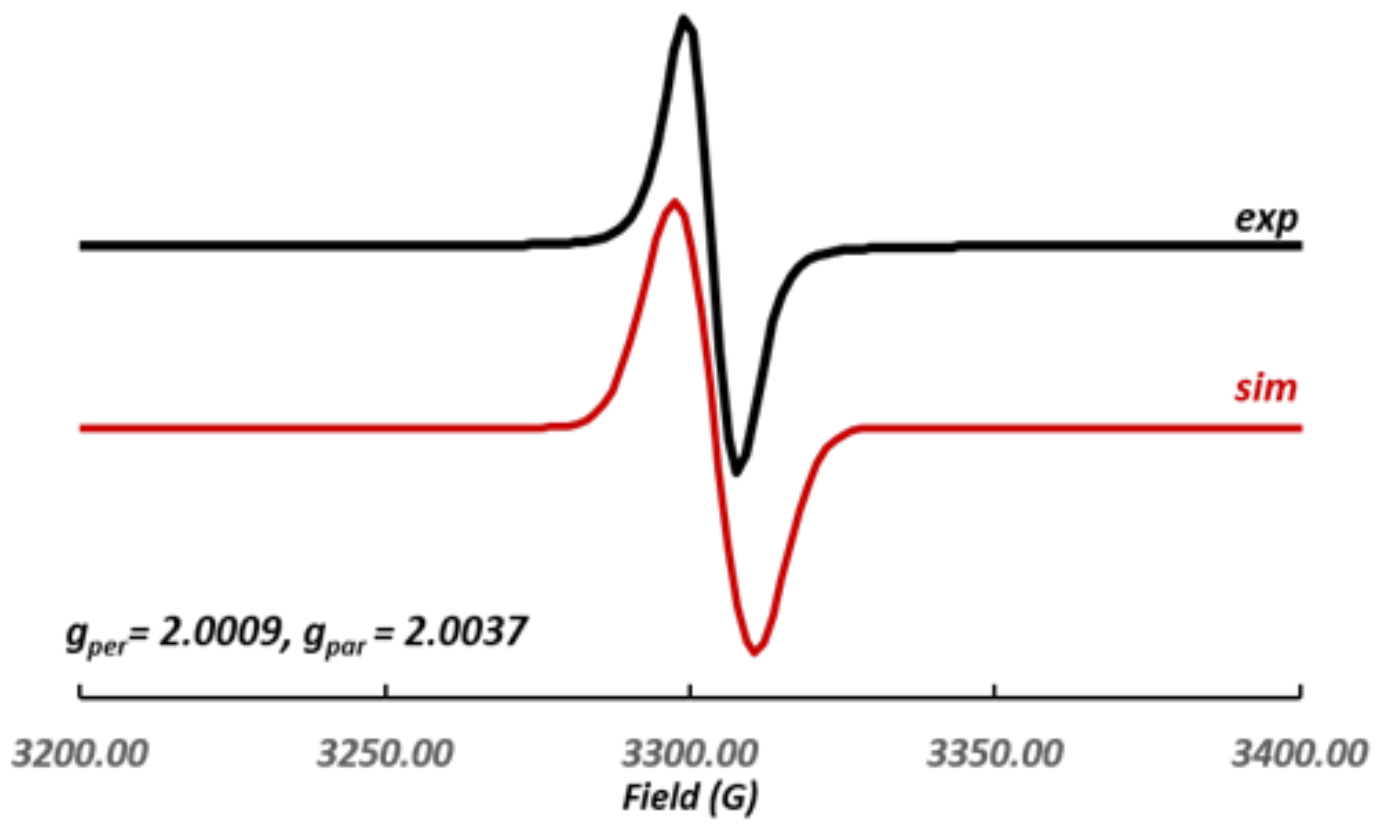

Figure S14. X-band EPR spectrum of [K(crypt)][Re(bpy-TAz-PDI)] recorded in toluene at 298K

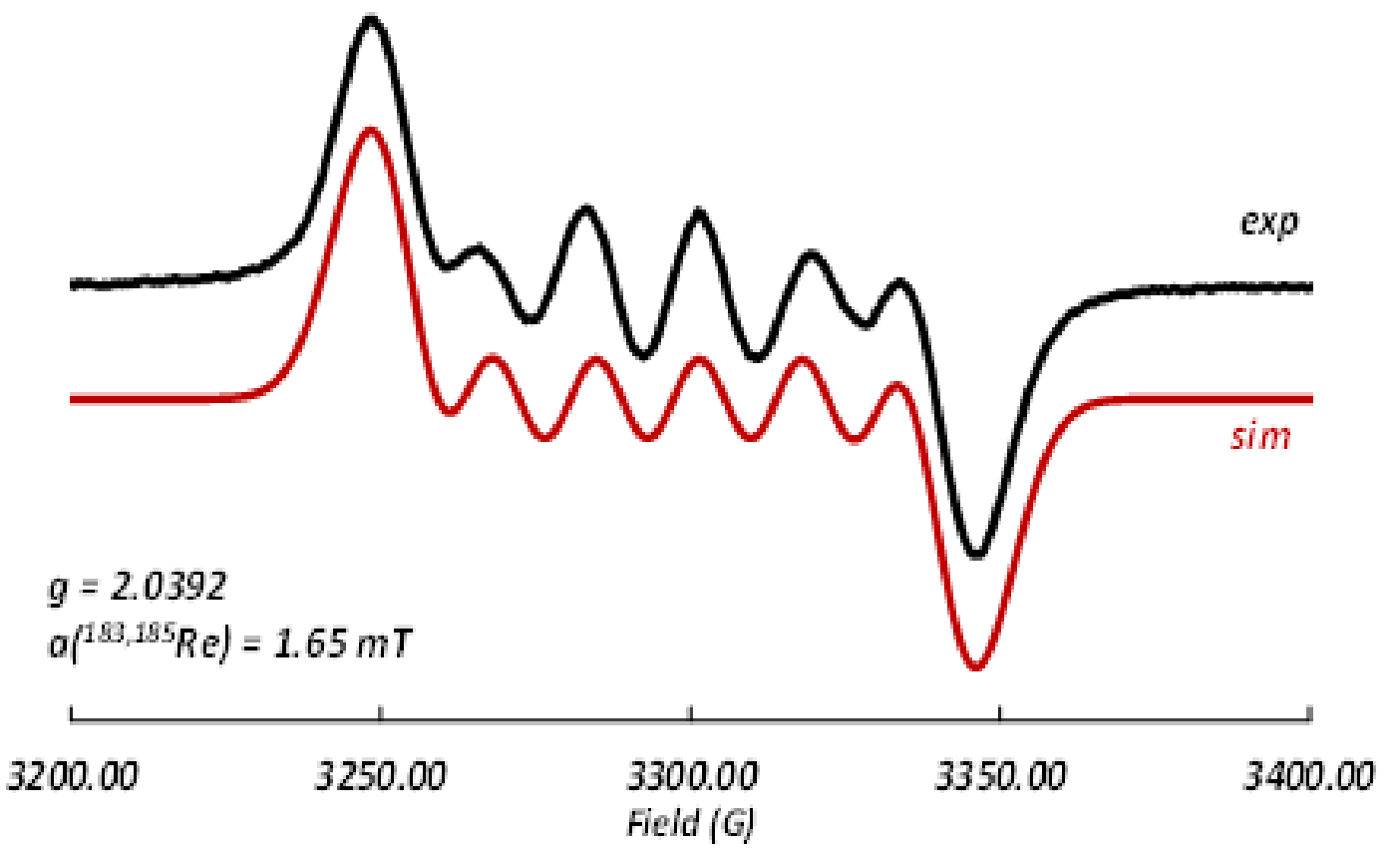

Figure S15. X-band EPR spectrum of $[\mathrm{K}(\mathrm{crypt})]_{3}[\mathrm{Re}(\mathrm{bpy}-\mathrm{TAz}-\mathrm{PDI})]^{3-}$ recorded in THF at $298 \mathrm{~K}$ 


\section{MALDI-TOF MS \& CHN Elemental Analysis}

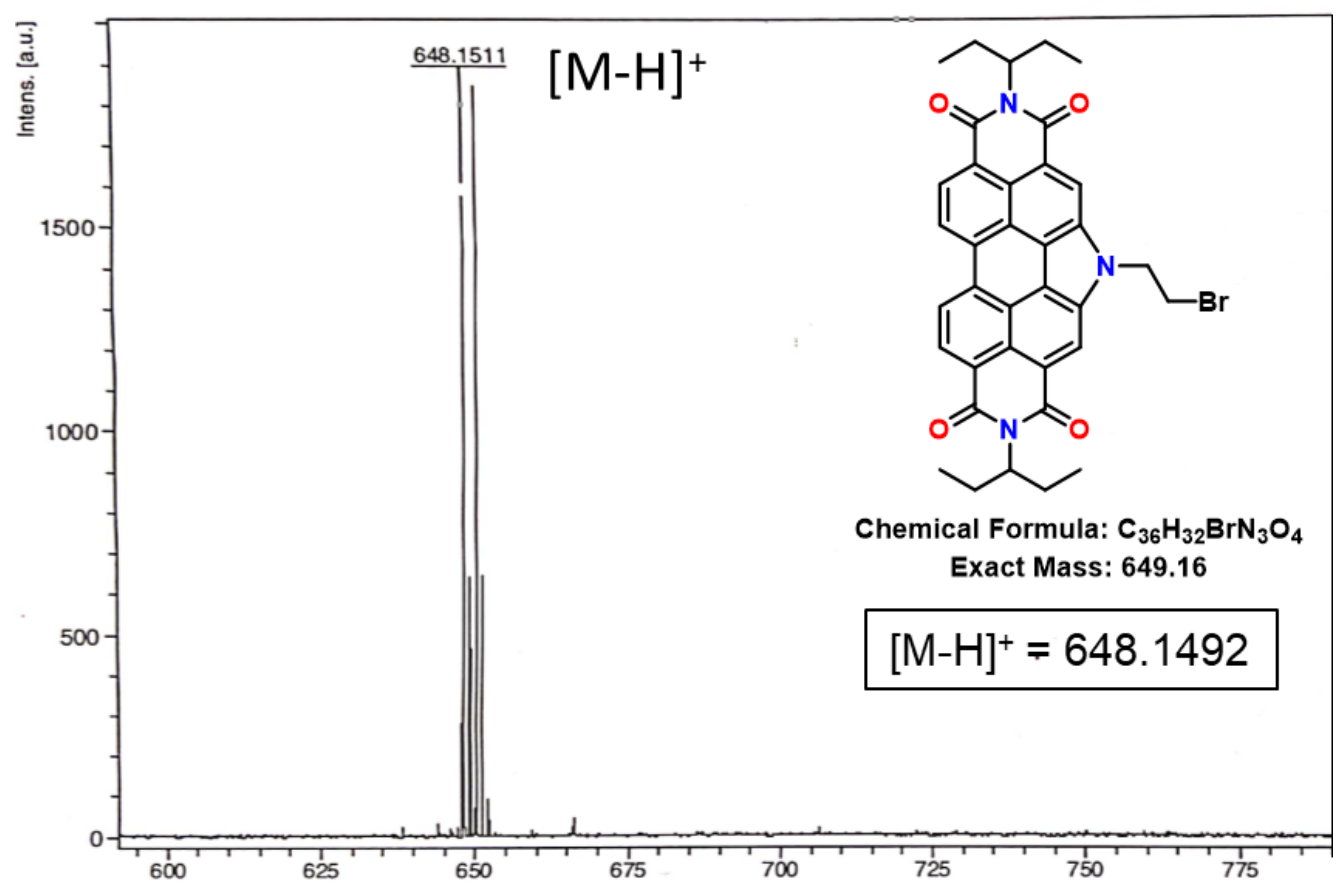

Figure S16. HR-MALDI-TOF mass spectrum of BrEt-PDI

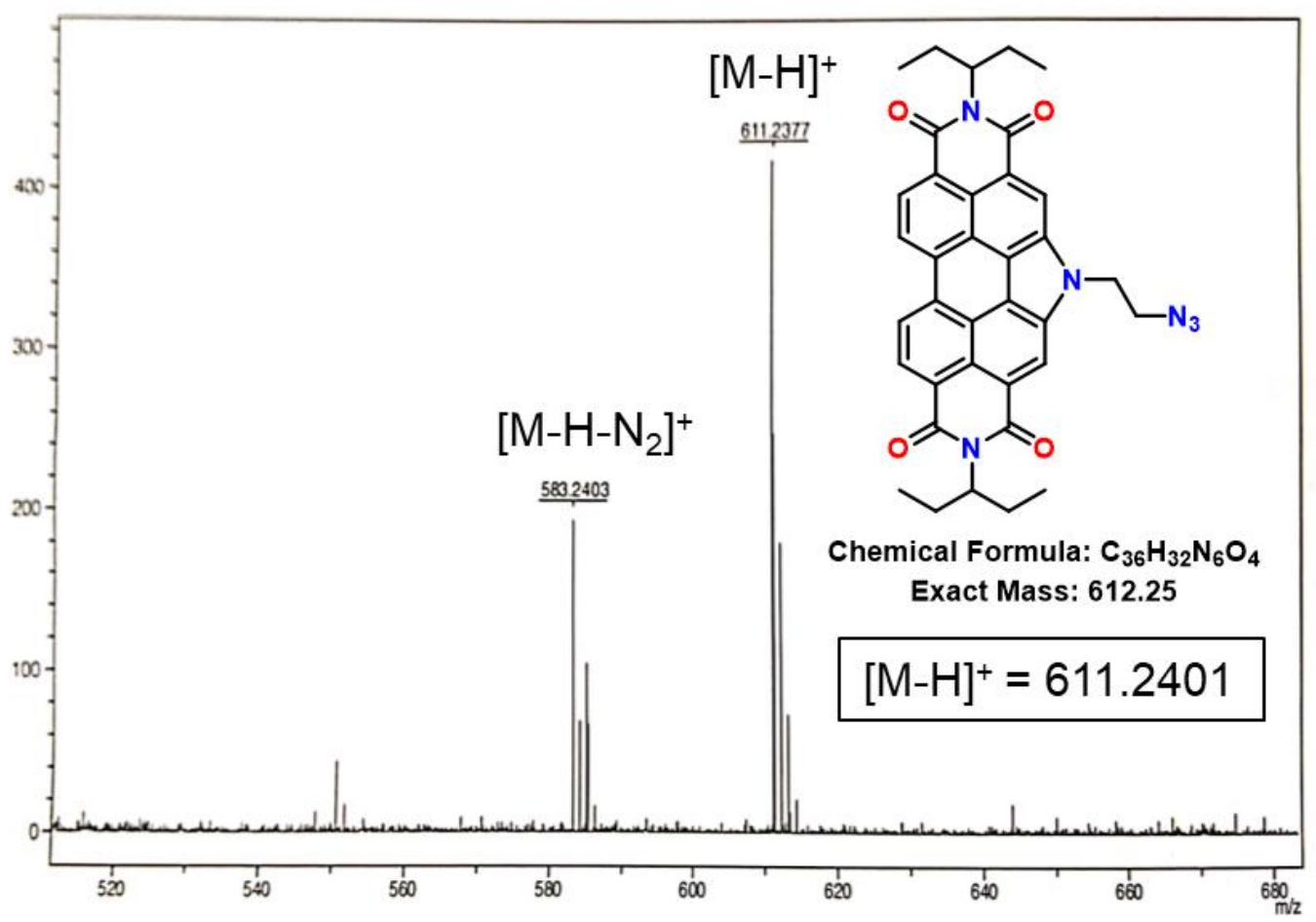

Figure S17. HR-MALDI-TOF mass spectrum of N3-PDI 


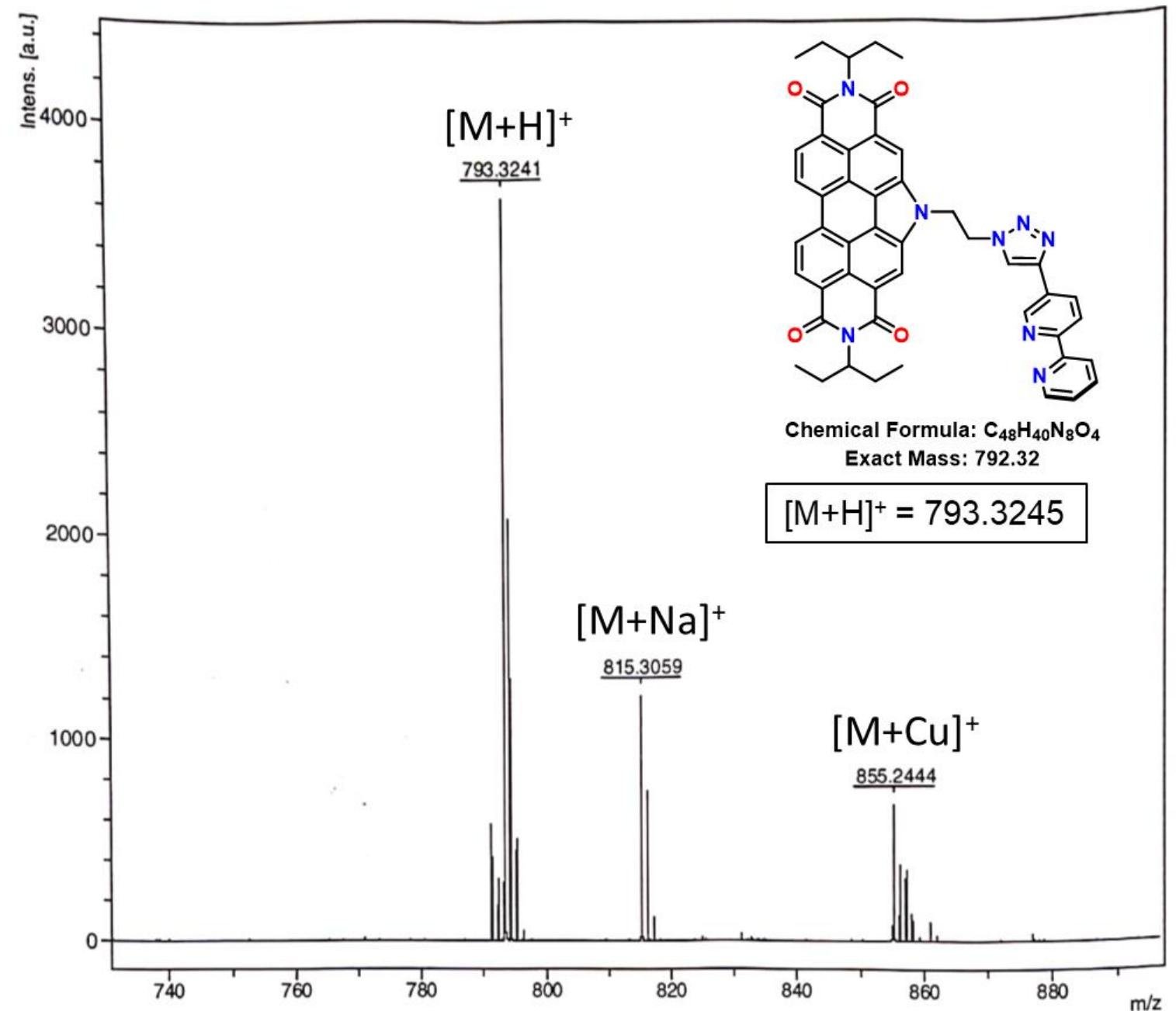

Figure S18. HR-MALDI-TOF mass spectrum of bpy-TAz-PDI

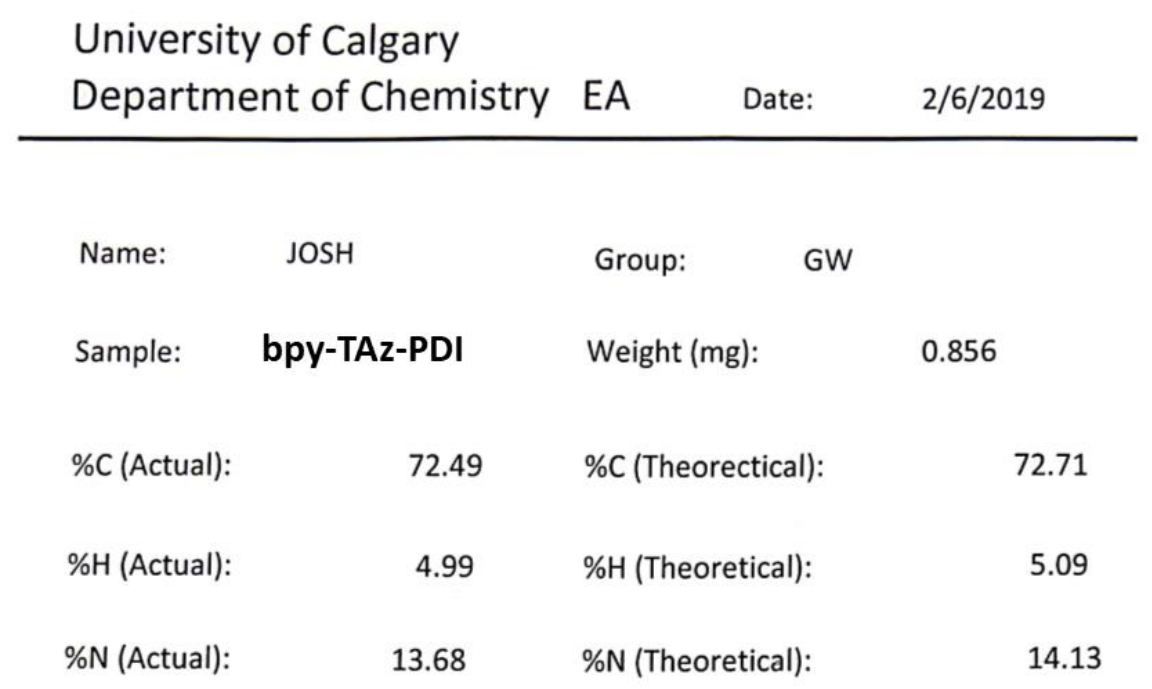

Figure S19. CHN elemental analysis of bpy-TAz-PDI 


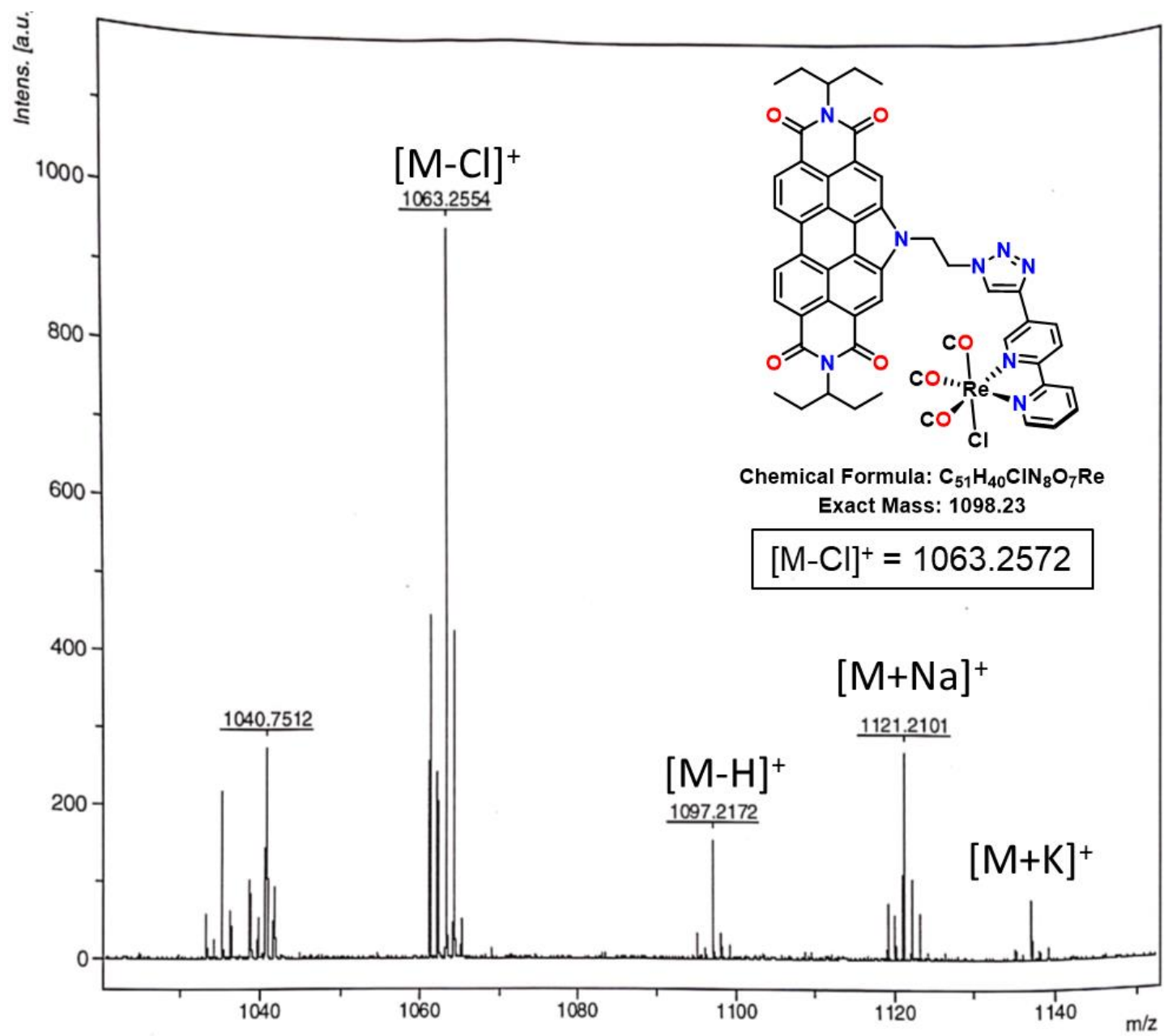

Figure S20. HR-MALDI-TOF mass spectrum of Re(bpy-TAz-PDI)

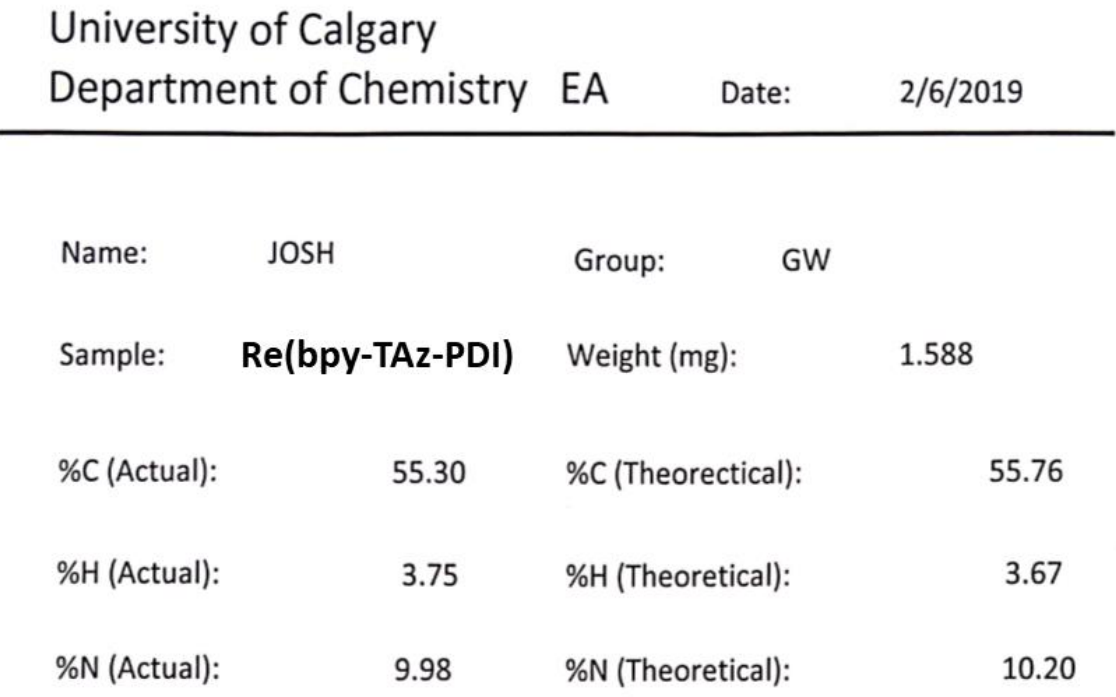

Figure S21. CHN elemental analysis of Re(bpy-TAz-PDI) 


\section{UV-Vis \& FTIR Spectroscopy}

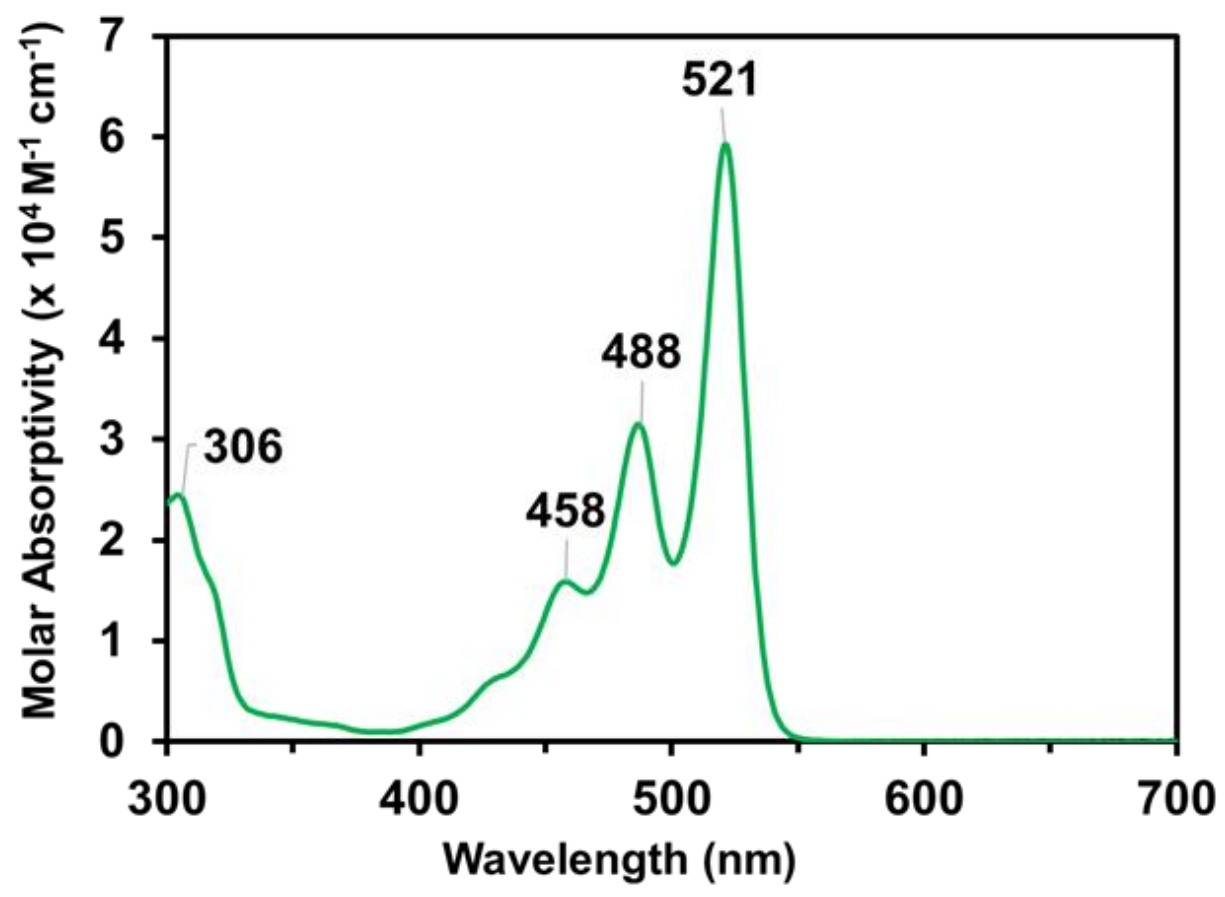

Figure S22. UV-vis absorption spectrum of bpy-TAz-PDI in $\mathrm{CHCl}_{3}$

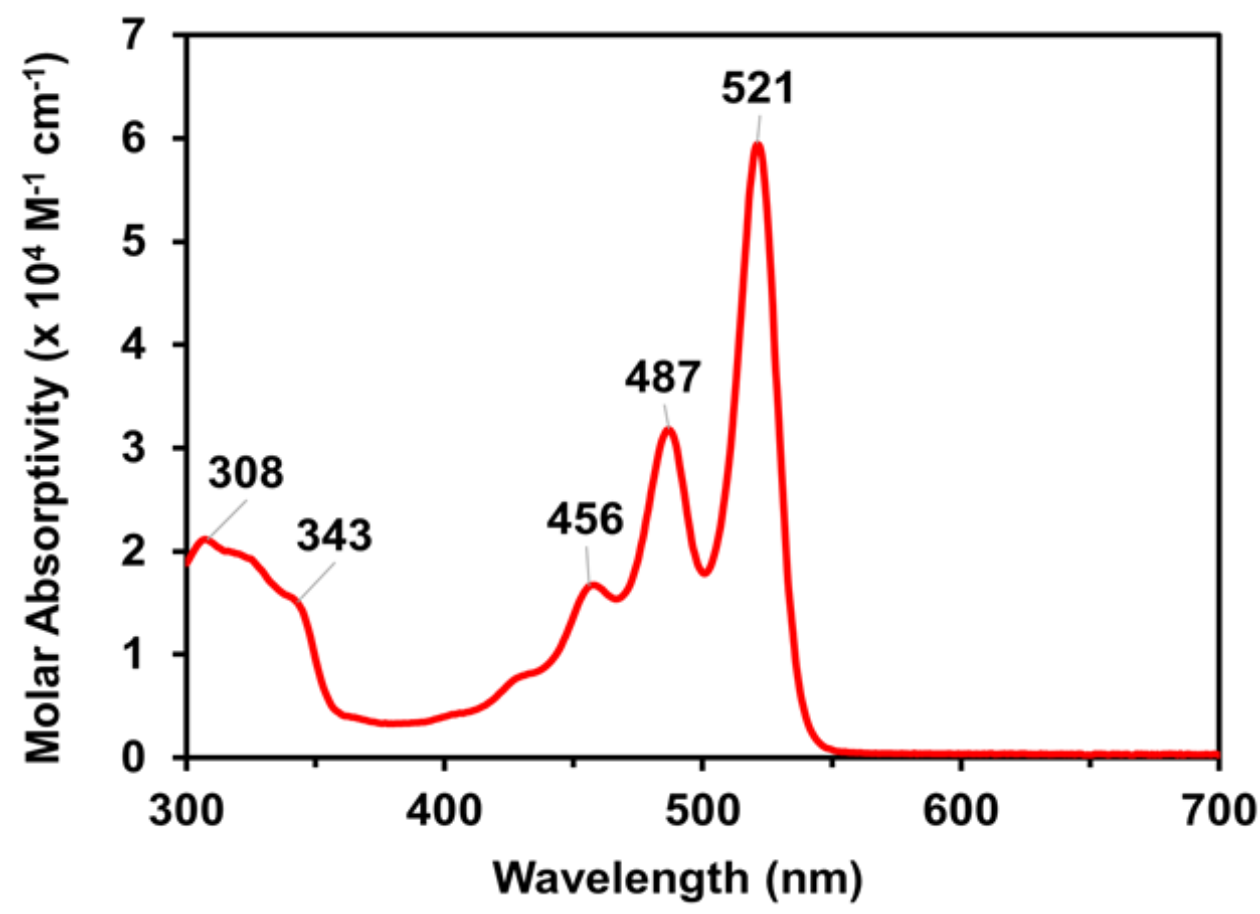

Figure S23. UV-vis absorption spectrum of $\mathrm{Re}(\mathrm{bpy}-\mathrm{TAz}-\mathrm{PDI})$ in $\mathrm{CHCl}_{3}$ 


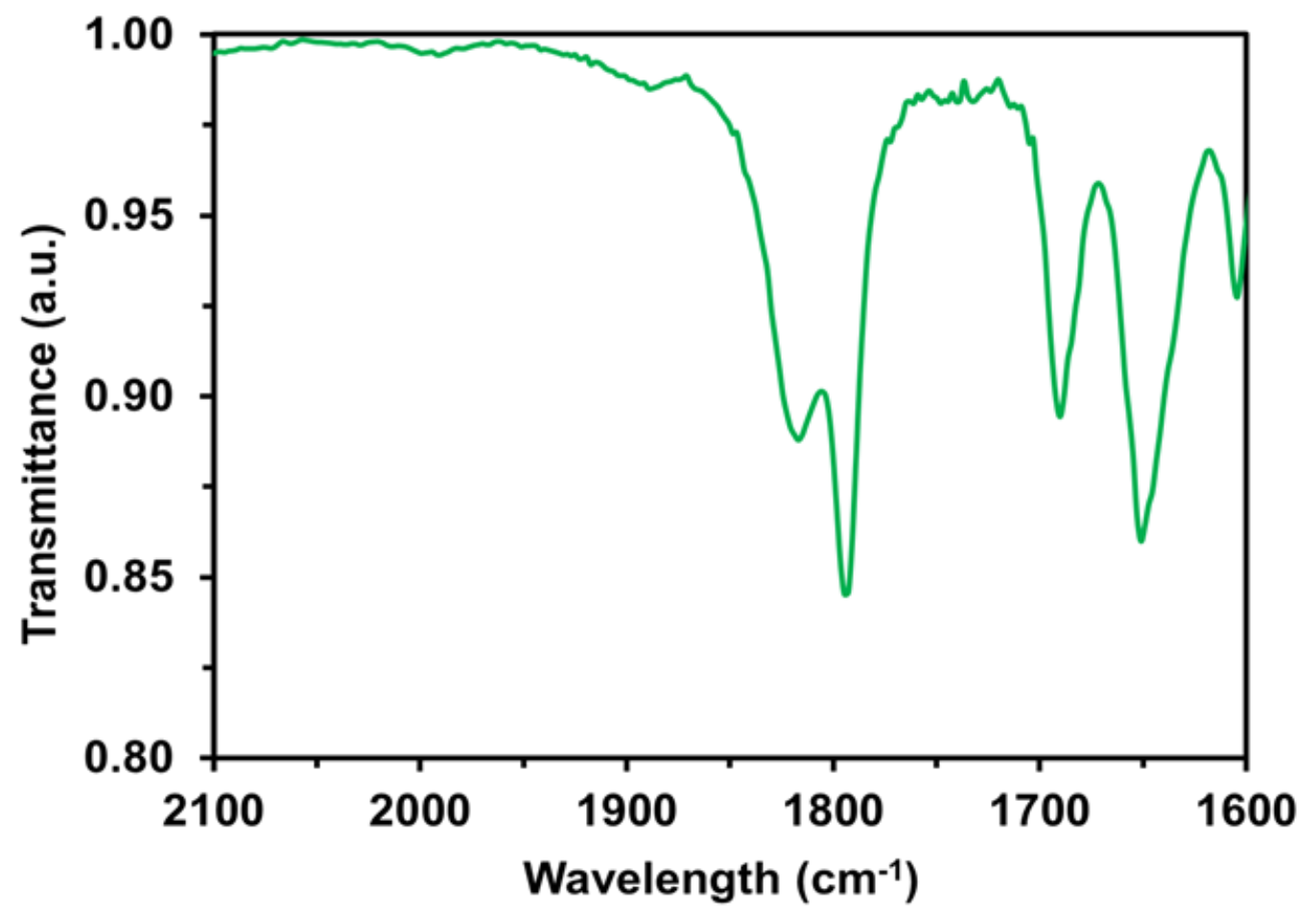

Figure S24. FTIR transmission spectrum of bpy-TAz-PDI in $\mathrm{CH}_{2} \mathrm{Cl}_{2}$

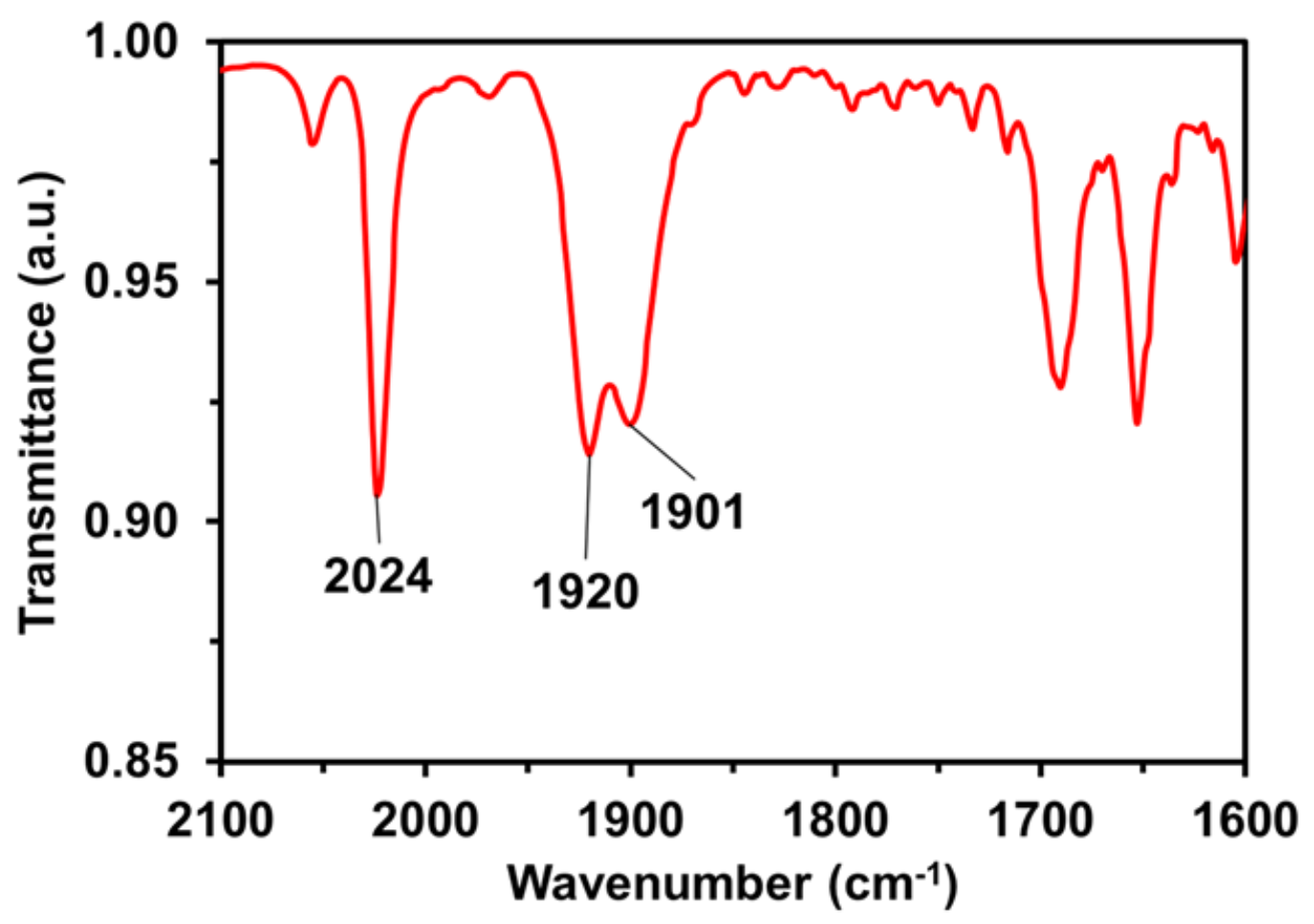

Figure S25. FTIR transmission spectrum of $\mathrm{Re}(\mathrm{bpy}-\mathrm{TAz}-\mathrm{PDI})$ in $\mathrm{CH}_{2} \mathrm{Cl}_{2}$ 


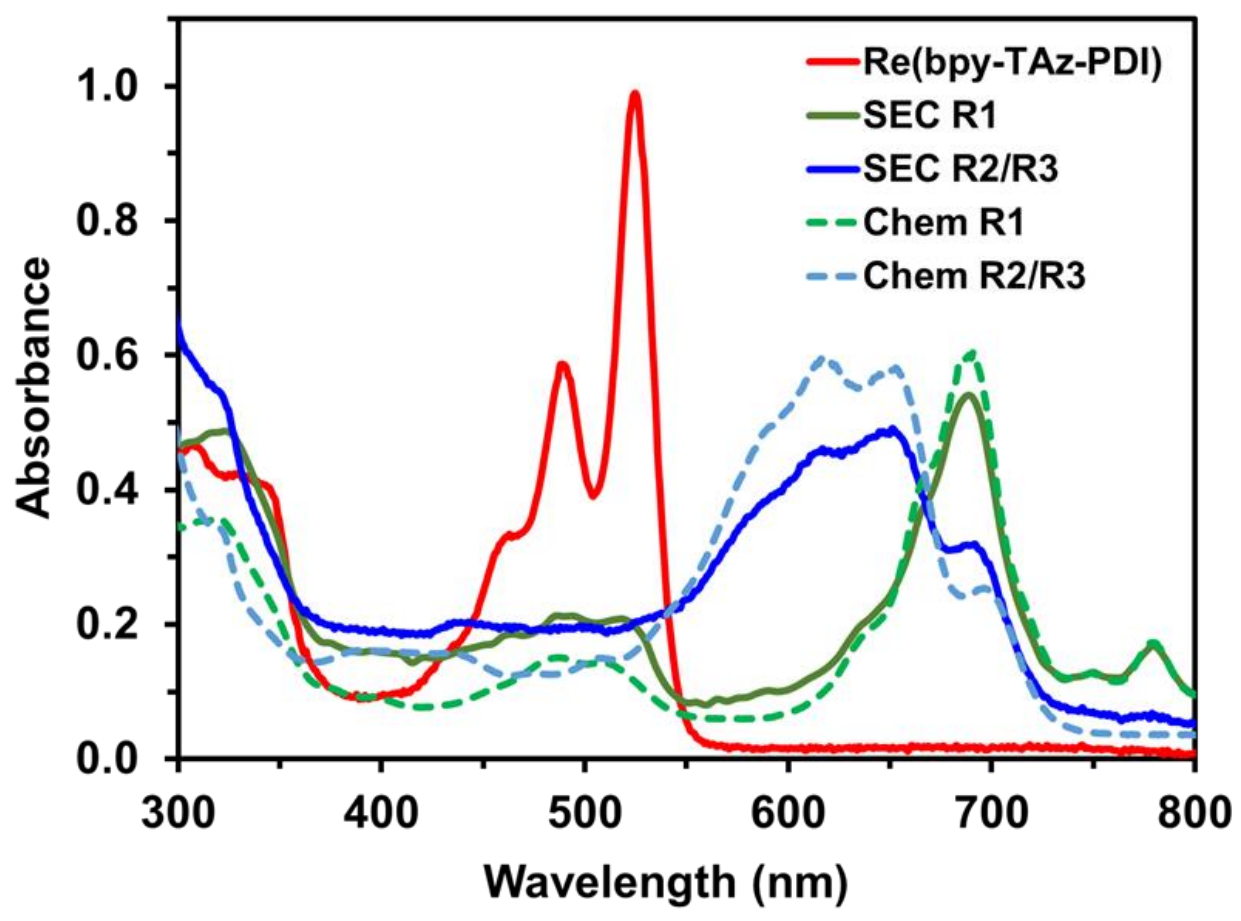

Figure S26. Comparing the UV-vis-nIR absorption spectra of electrochemically reduced (solid lines) and chemically reduced (dashed lines) Re(bpy-TAz-PDI) species, where R1, R2, and R3 denote the singly-, doubly-, and triply- reduced products

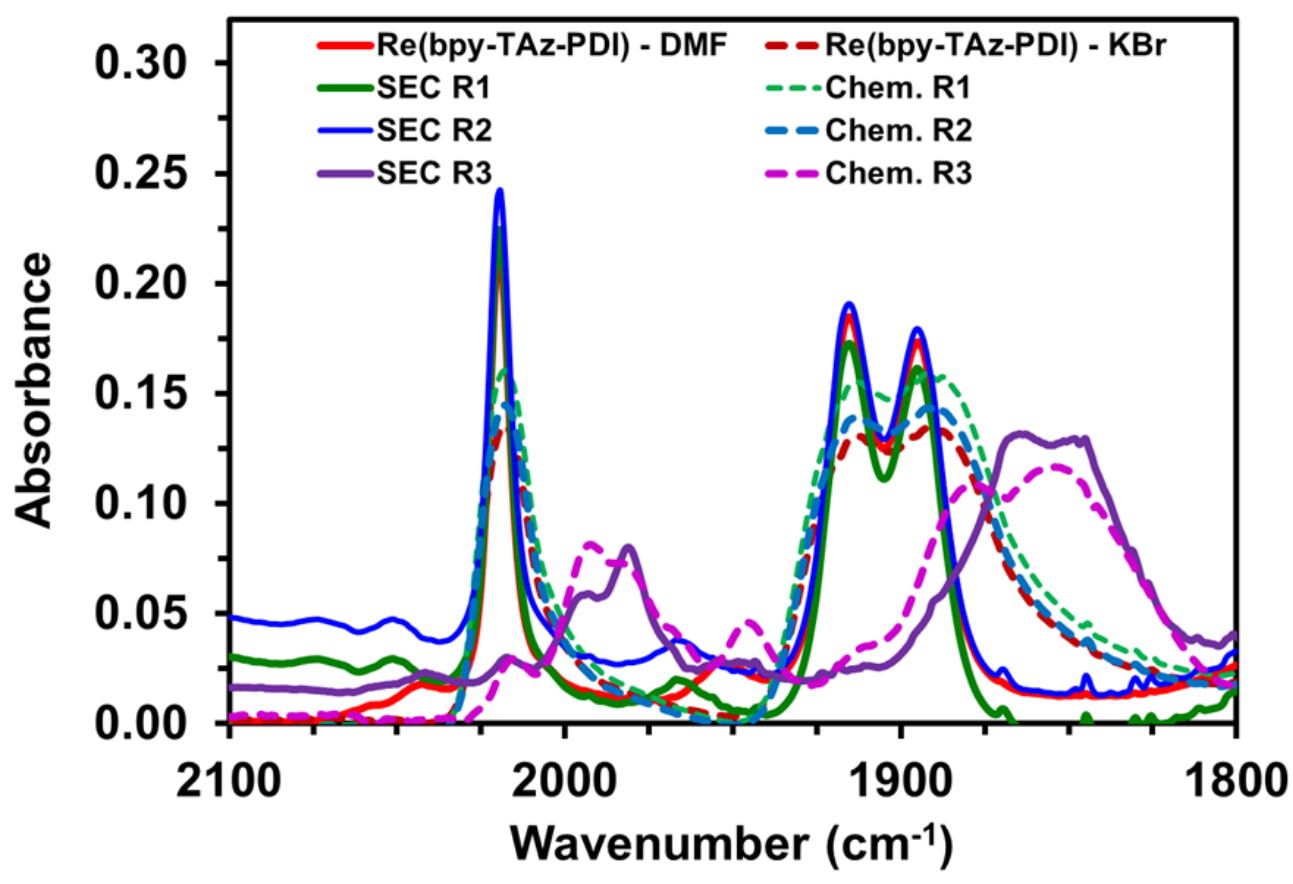

Figure S27. Comparing the FTIR absorption spectra of electrochemically reduced (solid lines) and chemically reduced (dashed lines) Re(bpy-TAz-PDI) species, where R1, R2, and R3 denote the singly-, doubly-, and triply- reduced products 


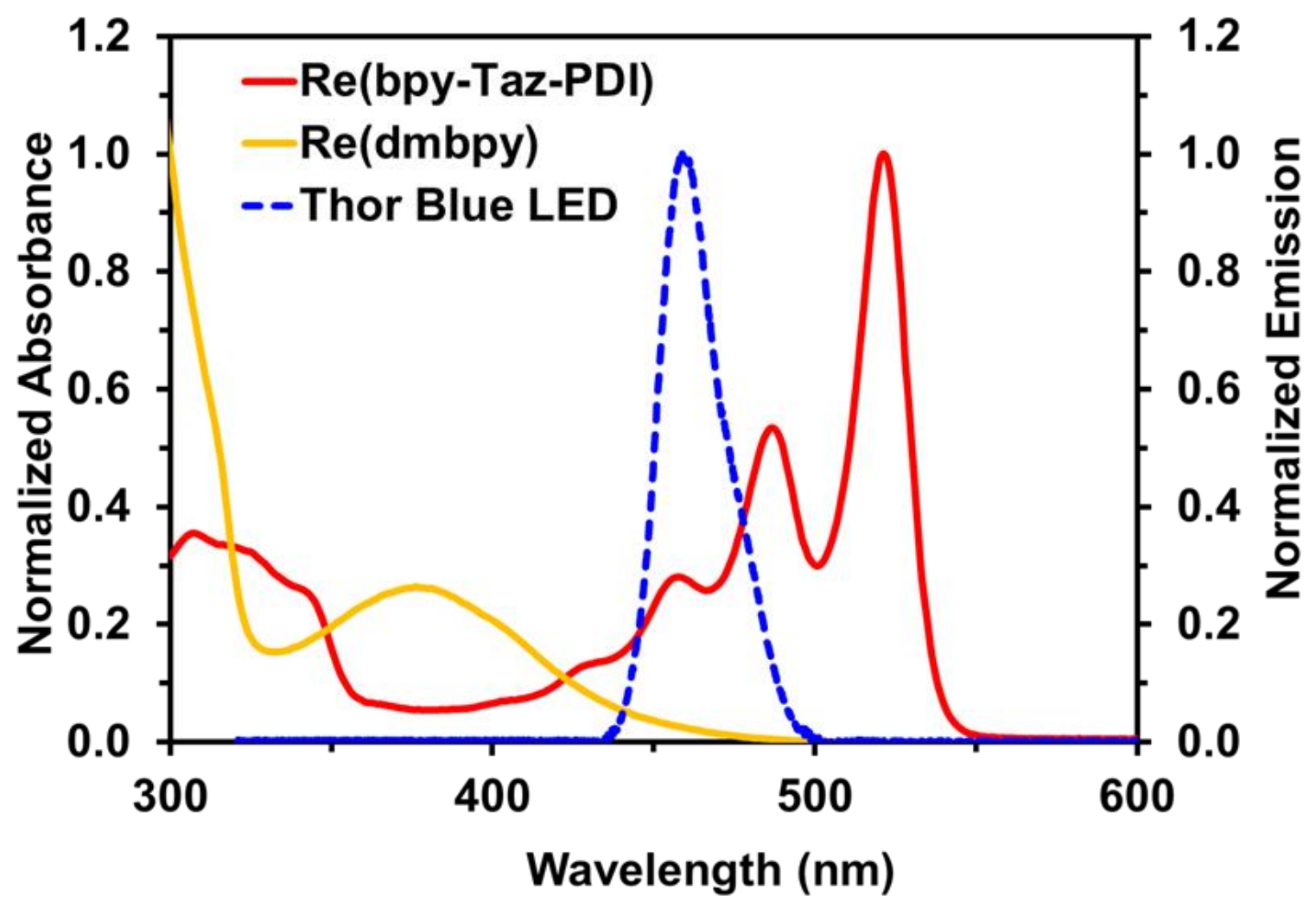

Figure S28. UV-vis absorbance spectra of Re(bpy-TAz-PDI) (red) and $\operatorname{Re(dmbpy)~(yellow),~}$ overlaid with the UV-vis emission spectrum of the Thor Labs Blue LED (dashed blue) 


\section{Cyclic Voltammetry \& Spectroelectrochemistry}

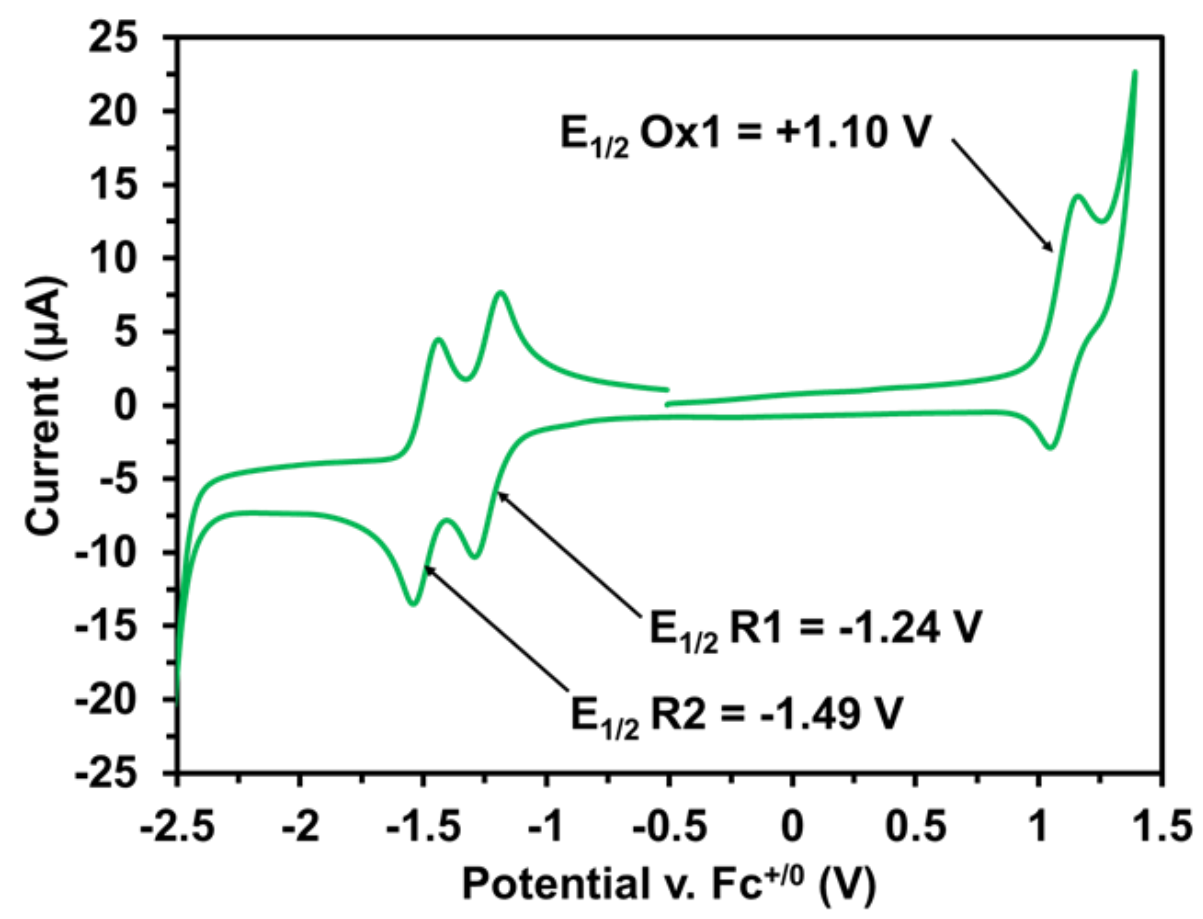

Figure S29. $\mathrm{CV}$ of bpy-TAz-PDI recorded at $100 \mathrm{mV} / \mathrm{s}$, under argon in $\mathrm{CH}_{2} \mathrm{Cl}_{2}$ with $0.1 \mathrm{M}$ $\mathrm{TBAPF}_{6}$ as supporting electrolyte and $\mathrm{Fc}^{+/ 0}$ as internal reference

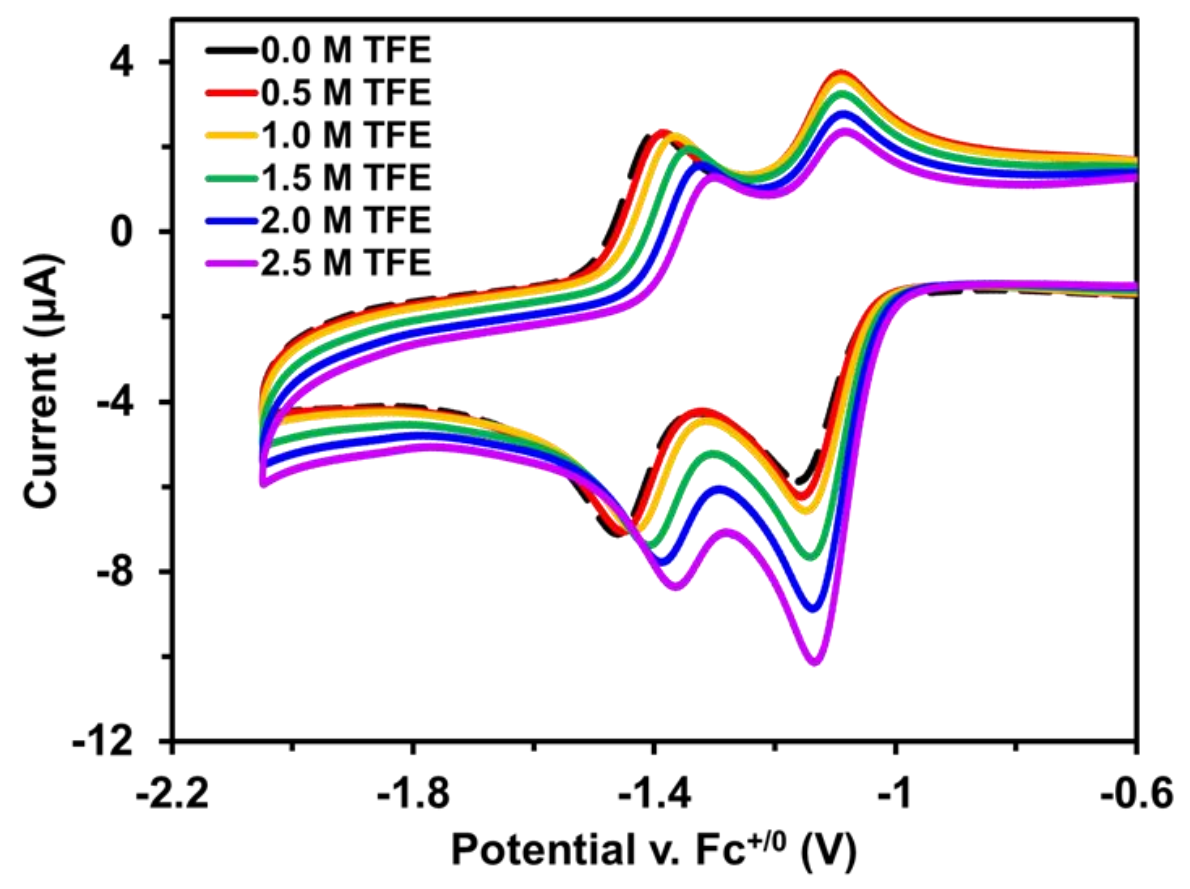

Figure S30. CV of bpy-TAz-PDI as a function of TFE concentration, recorded at $100 \mathrm{mV} / \mathrm{s}$, under argon in DMF with $0.1 \mathrm{M} \mathrm{TBAPF}_{6}$ as supporting electrolyte and $\mathrm{Fc}^{+/ 0}$ as internal reference 

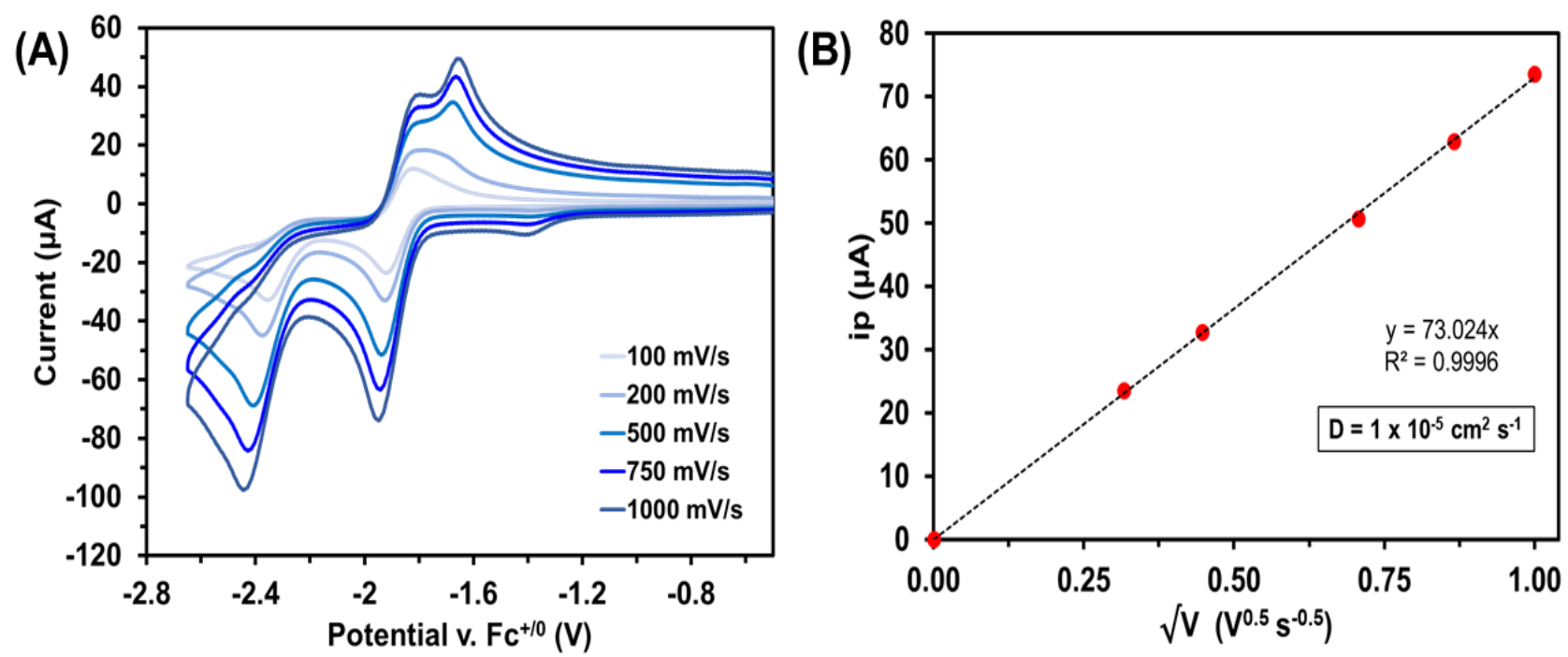

Figure S31. CVs of Re(dmbpy) recorded at variable scan rate (A), under argon in DMF with 0.1 $\mathrm{M}$ TBAPF6 supporting electrolyte $\left(\mathrm{WE}=\right.$ glassy carbon, $\mathrm{CE}=\mathrm{Pt}$-wire, $\mathrm{RE}=\mathrm{Ag} / \mathrm{AgCl}$, and $\mathrm{Fc}^{+/ 0}$ as internal reference standard). Linear fitting of the scan rate to the Randles-Sevcik equation (B) demonstrates that $\operatorname{Re}(\mathrm{dmbpy})$ undergoes a diffusion-limited current response
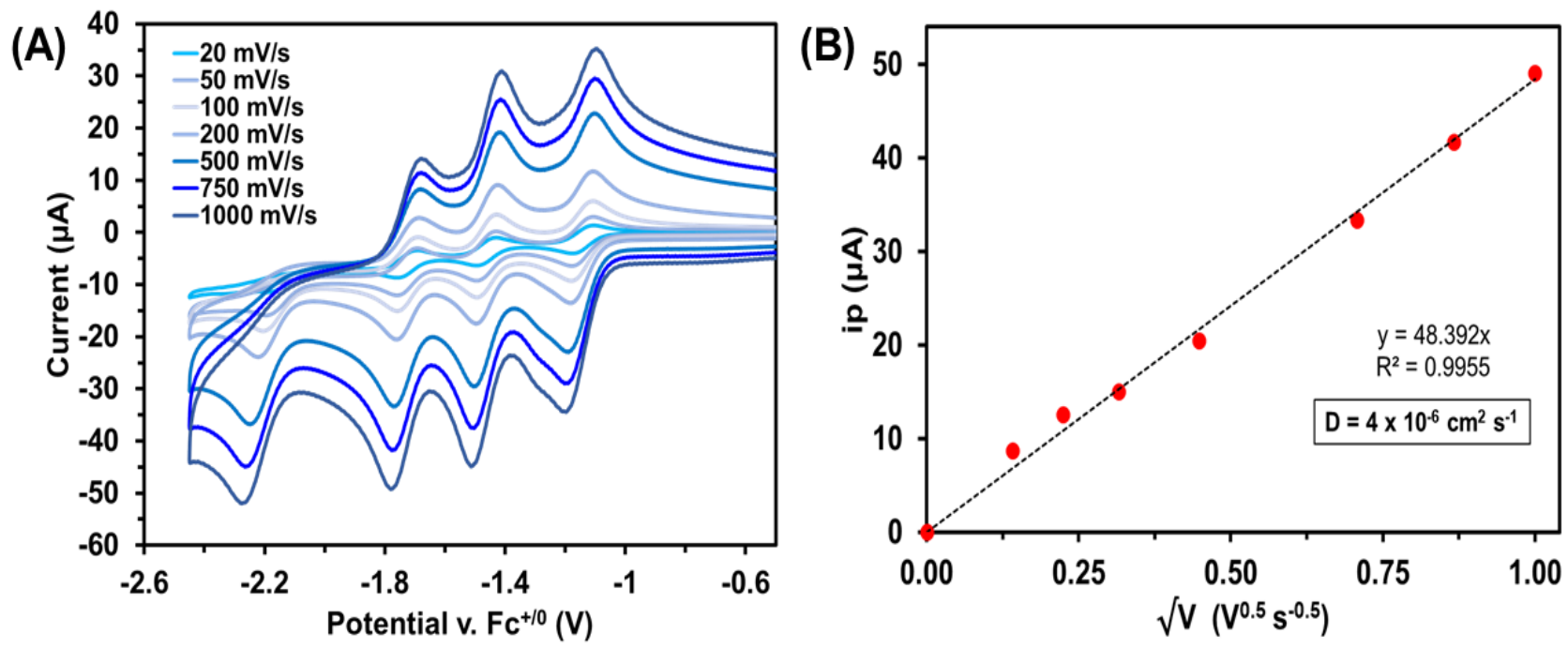

Figure S32. CVs of Re(bpy-TAz-PDI) recorded at variable scan rate (A), under argon in DMF with $0.1 \mathrm{M} \mathrm{TBAPF}_{6}$ supporting electrolyte $(\mathrm{WE}=$ glassy carbon, $\mathrm{CE}=\mathrm{Pt}$-wire, $\mathrm{RE}=\mathrm{Ag} / \mathrm{AgCl}$, and $\mathrm{Fc}^{+/ 0}$ as internal reference standard). Linear fitting of the scan rate to the Randles-Sevcik equation (B) demonstrates that Re(bpy-TAz-PDI) undergoes a diffusion-limited current response 

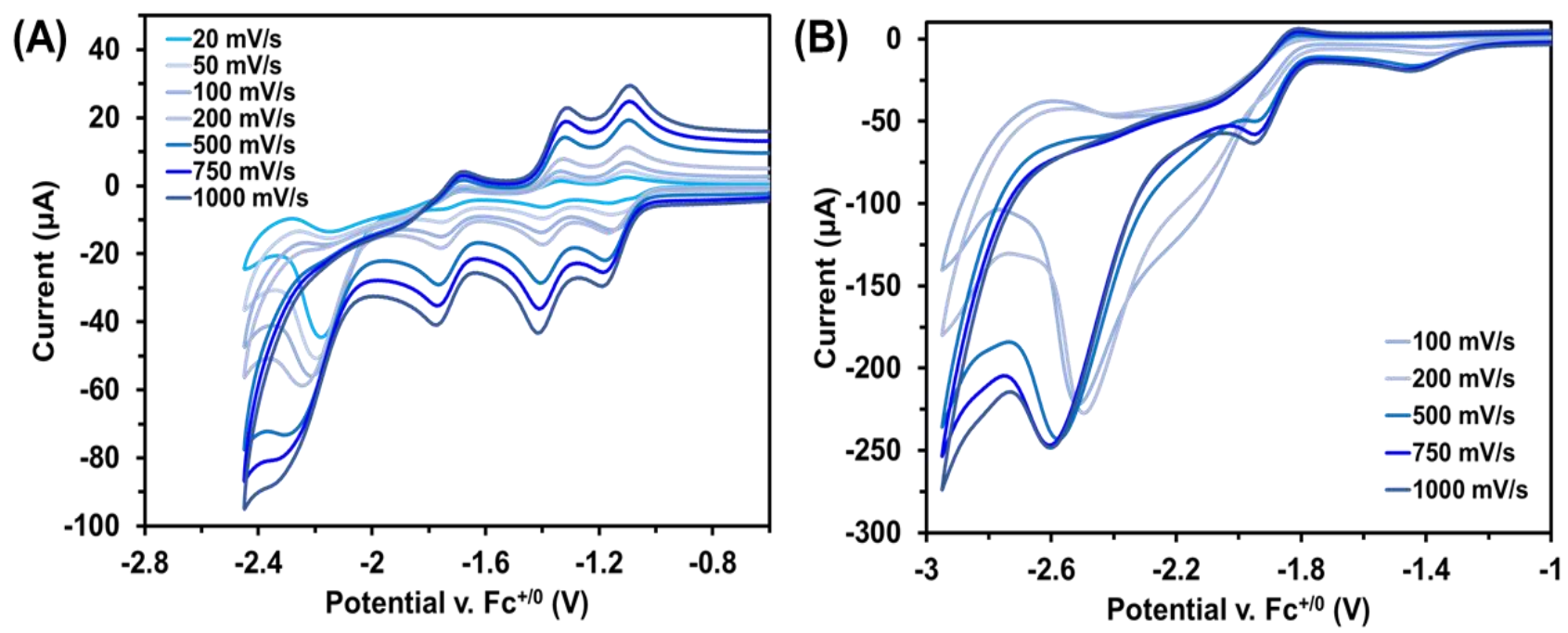

Figure S33. CVs of Re(bpy-TAz-PDI) (A) and Re(dmbpy) (B) recorded at variable scan rate (A), under $\mathrm{CO}_{2}$-saturated DMF with $2.0 \mathrm{M}$ TFE and $0.1 \mathrm{M} \mathrm{TBAPF}_{6}$ supporting electrolyte (WE $=$ glassy carbon, $\mathrm{CE}=\mathrm{Pt}$-wire, $\mathrm{RE}=\mathrm{Ag} / \mathrm{AgCl}$, and $\mathrm{Fc}^{+/ 0}$ as internal reference standard)
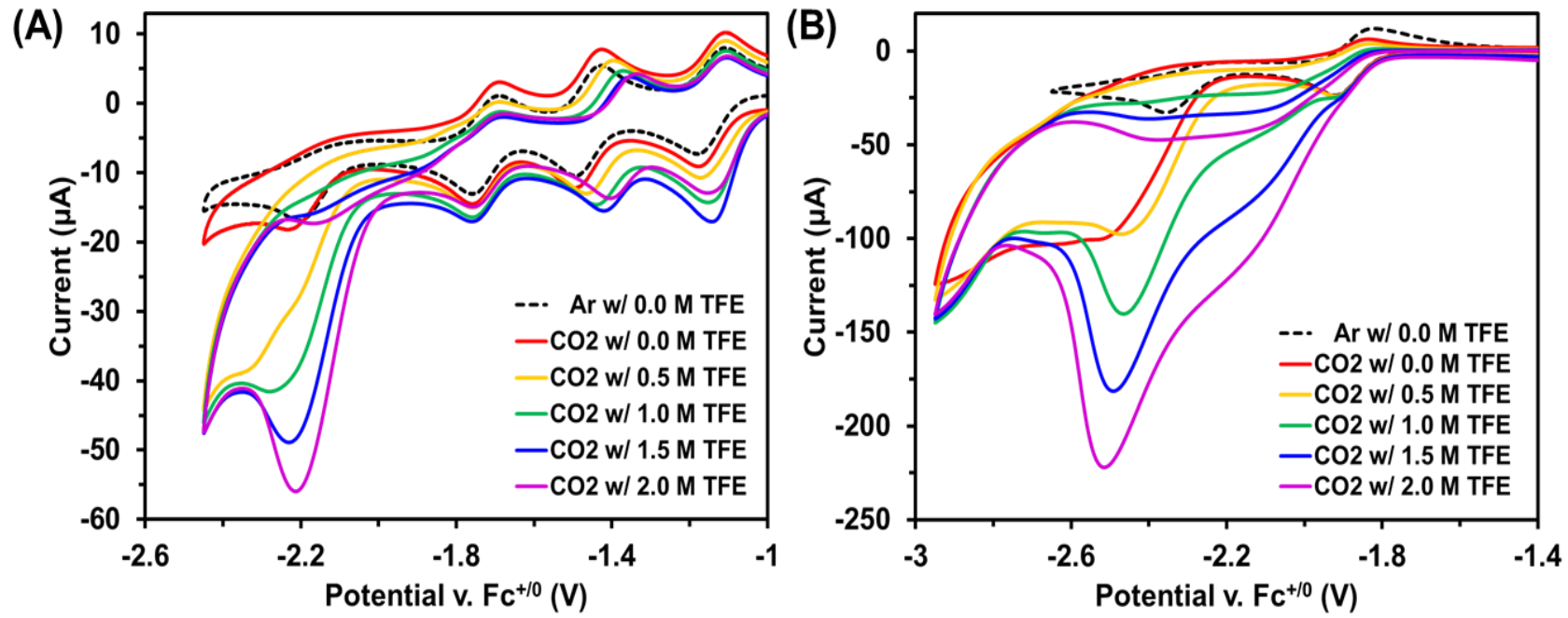

Figure S34. Comparing catalytic current enhancement of Re(bpy-TAz-PDI) (A) and $\operatorname{Re}(\mathrm{dmbpy})$ (B) in $\mathrm{CO}_{2}$ saturated DMF solutions, as a function of proton source (TFE) 


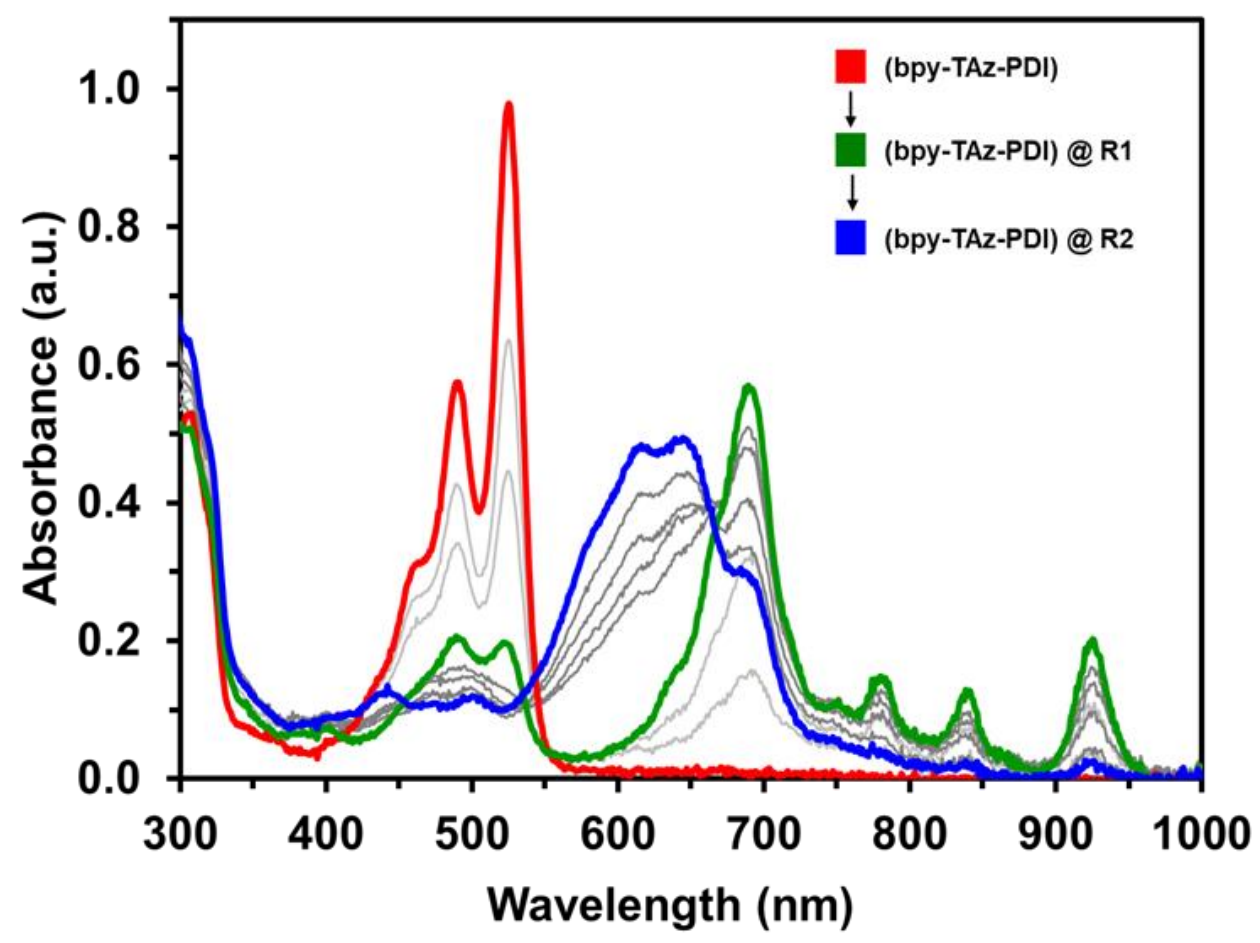

Figure S35. UV-vis-nIR spectroelectrochemical absorption profile of bpy-TAz-PDI under argon in $\mathrm{DMF}$ with $0.1 \mathrm{M}$ TBAPF6 electrolyte $(\mathrm{WE}=\mathrm{Pt}$-mesh, $\mathrm{CE}=\mathrm{Pt}$-wire, pseudo-RE = Ag-wire $)$
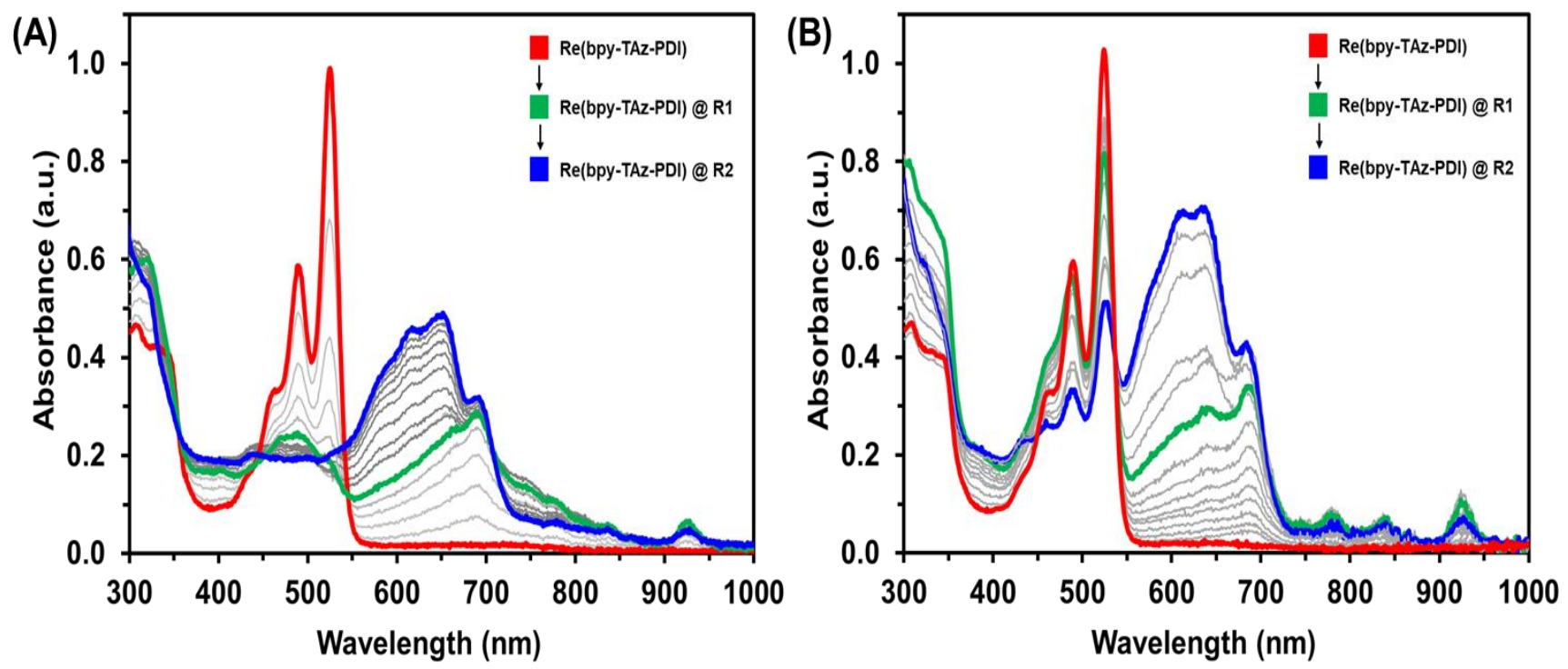

Figure S36. Comparing UV-vis-nIR spectroelectrochemical absorption profiles of Re(bpy-TAzPDI) without TFE (A) and with TFE (B), using a constant applied potential of $-1.5 \mathrm{~V} \mathrm{vs.} \mathrm{Fc}^{+/ 0}$. All experiments were performed under argon, in DMF, with $0.1 \mathrm{M}$ TBAPF6 electrolyte $(\mathrm{WE}=$ Pt-mesh, $\mathrm{CE}=\mathrm{Pt}$-wire, pseudo-RE = Ag-wire). Spectra obtained for SEC experiments performed with TFE were complicated by the evolution of $\mathrm{H}_{2}$ gas. It is possible that $\mathrm{H}_{2}$ could have been evolved from either the Pt-mesh WE or Re(bpy-TAz-PDI) 


\section{Electro- and Photocatalytic $\mathrm{CO}_{2}$ Reduction}

Table S1. Homogeneous $\mathrm{Re}(\mathrm{bpy})$-based catalysts for electrocatalytic $\mathrm{CO}_{2}$ reduction.

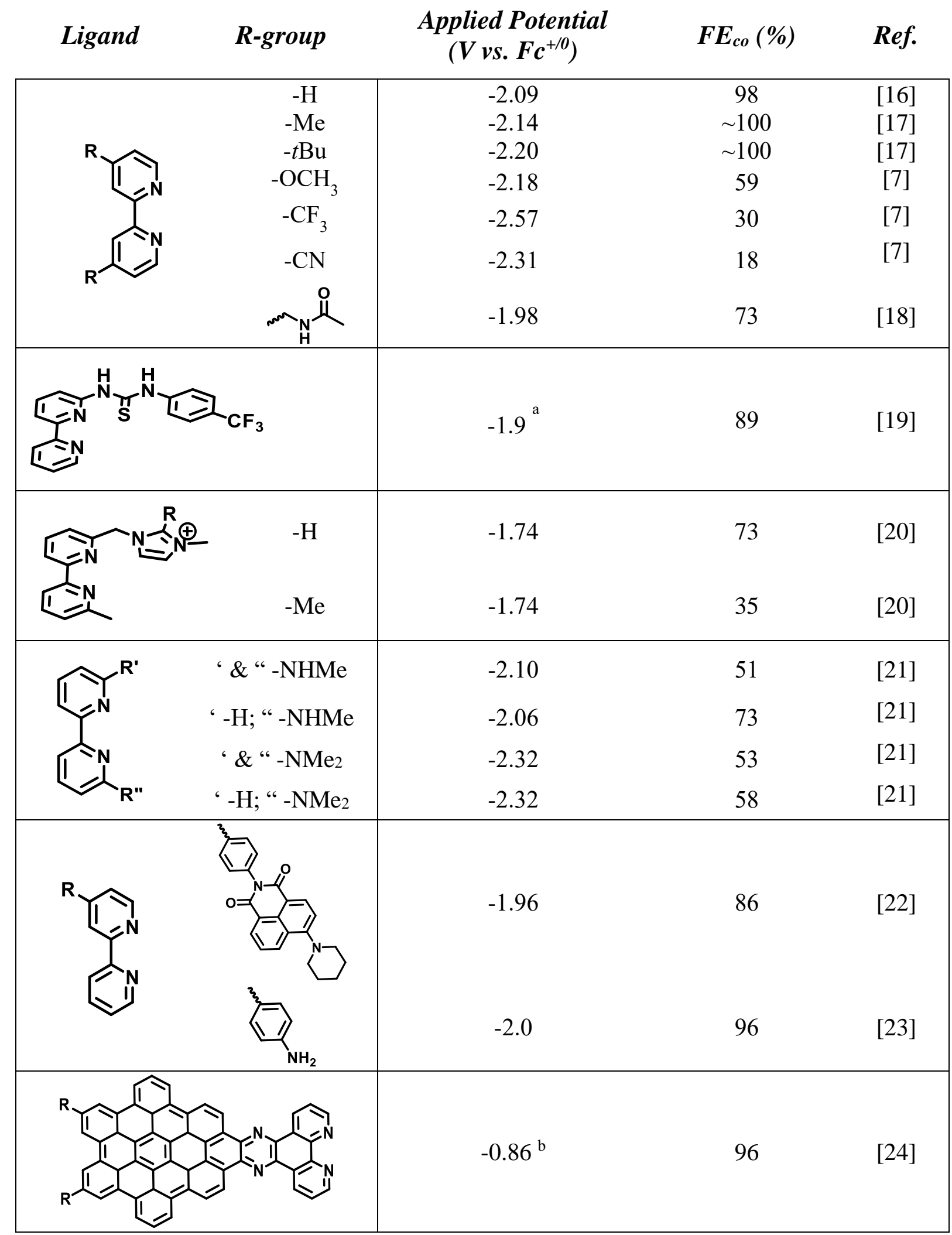

$\mathrm{a}=\left(\right.$ vs. $\left.\mathrm{Ag} / \mathrm{AgNO}_{3}\right) ; \quad \mathrm{b}=($ vs. NHE$)$ 

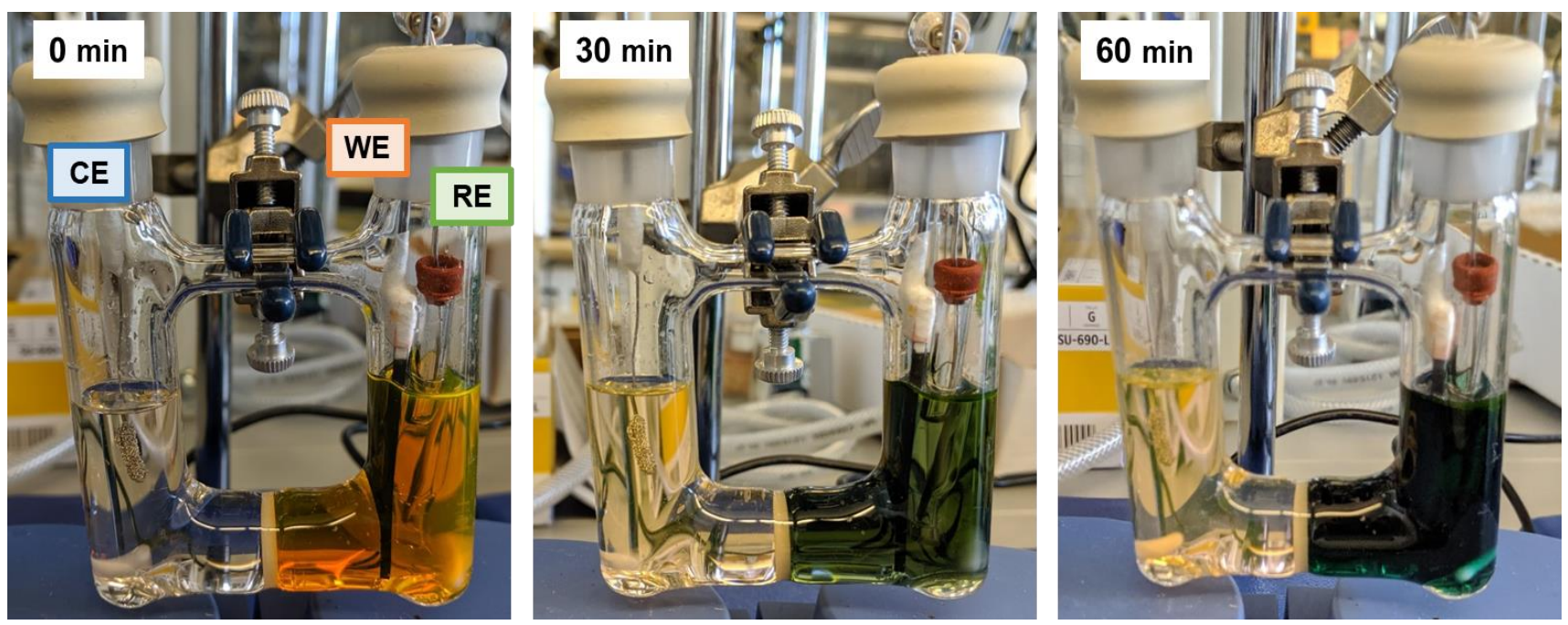

Figure S37. Representative time-lapse (left to right) of Re(bpy-TAz-PDI) CPE experiments performed in two-compartment $\mathrm{H}$-shaped cell. The 3-electrode setup consisted of a glassy carbon plate working electrode (WE), a Pt-mesh counter electrode (CE), and a non-aqueous $\mathrm{Ag} / \mathrm{AgCl}$ reference electrode $(\mathrm{RE})$
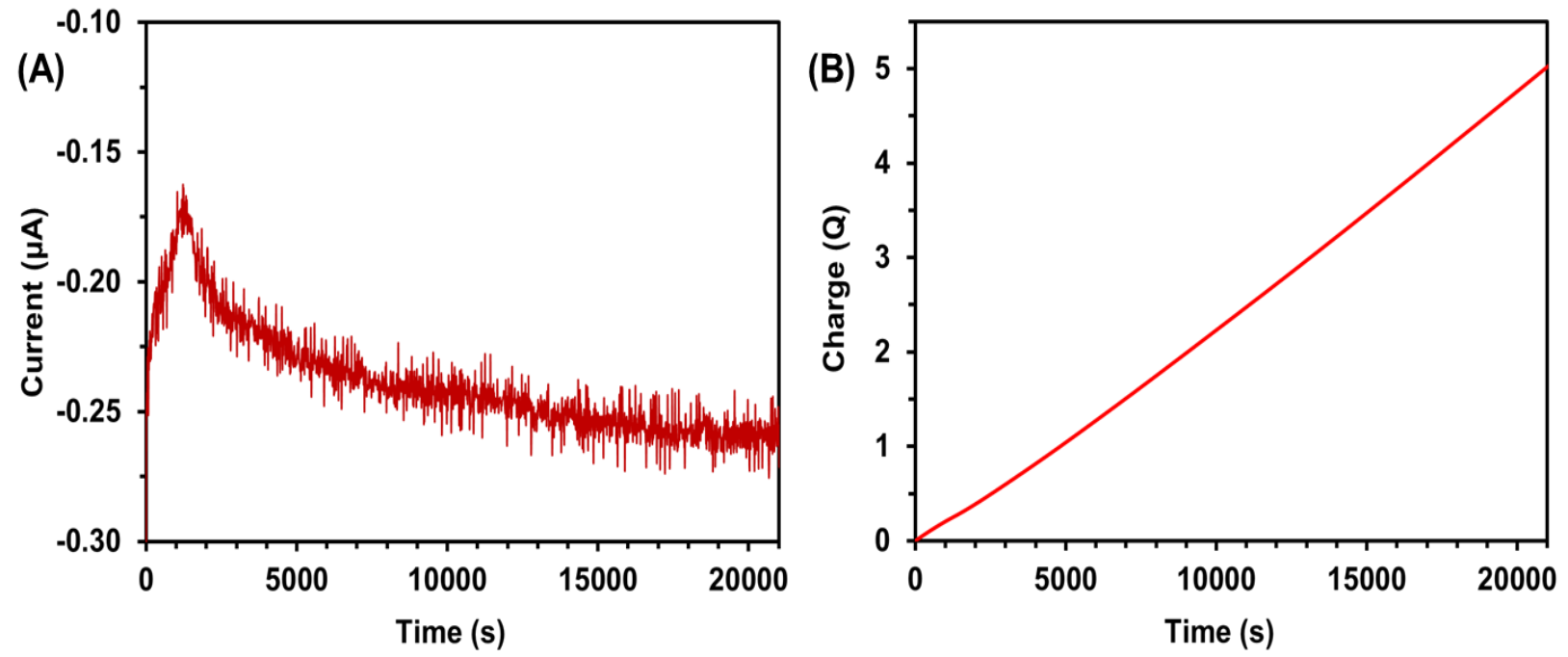

Figure S38. Representative current versus time (A) and charge passed versus time (B) plots for $\mathrm{Re}(\mathrm{bpy}-\mathrm{TAz}-\mathrm{PDI}) \mathrm{CPE}$ experiments performed at $\mathrm{E}=-1.8 \mathrm{~V}$ vs. $\mathrm{Fc}^{+/ 0}$ in $\mathrm{DMF}(\mathrm{WE}=$ glassy carbon plate, $\mathrm{CE}=\mathrm{Pt}-\mathrm{mesh}, \mathrm{RE}=\mathrm{Ag} / \mathrm{AgCl}$ ) 
(A)

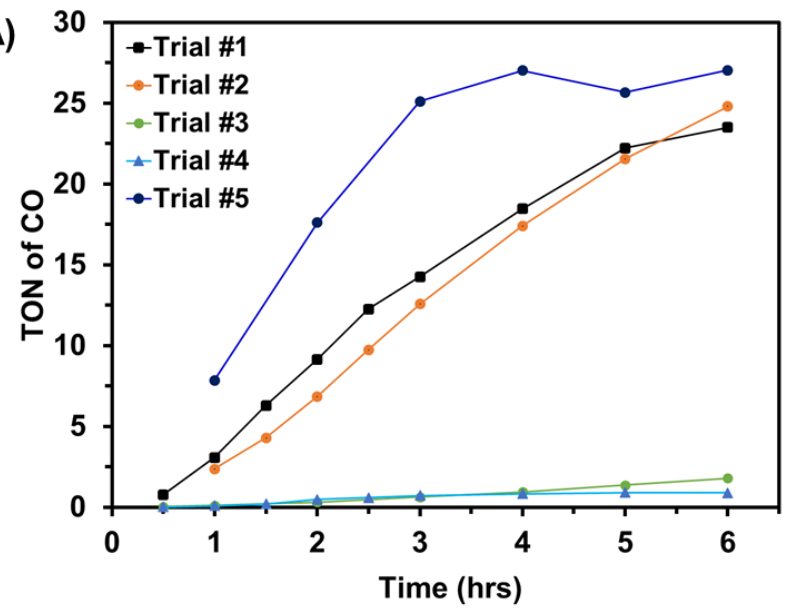

(C)

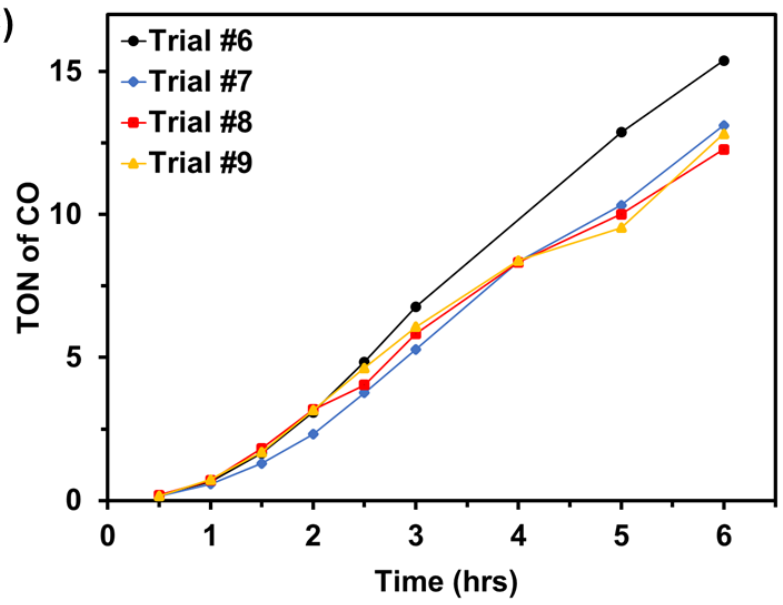

(E)

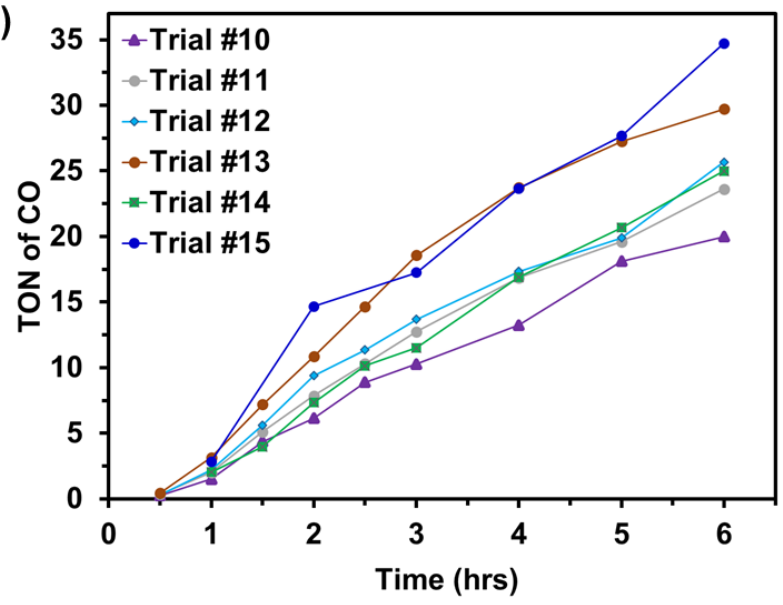

(B)

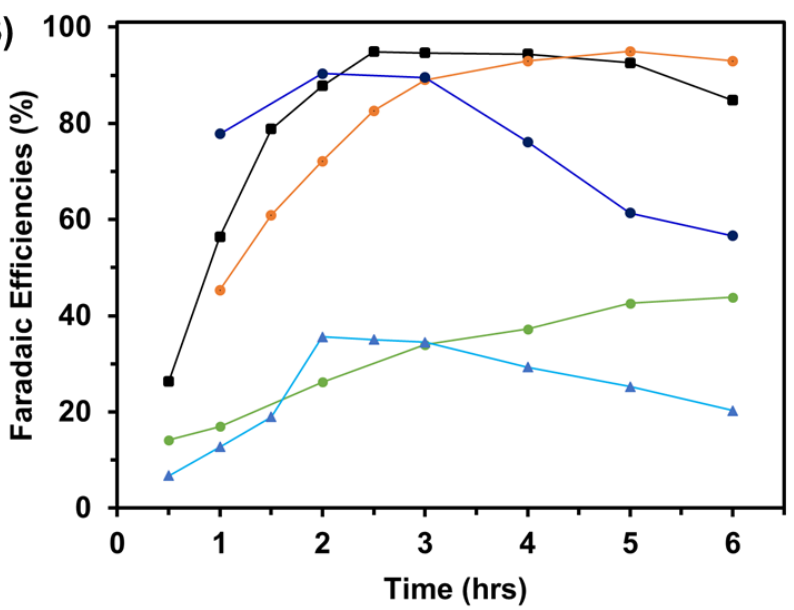

(D)

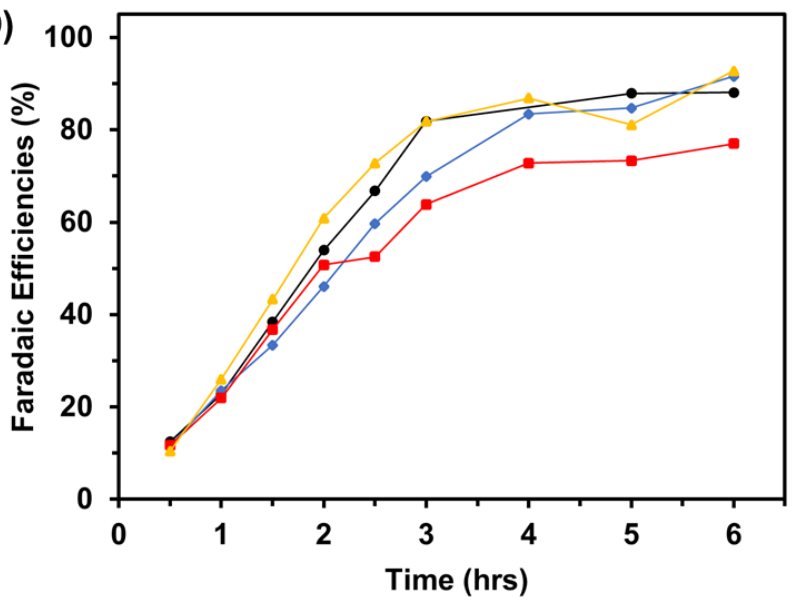

(F)

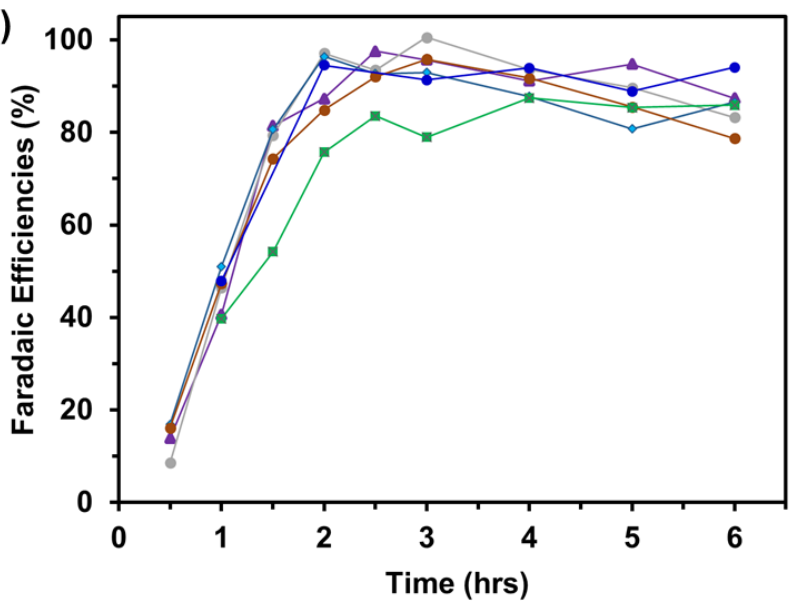

Figure S39. Controlled potential electrolysis (CPE) determined $\mathrm{TON}_{\mathrm{co}}$ and faradaic efficiencies of $\mathrm{CO}$ formation for $\mathrm{Re}\left(\mathrm{dmbpy}\right.$ ) (A and $\mathrm{B}$, respectively), $\operatorname{Re}\left(\mathrm{bpy}-\mathrm{TAz}-\mathrm{PDI}\right.$ ) at $-2.20 \mathrm{~V} \mathrm{vs}$. Fc $\mathrm{F}^{+/ 0}$ (C and D, respectively), and $\mathrm{Re}\left(\right.$ bpy-TAz-PDI) at $-1.80 \mathrm{~V}$ vs. $\mathrm{Fc}^{+/ 0}$ (E and $\mathrm{F}$, respectively). Full experiment details for each trail are described in Table S2 
(A)

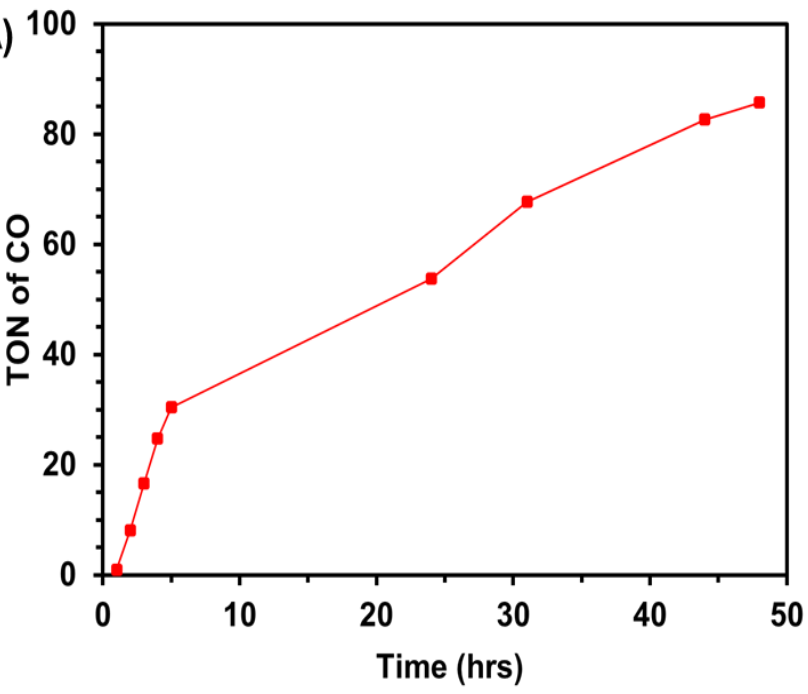

(B)

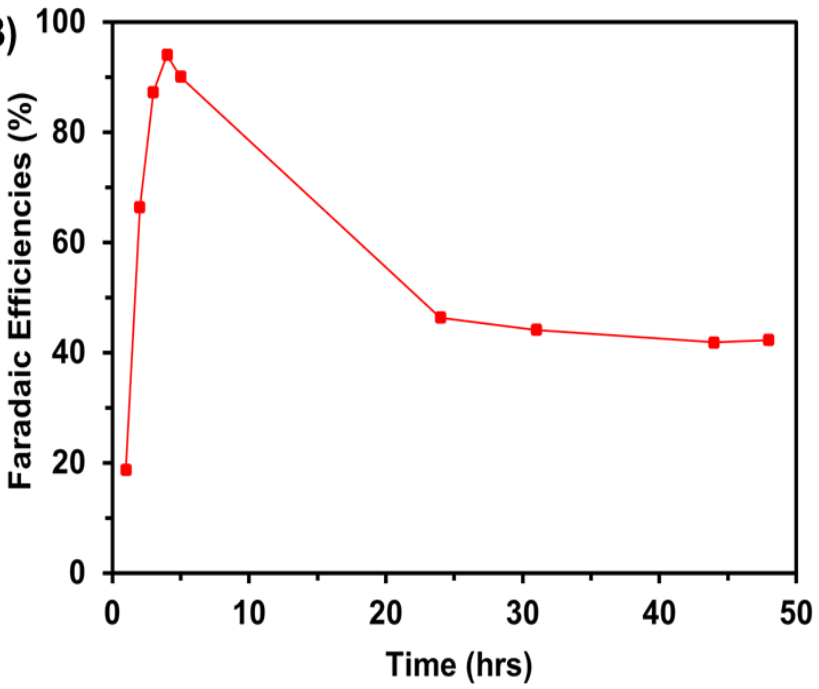

Figure S40. Prolonged controlled potential electrolysis determined $\mathrm{TON}_{\mathrm{co}}$ (A) and faradaic efficiency of $\mathrm{CO}$ formation (B) for $\mathrm{Re}(\mathrm{bpy}-\mathrm{TAz}-\mathrm{PDI})$ at $-1.80 \mathrm{~V}$ vs. $\mathrm{Fc}^{+/ 0}$. Prolonging the $\mathrm{CPE}$ experiment to 24 hours resulted in a $\mathrm{TON}_{\mathrm{co}}=54$, while the $\mathrm{FE}$ dropped to $47 \%$. Following 48 hours of CPE, the TON $\mathrm{N}_{\mathrm{co}}$ further increased to 86 , with a stable FE of $42 \%$.
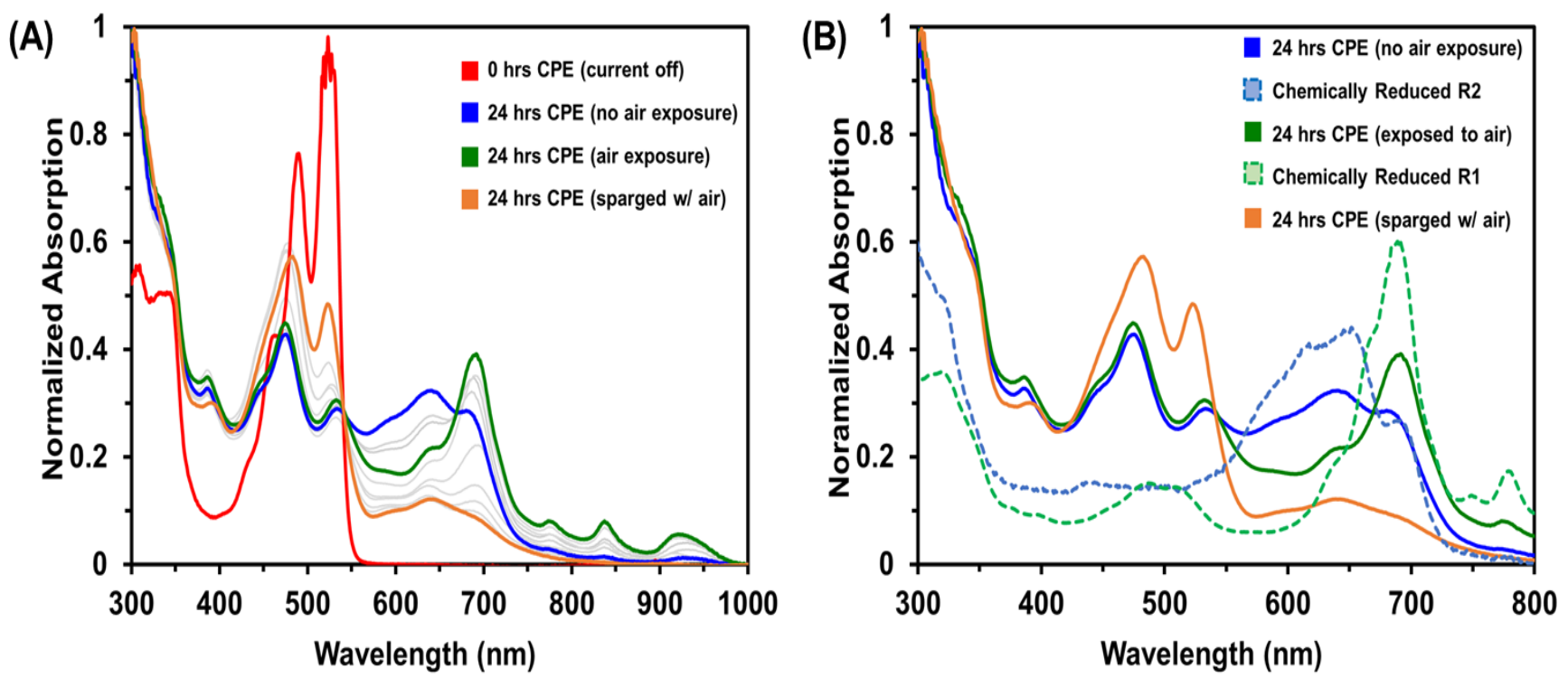

Figure S41. UV-vis-nIR absorption profiles tracking the controlled potential electrolysis of $\operatorname{Re}\left(\right.$ bpy-TAz-PDI) at $-1.80 \mathrm{~V}$ vs. $\mathrm{Fc}^{+/ 0}$ (A). The initial profile (red) converts to a new profile prior to exposing to air (blue). Initial exposure to air quenches dianionic PDI character in favor of monoanionic character (green), while sparging the solution with air for 1 hour affords the final profile (orange). Absorbance profiles are compared with measured UV-vis-nIR absorption profiles of singly- (dashed green) and doubly- (dashed blue) Re(bpy-TAz-PDI) (B). Final absorption profile following 24 hours of CPE (orange) does not match initial Re(bpy-TAz-PDI), likely indicating some form of PDI-related degradation. 
Table S2. Replicate photocatalytic $\mathrm{CO}_{2}$ reduction of $\operatorname{Re}(\mathrm{dmbpy})$ and $\mathrm{Re}(\mathrm{bpy}-\mathrm{TAz}-\mathrm{PDI})$. All experiments were completed in $0.5 \mathrm{mM}$ catalyst and $0.1 \mathrm{M} \mathrm{TBAPF}_{6}$ in $\mathrm{CO}_{2}$ saturated DMF, with $2 \mathrm{M}$ TFE as proton source. Product distribution was analyzed by GC. The maximum TON ${ }_{\text {co }}$ was calculated based on bulk catalyst concentration and reported faradaic efficiency (FE) for CO was the maximum measured value during the 6-hour CPE experiments. Remainder of passed current led to evolution of $\mathrm{H}_{2}$. No other gaseous products (i.e. $\mathrm{CH}_{4}$ or $\mathrm{C}_{2} \mathrm{H}_{4}$ ) were detected by $\mathrm{GC}$.

\begin{tabular}{|c|c|c|c|c|}
\hline Entry & Catalyst & $\begin{array}{c}\text { Potential } \\
\left(V \text { vs. } F c^{+/ 0}\right)\end{array}$ & TONCO & $\underset{(\%)}{F E C O}$ \\
\hline 1 & $\operatorname{Re}(d m b p y)$ & -2.20 & $\begin{array}{l}23.5 \\
48.6^{\wedge}\end{array}$ & $\begin{array}{l}93 \\
61^{\wedge}\end{array}$ \\
\hline \multirow[t]{2}{*}{2} & $\operatorname{Re}(d m b p y)$ & -2.20 & 24.8 & 95 \\
\hline & & & $24 \pm 1$ & $94 \pm 2$ \\
\hline \multirow{3}{*}{$\begin{array}{l}3 \\
4\end{array}$} & $\operatorname{Re}(d m b p y)$ & -1.80 & 1.8 & 43 \\
\hline & $\operatorname{Re}(d m b p y)$ & -1.80 & 0.9 & 35 \\
\hline & & & $1.3 \pm 0.8$ & $39 \pm 8$ \\
\hline $5^{\#}$ & $\operatorname{Re}(d m b p y)$ & -2.20 & 27.0 & 90 \\
\hline 6 & Re(bpy-TAz-PDI) & -2.20 & 15.4 & 88 \\
\hline 7 & $\operatorname{Re}(b p y-T A z-P D I)$ & -2.20 & $\begin{array}{c}13.1 \\
33.5^{\wedge}\end{array}$ & $\begin{array}{c}92 \\
79^{\wedge}\end{array}$ \\
\hline 8 & Re(bpy-TAz-PDI) & -2.20 & 12.3 & 77 \\
\hline \multirow[t]{2}{*}{9} & $\operatorname{Re}(b p y-T A z-P D I)$ & -2.20 & 12.8 & 93 \\
\hline & & & $13 \pm 1$ & $87 \pm 10$ \\
\hline 10 & $\operatorname{Re}(b p y-T A z-P D I)$ & -1.80 & 20.0 & 95 \\
\hline 11 & $\operatorname{Re}(b p y-T A z-P D I)$ & -1.80 & $\begin{array}{c}23.6 \\
53.8^{\wedge} \\
86.2^{\wedge}\end{array}$ & $\begin{array}{l}101 \\
47^{\wedge} \\
42^{\wedge}\end{array}$ \\
\hline 12 & $\operatorname{Re}(b p y-T A z-P D I)$ & -1.80 & 25.7 & 93 \\
\hline 13 & $\operatorname{Re}(b p y-T A z-P D I)$ & -1.80 & 29.7 & 88 \\
\hline \multirow[t]{2}{*}{$14 *$} & $\operatorname{Re}(b p y-T A z-P D I)$ & -1.80 & 24.9 & 87 \\
\hline & & & $24 \pm 4$ & $92 \pm 7$ \\
\hline $15^{\#}$ & $\operatorname{Re}(b p y-T A z-P D I)$ & -1.80 & 34.7 & 95 \\
\hline $16^{\dagger}$ & $\operatorname{Re}(b p y-T A z-P D I)$ & -1.80 & 0 & 0 \\
\hline $17 \mathbb{P}^{\mathbb{2}}$ & $\operatorname{Re}(b p y-T A z-P D I)$ & -1.80 & 0 & 0 \\
\hline 18 & none & -1.80 & 0 & 0 \\
\hline 19 & $\begin{array}{l}\operatorname{Re}(\mathrm{dmbpy}) \& \\
\text { bpy-TAz-PDI }\end{array}$ & -1.80 & 1.3 & 32 \\
\hline
\end{tabular}

$\wedge=$ measured after $24 \mathrm{hrs}$ of electrocatalysis; \# = electrolysis performed in presence of Thor Labs blue LED;

$*=$ performed in the dark; ${ }^{\dagger}=$ control experiment under argon; ${ }^{\mathbb{P}}=$ control experiment under $\mathrm{CO}_{2}$ with no TFE added; 
Table S3. Replicate controlled potential electrolyses of Re(dmbpy) and $\operatorname{Re}(b p y-T A z-P D I)$. All experiments were completed in septum-sealed glass pressure vials using $65 \mu \mathrm{M}$ catalyst. The maximum $\mathrm{TON}_{\mathrm{co}}$ and $\mathrm{TON}_{\mathrm{H}_{2}}$ were calculated based on bulk catalyst concentration. Product distribution was analyzed by GC. No other gaseous products (i.e. $\mathrm{CH}_{4}, \mathrm{C}_{2} \mathrm{H}_{4}$, or $\mathrm{C}_{2} \mathrm{H}_{6}$ ) were detected by GC.

\begin{tabular}{|c|c|c|c|c|c|}
\hline Entry & Catalyst & $\begin{array}{c}\text { Solvent } \\
(D M F: T E O A: T F E)\end{array}$ & $\begin{array}{l}\text { Time } \\
\text { (hrs) }\end{array}$ & $T O N_{C O}$ & $\mathrm{TON}_{\mathrm{H}_{2}}$ \\
\hline $1 a$ & $\operatorname{Re}(d m b p y)$ & $5: 1: 0$ & 2 & 0.9 & 0.0 \\
\hline $1 b$ & $\operatorname{Re}(d m b p y)$ & $5: 1: 0$ & 4 & 1.5 & 0.0 \\
\hline $1 c$ & $\operatorname{Re}(d m b p y)$ & $5: 1: 0$ & 6 & 1.7 & 0.0 \\
\hline $1 d$ & $\operatorname{Re}(d m b p y)$ & $5: 1: 0$ & 18 & 2.1 & 0.0 \\
\hline 2 & $\operatorname{Re}(d m b p y)$ & $5: 1: 0$ & 18 & 1.8 & 0.0 \\
\hline \multirow[t]{2}{*}{3} & $\operatorname{Re}(d m b p y)$ & $5: 1: 0$ & 18 & 1.7 & 0.0 \\
\hline & & & & $1.9 \pm 0.2$ & 0 \\
\hline 4 & $\operatorname{Re}(d m b p y)$ & $4: 1: 1$ & 18 & 0.0 & 0.0 \\
\hline 5 & $\operatorname{Re}(d m b p y)$ & $4: 1: 1$ & 18 & 0.0 & 0.0 \\
\hline 6 & $\operatorname{Re}(d m b p y)$ & $4: 1: 1$ & 18 & 0.0 & 0.0 \\
\hline $7 a$ & $\operatorname{Re}(b p y-T A z-P D I)$ & $5: 1: 0$ & 2 & 0.2 & 0.0 \\
\hline $7 b$ & $\operatorname{Re}(b p y-T A z-P D I)$ & $5: 1: 0$ & 4 & 1.5 & 0.0 \\
\hline $7 c$ & Re(bpy-TAz-PDI) & $5: 1: 0$ & 6 & 2.2 & 0.0 \\
\hline $7 d$ & Re(bpy-TAz-PDI) & $5: 1: 0$ & 18 & 8.7 & 1.0 \\
\hline 8 & Re(bpy-TAz-PDI) & $5: 1: 0$ & 18 & 7.4 & 0.6 \\
\hline \multirow[t]{2}{*}{9} & $\operatorname{Re}(b p y-T A z-P D I)$ & $5: 1: 0$ & 18 & 9.1 & 0.0 \\
\hline & & & & $8.4 \pm 0.9$ & 0.5 \\
\hline 10 & $\operatorname{Re}(b p y-T A z-P D I)$ & $4: 1: 1$ & 18 & 4.3 & 0.0 \\
\hline 11 & $\operatorname{Re}(b p y-T A z-P D I)$ & $4: 1: 1$ & 18 & 5.6 & 0.2 \\
\hline \multirow[t]{2}{*}{12} & Re(bpy-TAz-PDI) & $4: 1: 1$ & 18 & 3.9 & 0.0 \\
\hline & & & & $4.6 \pm 0.9$ & 0.1 \\
\hline
\end{tabular}

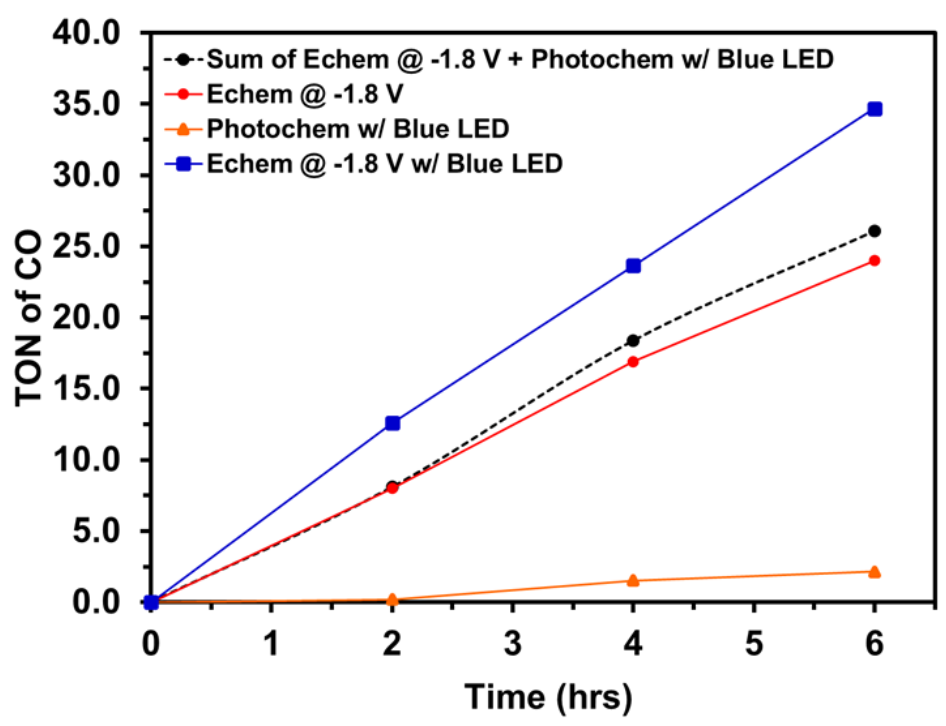

Figure S42. Comparing individual photo- and electrocatalytic $\mathrm{CO}_{2}$ reductions of $\mathrm{Re}(\mathrm{bpy}-\mathrm{TAz}-$ $\mathrm{PDI})$ relative to the electrocatalysis of $\operatorname{Re}(\mathrm{bpy}-\mathrm{TAz}-\mathrm{PDI})$ performed in presence of blue light. 


\section{Density Functional Theory Calculations}

Density functional theory (DFT) calculations were carried with the Gaussian16 (Revision A.03) ${ }^{25}$ software suite. The M06 functional was used for all calculations as it was developed for use with both transition metals and non-metals. ${ }^{26}$ The 6-31G(d,p) Pople basis set ${ }^{27-29}$ was used for all non-metal elements, and the LANL2DZ basis set ${ }^{30-32}$ was used for Re, with 60 core electrons subsumed into the effective core potentials. For all optimized geometries, normal mode analyses were carried out to ensure that no negative frequencies were present. To reduce computational cost, all terminal $\mathrm{N}$-alkyl groups were truncated to methyl groups. For highly charged species, full convergence was first obtained by using the loose criteria for convergence, followed by the tighter, default grid. In addition, the NoSymm tag was used for initial convergence of the -3 charged species and then removed to attain full convergence. Molecular orbitals and spin densities were visualized using GaussView 5.0.9. ${ }^{33}$

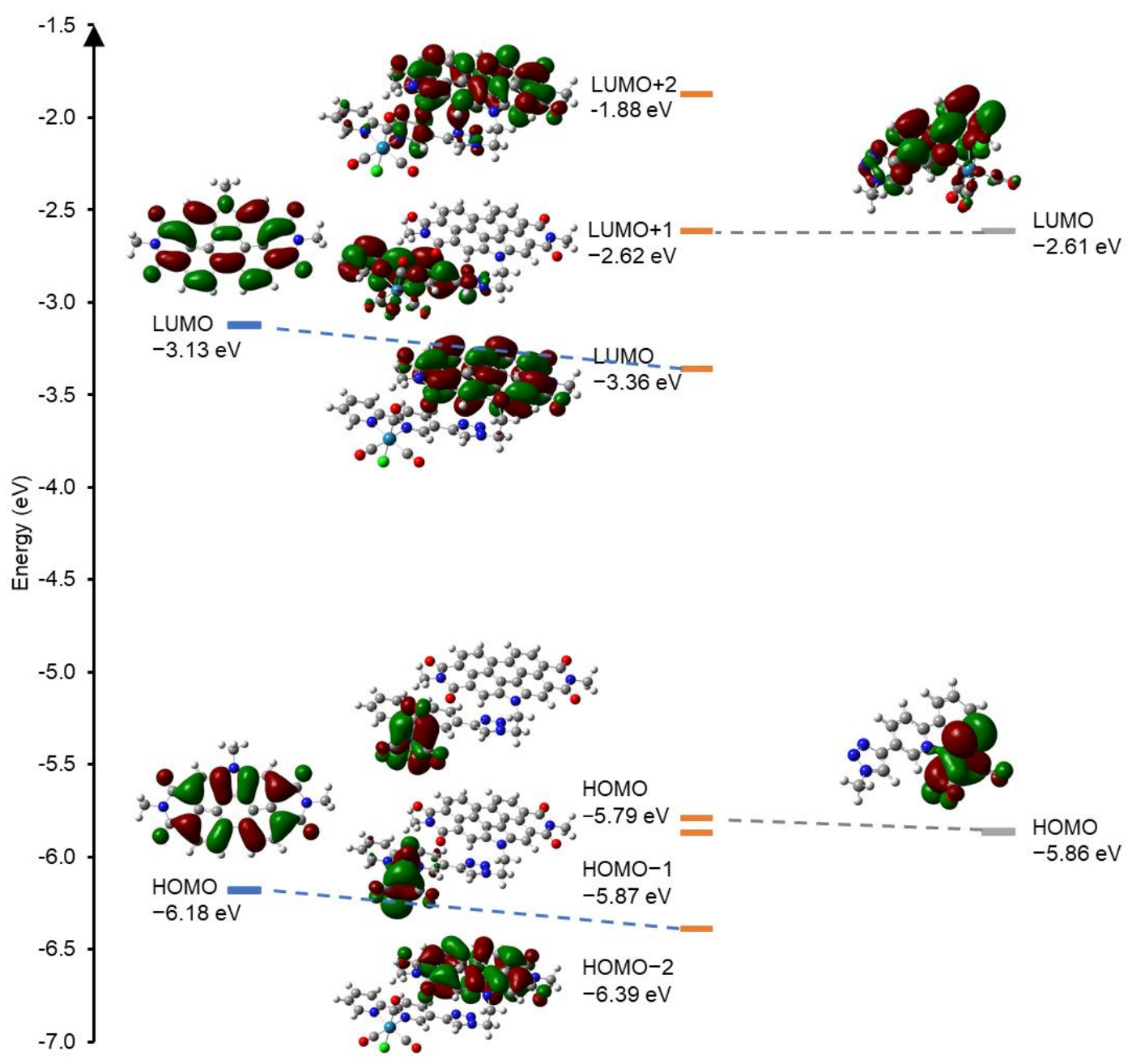

Figure S43. Molecular orbital diagram of Re(bpy-TAz-PDI) (center), comprised of $\mathrm{N}$-annulated PDI (left) and Re(bpy-TAz) (right) as determined at the M06/6-31G(d,p)/LANL2DZ level of theory. 

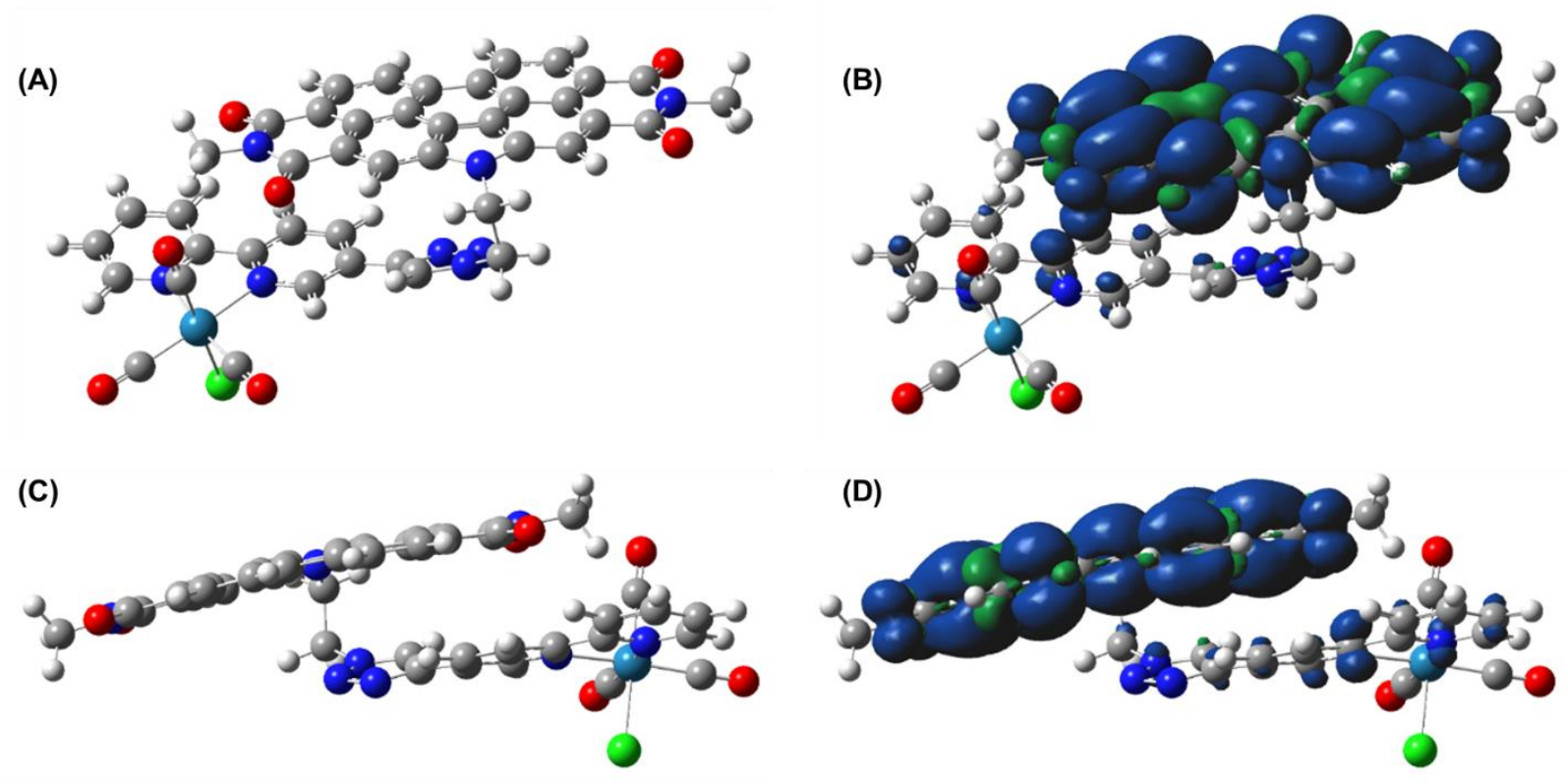

Figure S44. Face-on and side-on perspectives of the optimized geometry (A \& C) and spin density map (B \& D) for the doublet state of $\operatorname{Re}^{\mathrm{I}}(\mathrm{bpy}-\mathrm{TAz}-\mathrm{PDI})^{-}$as determined at the M06/6$31 \mathrm{G}(\mathrm{d}, \mathrm{p}) / \mathrm{LANL} 2 \mathrm{DZ}$ level of theory.
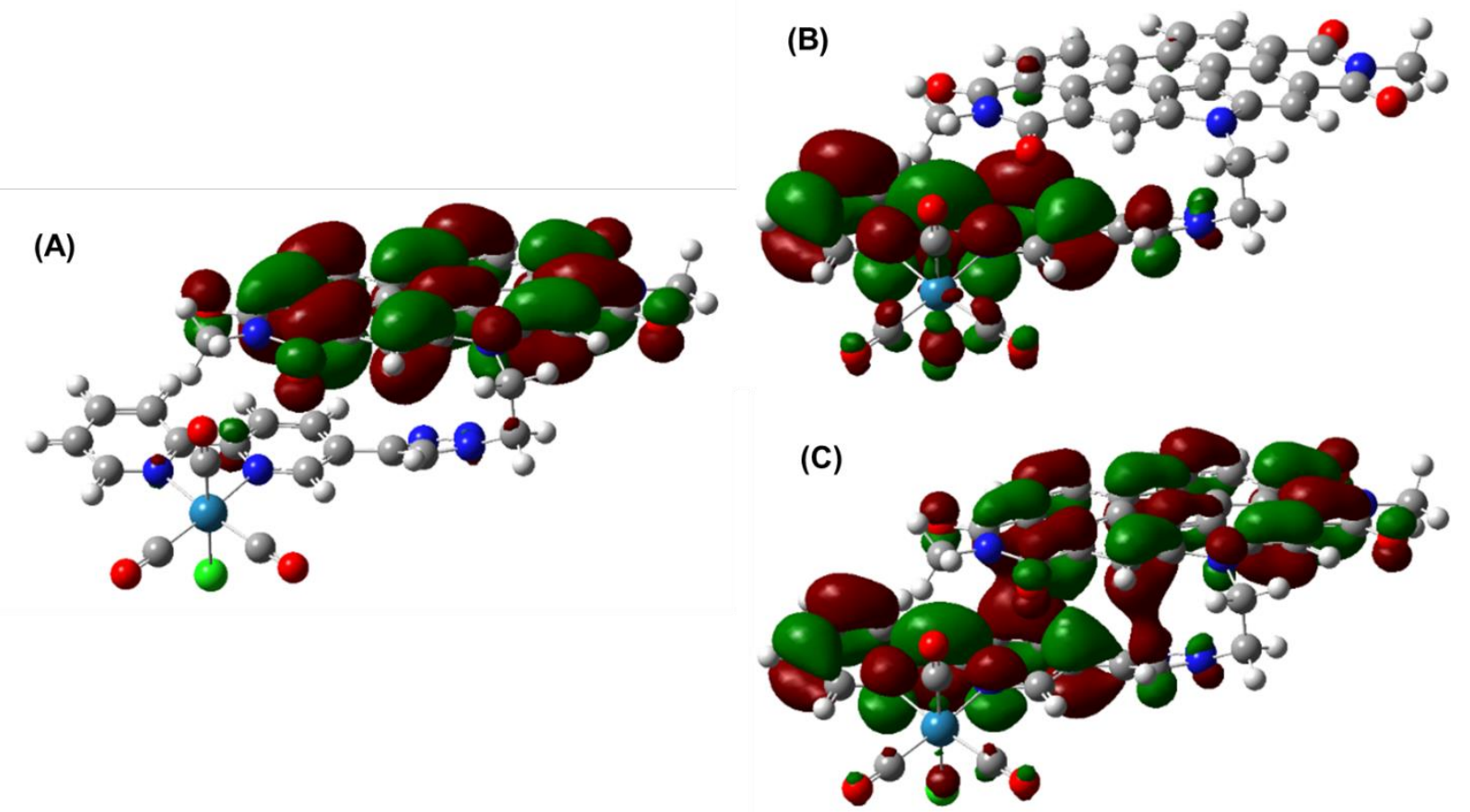

Figure S45. Frontier molecular orbitals of the doublet state of $\operatorname{Re}^{\mathrm{I}}(\mathrm{bpy}-\mathrm{TAz}-\mathrm{PDI})^{-}$at the M06/6$31 \mathrm{G}(\mathrm{d}, \mathrm{p}) / \mathrm{LANL} 2 \mathrm{DZ}$ level of theory, where (A) represents $\mathrm{HO} \alpha \mathrm{O}$ and $(\mathrm{B} \& \mathrm{C})$ represent the $\mathrm{LU} \alpha \mathrm{O}$ and LU $\beta \mathrm{O}$ with $\alpha$ - and $\beta$-spins, respectively. 
(A)
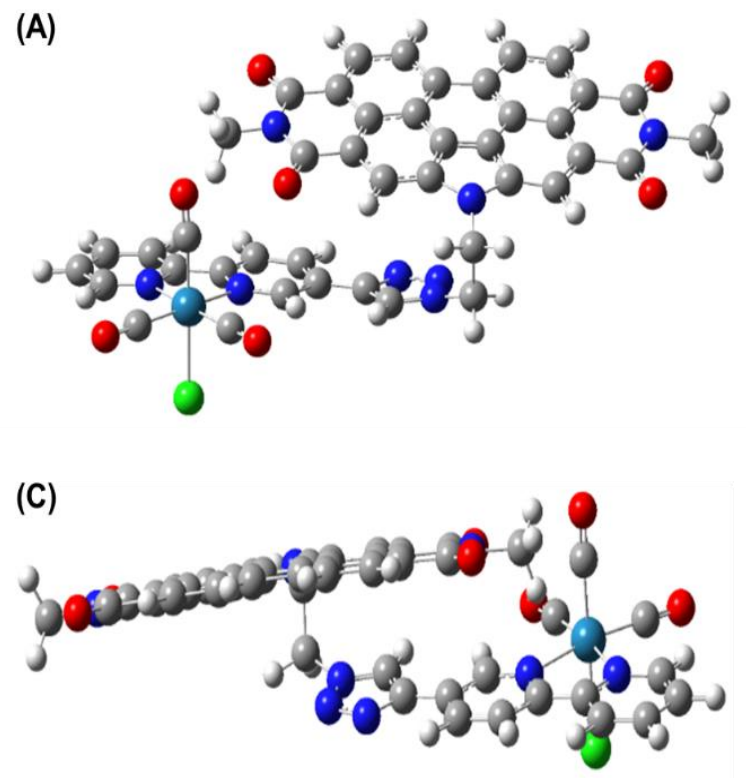

(B)

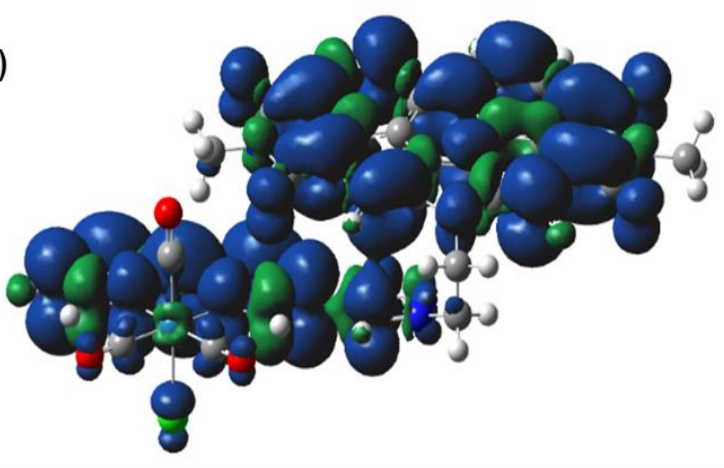

(D)

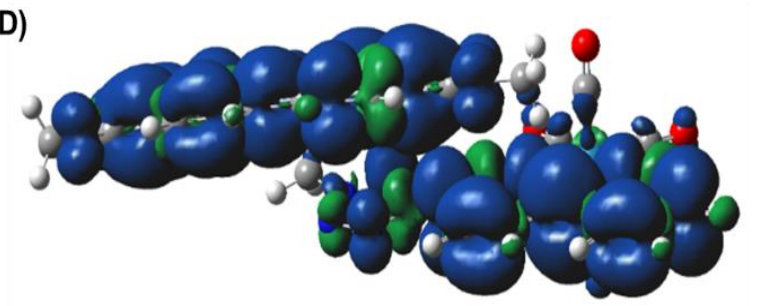

Figure S46. Face-on and side-on perspectives of the optimized geometry (A \& C) and spin density $\operatorname{map}(\mathrm{B} \& \mathrm{D})$ for the triplet state of $\operatorname{Re}^{\mathrm{I}}(\mathrm{bpy}-\mathrm{TAz}-\mathrm{PDI})^{2-}$ as determined at the M06/6$31 \mathrm{G}(\mathrm{d}, \mathrm{p}) / \mathrm{LANL} 2 \mathrm{DZ}$ level of theory.
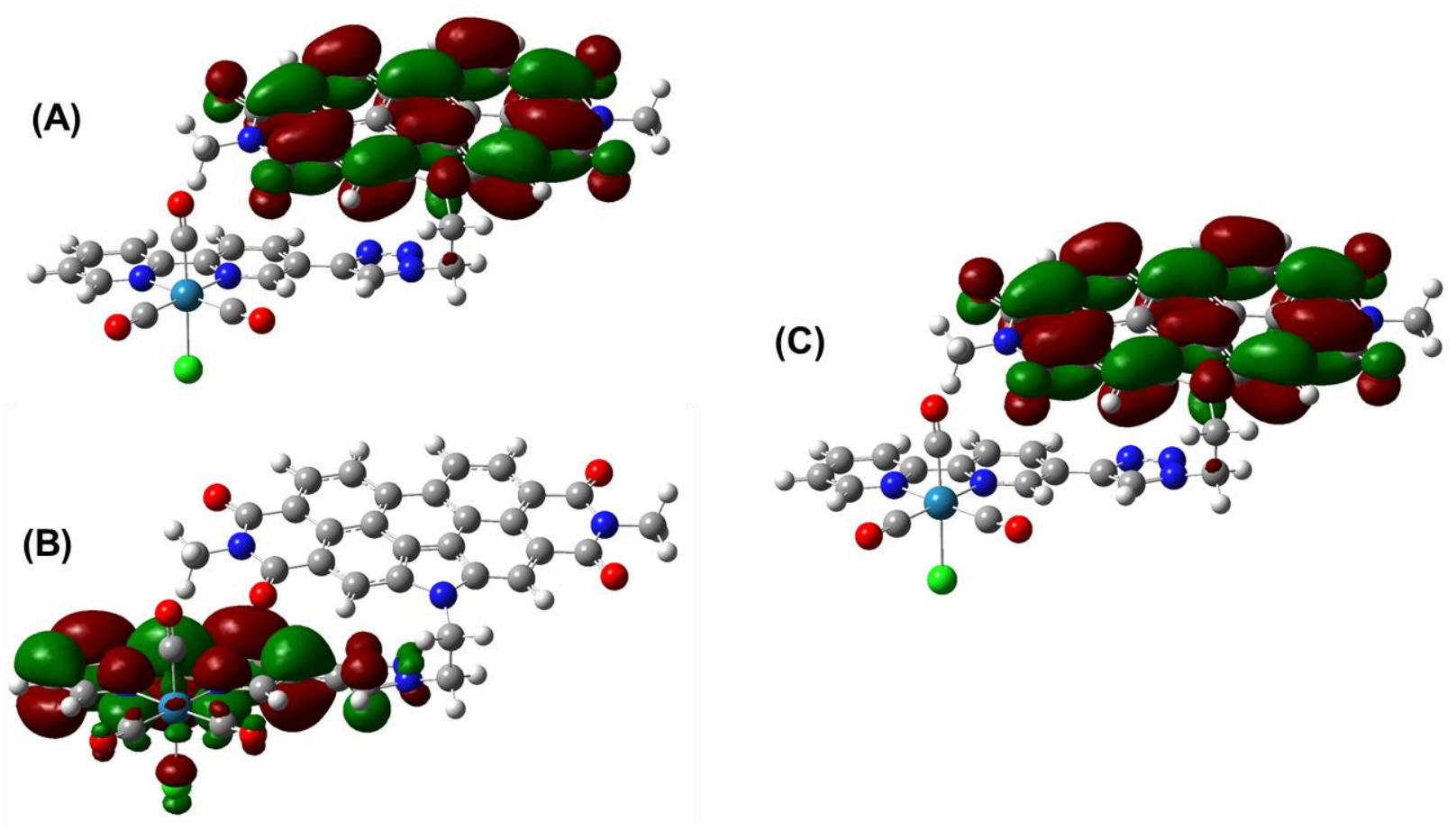

Figure S47. Frontier molecular orbitals of the triplet state of $\operatorname{Re}^{\mathrm{I}}(\mathrm{bpy}-\mathrm{TAz}-\mathrm{PDI})^{2-}$ at the M06/6$31 \mathrm{G}(\mathrm{d}, \mathrm{p}) / \mathrm{LANL} 2 \mathrm{DZ}$ level of theory, where (A \& B) represent the $\mathrm{HO} \alpha \mathrm{O}-1$ and $\mathrm{HO} \alpha \mathrm{O}$ with $\alpha$ spins, respectively, and $(\mathrm{C})$ is the LU $\beta O$ with $\beta$-spin. 

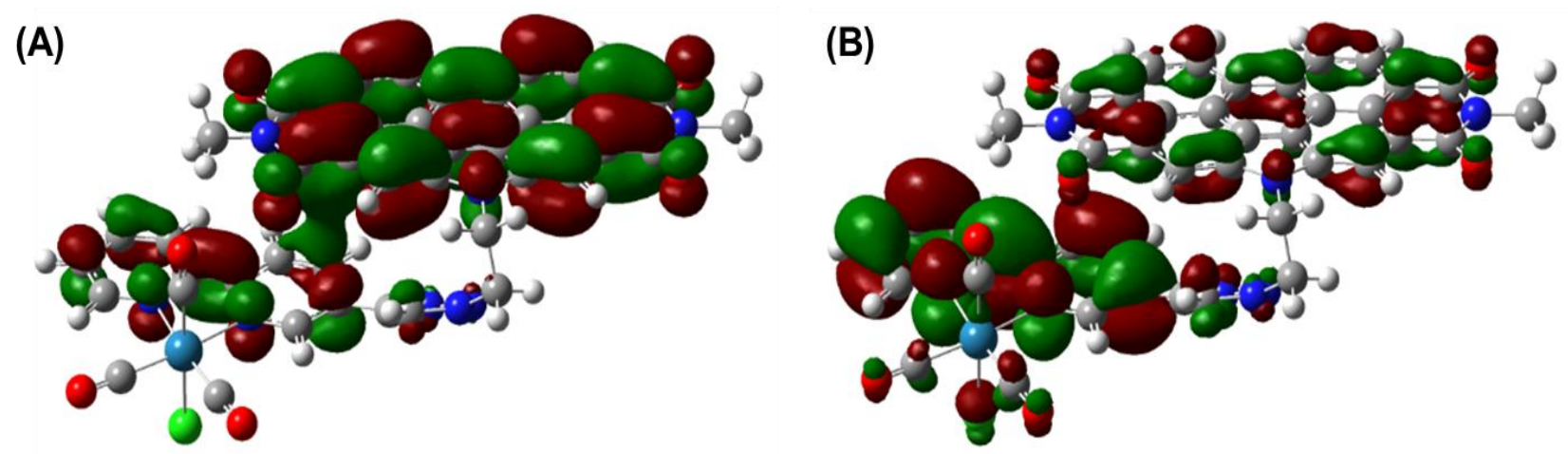

Figure S48. Frontier molecular orbitals of the singlet state of $\operatorname{Re}^{\mathrm{I}}(\mathrm{bpy}-\mathrm{TAz}-\mathrm{PDI})^{2-}$ at the M06/6$31 \mathrm{G}(\mathrm{d}, \mathrm{p}) / \mathrm{LANL} 2 \mathrm{DZ}$ level of theory, where (A) represents the HOMO and (B) is the LUMO.
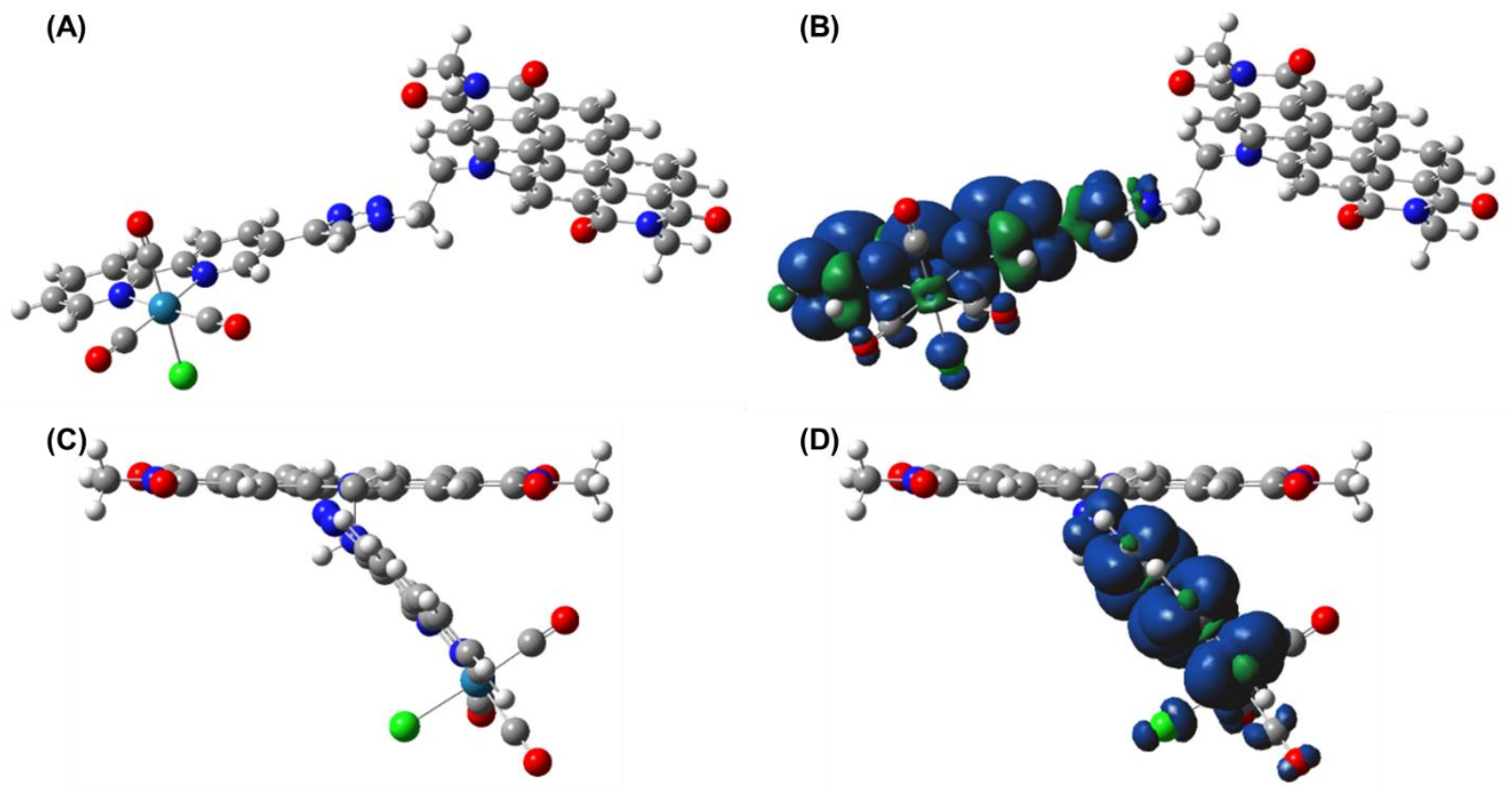

Figure S49. Face-on and side-on perspectives of the optimized geometry (A \& C) and spin density map (B \& D) for the doublet state of $\operatorname{Re}^{\mathrm{I}}(\mathrm{bpy}-\mathrm{TAz}-\mathrm{PDI})^{3-}$ as determined at the M06/6$31 \mathrm{G}(\mathrm{d}, \mathrm{p}) / \mathrm{LANL} 2 \mathrm{DZ}$ level of theory. 

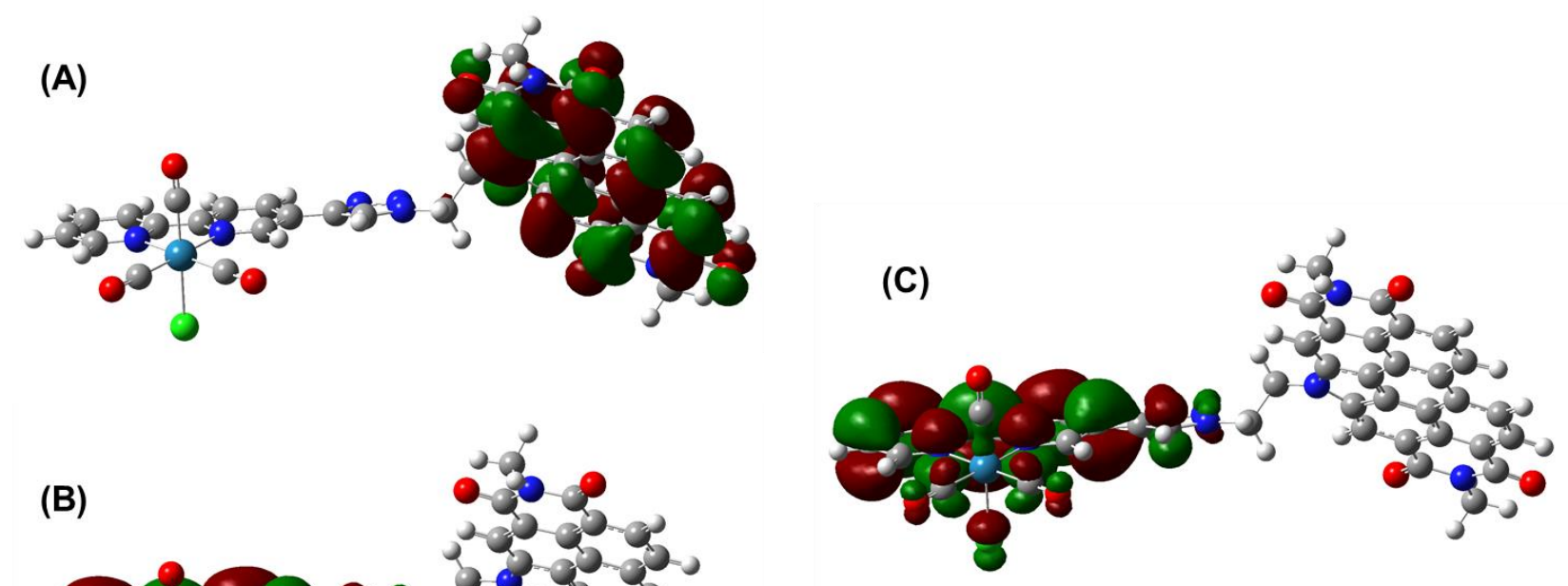

Figure S50. Frontier molecular orbitals of the doublet state of $\operatorname{Re}^{\mathrm{I}}(\mathrm{bpy}-\mathrm{TAz}-\mathrm{PDI})^{3-}$ at the M06/6-31G(d,p)/LANL2DZ level of theory, where (A) represents the HOMO with electrons paired on PDI, while (B \& C) represent the $\mathrm{HO} \alpha \mathrm{O}$ and $\mathrm{LU} \beta \mathrm{O}$ with $\alpha$ - and $\beta$-spins, respectively.
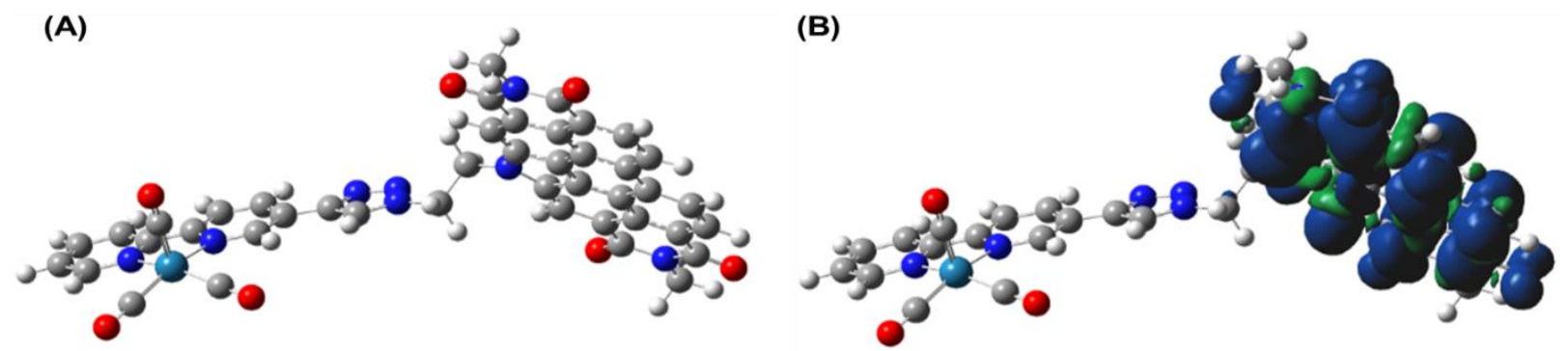

(C)

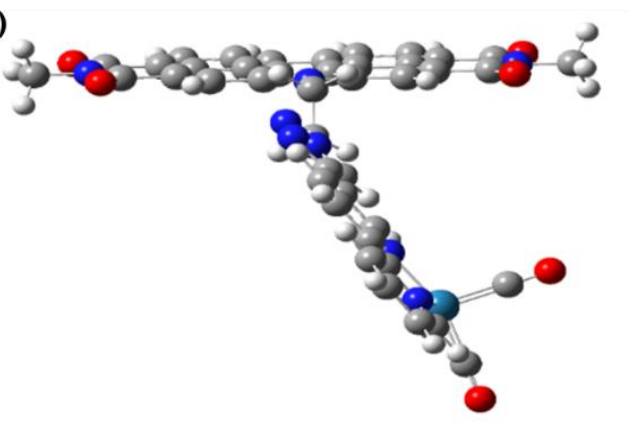

(D)

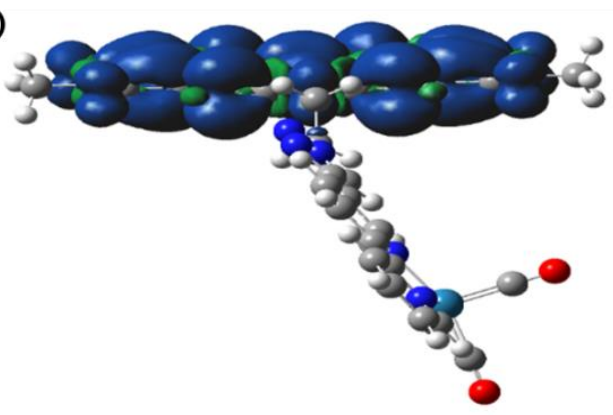

Figure S51. Face-on and side-on perspectives of the optimized geometry (A \& C) and spin density map (B \& D) for the doublet state of $\operatorname{Re}^{0}(\mathrm{bpy}-\mathrm{TAz}-\mathrm{PDI})^{2-}$ as determined at the M06/6$31 \mathrm{G}(\mathrm{d}, \mathrm{p}) / \mathrm{LANL} 2 \mathrm{DZ}$ level of theory. 

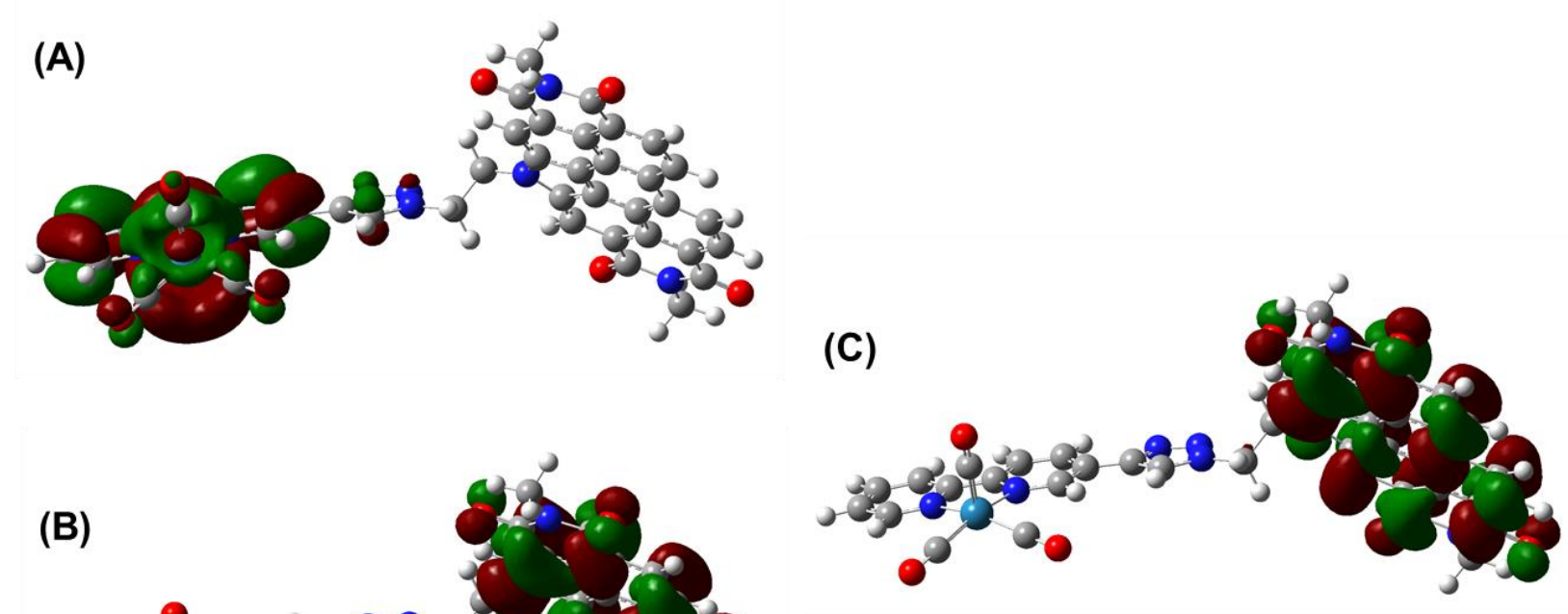

Figure S52. Frontier molecular orbitals of the doublet state of $\operatorname{Re}^{0}(\text { bpy-TAz-PDI })^{2-}$ at the M06/6-31G(d,p)/LANL2DZ level of theory, where (A) represents the HOMO with paired electrons on $\mathrm{Re}(\mathrm{bpy})$, and (B \& C) are the $\mathrm{HO} \alpha \mathrm{O}$ and $\mathrm{LU} \beta \mathrm{O}$ with $\alpha$ - and $\beta$-spins, respectively.
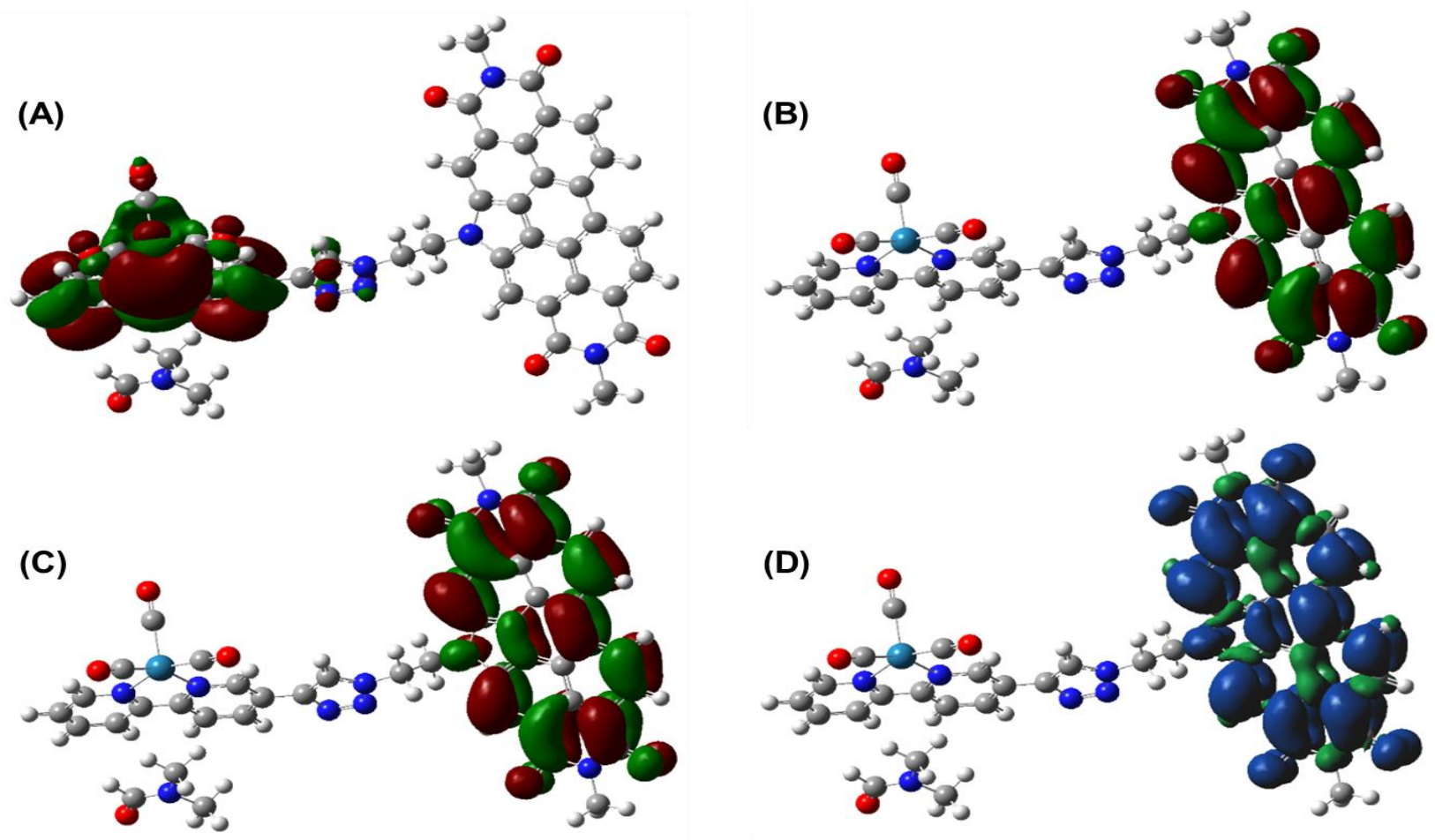

Figure S53. Frontier molecular orbitals and spin density mapping at the M06/6-31G(d,p)/ LANL2DZ level of theory for the doublet state of $\operatorname{Re}^{0}(\text { bpy-TAz-PDI })^{2-}$ stabilized by an explicit molecule of DMF, where (A) represents the HOMO with paired electrons on $\operatorname{Re}($ bpy), and (B \& C) are the $\mathrm{HO} \alpha \mathrm{O}$ and $\mathrm{LU} \beta \mathrm{O}$ with $\alpha$ - and $\beta$-spins, respectively, and (D) is the spin density map. 


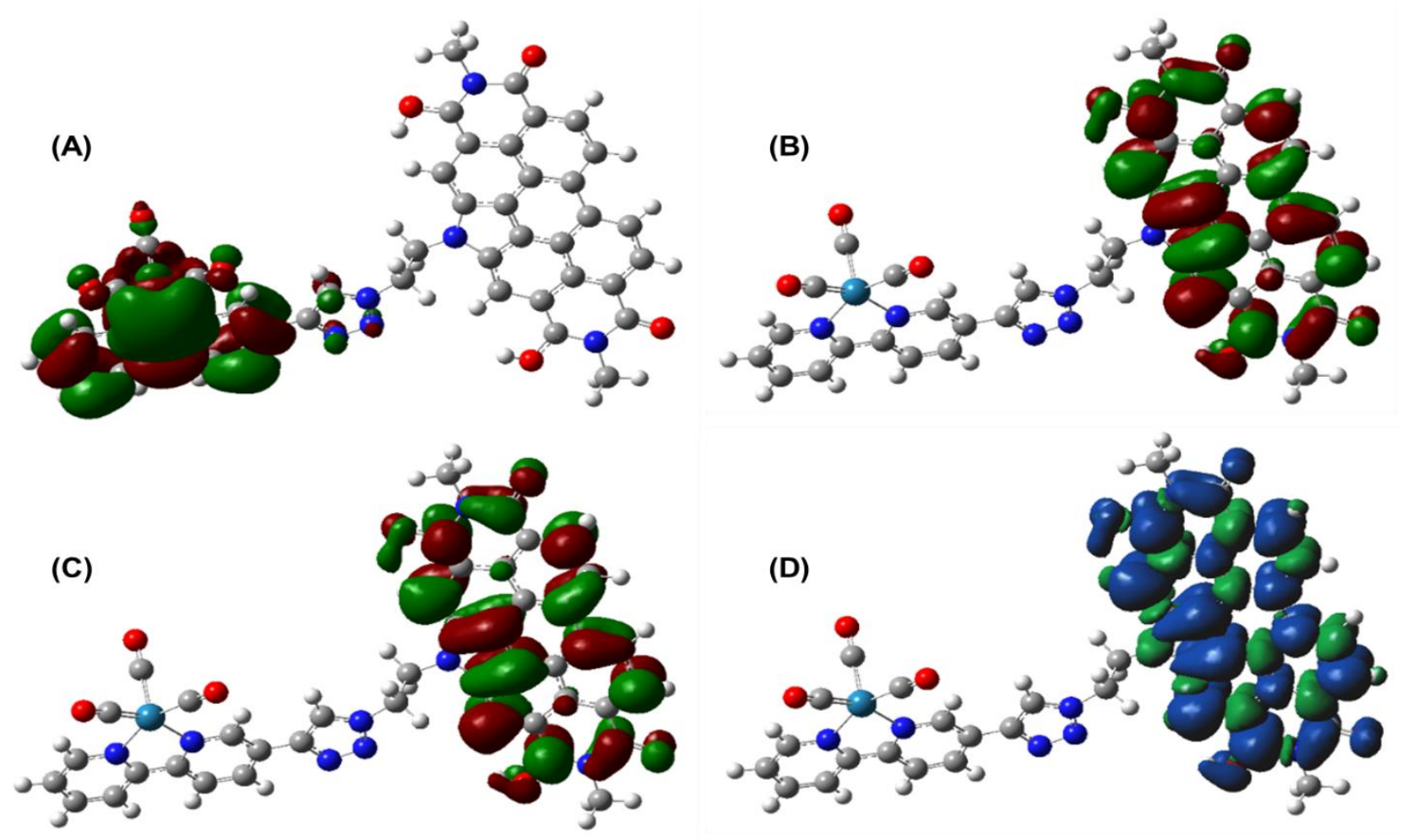

Figure S54. Frontier molecular orbitals and spin density mapping at the M06/6-31G(d,p)/ LANL2DZ level of theory for the doublet state of $\mathrm{Re}^{0}\left(\right.$ bpy-TAz-PDI) ${ }^{2-}$ stabilized by explicit protonation of PDI imide oxygens, where (A) represents the HOMO with paired electrons on $\mathrm{Re}(\mathrm{bpy})$, and (B \& C) are the $\mathrm{HO} \alpha \mathrm{O}$ and $\mathrm{LU} \beta \mathrm{O}$ with $\alpha$ - and $\beta$-spins, respectively, and (D) is the spin density map.
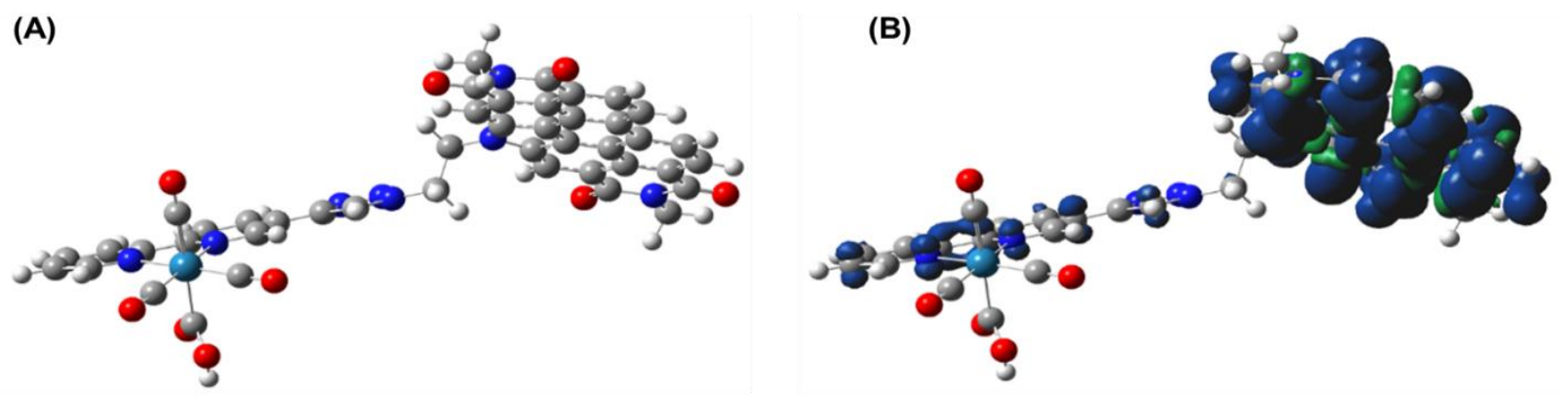

(C)

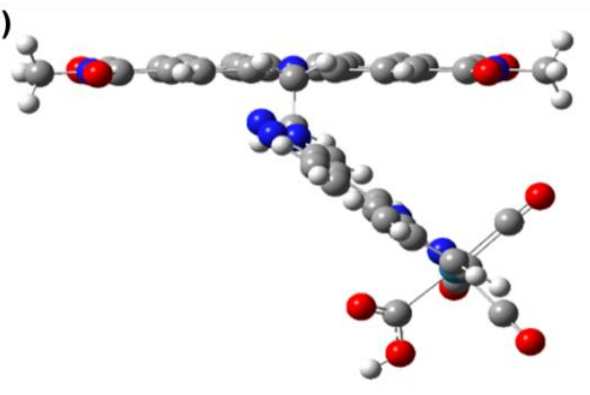

(D)

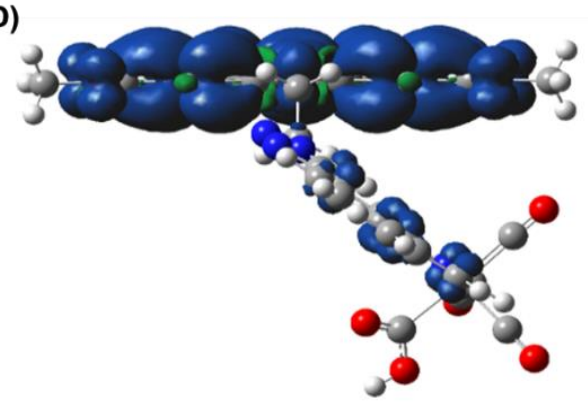

Figure S55. Face-on and side-on perspectives of the optimized geometry (A \& C) and spin density map (B \& D) for the doublet state of $\operatorname{Re}^{\mathrm{I}}\left[(\mathrm{COOH})(\text { bpy-TAz-PDI) }]^{-}\right.$as determined at the M06/6-31G(d,p)/LANL2DZ level of theory. 

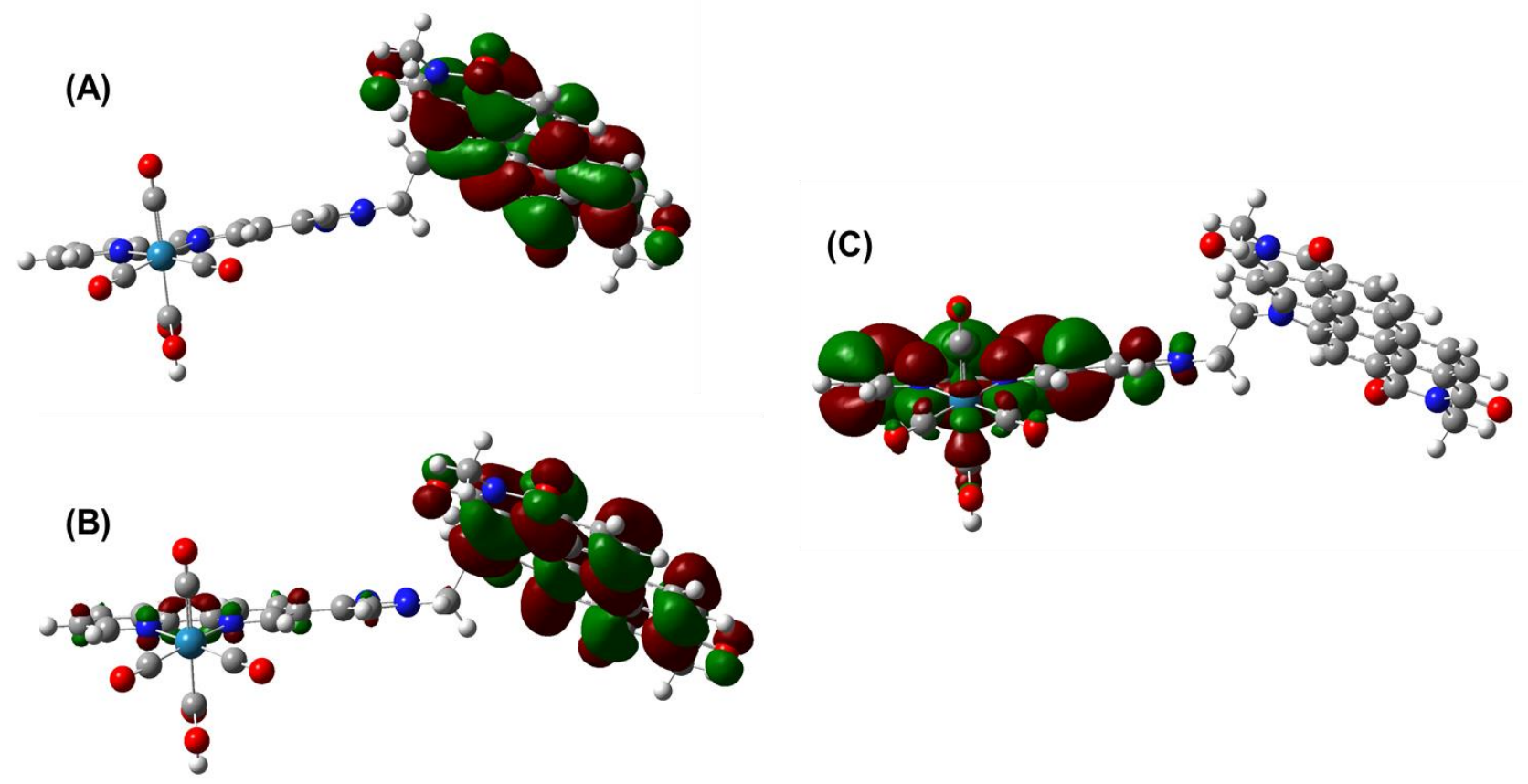

Figure S56. Frontier molecular orbitals of the doublet state of $\operatorname{Re}^{\mathrm{I}}[(\mathrm{COOH})(\mathrm{bpy}-\mathrm{TAz}-\mathrm{PDI})]^{-}$at the M06/6-31G(d,p)/LANL2DZ level of theory, where (A) represents the HOMO, and (B \& C) are the $\mathrm{HO} \alpha \mathrm{O}$ and $\mathrm{LU} \beta \mathrm{O}$ with $\alpha$ - and $\beta$-spins, respectively.
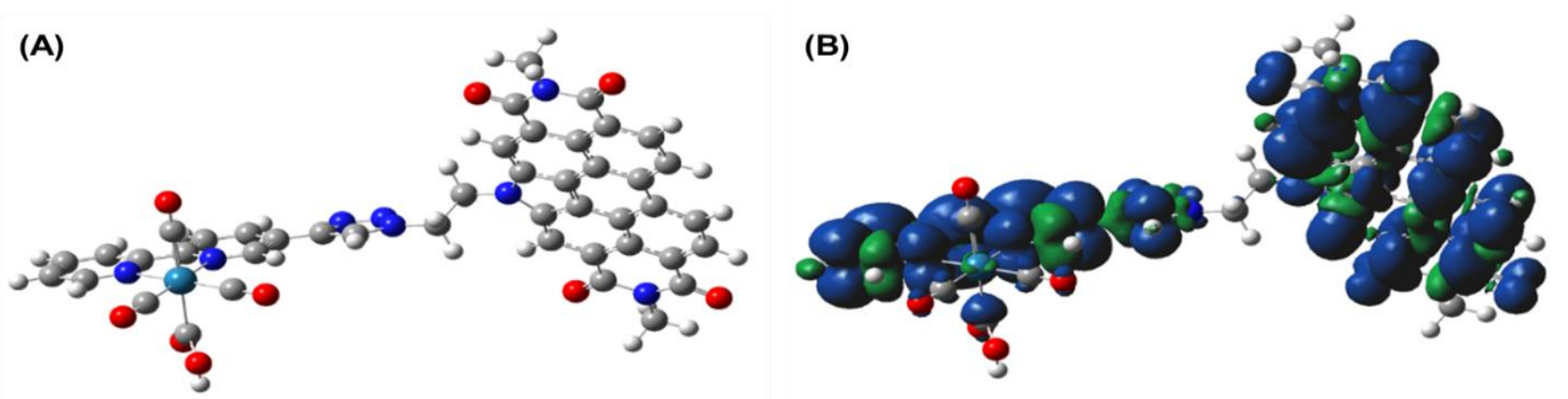

(C)
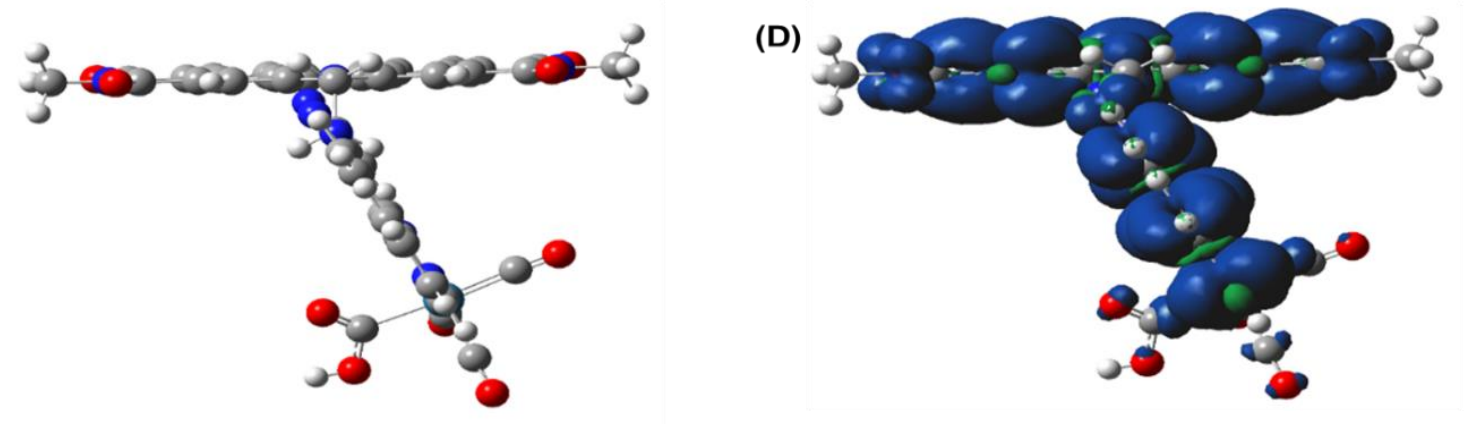

Figure S57. Face-on and side-on perspectives of the optimized geometry (A \& C) and spin density map (B \& D) for the triplet state of $\operatorname{Re}^{\mathrm{I}}\left[(\mathrm{COOH})(\text { bpy-TAz-PDI) }]^{2-}\right.$ as determined at the M06/6-31G(d,p)/LANL2DZ level of theory. 


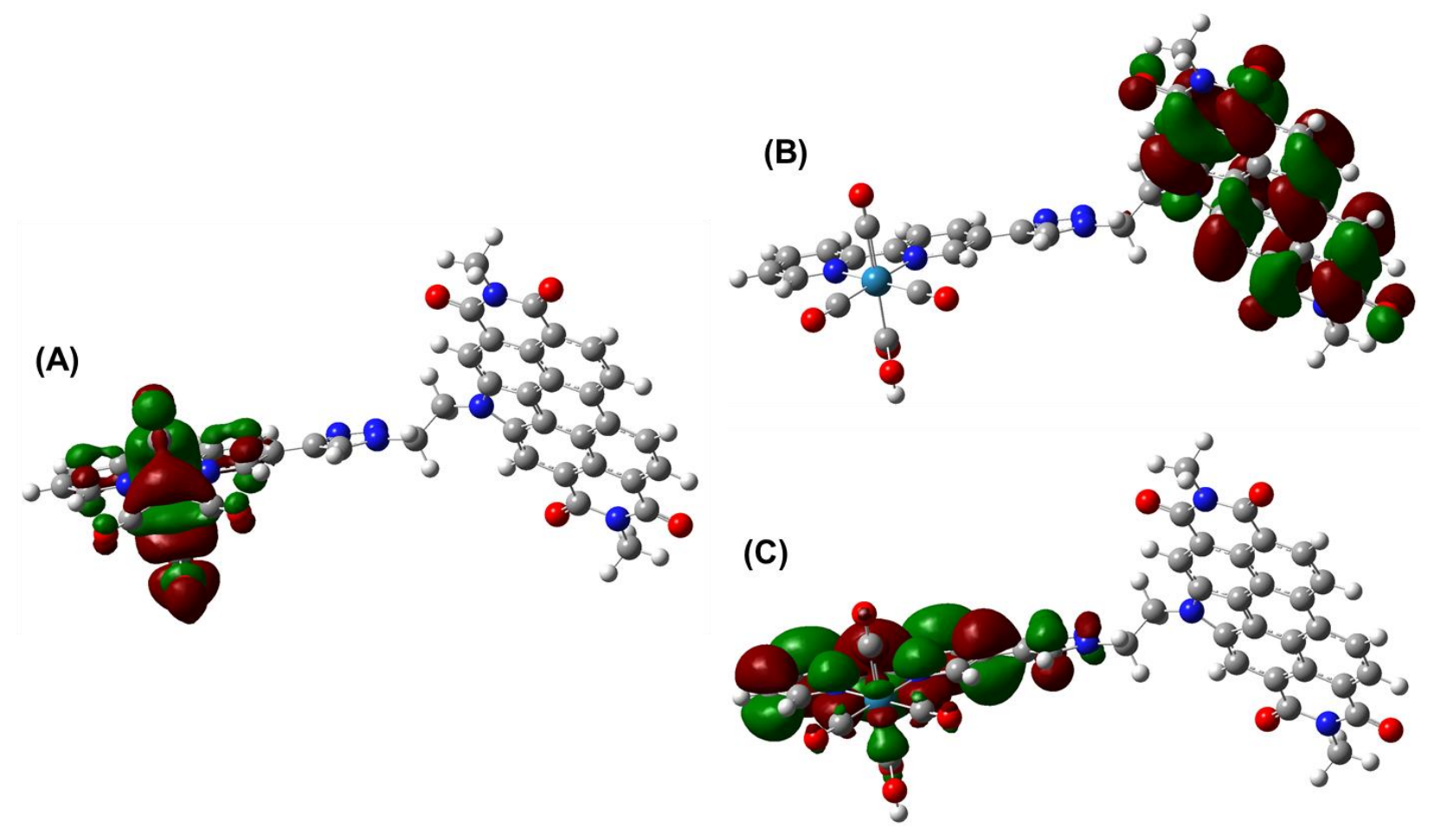

Figure S58. Frontier molecular orbitals of the triplet state of $\operatorname{Re}^{\mathrm{I}}[(\mathrm{COOH})(\mathrm{bpy}-\mathrm{TAz}-\mathrm{PDI})]^{2-}$ at the M06/6-31G(d,p)/LANL2DZ level of theory, where (A) represents the HOMO, and (B \& C) are the $\mathrm{HO} \alpha \mathrm{O}-1$ and $\mathrm{HO} \alpha \mathrm{O}$ with $\alpha$-electrons, respectively.
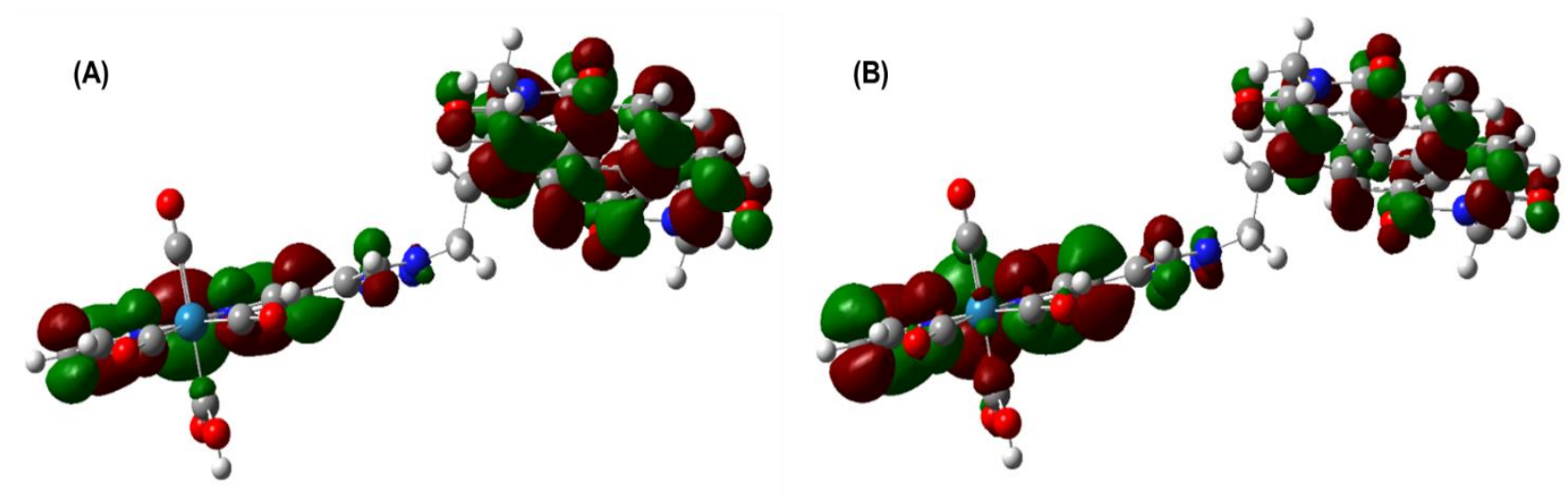

Figure S59. Frontier molecular orbitals of the singlet state of $\operatorname{Re}^{\mathrm{I}}[(\mathrm{COOH})(\mathrm{bpy}-\mathrm{TAz}-\mathrm{PDI})]^{2-}$ at the M06/6-31G(d,p)/LANL2DZ level of theory, where (A) is the HOMO and (B) is the LUMO. 
(A)

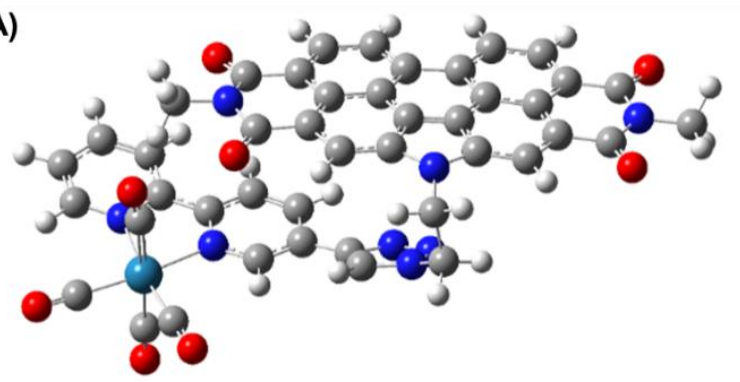

(C)

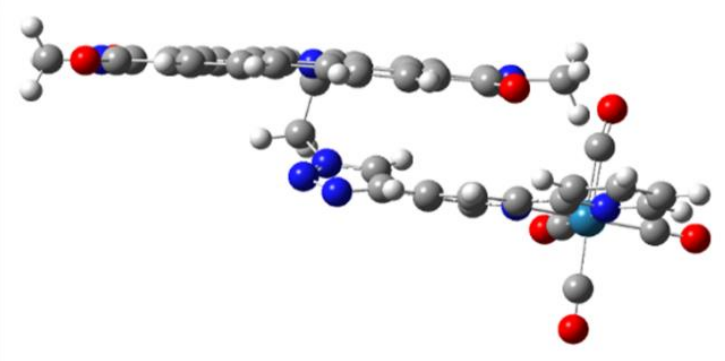

(B)

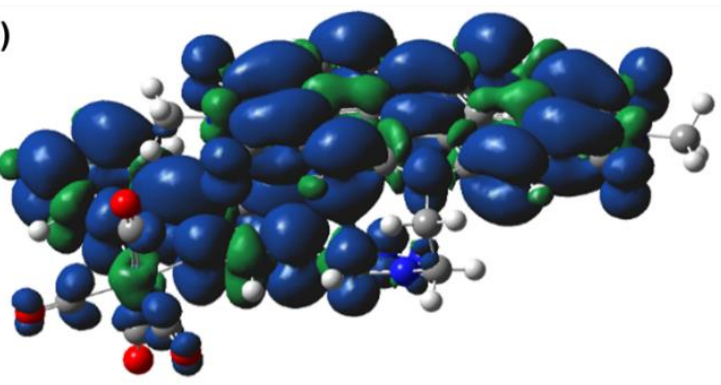

(D)

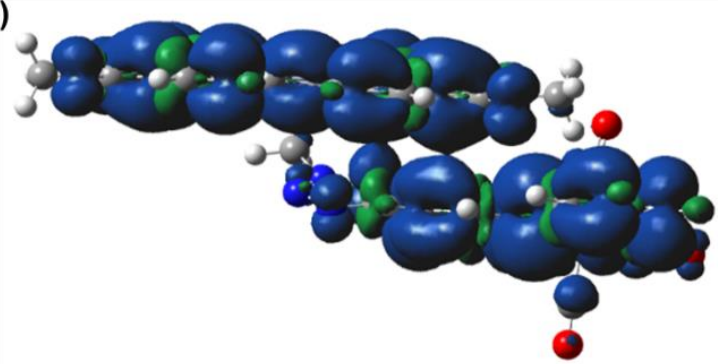

Figure S60. Face-on and side-on perspectives of the optimized geometry (A \& C) and spin density map (B \& D) for the triplet state of $\operatorname{Re}^{\mathrm{I}}\left[(\mathrm{CO})_{4}(\text { bpy-TAz-PDI) }]^{-}\right.$as determined at the M06/6-31G(d,p)/LANL2DZ level of theory.
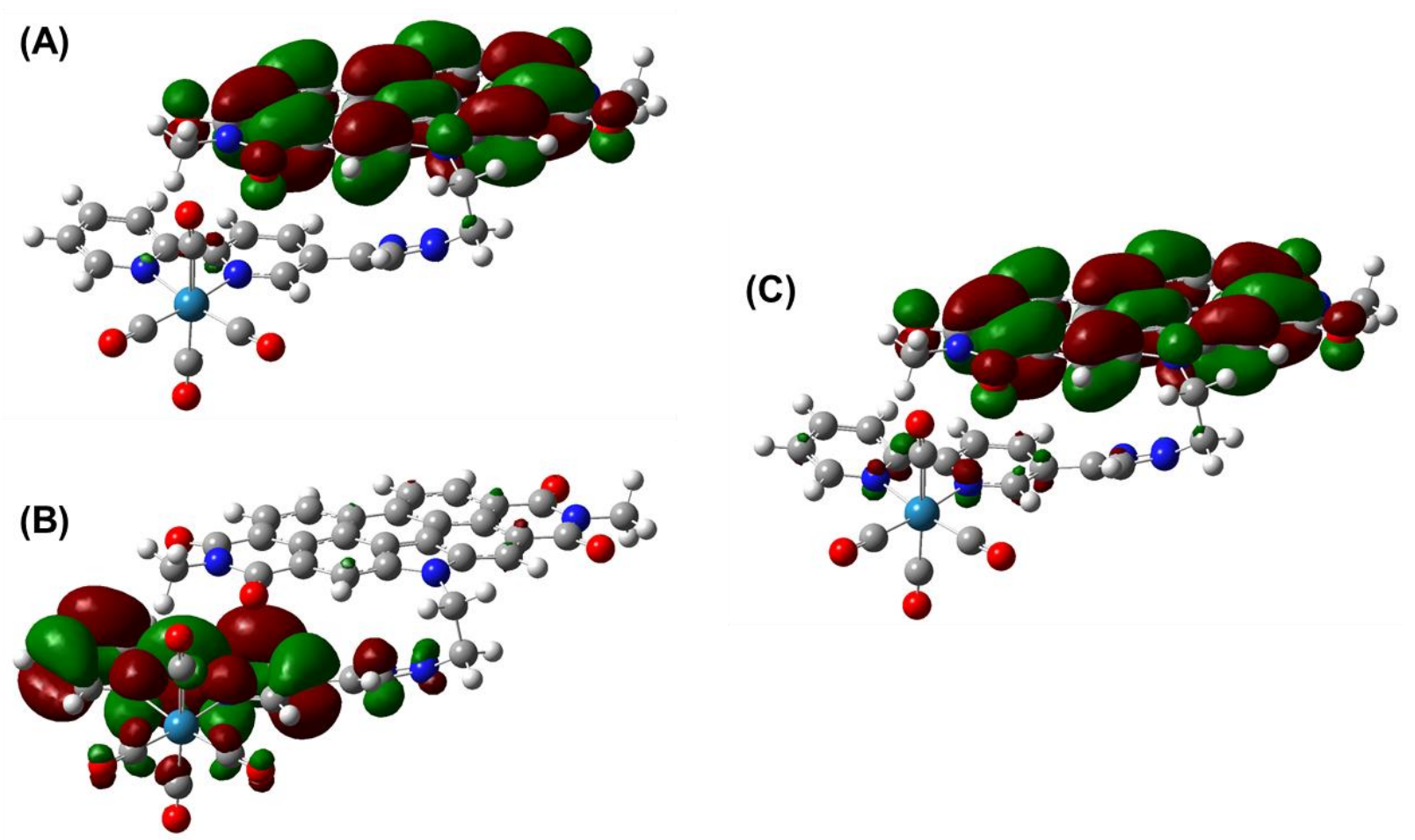

Figure S61. Frontier molecular orbitals of the triplet state of $\operatorname{Re}^{\mathrm{I}}\left[(\mathrm{CO})_{4}(\mathrm{bpy}-\mathrm{TAz}-\mathrm{PDI})\right]^{-}$at the M06/6-31G(d,p)/LANL2DZ level of theory, where (A \& B) represent the HO $\alpha \mathrm{O}-1$ and $\mathrm{HO} \alpha \mathrm{O}$ with $\alpha$-electrons, and $(\mathrm{C})$ is the LU $\beta \mathrm{O}$ with $\beta$-spin. 
(A)

(B)
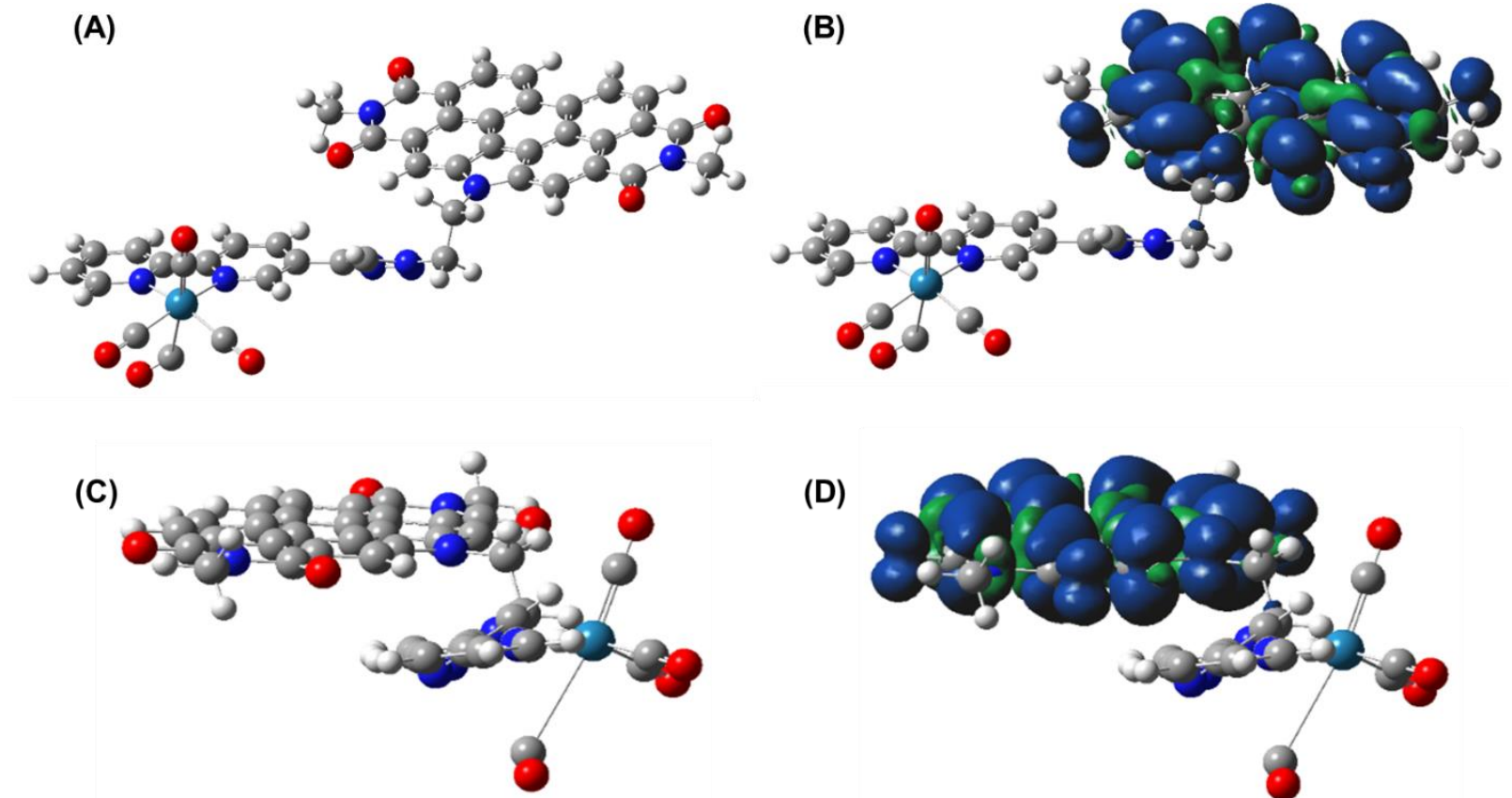

(D)

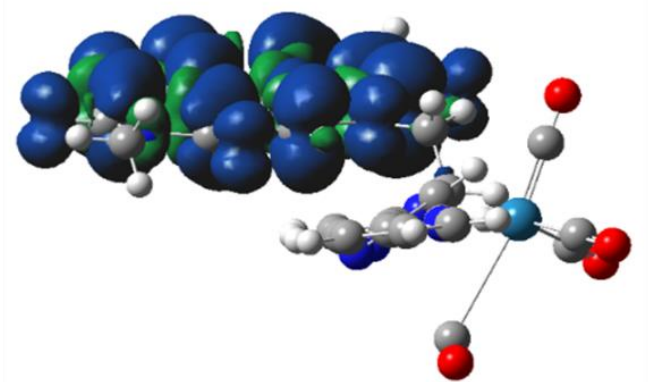

Figure S62. Face-on and side-on perspectives of the optimized geometry (A \& C) and spin density map (B \& D) for the doublet state of $\operatorname{Re}^{\mathrm{I}}\left[(\mathrm{CO})_{4}(\mathrm{bpy}-\mathrm{TAz}-\mathrm{PDI})\right]^{2-}$ as determined at the M06/6-31G(d,p)/LANL2DZ level of theory.

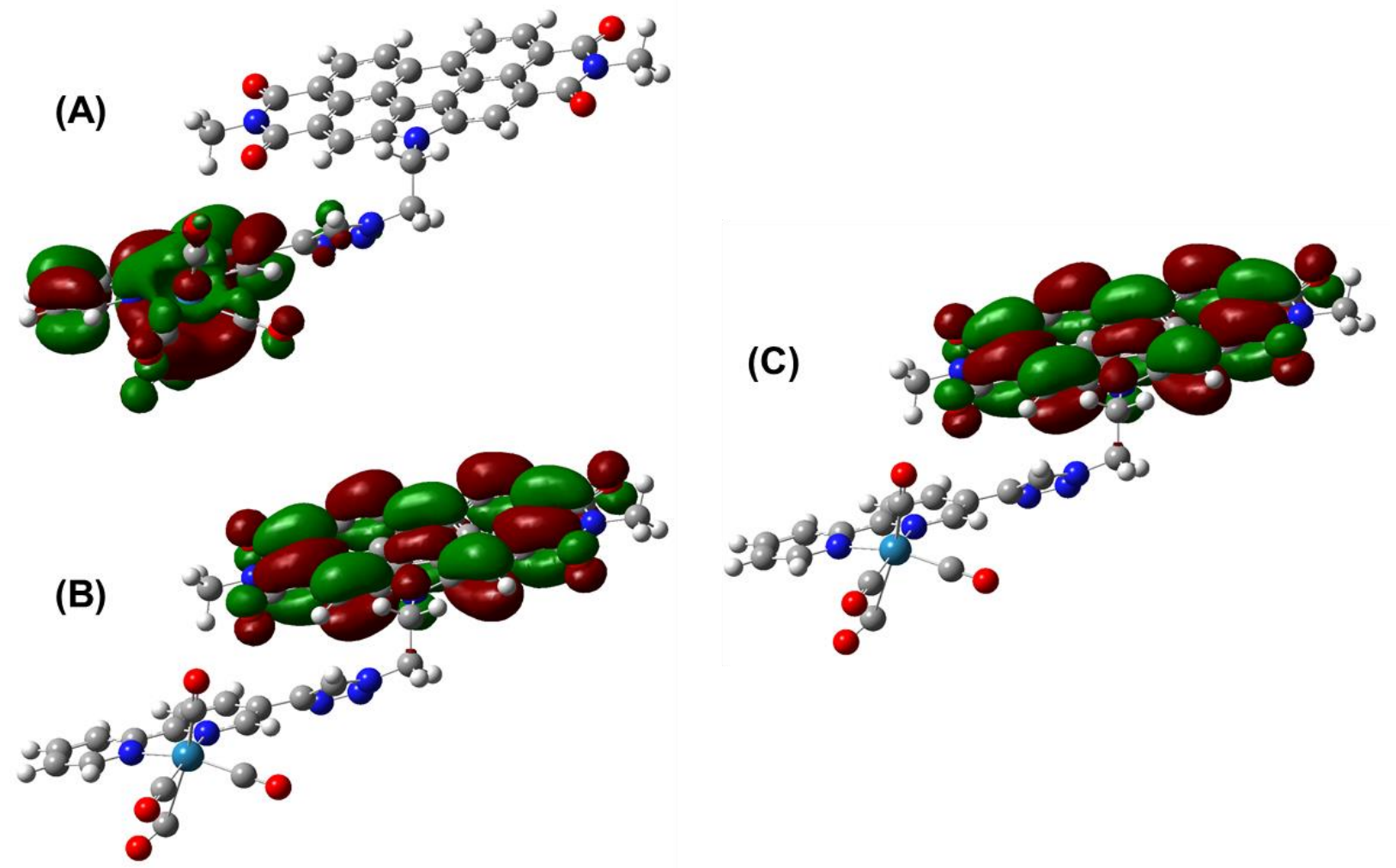

Figure S63. Frontier molecular orbitals of the triplet state of $\operatorname{Re}^{\mathrm{I}}\left[(\mathrm{CO})_{4}(\mathrm{bpy}-\mathrm{TAz}-\mathrm{PDI})\right]^{2-}$ at the M06/6-31G(d,p)/LANL2DZ level of theory, where (A) represents the HOMO, and (B \&C) are the $\mathrm{HO} \alpha \mathrm{O}$ with $\alpha$ - and $\beta$-spins, respectively. 


\section{X-ray Diffraction}

The selected crystal was mounted on a glass loop using Paratone. Diffraction experiments were performed on a Bruker Smart diffractometer equipped with an Incoatec Microfocus $(\mathrm{Cu} \mathrm{K} \alpha, \lambda=$ $1.54178 \AA$ ) and an APEX II CCD detector. The crystal was kept at $173 \mathrm{~K}$ during data collection. Diffractions spots were integrated and scaled with SAINT ${ }^{34}$ and the space group was determined with XPREP. ${ }^{35}$ Using Olex2, ${ }^{36}$ the structure was solved with the ShelXT ${ }^{37}$ structure solution program using Intrinsic Phasing and refined with the ShelXL ${ }^{38}$ refinement package using Least Squares minimisation. Weak diffraction and unresolvable twinning prevented a complete structural solution and required that several restraints be used to obtain a stable model; notably, restraining the Uij components (SIMU) for the whole structure and the carbonyl and pentyl distances via SADI.

(A)

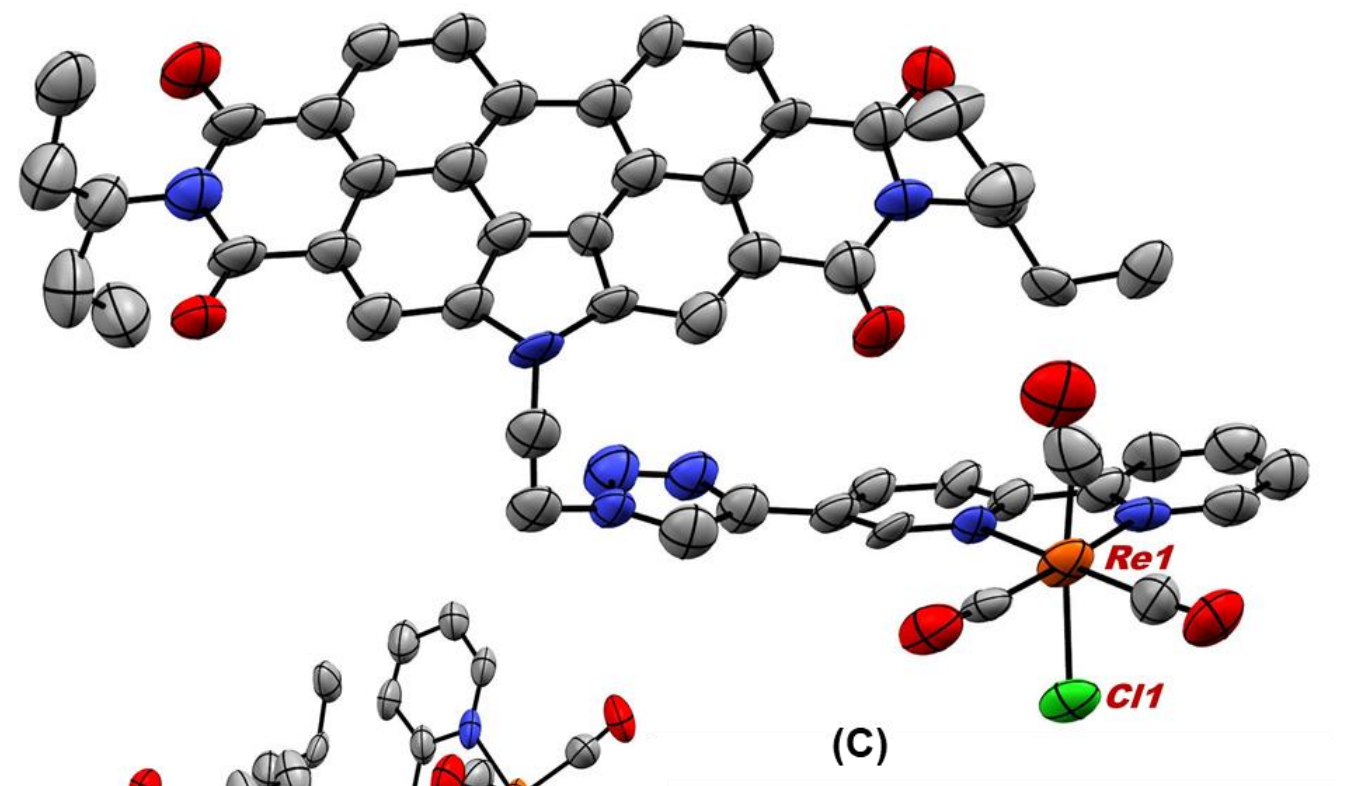

(B)
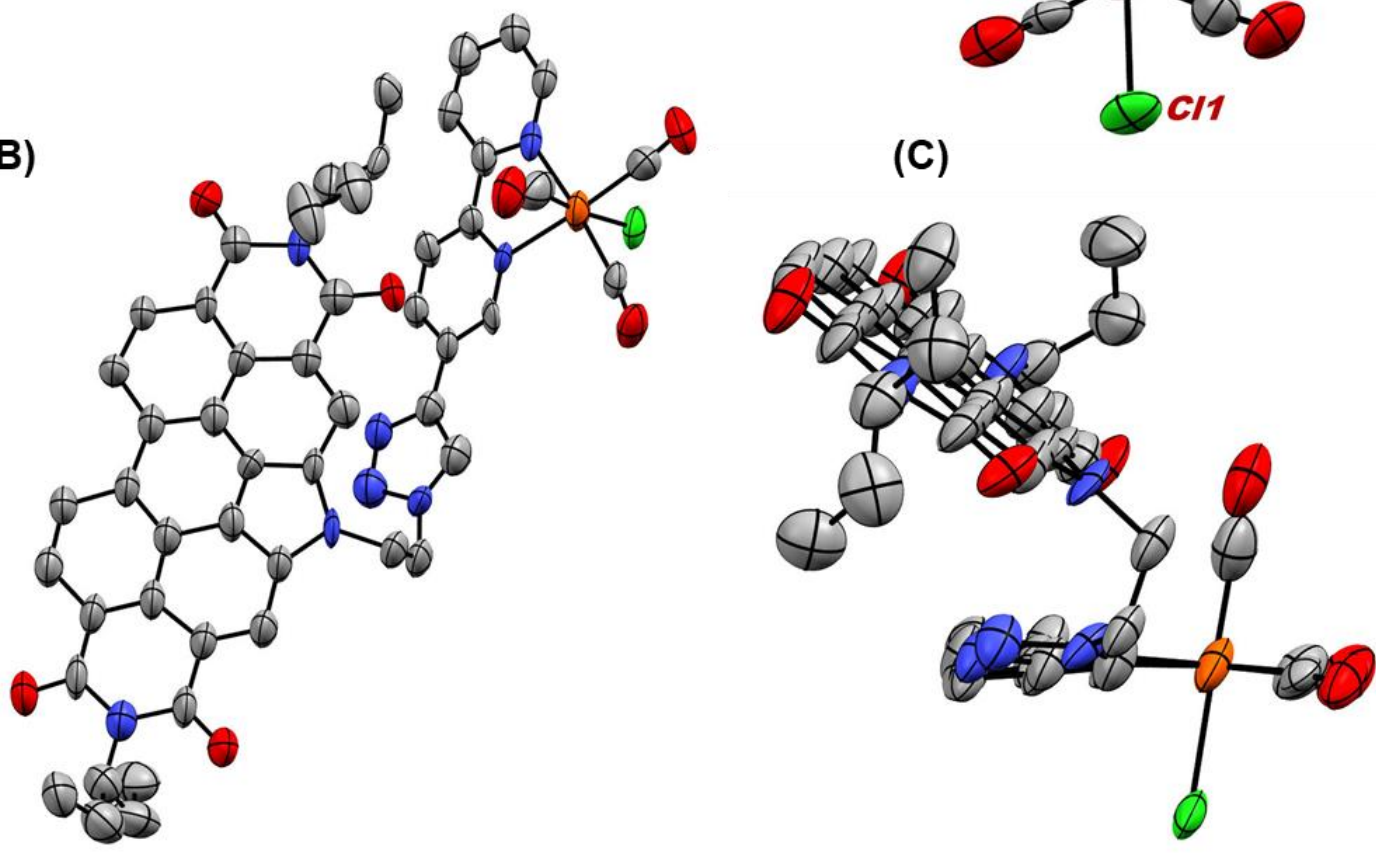

Figure S64. Single-crystal X-ray diffraction connectivity map of Re(bpy-TAz-PDI), showing the face-on (A), top-view (B), and side-view (C), as determined by X-ray diffraction crystallography (where: grey $=$ carbon, blue $=$ nitrogen, red $=$ oxygen, green $=$ chlorine, and orange $=$ rhenium). Hydrogen atoms and outer-sphere solvent molecules have been omitted for clarity. 
Table S4. Re(bpy-TAz-PDI) crystal data and structure refinement for repdi_sq

\begin{tabular}{|c|c|}
\hline Identification code & repdi_sq \\
\hline Empirical formula & $\mathrm{C}_{51} \mathrm{H}_{40} \mathrm{ClN}_{8} \mathrm{O}_{7} \mathrm{Re}$ \\
\hline Formula weight & 1098.56 \\
\hline Temperature/K & 173.0 \\
\hline Crystal system & triclinic \\
\hline Space group & $\mathrm{P}-1$ \\
\hline $\mathbf{a} / \AA_{0}$ & $11.2408(10)$ \\
\hline b/Å & $17.2057(16)$ \\
\hline c/Å & $18.3623(16)$ \\
\hline $\boldsymbol{\alpha} /{ }^{\circ}$ & $113.446(6)$ \\
\hline$\beta /{ }^{\circ}$ & $100.320(7)$ \\
\hline$\gamma /{ }^{\circ}$ & $103.520(7)$ \\
\hline Volume/Å ${ }^{3}$ & $3016.8(5)$ \\
\hline $\mathbf{Z}$ & 2 \\
\hline$\rho_{\text {calcg }} / \mathrm{cm}^{3}$ & 1.209 \\
\hline $\boldsymbol{\mu} / \mathbf{m m}^{-1}$ & 4.744 \\
\hline $\mathbf{F}(000)$ & 1100.0 \\
\hline Crystal size $/ \mathrm{mm}^{3}$ & $0.354 \times 0.119 \times 0.117$ \\
\hline Radiation & $\operatorname{CuK} \alpha(\lambda=1.54178)$ \\
\hline $2 \Theta$ range for data collection $/{ }^{\circ}$ & 17.184 to 99.998 \\
\hline Index ranges & $-9 \leq \mathrm{h} \leq 11,-17 \leq \mathrm{k} \leq 14,-18 \leq 1 \leq 18$ \\
\hline Reflections collected & 5575 \\
\hline Independent reflections & $5575\left[\mathrm{R}_{\text {int }}=0.0561, \mathrm{R}_{\text {sigma }}=0.0905\right]$ \\
\hline Data/restraints/parameters & $5575 / 1463 / 617$ \\
\hline Goodness-of-fit on $F^{2}$ & 1.114 \\
\hline Final $R$ indexes $[I>=2 \sigma(I)]$ & $\mathrm{R}_{1}=0.1250, \mathrm{wR}_{2}=0.3165$ \\
\hline Final $\mathbf{R}$ indexes [all data] & $\mathrm{R}_{1}=0.1466, \mathrm{wR}_{2}=0.3437$ \\
\hline Largest diff. peak/hole / e $\AA^{-3}$ & $4.33 /-1.41$ \\
\hline
\end{tabular}


Table S5. Fractional Atomic Coordinates $\left(\times 10^{4}\right)$ and Equivalent Isotropic Displacement Parameters $\left(\AA^{2} \times 10^{3}\right)$ for repdi_sq. Ueq is defined as $1 / 3$ of of the trace of the orthogonalised UIJ tensor.

\begin{tabular}{|c|c|c|c|c|}
\hline Atom & $x$ & $y$ & $z$ & $\mathbf{U}(\mathbf{e q})$ \\
\hline $\operatorname{Re} 1$ & $6104.6(9)$ & $3170.9(8)$ & $3855.1(7)$ & $70.0(6)$ \\
\hline $\mathrm{Cl1}$ & $6887(5)$ & $4450(4)$ & $3564(4)$ & $65.8(15)$ \\
\hline $\mathrm{O} 1$ & $6666(18)$ & $3063(12)$ & $6385(10)$ & $88(5)$ \\
\hline $\mathrm{O} 2$ & $9420(16)$ & $1960(12)$ & $7501(10)$ & $85(5)$ \\
\hline $\mathrm{O} 3$ & $8812(18)$ & $6972(14)$ & $13777(11)$ & $97(5)$ \\
\hline $\mathrm{O} 4$ & $5969(18)$ & $7556(12)$ & $12167(11)$ & $86(5)$ \\
\hline $\mathrm{O} 5$ & $3735(13)$ & $3664(12)$ & $4197(11)$ & $83(5)$ \\
\hline O6 & $4590(20)$ & $1902(12)$ & $1999(9)$ & $103(6)$ \\
\hline $\mathrm{O} 7$ & $5080(18)$ & $1590(15)$ & $4213(14)$ & $121(7)$ \\
\hline N1 & $7976(18)$ & $2460(13)$ & $6936(12)$ & $72(4)$ \\
\hline $\mathrm{N} 2$ & $7470(20)$ & 7305 (15) & $13002(13)$ & $83(5)$ \\
\hline N3 & $5846(17)$ & $5319(12)$ & $9088(11)$ & $64(4)$ \\
\hline N4 & $7882(19)$ & $6488(14)$ & $8556(13)$ & $79(5)$ \\
\hline N5 & $6560(17)$ & $6207(12)$ & $8090(11)$ & $61(4)$ \\
\hline N7 & $7433(14)$ & $4086(11)$ & $5117(10)$ & $50(3)$ \\
\hline N8 & $7913(16)$ & $2994(11)$ & $3807(11)$ & $59(4)$ \\
\hline N37 & $8501(18)$ & $6187(13)$ & $8009(12)$ & $70(4)$ \\
\hline $\mathrm{C} 1$ & $6460(20)$ & $4694(15)$ & $8736(13)$ & $59(4)$ \\
\hline $\mathrm{C} 2$ & $6460(20)$ & $4157(16)$ & $7920(15)$ & $71(5)$ \\
\hline C3 & $7240(20)$ & $3632(16)$ & $7860(15)$ & $72(5)$ \\
\hline $\mathrm{C} 4$ & $7290(20)$ & $3060(17)$ & $7008(16)$ & $77(5)$ \\
\hline C5 & $8760(30)$ & $2419(17)$ & $7592(15)$ & $75(5)$ \\
\hline C6 & $8800(20)$ & $3041(15)$ & $8438(13)$ & $65(5)$ \\
\hline $\mathrm{C} 7$ & $9520(20)$ & $3094(16)$ & $9170(14)$ & $69(5)$ \\
\hline $\mathrm{C} 8$ & $9580(20)$ & $3699(16)$ & $9984(14)$ & $68(5)$ \\
\hline C9 & $8750(20)$ & $4218(17)$ & $10057(15)$ & $73(5)$ \\
\hline $\mathrm{C} 10$ & $8720(20)$ & $4885(16)$ & $10876(15)$ & $70(5)$ \\
\hline $\mathrm{C} 11$ & $9410(20)$ & $5050(17)$ & $11703(14)$ & $74(5)$ \\
\hline $\mathrm{C} 12$ & $9260(20)$ & $5693(16)$ & $12402(16)$ & $72(5)$ \\
\hline $\mathrm{C} 13$ & $8430(20)$ & $6186(17)$ & 12355 (15) & $70(5)$ \\
\hline $\mathrm{C} 14$ & $8290(20)$ & $6844(18)$ & $13089(16)$ & $78(5)$ \\
\hline $\mathrm{C} 15$ & $6690(20)$ & 7135 (17) & $12214(15)$ & $73(5)$ \\
\hline $\mathrm{C} 16$ & $6840(20)$ & $6468(16)$ & $11434(15)$ & $69(5)$ \\
\hline $\mathrm{C} 17$ & $6190(20)$ & $6380(17)$ & $10694(15)$ & $70(5)$ \\
\hline $\mathrm{C} 18$ & $6310(20)$ & $5684(16)$ & $9950(14)$ & $64(5)$ \\
\hline C19 & $8020(20)$ & $3603(16)$ & $8542(14)$ & $66(4)$ \\
\hline $\mathrm{C} 20$ & $8030(20)$ & $4181(17)$ & $9338(15)$ & $72(5)$ \\
\hline $\mathrm{C} 21$ & $7280(20)$ & $4673(15)$ & $9370(14)$ & $62(4)$ \\
\hline $\mathrm{C} 22$ & $7170(20)$ & $5249(16)$ & $10089(14)$ & $65(4)$ \\
\hline $\mathrm{C} 23$ & $7880(20)$ & $5368(17)$ & $10881(15)$ & $71(5)$ \\
\hline $\mathrm{C} 24$ & $7730(20)$ & $6033(16)$ & $11604(15)$ & $71(5)$ \\
\hline $\mathrm{C} 25$ & $8460(20)$ & $1427(15)$ & $4734(11)$ & $75(6)$ \\
\hline $\mathrm{C} 26$ & $8187(18)$ & $2124(12)$ & $5442(11)$ & $59(5)$ \\
\hline $\mathrm{C} 27$ & $7829(19)$ & $1748(14)$ & $6060(12)$ & $81(6)$ \\
\hline
\end{tabular}




$\begin{array}{lrrrr}\text { C28 } & 6440(20) & 1076(18) & 5739(14) & 99(7) \\ \text { C29 } & 6110(30) & 790(20) & 6387(17) & 124(11) \\ \text { C30 } & 8890(30) & 9270(17) & 13600(20) & 110(9) \\ \text { C31 } & 7680(30) & 8966(16) & 13830(20) & 112(8) \\ \text { C32 } & 7430(20) & 8015(15) & 13762(18) & 89(6) \\ \text { C33 } & 6210(20) & 7713(18) & 14000(20) & 107(8) \\ \text { C34 } & 6130(30) & 6887(18) & 14134(18) & 106(9) \\ \text { C35 } & 5010(20) & 5611(17) & 8628(16) & 73(5) \\ \text { C36 } & 5700(20) & 6428(17) & 8548(15) & 69(5) \\ \text { C37 } & 6400(20) & 5767(18) & 7311(17) & 80(6) \\ \text { C38 } & 7600(20) & 5695(16) & 7224(15) & 67(5) \\ \text { C39 } & 7140(20) & 4611(14) & 5751(12) & 53(4) \\ \text { C40 } & 8020(20) & 5234(15) & 6514(13) & 57(4) \\ \text { C41 } & 9267(19) & 5310(15) & 6593(13) & 57(4) \\ \text { C42 } & 9620(20) & 4785(15) & 5948(13) & 59(5) \\ \text { C43 } & 8688(19) & 4150(14) & 5204(12) & 53(4) \\ \text { C44 } & 8950(20) & 3515(15) & 4494(14) & 64(5) \\ \text { C45 } & 10210(20) & 3433(17) & 4503(16) & 74(5) \\ \text { C46 } & 10330(30) & 2826(17) & 3839(17) & 82(6) \\ \text { C47 } & 9290(20) & 2259(16) & 3078(15) & 72(5) \\ \text { C48 } & 8130(20) & 2384(16) & 3122(15) & 67(5) \\ \text { C49 } & 4552(17) & 3420(13) & 4005(12) & 53(4) \\ \text { C50 } & 5090(20) & 2383(15) & 2696(12) & 80(6) \\ \text { C51 } & 5500(30) & 2094(15) & 3986(19) & 92(6)\end{array}$


Table S6. Anisotropic Displacement Parameters $(\AA 2 \times 103)$ for repdi_sq. The Anisotropic displacement factor exponent takes the form: $-2 \pi 2[\mathrm{~h} 2 \mathrm{a} * 2 \mathrm{U} 11+2 \mathrm{hka} * \mathrm{~b} * \mathrm{U} 12+\ldots]$.

\begin{tabular}{|c|c|c|c|c|c|c|}
\hline $\begin{array}{l}\text { Atom } \\
\operatorname{Re} 1\end{array}$ & $\begin{array}{c}\mathbf{U}_{11} \\
52.3(8)\end{array}$ & $\begin{array}{c}\mathbf{U}_{\mathbf{2 2}} \\
117.0(11)\end{array}$ & $\begin{array}{c}\mathbf{U}_{33} \\
59.1(8)\end{array}$ & $\begin{array}{c}\mathbf{U}_{\mathbf{2 3}} \\
53.1(7)\end{array}$ & $\begin{array}{c}\mathbf{U}_{13} \\
10.0(5)\end{array}$ & $\begin{array}{c}\mathbf{U}_{\mathbf{1 2}} \\
42.6(6)\end{array}$ \\
\hline $\mathrm{Cl} 1$ & $42(3)$ & $100(4)$ & $67(3)$ & $54(3)$ & $2(2)$ & $28(3)$ \\
\hline $\mathrm{O} 1$ & $105(11)$ & $136(12)$ & $45(9)$ & $49(9)$ & $16(8)$ & $73(10)$ \\
\hline $\mathrm{O} 2$ & $80(10)$ & $114(11)$ & $67(10)$ & $36(9)$ & $15(8)$ & $60(9)$ \\
\hline $\mathrm{O} 3$ & 95 (12) & $152(14)$ & $63(10)$ & $59(10)$ & $11(9)$ & $66(10)$ \\
\hline $\mathrm{O} 4$ & $113(12)$ & $113(11)$ & $72(10)$ & $62(9)$ & $35(9)$ & $70(10)$ \\
\hline $\mathrm{O} 5$ & $53(9)$ & $146(14)$ & $98(12)$ & $86(11)$ & $35(8)$ & $54(9)$ \\
\hline O6 & $125(15)$ & $131(15)$ & $50(10)$ & 45 (11) & $6(10)$ & $48(12)$ \\
\hline $\mathrm{O} 7$ & $82(13)$ & $170(20)$ & $108(16)$ & $68(14)$ & $0(12)$ & $59(13)$ \\
\hline N1 & $77(8)$ & $97(8)$ & $56(8)$ & $47(7)$ & $3(7)$ & $44(7)$ \\
\hline N2 & $82(9)$ & $114(9)$ & $68(8)$ & $49(7)$ & $15(8)$ & $51(8)$ \\
\hline N3 & $68(8)$ & $104(8)$ & $48(7)$ & $56(7)$ & $10(6)$ & $47(7)$ \\
\hline N4 & $69(10)$ & $109(10)$ & $68(10)$ & $46(8)$ & $20(8)$ & $38(8)$ \\
\hline N5 & $71(8)$ & $100(9)$ & $56(8)$ & $53(7)$ & $32(7)$ & $63(7)$ \\
\hline N7 & $46(7)$ & $81(8)$ & $40(7)$ & $36(6)$ & $8(6)$ & $42(6)$ \\
\hline N8 & $61(6)$ & $67(6)$ & $55(6)$ & $41(5)$ & $-1(5)$ & $24(5)$ \\
\hline N37 & $63(9)$ & $108(10)$ & $58(9)$ & $48(8)$ & $16(8)$ & $46(8)$ \\
\hline $\mathrm{C} 1$ & $61(8)$ & $94(9)$ & $51(8)$ & $51(7)$ & $15(7)$ & $45(7)$ \\
\hline $\mathrm{C} 2$ & $67(9)$ & $103(10)$ & $60(9)$ & $46(8)$ & $22(8)$ & $38(8)$ \\
\hline $\mathrm{C} 3$ & $79(9)$ & $94(9)$ & $58(8)$ & $42(7)$ & $16(8)$ & $47(8)$ \\
\hline $\mathrm{C} 4$ & $83(10)$ & $95(10)$ & $60(10)$ & $34(8)$ & $18(9)$ & $47(8)$ \\
\hline C5 & $84(10)$ & $97(10)$ & $55(9)$ & $38(8)$ & $15(9)$ & $49(9)$ \\
\hline C6 & $75(9)$ & $99(9)$ & $47(8)$ & $48(7)$ & $15(7)$ & $52(7)$ \\
\hline $\mathrm{C} 7$ & $75(10)$ & $102(10)$ & $46(9)$ & $37(8)$ & $13(8)$ & $55(8)$ \\
\hline $\mathrm{C} 8$ & $67(10)$ & $106(10)$ & $52(9)$ & $42(8)$ & $25(8)$ & $52(8)$ \\
\hline C9 & $74(9)$ & $107(9)$ & $58(8)$ & $48(7)$ & $13(8)$ & $49(8)$ \\
\hline $\mathrm{C} 10$ & $69(9)$ & $102(9)$ & $58(8)$ & $49(7)$ & $10(8)$ & $45(7)$ \\
\hline C11 & $76(10)$ & $104(10)$ & $54(10)$ & $42(9)$ & $11(9)$ & $47(9)$ \\
\hline C12 & $64(10)$ & $104(10)$ & $63(10)$ & $50(8)$ & $13(9)$ & $39(8)$ \\
\hline C13 & $63(9)$ & $104(9)$ & $64(9)$ & $51(8)$ & $10(8)$ & $44(8)$ \\
\hline C14 & $76(10)$ & $116(10)$ & $64(10)$ & $62(8)$ & $5(9)$ & $45(9)$ \\
\hline C15 & $75(10)$ & $109(10)$ & $63(9)$ & $60(8)$ & $15(8)$ & $48(9)$ \\
\hline C16 & $72(9)$ & $97(9)$ & $64(9)$ & $52(7)$ & $19(8)$ & $48(7)$ \\
\hline C17 & $60(9)$ & $110(10)$ & $62(9)$ & $51(8)$ & $17(8)$ & $46(8)$ \\
\hline C18 & $59(8)$ & $103(9)$ & $53(8)$ & $47(7)$ & $14(7)$ & $45(7)$ \\
\hline C19 & $64(8)$ & $98(8)$ & $56(8)$ & $42(7)$ & $15(7)$ & $50(7)$ \\
\hline $\mathrm{C} 20$ & $70(8)$ & $104(8)$ & $59(8)$ & $49(7)$ & $15(7)$ & $42(7)$ \\
\hline $\mathrm{C} 21$ & $64(8)$ & $94(8)$ & $54(8)$ & $41(7)$ & $22(7)$ & $55(7)$ \\
\hline $\mathrm{C} 22$ & $63(8)$ & $100(8)$ & $55(8)$ & $52(7)$ & $16(7)$ & $38(7)$ \\
\hline $\mathrm{C} 23$ & $64(8)$ & $105(8)$ & $58(8)$ & $46(7)$ & $13(7)$ & $43(7)$ \\
\hline $\mathrm{C} 24$ & $69(8)$ & $104(8)$ & $58(8)$ & $51(7)$ & $11(7)$ & $44(7)$ \\
\hline $\mathrm{C} 25$ & $46(12)$ & $129(16)$ & $54(11)$ & 45 (11) & $9(10)$ & $34(11)$ \\
\hline C26 & $52(8)$ & $66(8)$ & $59(8)$ & $29(6)$ & $-7(6)$ & $33(6)$ \\
\hline $\mathrm{C} 27$ & $93(11)$ & $85(10)$ & $68(10)$ & $39(9)$ & $8(9)$ & $39(9)$ \\
\hline $\mathrm{C} 28$ & $110(14)$ & $86(12)$ & 75 (12) & $40(10)$ & $-3(11)$ & $7(11)$ \\
\hline
\end{tabular}




$\begin{array}{rrrrrrr}\text { C29 } & 150(20) & 111(18) & 87(17) & 64(15) & -6(15) & -1(17) \\ \text { C30 } & 130(20) & 94(18) & 110(20) & 40(16) & 51(18) & 47(16) \\ \text { C31 } & 109(14) & 123(14) & 90(14) & 25(12) & 49(12) & 45(12) \\ \text { C32 } & 93(11) & 116(11) & 74(10) & 49(9) & 34(10) & 47(10) \\ \text { C33 } & 111(15) & 128(15) & 79(13) & 42(12) & 33(12) & 41(13) \\ \text { C34 } & 106(19) & 150(20) & 69(16) & 49(15) & 14(15) & 57(16) \\ \text { C35 } & 61(10) & 112(11) & 66(10) & 49(9) & 16(9) & 53(9) \\ \text { C36 } & 57(10) & 110(11) & 67(10) & 54(9) & 17(9) & 50(9) \\ \text { C37 } & 64(10) & 109(11) & 72(10) & 44(9) & 9(9) & 42(9) \\ \text { C38 } & 55(9) & 100(10) & 60(9) & 43(8) & 16(8) & 41(8) \\ \text { C39 } & 56(9) & 94(10) & 38(8) & 50(8) & 16(7) & 38(8) \\ \text { C40 } & 54(8) & 92(9) & 48(8) & 48(7) & 14(7) & 39(7) \\ \text { C41 } & 50(9) & 90(9) & 46(9) & 42(8) & 13(7) & 32(7) \\ \text { C42 } & 51(9) & 97(10) & 43(9) & 42(8) & 15(8) & 30(8) \\ \text { C43 } & 49(8) & 86(9) & 45(8) & 43(7) & 17(7) & 32(7) \\ \text { C44 } & 59(9) & 89(9) & 50(8) & 41(7) & 6(8) & 29(8) \\ \text { C45 } & 60(10) & 102(11) & 62(10) & 40(9) & -4(9) & 42(8) \\ \text { C46 } & 76(11) & 94(11) & 72(11) & 40(9) & 0(10) & 33(9) \\ \text { C47 } & 71(10) & 95(11) & 56(10) & 38(9) & 11(9) & 37(9) \\ \text { C48 } & 67(10) & 90(11) & 62(10) & 48(9) & 8(9) & 40(9) \\ \text { C49 } & 54(7) & 70(8) & 52(8) & 45(6) & 12(6) & 26(6) \\ \text { C50 } & 90(12) & 108(12) & 71(12) & 49(10) & 35(11) & 62(10) \\ \text { C51 } & 72(9) & 102(9) & 91(9) & 31(7) & 8(7) & 46(7)\end{array}$




\section{References}

(1) Williams, D. B. G.; Lawton, M. Drying of Organic Solvents: Quantitative Evaluation of the Efficiency of Several Desiccants. J. Org. Chem. 2010, 75 (24), 8351-8354. https://doi.org/10.1021/jo101589h.

(2) Lalancette, J.-M.; Rollin, G.; Dumas, P. Metals Intercalated in Graphite. I. Reduction and Oxidation. Can. J. Chem. 1972, 50 (18), 3058-3062. https://doi.org/10.1139/v72-485.

(3) Stoll, S.; Schweiger, A. EasySpin, a Comprehensive Software Package for Spectral Simulation and Analysis in EPR. J. Magn. Reson. 2006, 178 (1), 42-55. https://doi.org/10.1016/j.jmr.2005.08.013.

(4) Molton, F. Simultispin: A Versatile Graphical User Interface for the Simulation of SolidState Continuous Wave EPR Spectra. Magn. Reson. Chem. 2020, 58 (8), 718-726. https://doi.org/10.1002/mrc.5019.

(5) Koenig, J. D. B.; Willkomm, J.; Roesler, R.; Piers, W. E.; Welch, G. C. Electrocatalytic CO2 Reduction at Lower Overpotentials Using Iron(III) Tetra(Meso-Thienyl)Porphyrins. ACS Appl. Energy Mater. 2019, 2 (6), 4022-4026. https://doi.org/10.1021/acsaem.9b00761.

(2) Bard, A. J.; Faulkner, L. R. Electrochemical Methods: Fundamentals and Applications, 2nd Edition | Wiley: 2008.

(7) Clark, M. L.; Cheung, P. L.; Lessio, M.; Carter, E. A.; Kubiak, C. P. Kinetic and Mechanistic Effects of Bipyridine (Bpy) Substituent, Labile Ligand, and Brønsted Acid on Electrocatalytic CO2 Reduction by Re(Bpy) Complexes. ACS Catal. 2018, 8 (3), 20212029. https://doi.org/10.1021/acscatal.7b03971.

(8) Azcarate, I.; Costentin, C.; Robert, M.; Savéant, J.-M. Through-Space Charge Interaction Substituent Effects in Molecular Catalysis Leading to the Design of the Most Efficient Catalyst of CO2-to-CO Electrochemical Conversion. J. Am. Chem. Soc. 2016, 138 (51), 16639-16644. https://doi.org/10.1021/jacs.6b07014.

(9) Smith, T. J.; Stevenson, K. J. 4 - Reference Electrodes. In Handbook of Electrochemistry; Zoski, C. G., Ed.; Elsevier: Amsterdam, 2007; pp 73-110. https://doi.org/10.1016/B978044451958-0.50005-7.

(10) D’Souza, D. M.; Leigh, D. A.; Papmeyer, M.; Woltering, S. L. A Scalable Synthesis of 5,5'-Dibromo-2,2'-Bipyridine and Its Stepwise Functionalization via Stille Couplings. Nat. Protoc. 2012, 7 (11), 2022-2028. https://doi.org/10.1038/nprot.2012.122.

(11) Grosshenny, V.; Romero, F. M.; Ziessel, R. Construction of Preorganized Polytopic Ligands via Palladium-Promoted Cross-Coupling Reactions. J. Org. Chem. 1997, 62 (5), 1491-1500. https://doi.org/10.1021/jo962068w.

(12) Hendsbee, A. D.; Sun, J.-P.; Law, W. K.; Yan, H.; Hill, I. G.; Spasyuk, D. M.; Welch, G. C. Synthesis, Self-Assembly, and Solar Cell Performance of N-Annulated Perylene Diimide Non-Fullerene Acceptors. Chem. Mater. 2016, 28 (19), 7098-7109. https://doi.org/10.1021/acs.chemmater.6b03292.

(13) Cann, J. R.; Cabanetos, C.; Welch, G. C. Synthesis of Molecular Dyads and Triads Based Upon N-Annulated Perylene Diimide Monomers and Dimers. Eur. J. Org. Chem. 2018, 2018 (48), 6933-6943. https://doi.org/10.1002/ejoc.201801383.

(14) Dubrawski, Z.; Heidebrecht, J.; Lombardi, B. M. P.; Hyla, A. S.; Willkomm, J.; Radford, C. L.; Lin, J.-B.; Welch, G. C.; Ponnurangam, S.; Roesler, R.; Prokopchuk, D. E.; Piers, W. E. Ligand-Centered Electrochemical Processes Enable CO2 Reduction with a Nickel Bis(Triazapentadienyl) Complex. Sustain. Energy Fuels 2019, 3 (5), 1172-1181. https://doi.org/10.1039/C8SE00623G.

(15) Fulmer, G. R.; Miller, A. J. M.; Sherden, N. H.; Gottlieb, H. E.; Nudelman, A.; Stoltz, B. M.; Bercaw, J. E.; Goldberg, K. I. NMR Chemical Shifts of Trace Impurities: Common 
Laboratory Solvents, Organics, and Gases in Deuterated Solvents Relevant to the Organometallic Chemist. Organometallics 2010, 29 (9), 2176-2179.

https://doi.org/10.1021/om100106e.

(16) Hawecker, J.; Lehn, J.-M.; Ziessel, R. Electrocatalytic Reduction of Carbon Dioxide Mediated by $\operatorname{Re}($ Bipy $)(\mathrm{CO}) 3 \mathrm{Cl}$ (Bipy =2,2'-Bipyridine). J. Chem. Soc. Chem. Commun. 1984, $O$ (6), 328-330. https://doi.org/10.1039/C39840000328.

(17) Smieja, J. M.; Kubiak, C. P. Re(Bipy-TBu)(CO)3Cl-improved Catalytic Activity for Reduction of Carbon Dioxide: IR-Spectroelectrochemical and Mechanistic Studies. Inorg. Chem. 2010, 49, 9283-9289. https://doi.org/10.1021/ic1008363.

(18) Machan, C. W.; Chabolla, S. A.; Yin, J.; Gilson, M. K.; Tezcan, F. A.; Kubiak, C. P. Supramolecular Assembly Promotes the Electrocatalytic Reduction of Carbon Dioxide by Re(I) Bipyridine Catalysts at a Lower Overpotential. J. Am. Chem. Soc. 2014, 136 (41), 14598-14607. https://doi.org/10.1021/ja5085282.

(19) Haviv, E.; Azaiza-Dabbah, D.; Carmieli, R.; Avram, L.; Martin, J. M. L.; Neumann, R. A Thiourea Tether in the Second Coordination Sphere as a Binding Site for CO2 and a Proton Donor Promotes the Electrochemical Reduction of CO2 to CO Catalyzed by a Rhenium Bipyridine-Type Complex. J. Am. Chem. Soc. 2018, 140 (39), 12451-12456. https://doi.org/10.1021/jacs.8b05658.

(20) Sung, S.; Kumar, D.; Gil-Sepulcre, M.; Nippe, M. Electrocatalytic CO2 Reduction by Imidazolium-Functionalized Molecular Catalysts. J. Am. Chem. Soc. 2017, 139 (40), 13993-13996. https://doi.org/10.1021/jacs.7b07709.

(21) Hellman, A. N.; Haiges, R.; Marinescu, S. C. Rhenium Bipyridine Catalysts with Hydrogen Bonding Pendant Amines for CO2 Reduction. Dalton Trans. 2019, 48 (38), 14251-14255. https://doi.org/10.1039/C9DT02689D.

(22) Franco, F.; Cometto, C.; Garino, C.; Minero, C.; Sordello, F.; Nervi, C.; Gobetto, R. Photoand Electrocatalytic Reduction of $\mathrm{CO} 2$ by $\left[\mathrm{Re}(\mathrm{CO}) 3 \alpha, \mathrm{A}^{\prime}\right.$-Diimine-(4-Piperidinyl-1,8Naphthalimide)Cl] Complexes. Eur. J. Inorg. Chem. 2015, 2015 (2), 296-304. https://doi.org/10.1002/ejic.201402912.

(23) Sun Cunfa; Rotundo Laura; Garino Claudio; Nencini Luca; Yoon Sam S.; Gobetto Roberto; Nervi Carlo. Electrochemical CO2 Reduction at Glassy Carbon Electrodes Functionalized by MnI and ReI Organometallic Complexes. ChemPhysChem 2017, 18 (22), 3219-3229. https://doi.org/10.1002/cphc.201700739.

(24) Qiao, X.; Li, Q.; Schaugaard, R. N.; Noffke, B. W.; Liu, Y.; Li, D.; Liu, L.; Raghavachari, K.; Li, L. Well-Defined Nanographene-Rhenium Complex as an Efficient Electrocatalyst and Photocatalyst for Selective CO2 Reduction. J. Am. Chem. Soc. 2017, 139 (11), 39343937. https://doi.org/10.1021/jacs.6b12530.

(25) Frisch, M. J.; Trucks, G. W.; Schlegel, H. B.; Scuseria, G. E.; Robb, M. A.; Cheeseman, J. R.; Scalmani, G.; Barone, V.; Petersson, G. A.; Nakatsuji, H.; Li, X.; Caricato, M.; Marenich, A. V.; Bloino, J.; Janesko, B. G.; Gomperts, R.; Mennucci, B.; Hratchian, H. P.; Ortiz, J. V.; Izmaylov, A. F.; Sonnenberg, J. L.; Williams-Young, D.; Ding, F.; Lipparini, F.; Egidi, F.; Goings, J.; Peng, B.; Petrone, A.; Henderson, T.; Ranasinghe, D.; Zakrzewski, V. G.; Gao, J.; Rega, N.; Zheng, G.; Liang, W.; Hada, M.; Ehara, M.; Toyota, K.; Fukuda, R.; Hasegawa, J.; Ishida, M.; Nakajima, T.; Honda, Y.; Kitao, O.; Nakai, H.; Vreven, T.; Throssell, K.; Montgomery, J. A., Jr.; Peralta, J. E.; Ogliaro, F.; Bearpark, M. J.; Heyd, J. J.; Brothers, E. N.; Kudin, K. N.; Staroverov, V. N.; Keith, T. A.; Kobayashi, R.; Normand, J.; Raghavachari, K.; Rendell, A. P.; Burant, J. C.; Iyengar, S. S.; Tomasi, J.; Cossi, M.; Millam, J. M.; Klene, M.; Adamo, C.; Cammi, R.; Ochterski, J. W.; Martin, R. L.; Morokuma, K.; Farkas, O.; Foresman, J. B.; Fox, D. J. Gaussian 16 Revision A.03, Gaussian Inc: Wallingford CT, 2016. 
(26) Zhao, Y.; Truhlar, D. G. The M06 Suite of Density Functionals for Main Group Thermochemistry, Thermochemical Kinetics, Noncovalent Interactions, Excited States, and Transition Elements: Two New Functionals and Systematic Testing of Four M06-Class Functionals and 12 Other Functionals. Theor. Chem. Acc. 2008, 120 (1), 215-241. https://doi.org/10.1007/s00214-007-0310-x.

(27) Hariharan, P. C.; Pople, J. A. The Influence of Polarization Functions on Molecular Orbital Hydrogenation Energies. Theor. Chim. Acta 1973, 28 (3), 213-222. https://doi.org/10.1007/BF00533485.

(28) Petersson, G. A.; Bennett, A.; Tensfeldt, T. G.; Al-Laham, M. A.; Shirley, W. A.; Mantzaris, J. A Complete Basis Set Model Chemistry. I. The Total Energies of Closed-shell Atoms and Hydrides of the First-row Elements. J. Chem. Phys. 1988, 89 (4), 2193-2218. https://doi.org/10.1063/1.455064.

(29) Petersson, G. A.; Al-Laham, M. A. A Complete Basis Set Model Chemistry. II. Open-shell Systems and the Total Energies of the First-row Atoms. J. Chem. Phys. 1991, 94 (9), 60816090. https://doi.org/10.1063/1.460447.

(30) Hehre, W. J.; Ditchfield, R.; Pople, J. A. Self-Consistent Molecular Orbital Methods. XII. Further Extensions of Gaussian-Type Basis Sets for Use in Molecular Orbital Studies of Organic Molecules. J. Chem. Phys. 1972, 56 (5), 2257-2261. https://doi.org/10.1063/1.1677527.

(31) Hay, P. J.; Wadt, W. R. Ab Initio Effective Core Potentials for Molecular Calculations. Potentials for the Transition Metal Atoms Sc to Hg. J. Chem. Phys. 1985, 82 (1), 270-283. https://doi.org/10.1063/1.448799.

(32) Wadt, W. R.; Hay, P. J. Ab Initio Effective Core Potentials for Molecular Calculations. Potentials for Main Group Elements Na to Bi. J. Chem. Phys. 1985, 82 (1), 284-298. https://doi.org/10.1063/1.448800.

(33) Dennington, R.; Keith, T. A.; Millam, J. M. GaussView, Version 5.0.9, Semichem Inc., Shawnee Mission: KS, 2009.

(34) Bruker-AXS. SAINT; Madison, Wisconsin, USA, 2017.

(35) Bruker-AXS. XPREP; Madison, Wisconsin, USA, 2017.

(36) Dolomanov, O. V.; Bourhis, L. J.; Gildea, R. J.; Howard, J. a. K.; Puschmann, H. OLEX2: A Complete Structure Solution, Refinement and Analysis Program. J. Appl. Crystallogr. 2009, 42 (2), 339-341. https://doi.org/10.1107/S0021889808042726.

(37) Sheldrick, G.M. (2015). Acta Cryst. A71, 3-8.

(38) Sheldrick, G.M. (2015). Acta Cryst. C71, 3-8. 